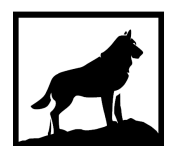

Michigan Technological

18 8 5 University
Michigan Technological University Digital Commons @ Michigan Tech

\title{
INTEGRATED TORREFACTION-EXTRUSION SYSTEM FOR CONVERSION OF FIBER-PLASTIC WASTES INTO SOLID FUELS
}

Shreyas Kolapkar

Michigan Technological University, sskolapk@mtu.edu

Copyright 2021 Shreyas Kolapkar

Recommended Citation

Kolapkar, Shreyas, "INTEGRATED TORREFACTION-EXTRUSION SYSTEM FOR CONVERSION OF FIBERPLASTIC WASTES INTO SOLID FUELS", Open Access Dissertation, Michigan Technological University, 2021.

https://doi.org/10.37099/mtu.dc.etdr/1333

Follow this and additional works at: https://digitalcommons.mtu.edu/etdr

Part of the Heat Transfer, Combustion Commons 


\title{
INTEGRATED TORREFACTION-EXTRUSION SYSTEM FOR CONVERSION OF FIBER-PLASTIC WASTES INTO SOLID FUELS
}

By

Shreyas S. Kolapkar

\begin{abstract}
A DISSERTATION
Submitted in partial fulfillment of the requirements for the degree of DOCTOR OF PHILOSOPHY

In Mechanical Engineering - Engineering Mechanics
\end{abstract}

MICHIGAN TECHNOLOGICAL UNIVERSITY

2021

(C) 2021 Shreyas S. Kolapkar 
This dissertation has been approved in partial fulfillment of the requirements for the Degree of DOCTOR OF PHILOSOPHY in Mechanical Engineering - Engineering Mechanics.

Department of Mechanical Engineering- Engineering Mechanics

Dissertation Advisor: Dr. Ezra Bar-Ziv

Committee Member: Dr. Jeffrey D. Naber

Committee Member: Dr. Armando G. McDonald

Committee Member: $\quad$ Dr. Scott W. Wagner

Committee Member: Dr. Jordan L. Klinger

Department Chair: Dr. William W. Predebon 
Dedicated to Aai 


\section{Table of Contents}

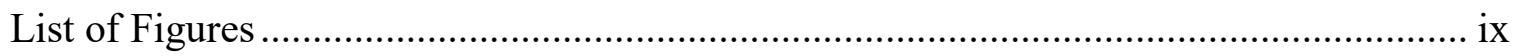

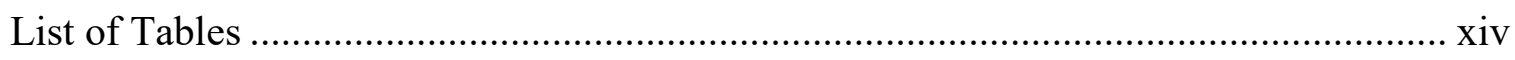

Author Contribution Statement............................................................................

Acknowledgments....................................................................................... xvii

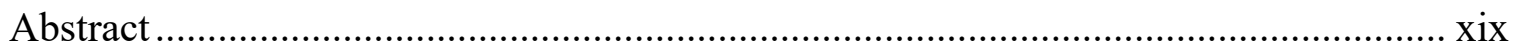

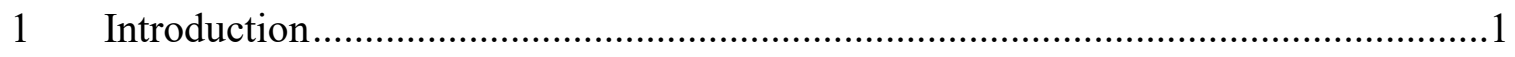

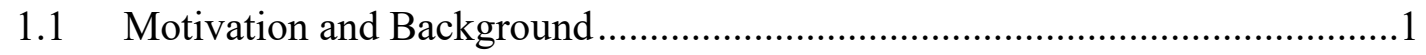

1.2 Review of Torrefaction Technologies .......................................................

1.2.1 Fixed Bed Reactor.......................................................................

1.2.2 Moving Bed Reactor ........................................................................

1.2.3 Microwave Reactor ........................................................................

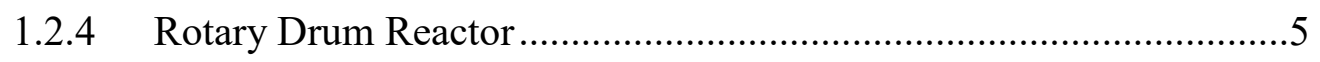

1.2.5 Fluidized Bed Reactor.................................................................6

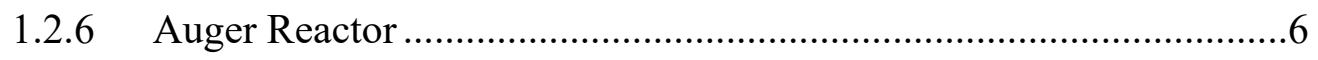

1.2.7 Indicators for Technical Performance................................................

1.3 Objectives and Dissertation Structure …………........................................

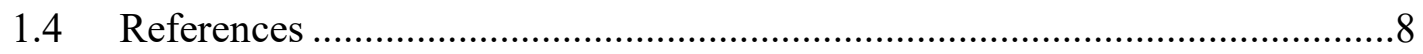

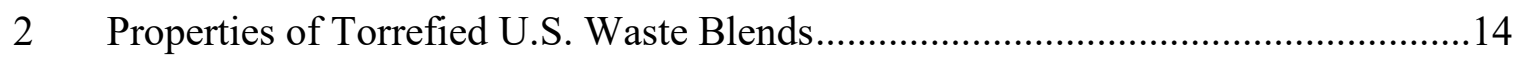

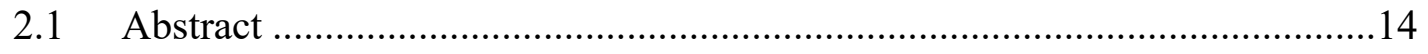

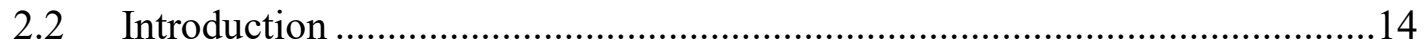

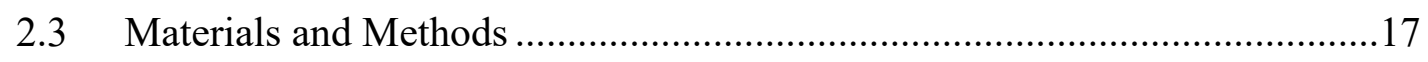

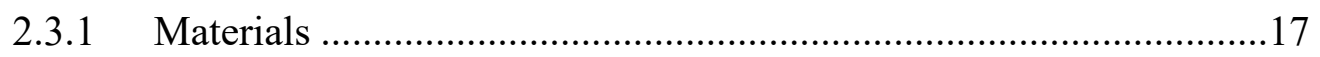

2.3.2 Waste and Product Characterization.................................................18

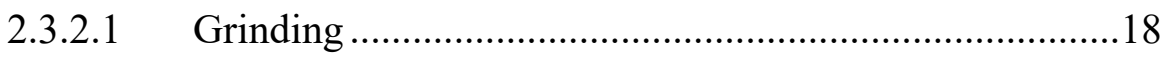

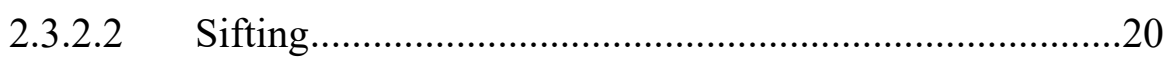

2.3.2.3 Chloride and Chlorine .....................................................20

2.3.2.4 Heat Content .............................................................21 
2.3.2.5 Moisture Content ...................................................21

2.3.2.6 Density Measurements ..............................................21

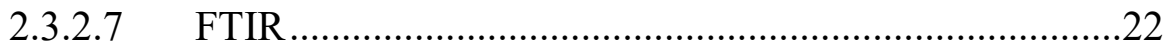

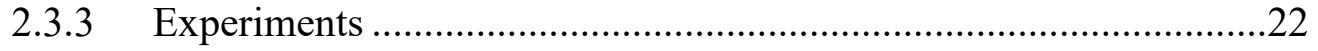

2.3.3.1 Torrefaction................................................................22

2.3.3.2 Removal of Soluble Minerals ......................................22

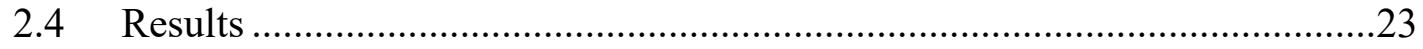

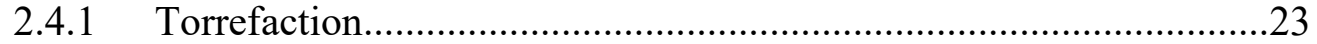

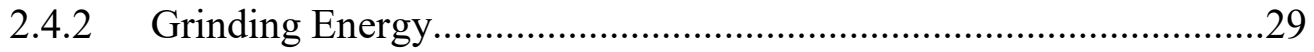

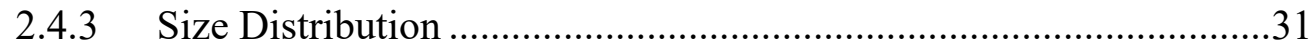

2.4.4 FTIR Spectroscopic Characterization ............................................33

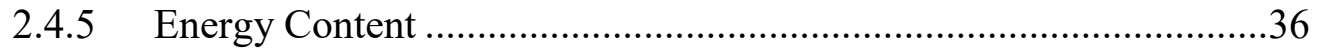

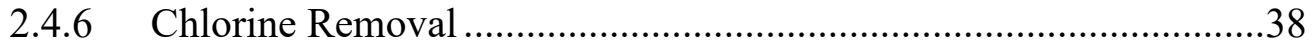

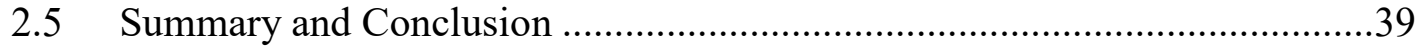

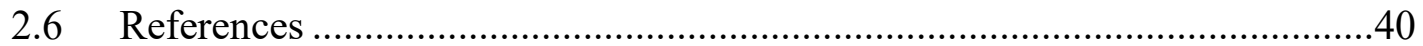

3 Properties of Pellets of Torrefied U.S. Waste Blends............................................48

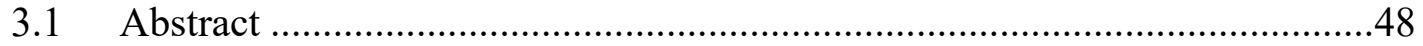

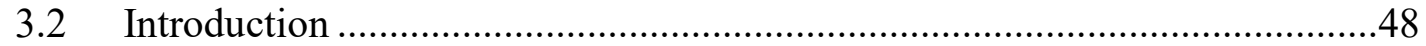

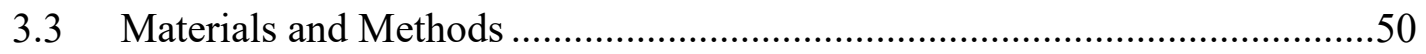

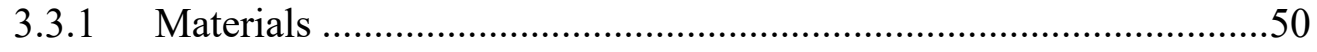

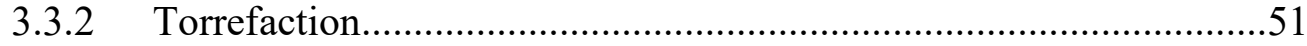

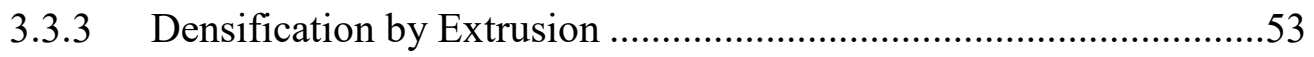

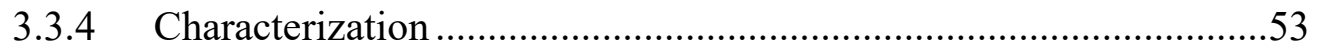

3.3.4.1 FTIR Characterization ............................................53

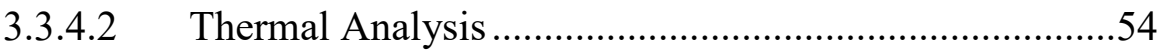

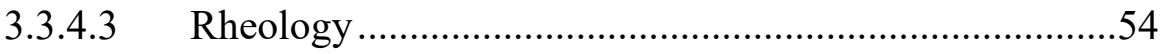

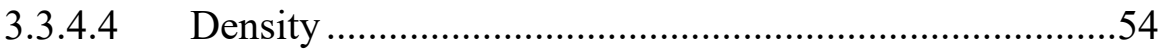

3.3.4.5 Flexural Testing ......................................................55

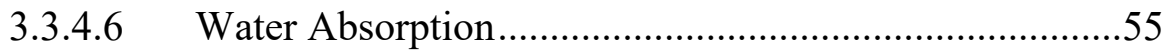

3.3.4.7 Size Distribution Analysis ...........................................55 
3.3.4.8 Heat Content ...................................................................56

3.3.4.9 Combustion Test ............................................................

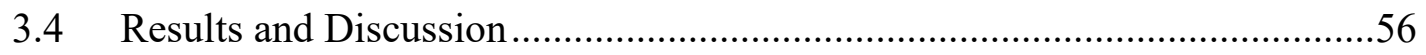

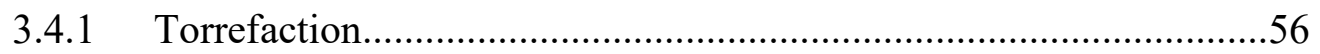

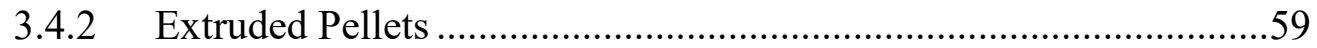

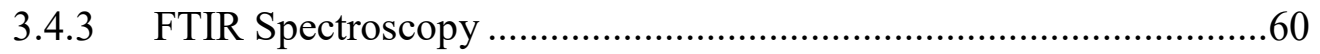

3.4.4 Material Variability and Homogeneity ............................................62

3.4.5 Thermomechanical Analysis (TMA) ..............................................63

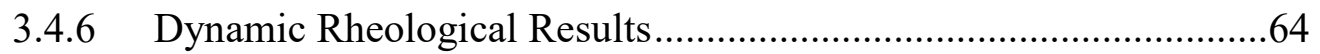

3.4.7 Density and Mechanical Properties ……………….........................65

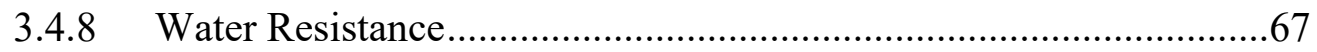

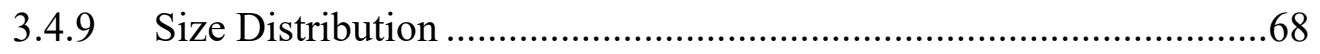

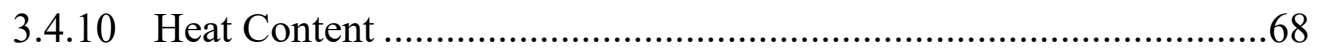

3.4.11 Combustion Test .......................................................................... 69

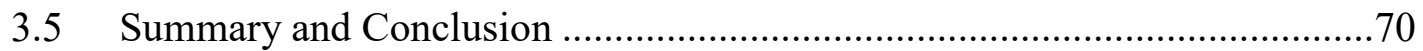

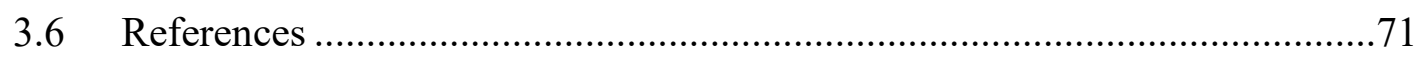

$4 \quad$ Integration of Thermal Treatment and Extrusion by Compounding for Processing Various Wastes for Energy Applications..................................................................78

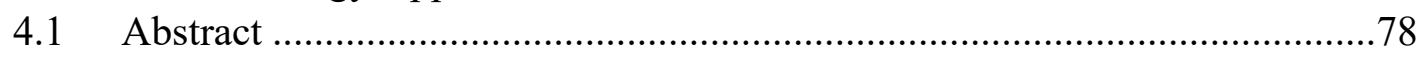

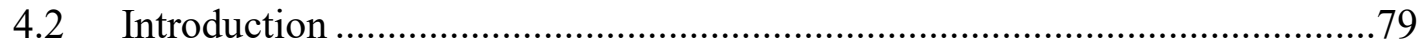

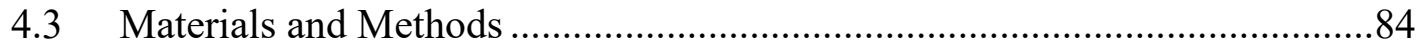

4.3.1 Material Identification and Preparation. ............................................84

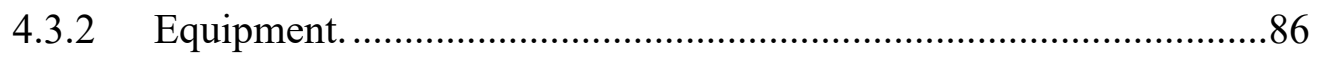

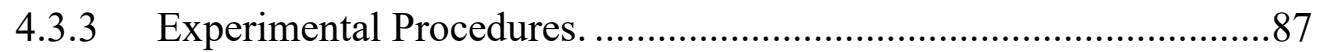

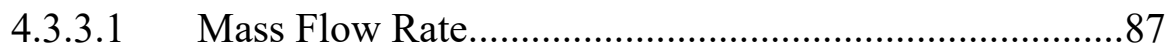

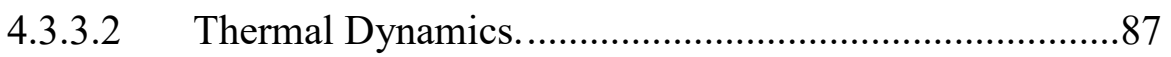

4.3.3.3 Residence Time............................................................... 88

4.3.3.4 Specific Heat............................................................... 90

4.3.3.5 Temperature Profile. .........................................................90

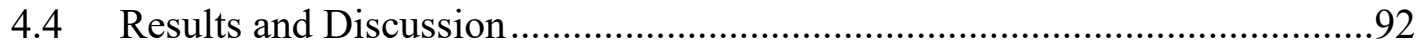


4.5 Conclusion. .102

4.6 References

.104

$5 \quad$ Integrated Torrefaction-Extrusion System for Solid Fuel Pellet Production from Mixed Fiber-Plastic Wastes: Techno-Economic Analysis and Life Cycle Assessment..111

5.1 Abstract .111

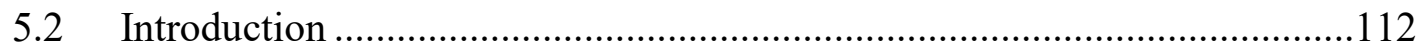

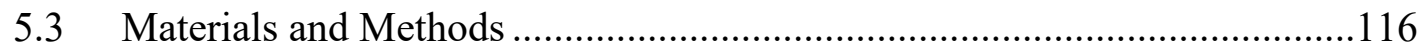

5.3.1 The Pilot-Scale Integrated Torrefaction-Extrusion System ............118

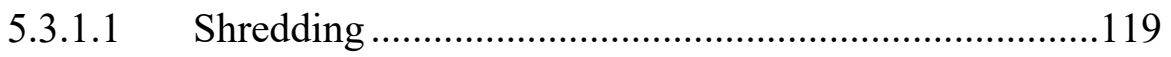

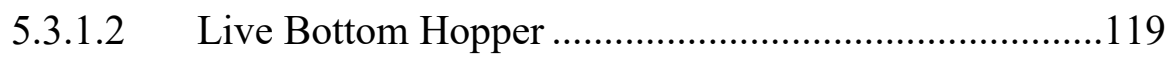

5.3.1.3 Bucket Elevators .....................................................120

5.3.1.1 Airlock and Crammer .................................................121

5.3.1.2 Torrefaction-Extrusion Reactor .................................122

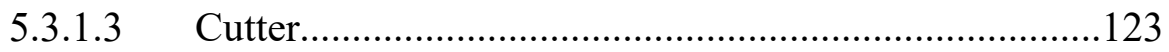

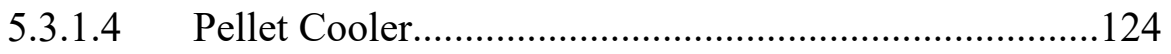

5.3.2 Mass Flow Rate and Energy Measurements .................................124

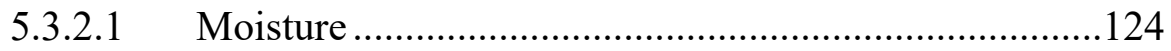

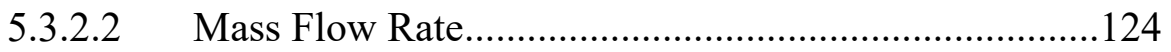

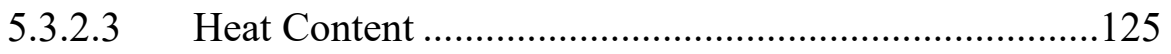

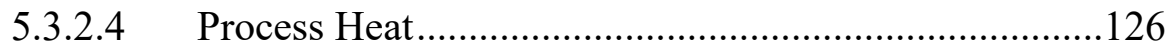

5.3.2.5 Specific Electrical Energy (e) ...................................126

5.3.3 TEA Process Modeling for Commercial Scale.............................127

5.3.3.1 Process Modeling Boundary …...................................127

5.3.3.2 Cost Estimation Methodology ..................................128

5.3.3.3 Assumption and Cost Breakdown..............................129

5.3.4 LCA Process Modeling for Commercial Scale.............................131

5.3.4.1 Life Cycle Inventory Development: ...........................132

5.3.4.2 Life Cycle Impact Assessment...................................134

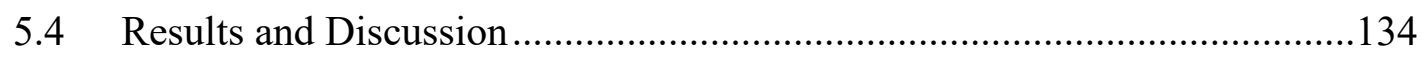

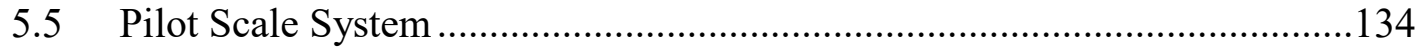


5.5.1.1 Shredding ..................................................................

5.5.1.2 Live Bottom Hopper ....................................................135

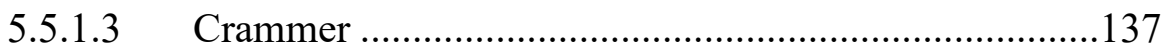

5.5.1.4 Torrefaction-Extrusion Reactor .....................................138

5.5.1.5 Bucket Elevators ..........................................................139

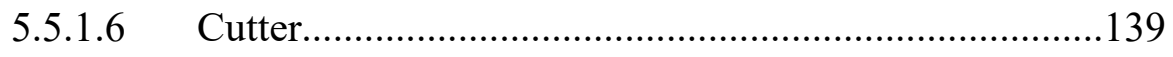

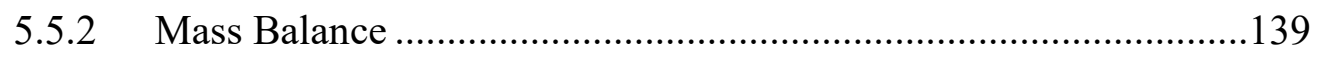

5.5.3 Heat and Chlorine Contents ........................................................140

5.5.4 Commercial Scale System TEA.....................................................141

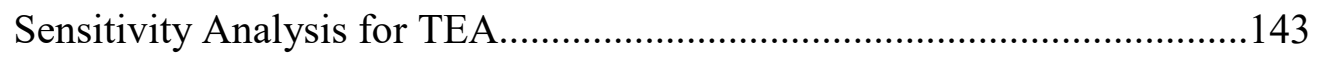

5.5.5 Commercial Scale System LCA ……………................................144

5.5.6 Sensitivity Analysis for LCA .......................................................146

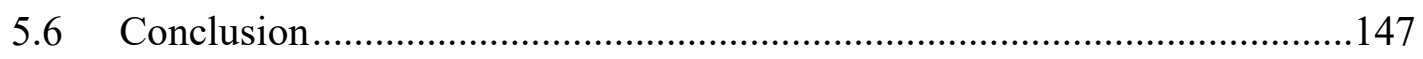

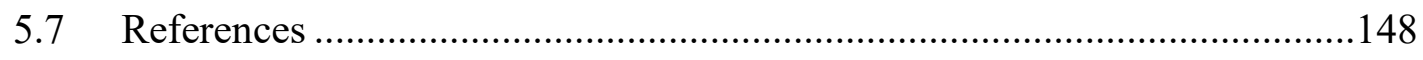

$6 \quad$ Continuous Production Run and Test Burn .....................................................156

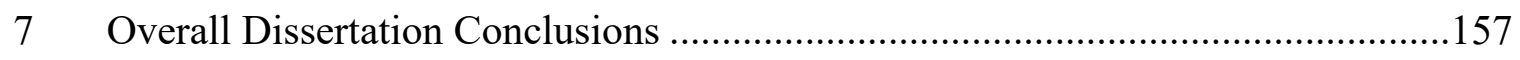

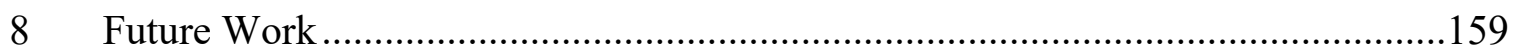

A Appendix: Torrefaction System Photo.....................................................................160

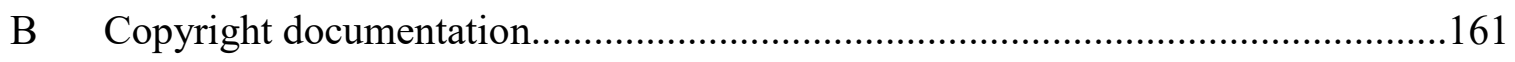




\section{List of Figures}

Figure 2.1. (a) Un-densified CE material. (b) Densified (pellets) CE material...............18

Figure 2.2. Examples of power vs. time traces of the grinder without material and with $200 \mathrm{~g}$ torrefied un-densified material................................................................. 19

Figure 2.3. Temperature transient for the un-densified material and the pellets, using Eq. (2.7) and characteristic times of 160 (s) for the former and 475 (s) for the later. .28

Figure 2.4. Experimental and modeled mass loss transients for the un-densified material and the pellets, using Eq. (2.11), the temperature transients of Figure 3, and fitting for Ta and $\mathrm{A} \uparrow$. .28

Figure 2.5. Symbols - measured net power vs. time of $200 \mathrm{~g}$ samples during grinding of torrefied CE, un-densified material and pellets. Dashed lines, fits of net power to Eq. (2.12) for the short characteristic time, $\tau_{1}=9.2 \mathrm{~s}$; and characteristic time $\tau_{2}=203.0 \mathrm{~s}$.

Figure 2.6. Normalized net grinding power vs time for torrefied material at various mass losses; with $\tau_{\mathrm{g}}=9.1$ (s) 30

Figure 2.7. Grinding power vs. time for PRB coal with $\tau_{\mathrm{g}}=9.1$ (s). .30

Figure 2.8. Size fraction for the torrefied un-densified material and pellets vs. mass loss for size fractions under and above $850 \mu \mathrm{m}$. .32

Figure 2.9. FTIR spectra of (a) CE-fiber mix and ground/screened (425-850 $\mu \mathrm{m})$ torrefied $(10,20$ and $42 \%$ mass loss) densified material and (b) ground/screened $(<150 \mu \mathrm{m}$, 150-250 $\mu \mathrm{m}, 250-425 \mu \mathrm{m}, 425-850 \mu \mathrm{m}$, and $>850 \mu \mathrm{m})$ un-densified torrefied (30\% mass loss) material.

Figure 2.10. Plots showing changes in (a) carbonyl index (CI), (b) cellulose index (CeI), and (c) hydroxyl index (HI) for ground screened fractions ( $<150 \mu \mathrm{m}, 150<\mathrm{x}<250$ $\mu \mathrm{m}, 250<\mathrm{x}<425 \mu \mathrm{m}, 425<\mathrm{x}<850 \mu \mathrm{m}$, and $>850 \mu \mathrm{m}$ ) of torrefied densified (D) and un-densified (U) material .35 
Figure 2.11. Top left. The heat content of the size fraction $\mathrm{x}<150 \mu \mathrm{m}$. Top right, same for $150<\mathrm{x}<850 \mu \mathrm{m}$. Bottom left. Same for $\mathrm{x}>850 \mu \mathrm{m}$. Bottom right. Total heat content.

Figure 2.12. The energy contribution of the above and under $850 \mu \mathrm{m}$ size fractions to the total heat content of both un-densified material and pellets as a function of mass loss.

Figure 2.13. Chlorine in solid filtrate after high shear mixing and chloride in the aqueous solution (adjusted for dilution) 39

Figure 3.1. (a) fiber waste, (b) plastic waste, and (c) $60 \%$ fiber and $40 \%$ plastic blend. .51

Figure 3.2. Schematic of Torrefaction system. .51

Figure 3.3. The photograph shows the original waste plastic mix and torrefied material at $11 \%, 32 \%$, and $51 \%$ mass loss .57

Figure 3.4. Top - temperature transients are calculated by Eq.(4.1) or the fiber, plastic, and the blend, reaching $300{ }^{\circ} \mathrm{C}$. Bottom - a mass loss for the fiber, plastic, and blend. The figure also shows model results for each component and the expected model behavior for the blend. .58

Figure 3.5. Photograph showing the extruded rods made from a non-torrefied waste blend ( $0 \%$ mass loss) and torrefied materials at $11 \%, 32 \%$, and $51 \%$ mass loss. .59

Figure 3.6. Materials identified from raw feedstock, (a) plastics; (b) fibers. .60

Figure 3.7. FTIR spectra of a composite average of 30 waste blend pieces, extruded mixed plastic (0\% mass loss), and extruded torrefied (11\%, $32 \%$, and $51 \%$ mass loss) material.

Figure 3.8. Plot showing changes in hydroxyl (HI), carbonyl (CI), and cellulose (CeI) indices with the extent of torrefaction (mass loss).

Figure 3.9. Heterogeneity as defined by STD/IN of IR spectra measured. .62

Figure 3.10. TMA thermograms of the extruded torrefied ( $0 \%$ to $51 \%$ mass loss) samples. 
Figure 3.11. Dynamic rheology showing (a) elastic moduli $\left(\mathrm{G}^{\prime}\right)$, (b) viscous moduli (G") and (c) complex viscosity $\left(\eta^{*}\right)$ as a function of frequency for torrefied waste blend extrudates at $180^{\circ} \mathrm{C}$

Figure 3.12. (a) storage modulus (E') and (b) loss modulus (E") .66

Figure 3.13. Water intake of extruded, $20 \%$ mass loss, torrefied material as a function in time.

Figure 3.14. Size fractions of the extruded pellets after grinding. .68

Figure 3.15. The total heat content of the extruded pellets at a different mass loss .68

Figure 3.16. Volatile content and fixed carbon as measured as a function of torrefaction mass loss (a). Combustion tests plotted as mass loss fraction vs. time for nontorrefied pellets (b), torrefied pellets at $11-51 \%$ mass loss (c-f).

Figure 4.1. Various stages of the fiber-plastic waste pre-processing and corresponding particle sizes: a. Tipping-floor stage where fibers and plastics are blended $(\geq 300$ $\mathrm{mm})$; b. Shredding Stage $1(\leq 50 \mathrm{~mm})$; c. Shredding Stage $3(\leq 3 \mathrm{~mm})$. .84

Figure 4.2. Integrated Torrefaction-Extrusion system showing the heaters (H1 to H14) and thermocouples (TT1 to TT17). .85

Figure 4.3. Reactor and Feed Motor Load vs. Time showing the measurement procedure of residence time. .89

Figure 4.4. Infrared spectra of various materials identified in waste feedstock showing various plastic polymers, rubbers, and fibers: LDPE, PP, PET, Polyamide-Nylon, Polyvinyl, Acrylate, Polyester with kaolin filler; Rubber: Silopren and Fiber: Cellophane/cellulose. .93

Figure 4.5. Mass flow rate vs. feed auger rotation frequency.....

Figure 4.6. Thermal Dynamics of the system showing five regions, R1 - no heating region; R2 - ramp up region; R3- stability without material region; R4 - material flow startup region, and R5 - stability region with material for (A) Temperature of the system; (B) DC of the heaters. 
Figure 4.7. A. Residence Time vs. Inverse Shaft Speed for different shaft configurations (Auger: $0 \%$ cut, 20\% cut auger, and 40\% cut auger); B. SolidWorks ${ }^{\circledR}$ model showing modified auger with $40 \%$ cuts

Figure 4.8. Average Net Heat Input (moisture-free basis) vs. Mass flow rate. Specific Heat (C) of material can be calculated as $1.58 \mathrm{~kJ} / \mathrm{kg}-{ }^{\circ} \mathrm{C}$. .96

Figure 4.9. Material temperature profile vs. residence time. .97

Figure 4.10. Average heat transfer coefficient (U) based on the slope of heat flux vs. $\Delta \mathrm{T}$ plot. .98

Figure 4.11. Specific mechanical energy (SME) vs. mass flow rate of the torrefactionextrusion process. Inset shows the plot of $\dot{\mathrm{m}}^{-0.684}$ vs. specific mechanical energy.99

Figure 4.12. Pellets produced from fiber-plastic mix waste (60:40 ratio) of $\phi 12.7 \mathrm{~mm}$ diameter and $25.4 \mathrm{~mm}$ length

Figure 4.13. Thermomechanical analysis thermogram of extruded pellets showing two softening temperatures at $102^{\circ} \mathrm{C}$ and $164^{\circ} \mathrm{C}$ .100

Figure 4.14. Flow curves showing complex viscosity vs. shear rate of plastic waste at $180^{\circ} \mathrm{C}$ .102

Figure 5.1. (a) Presorted mixed fiber-plastic 'as-received' on the tipping floor; (b) mixed fiber-plastic after three-stage shredding to size $\leq 50 \mathrm{~mm}$. .116

Figure 5.2. (a) Mixed fiber-plastic waste after shredding to $<3 \mathrm{~mm}$, and (b) Pellets produced in the pilot-scale system using the mixed fiber-plastic waste at different levels of torrefaction.

Figure 5.3. Scheme of the pilot-scale torrefaction-extrusion process. .118

Figure 5.4. Live bottom hopper with positive angles and independently controlled variable pitch screws .120

Figure 5.5. Schematic showing the airlock and various components of the crammer....120 
Figure 5.6. Integrated torrefaction-extrusion reactor showing the scale and various zones.

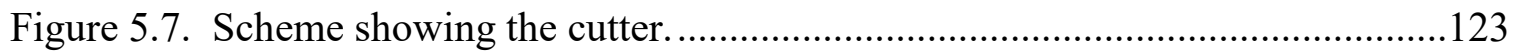

Figure 5.8. Simplified block diagram of the commercial scale torrefaction process. ....128

Figure 5.9. (a) Specific energy vs. volume flow rate for the stage III shredder; (b) Specific energy vs. mass flow rate for the stage III shredder. .......................................135

Figure 5.10. Mass flow rate vs. rotation speed of live bottom hopper shaft for (a) bridging material; and (b) non-bridging material. The inset in (a) shows the strip-shaped flakes material with a tendency to bridge, and the inset in (b) shows the squareshaped flakes

Figure 5.11. Specific electrical energy (e) vs. mass flow $(\dot{\mathrm{m}})$ rate for live bottom hopper.

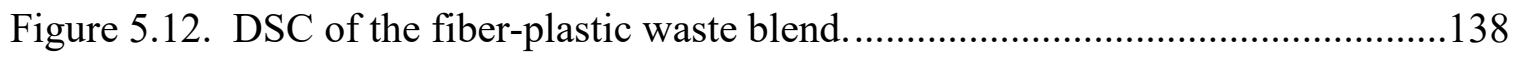

Figure 5.13. Typical load cell measurements show mass input at the live bottom hopper and mass output at the pellet cooler. Mass loss can be calculated from the difference

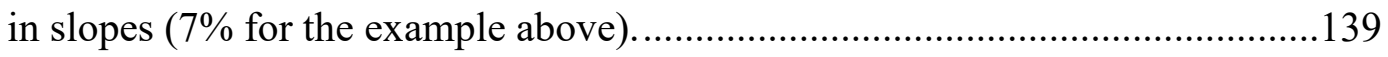

Figure 5.14. Heat Content vs. Mass Loss and Normalized Cl content vs. Mass Loss using batch and continuous reactor setup. 140

Figure 8.1. Shingle produced from mixed plastic waste alloy. Credits: Dr. Armando McDonald (University of Idaho). 


\section{List of Tables}

Table 1.1. Different thermochemical conversion processes for waste to fuel conversion. 4

Table 1.2. Key technical performance indicators of torrefaction plant. ..............................7

Table 2.1. U.S. wastes, quantities, and heat content (on a dry basis)...............................16

Table 2.2. Properties of CE material averaged over seven years.......................................17

Table 2.3. Estimated values for the parameters to determine the Bi and M.....................25

Table 2.4. Specific grinding energy ……………………............................................ 31

Table 2.5. Fraction $<200$ mesh of torrefied material in various mass losses.....................32

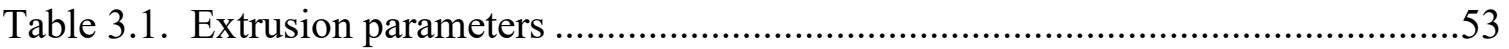

Table 3.2. Softening temperatures for the extruded material determined using TMA.....64

Table 3.3. Softening temperatures for the extruded material determined by TMA..........66

Table 4.1. Flexural modulus and strength values of extruded mixed plastic-paper, LDPE,

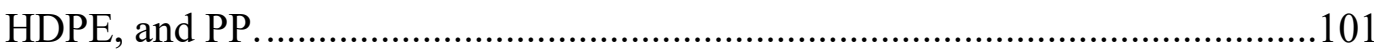

Table 5.1. Operation parameters used for the TEA.....................................................129

Table 5.2. General assumptions made for the TEA. Costs are presented in $2020 \$ \ldots . . . .130$

Table 5.3. Key life cycle input data and assumptions..................................................133

Table 5.4. Breakdown of costs for fiber-plastic pre-processing and torrefaction unit

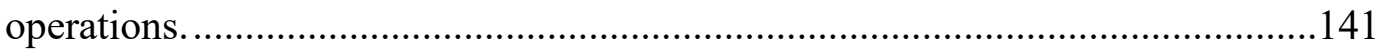

Table 5.5. Breakdown of total costs at the plant. Costs are reported in $2020 \$ \ldots \ldots \ldots \ldots \ldots . . .142$

Table 5.6. Energy consumption by fuel type............................................................142

Table 5.7. Energy consumption by equipment type. .....................................................143

Table 5.8. Sensitivity Analysis for Crammer-Torrefier Unit...........................................144

Table 5.9. LCA results for torrefaction system compared to wood chips. .....................145

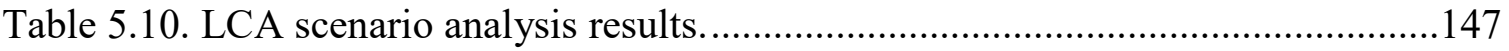




\section{Author Contribution Statement}

This doctoral dissertation contains material that has been reviewed and previously published in scientific journals. Details of the content of each chapter, author contributions, and full citations for these works are provided below:

Chapter 1: is an introduction to this thesis. This chapter focuses on the characterization of the waste, its torrefaction at various conditions, reactor modeling, and characterization of the torrefied waste.

Chapter 2: is a detailed study of industrial wastes used as the main feedstock for this work. This chapter focuses on the torrefaction of waste, its detailed characterization after torrefaction.

This chapter is based on the following published paper: Z. Xu, S. Zinchik, S.S. Kolapkar, E. Bar-Ziv, T. Hansen, D. Conn, A.G. McDonald, Properties of Torrefied U.S. Waste Blends, Frontiers in Energy Research, 6 (2018). https://doi.org/10.3389/fenrg.2018.00065

In this study, Z. Xu, S. Zinchik, and S.S. Kolapkar performed experiments, data collection, and analysis, data interpretation. E. Bar-Ziv is the advisor and Conn, and Hansen performed some characterization and provided feedstock. A. McDonald helped in product characterization and interpretation.

Chapter 3 is a detailed study on the pellets produced from both non-torrefied and torrefied wastes. It focuses on details of torrefaction, extrusion, and different material characterizations used to understand the pellet properties.

This chapter is based on the following published paper: S. Zinchik, Z. Xu, S.S. Kolapkar, E. Bar-Ziv, A.G. McDonald, Properties of pellets of torrefied U.S. waste blends, Waste Management, 104 (2020) 130-138. https://doi.org/10.1016/j.wasman.2020.01.009 
In this study, S. Zinchik, Z. Xu, and S.S. Kolapkar performed experiments, data collection analysis, and interpretation. E. Bar-Ziv is the advisor A. McDonald performed extrusion, some product characterization, and data interpretation.

Chapter 4 is a detailed study on the integrated torrefaction-extrusion auger. It shows indepth design and development work and study of thermal-mechanical properties that can be used for scaleup.

This chapter is based on the following published paper: S.S. Kolapkar, S. Zinchik, Z. $\mathrm{Xu}$, A.G. McDonald, E. Bar-Ziv, Integration of Thermal Treatment and Extrusion by Compounding for Processing Various Wastes for Energy Applications, Energy \& Fuels, 35 (2021) 12227-12236. https://doi.org/10.1021/acs.energyfuels.1c01836

In this study, S.S. Kolapkar and S. Zinchik carried out the design, construction, fabrication, assembly, and testing. Together with $\mathrm{Z}$. Xu, they also performed experiments, data collection, analysis, and data interpretation. E. Bar-Ziv is the advisor A. McDonald performed product characterization and data interpretation.

Chapter $\mathbf{5}$ is the detailed study on the complete system, including the integrated torrefaction-extrusion auger detailed previously. It shows in-depth design and development work and study of the system and presents key energy and performance data. It also presents the techno-economic and life cycle assessment of the entire system.

This chapter is based on the following published paper: S.S. Kolapkar, S. Zinchik, P. Burli, Y. Lin, D.S. Hartley, J. Klinger, R. Handler, E. Bar-Ziv, Integrated torrefactionextrusion system for solid fuel pellet production from mixed fiber-plastic wastes: Technoeconomic analysis and life cycle assessment, Fuel Processing Technology, 226 (2022) 107094. https://doi.org/10.1016/j.fuproc.2021.107094

In this study, S.S. Kolapkar and S. Zinchik carried out the design, construction, fabrication, assembly, and testing; and performed experiments, data collection, and analysis, data interpretation. E. Bar-Ziv is the advisor. P. Burli, Y. Lin, D. Hartley, J. Klinger collaborated with techno-economic assessment. R. Handler collaborated with life cycle assessment. 
Chapter 6 is the conclusion of the entire dissertation and various studies therein.

Chapter 7 details the work needed in the future along with some on the future applications.

Further, not included in this thesis are the following studies authored by S.S. Kolapkar:

Z. Xu, S.S. Kolapkar, S. Zinchik, E. Bar-Ziv, A.G. McDonald, Comprehensive kinetic study of thermal degradation of polyvinylchloride (PVC), Polymer Degradation and Stability, 176 (2020). https://doi.org/10.1016/j.polymdegradstab.2020.109148

Z. Xu, J.W. Albrecht, S.S. Kolapkar, S. Zinchik, E. Bar-Ziv, Chlorine Removal from U.S. Solid Waste Blends through Torrefaction, Applied Sciences, 10 (2020). https://doi.org/10.3390/app10093337

Z. Xu, S.S. Kolapkar, S. Zinchik, E. Bar-Ziv, J. Klinger, E. Fillerup, K. Schaller, C. Pilgrim, Kinetic Study of Paper Waste Thermal Degradation, Polymer Degradation and Stability, 191 (2021). https://doi.org/10.1016/j.polymdegradstab.2021.109681

Z. Xu, S.S. Kolapkar, S. Zinchik, E. Bar-Ziv, L. Ewurum, A.G. McDonald, J. Klinger, E. Fillerup, K. Schaller, C. Pilgrim, Bypassing Energy Barriers in Fiber-Polymer Torrefaction, Frontiers in Energy Research, 9 (2021). https://doi.org/10.3389/fenrg.2021.643371 


\section{Acknowledgments}

I would like to thank the Mechanical Engineering-Engineering Mechanics Department, National Science Foundation (NSF-PFI Award \#1827364), Idaho National Laboratory (INL Award \#209856), and Michigan MTRAC (Award \#RC-109248) for the financial support over the years.

I would like to thank my advisor, Dr. Ezra Bar-Ziv, for the constant motivation, support, and guidance. You have always gone above and beyond to support me throughout this journey. Thank you!

I am also thankful to my committee members Dr. Jeffrey Naber, Dr. Armando McDonald, Dr. Jordan Klinger, and Dr. Scott Wagner, for serving on my committee and carefully reviewing my work. Your critical feedback, thoughtful insights, and research collaborations have played a major role in the accomplishment of this work.

I would also like to acknowledge several critical discussions, contributions, and advice from my colleagues Stas Zinchik and Zhuo Xu. I am very thankful to both of you. I would also like to thank everyone at the MEEM department and APSRC for always playing a part in my success along this journey. I would also like to acknowledge and thank fellow/past colleagues Victor, Basha, Josh, Niranjan, who always provide valuable suggestions and are always happy to help.

Last but not least, I would like to thank my father, Sunil, my brother Sagar and Kasturi vahini for their continuous support and numerous sacrifices. I would like to thank my wife, Tejal, for always being on my side during the tough times and always believing in me. This journey would not have been possible without you. Thank you for everything! 


\section{Abstract}

Waste generation is increasing, and a significant portion is being landfilled. In parallel, we are constantly pursuing cleaner fuels due to environmental and regulatory factors. To address both these challenges, torrefaction of wastes to produce clean fuels and feedstock for other thermochemical processes is one of the potential solutions. This work focuses on (a) fundamental understanding of the properties of un-torrefied and torrefied wastes and (b) development of a pilot-scale integrated torrefaction-extrusion system for converting fiber-plastic wastes to solid fuels.

In this study, a 60:40 fiber-plastic waste blend was used for performing extensive experiments on densified and un-densified wastes to understand the effect of torrefaction. Wastes were torrefied at $300^{\circ} \mathrm{C}$ and mass loss between $0 \%$ and $51 \%$. The product was characterized for moisture content, particle size distribution, energy content, grinding behavior, and chlorine. This was followed by a study to understand the effect of extrusion. The torrefied feedstock was extruded into rods, and products were characterized using thermomechanical, rheological, flexural, water absorption, size distribution, heat content, and combustion tests. It was shown that plastic in the feedstock acts as an enabler and improves properties like binding, water resistance, heat content, and increased degradation rate. Overall benefits of both torrefaction and extrusion in the production of clean and highcalorific value fuel were observed.

An integrated pilot-scale torrefaction-extrusion reactor $(70 \mathrm{~kg} / \mathrm{h}$ throughput $)$ has been developed to demonstrate a continuous process close to industry setting and produce large quantities that potential end users can use for combustion. We experimentally measured the thermo-mechanical properties of the torrefaction-extrusion reactor and the produced pellets. We present thermal dynamics, the effect of shaft configuration on residence time, specific mechanical energy, heat transfer coefficient, the specific heat of mixed wastes, and properties of pellets. The residence time was studied using different screw configurations; with cuts in the flighting, the residence time increased by a factor of 3.7. The overall reactor heat transfer coefficient was measured to yield $52.5 \mathrm{~W} / \mathrm{m}^{2 \circ} \mathrm{C}$. The specific mechanical 
energy for each mechanical component was measured as a function of mass flow rate; generally, the specific mechanical energy showed a threefold decrease in specific energy from $\sim 10$ to $50 \mathrm{~kg} / \mathrm{h}$.

Lastly, we present the complete pilot-scale system, including the pre- and post- processing equipment. The techno-economic analysis (TEA) and life cycle assessment (LCA) showed baseline cost of producing uniform pellets is $\$ 55.28 /$ dry tonne (2020\$) and that the torrefied product has net negative cradle-to-gate embodied greenhouse gas emissions. 


\section{Introduction}

\subsection{Motivation and Background}

Global warming, the long-term heating of the earth's climate, has been observed by scientists since the pre-industrial period. The scientific evidence on climate change has grown increasingly stark. It has contributed to the increase of the global average surfaceair temperature by $1^{\circ} \mathrm{C}$ since 1900 and continues to increase at a rapid pace of $0.2^{\circ} \mathrm{C}$ every decade $[1,2]$. It can mainly be attributed to anthropogenic activities like the increased use of fossil fuels leading to increased levels of greenhouse gases (GHG) like carbon dioxide, methane, nitrous oxide, and fluorinated gases [3]. The levels of these GHS's are increasing at alarming levels, with the current concentration of carbon dioxide at $400 \mathrm{ppm}$, a level predicted to have last occurred 3 million years ago [1]. In 2021, a study by the United Nations intergovernmental panel released a report that concluded with high confidence that this climate crisis is becoming 'code red for humanity' [2]. Global warming and overall climate change lead to negative environmental impacts and pose profound risks to the national economy and financial systems $[4,5]$. In recent years, the U.S. has closely seen climate-related natural destruction and high physical and economic costs associated with it. In 2021 alone, 1 in 3 Americans was affected by extreme weather-related disasters like hurricanes in the Gulf region and east coast and Californian and west-coast wildfires in the west [6]. Along with this, there is an increased frequency and severity of calamities like rising sea levels, heavy rainfalls and floods, heatwaves, and wildfires, all having detrimental economic, social, ecological, and health effects $[1,2,7]$. Several other factors like the need for energy independence, rising energy needs of growing population, governmental regulations, etc. are becoming increasingly important. As a solution to these challenges, the need to drive our planet with efficient and greener fuel is paramount.

In the U.S., the Environmental Protection Agency (EPA) has constantly established new and more stringent regulatory actions and initiatives to reduce GHG emissions and expand the renewable fuels sector. One of the key initiatives is the renewable fuel standard (RFS) program, [8] created by congress to reduce GHG emissions and expand the renewable fuels 
sector. This program was authorized under the Energy Policy Act of 2005 and then expanded in 2007 under the Energy Independence and Security Act (EISA). While for the emission sources like the power plant, several policies like Clean Air Act [9], Acid Rain Program (ARP), Cross-State Air Pollution Rule (CSAPR) [10], and Mercury and Air Toxin Standards (MATS) [11] were enacted. The common objective of all these mandates is to reduce emissions and to have cleaner and efficient fuels. Consequently, these mandates have provided motivation and government funding opportunities to research alternative cleaner solid fuels and technologies for power plants and the overall energy sector.

In pursuit of cleaner fuels, biomass-based (without plastic or other wastes) fuels have been studied and used as a promising option. Several types of wood wastes and agricultural feedstocks such as reed, canary grass, wheat straw, willow, pine, oak waste wood, bamboo, banyan, eucalyptus, wood chips, sawdust, paper, and pulp waste, palm, spruce, willow, Arundo donax, miscanthus, sorghum, and numerous others have been widely explored [1215]. However, there as several limitations while using biomass as a fuel source, both as-is and as a feedstock for other conversion processes. Raw biomass has inherent issues like low heating value, low bulk density, high wear and tear of equipment, high moisture content, and hydrophilicity [16]. These issues further develop into other additional challenges preventing the success of several biomass-based facilities. One such issue is high moisture content, which at a large-scale operation, translates into challenges like reduced efficiency of the process, increased production cost due to reduced capacity, natural decomposition of biomass, off-gas emissions due to decomposition, and uncertainty of physiochemical properties of feedstock due to moisture [16].

In addition to the above-listed challenges, there are safety issues with thermally treated biomass like self-ignition of the torrefied biomass due to its high reactivity [17]. Other key processes like densification and pelletization of biomass, essential for ensuring safety, durability, easy transport, and outdoor storage, are also challenging due to biomass's lack of binding ability. Lastly, along with costs associated with resolving above listed issues, the cost of biomass itself is also a significant hindrance. It has been studied extensively and reported that biomass's cost significantly contributes to the overall cost [18, 19]. According 
to Whalley et al. [20], the delivered cost of biomass ranged between $\$ 9$ and $\$ 90 /$ green tonne. International Renewable Energy Agency found the cost of energy crops (corn stover, straw) between $\$ 43$ and $\$ 66 /$ tonne. Overall, it is observed that biomass cost largely depends on the type of biomass, production source, and transport cost and has been reported as high as $\$ 121 /$ tonne [19] based on these factors. Further, if this cost is normalized for moisture content, mass lost in thermal treatment, etc., it can reach even higher up to $\$ 210 /$ tonne. These costs make industrial processes economically prohibitive.

The solution to the above-listed challenges and especially the high feedstock cost can come through a different global challenge - a massive amount of waste generated worldwide. According to a report by the world bank, the world generates 2.01 billion tonnes of MSW annually, which is $1.63 \mathrm{lbs} /$ person/day [21]. This number is expected to grow further to 3.40 billion tonnes by 2050 . In the U.S. alone, waste generation increases at a record rate due to the increasing population and changing consumer habits. In 2018, the US generated municipal solid waste (MSW) at a rate of $4.9 \mathrm{lbs} /$ person/day [22]. Of the 292.4 million tons (1 tonne $=\sim 1.1$ U.S. short ton) of MSW material generated, paper and paperboard contributed about $23.05 \%$, and plastic contributed $12.1 \%$. Due to this high waste generation rate, disposal of such waste becomes a major logistical and environmental challenge. Currently, landfilling is the most prominent method of disposal of waste, along with the common practice of incineration. In 2018, a total of 146.1 million tons of waste was landfilled with paper and paperboard, constituting $11.78 \%$, and plastic continued to $18.46 \%$ [22]. Apart from this, there is a large quantity of waste in oceans, rivers, and improperly or unmanaged locations. These practices lead to GHG emissions, contamination of land and water resources, and affect human health. Also, large sums of money are spent on the extensive logistics and environmental management associated with the waste. For example, an average tipping fee ranging between $\$ 56.08$ to $\$ 61.43$ is paid for U.S. wastes (MSW and industrial waste consisting of fibers and plastic) [23]. Further, we note that MSW comprises $85 \%$ biogenic carbon [24]; thus, using it for power generation would decrease GHG emission, similarly to biomass. 
Table 1.1. Different thermochemical conversion processes for waste to fuel conversion.

\begin{tabular}{llll}
\hline Process & Temperatures & Requirement & Target product \\
\hline Combustion & $1000^{\circ} \mathrm{C}$ above & Air/ $\mathrm{O}_{2}$ & Heat and $\mathrm{CO}_{2}$ \\
\hline Gasification & $500^{\circ} \mathrm{C}$ above & Steam/air & Syngas \\
\hline Pyrolysis & $300-500^{\circ} \mathrm{C}$ above & Inert $/ \mathrm{O}_{2}$ starved & Pyrolysis oil and syngas \\
\hline Liquefaction & $200-300^{\circ} \mathrm{C}$ above & Inert, pressurized & Pyrolysis oil and hydrochar \\
\hline Torrefaction & $200-300^{\circ} \mathrm{C}$ above & Inert & Torrefied biomass/waste \\
\hline
\end{tabular}

For this work, the focus is on torrefaction, also referred to as mild pyrolysis. Torrefaction is a process of heating the feedstock at temperatures usually ranging from $200^{\circ} \mathrm{C}$ to as high as $350^{\circ} \mathrm{C}$ in the absence of oxygen or an oxygen-starved environment $[25,26]$. The conditions are varied, as reported in Table 1.1. Torrefaction is an endothermic process and thus requires energy to start the process as well as sustain it. This energy, however, can be sourced from the burning of produced fuels [27]. The key processes that feedstock undergoes during torrefaction involve (a) the devolatilization process: which results in large weight loss mainly from the biomass portion in the initial torrefaction stage. In this stage, most low molecular weight components vaporize into a gaseous state while the high molecular weight components break down into smaller ones [27]; (b) Deoxygenation process: which results in the removal of oxygen and increase of $\mathrm{C} / \mathrm{O}$ and $\mathrm{C} / \mathrm{H}$ ratios. This process also produces gases like $\mathrm{CO}_{2}, \mathrm{CO}, \mathrm{H}_{2} \mathrm{O}$, etc. [27, 28]; (c) Depolymerization process: which results in conversion of polymer into monomers [29, 30], (d) Carbonization process: which results in maximization of fixed carbon. Overall, torrefaction focuses on the production of a solid fraction that can be used as a solid fuel in cofiring boilers and cement kilns, and they can also be upgraded to transportation fuels [31], sustainable aviation fuels [32], and chemicals through catalytic pyrolysis [33] or gasification [27, 34]. The following section discusses the various torrefaction technologies.

\subsection{Review of Torrefaction Technologies}

Torrefaction technologies for the last few decades have primarily focused on the torrefaction biomass. Reactors can be classified into various ways, some of which are: (a) 
fixed bed reactor, (b) rotary drum reactor, (c) microwave reactor, (d) fluidized bed reactors, and (e) auger.

\subsubsection{Fixed Bed Reactor}

A fixed bed reactor for torrefaction is the simplest form of the reactor and operates on a batch basis. The material is fed into the reactor, allowed to stay there until the torrefaction is complete, and removed once the reactor is cooled down [35]. This reactor cannot be easily scaled up for torrefaction.

\subsubsection{Moving Bed Reactor}

Moving bed reactors are designed in order to achieve continuous operation. In this type of reactor, the feedstock travels in a vertical or horizontal direction depending on the reactor's design to ensure homogenous heating of the feedstock. The gases and flow can be both cocurrent and counter-current. The feedstock heating occurs directly because of the recirculation of produced gases. Several studies $[36,37]$ have successfully demonstrated the use of moving bed reactors, especially with biomass. The key limitations of this type of reactor are the difficulty in temperature control, non-uniform temperatures in the reactor, selective biomass size, and unproven scalability [38].

\subsubsection{Microwave Reactor}

In a microwave-type reactor, the feedstock is heated and torrefied using energy from microwave radiation. The reactor can provide heating for relatively large particle sizes. This microwave technology-based reactor has been built to a capacity of 110,000 tonnes/yr [39]. Some shortcomings of the reactor are difficulty in uniformly regulating the microwave power, expensive electromagnets, leakage of microwaves, and uneven heating due to irregular dielectric properties [38].

\subsubsection{Rotary Drum Reactor}

Rotary drum reactors have mainly evolved from drying technologies. In this type of reactor, the feedstock is fed through the inlet of an inclined hollow cylindrical reactor, torrefied, 
and then discharged from the reactor outlet. The rotation of the cylinder allows better mixing. Both direct and indirect heating methods are used in this type of reactor, the direct heating is usually done using superheated steam or flue gases, while indirect heating is done using burners that heat the external walls of the hollow cylinder. This technology is commonly used in the drying industry [38]. These reactors have been built to a capacity of 100,000 tonnes/yr [39]. Some shortcomings of the reactor are high cost and large footprint, poor temperature control, increased dust generation, and limited scalability of torrefied pellet production [39].

\subsubsection{Fluidized Bed Reactor}

In a fluidized bed reactor, hot gases are flown from the bottom of the reactor to make the fine feedstock particles float. This reactor is called a fluidized bed reactor due to its fluidlike behavior when the mix of feedstock particles and air (heat transfer material is also added at times) causes the floating action. For the operation of the fluidized bed reactor, maintaining the fluidizing velocity of the gas is critical. Some important shortcomings of the fluidized bed are the requirement of increased gas handling due to extensive recirculation of gases, high potential for attrition, and agglomeration of fine particles.

\subsubsection{Auger Reactor}

The auger reactor typically consists of one or twin helical screws. The auger could be placed horizontally or vertically. There are several advantages of augers such as (a) suitable to use with heat carriers (b) excellent control of both mass flow rate and residence time (c) less attrition of solid fraction (d) promotes mixing (e) simple to design, operate and maintain (f) less consumption of inert gas. The known shortcomings include heat transfer difficulties and specific operating conditions based on feedstock characteristics.

The auger reactors were chosen due to their advantages for torrefaction, specifically their simplicity and robustness. Also, the limitations of heat transfer and specific operating conditions were addressed throughout the various studies as part of this work. 


\subsubsection{Indicators for Technical Performance}

As an indicator to understand the technical performance parameters of any torrefaction system irrespective of its type, Batidzarai et al. summarized key performance parameters listed in Table 1.2. This can serve as a good reference point and base case for various torrefaction processes.

Table 1.2. Key technical performance indicators of torrefaction plant.

\begin{tabular}{|c|c|c|c|c|}
\hline Performance & Low & Nominal & High & Units \\
\hline Energy efficiency ${ }^{1}$ & 70 & 94 & 97 & $\%$ \\
\hline Feedstock to product ratio & 3.6 & 1.7 & 1.3 & \\
\hline Electricity use & 158 & 171 & 254 & $\mathrm{kWh} /$ tonne \\
\hline Plant scale & - & - & $<250$ & Ktonnes/yr \\
\hline Calorific value $^{2}$ & 19 & 21.5 & 24 & $\mathrm{GJ}_{\mathrm{LHV}} /$ tonne \\
\hline Volumetric density & 12 & 15.1 & 19 & $\mathrm{GJ}_{\mathrm{LHV}} /$ tonne \\
\hline Bulk density & 650 & 750 & 850 & Tonnes $/ \mathrm{m}^{3}$ \\
\hline Grindability $^{3}$ & 10 & 25 & 350 & $\mathrm{kWh} /$ tonnes \\
\hline Pelletability & 8 & 22 & 45 & $\mathrm{kWh} /$ tonne \\
\hline Hydrophobicity & $<10$ & 12 & 15 & $\begin{array}{l}\% \mathrm{wt} \text { saturated } \\
\text { moisture content }\end{array}$ \\
\hline
\end{tabular}

${ }^{1}$ The energy yield is the fraction of the chemical energy contained in the original biomass that remains in the torrefied biomass on a dry ash-free basis.

${ }^{2}$ For biomass

${ }^{3}$ Grindability of torrefied biomass depends on the severity of torrefaction.

\subsection{Objectives and Dissertation Structure}

The objectives of the present study are:

1. To demonstrate the properties of waste as a potential feedstock for torrefaction.

2. To demonstrate that the properties of torrefied extruded waste and pellets are suitable for power applications. 
3. To demonstrate the first-of-a-kind integrated torrefaction-extrusion reactor for conversion of waste into fuels.

4. To present the complete system, including the preprocessing and postprocessing system that can handle heterogeneous mixed fiber-plastic wastes.

5. To present the techno-economic and life-cycle assessment of the developed system.

The first objective is to understand if the wastes can be feasibility utilized as a feedstock and study the properties of the wastes. This was done by characterizing the wastes and understanding how torrefaction affects these wastes.

The second objective is to understand the properties of the torrefied product after the extrusion process in a lab-scale system. It is aimed at understanding the change in properties from the torrefaction and extrusion process separately.

The third objective is to demonstrate the utilization of waste as a feedstock in a first-of-akind combined torrefaction extrusion reactor. This reactor can continuously process waste and allows to mix, torrefy and extrude it. Thermo-mechanical behavior of the reactor and the material is studied in detail.

The fourth objective is to demonstrate the development of the complete system that includes the ability to handle low density, heterogeneous, mixed fiber-plastic wastes and convert them into uniform solid fuels.

The final objective of this work was two-fold (a) to understand the costs of the industrial scale system and the produced product using tech-economic analysis, (b) to understand the environmental impact of this product compared to existing pellet alternatives using a life cycle assessment.

\subsection{References}

[1] D.J. Wuebbles, D.W. Fahey, K.A. Hibbard, J.R. Arnold, B. DeAngelo, S. Doherty, D.R. Easterling, J. Edmonds, T. Edmonds, T. Hall, USGCRP: Climate science special report: 
Fourth national climate assessment (NCA4), Volume I, in, U.S. Global Change Research Program, Washington, DC, USA, 2017, pp. 470. https://doi.org/10.7930/J0J964J6

[2] M. Allen, O. Dube, W. Solecki, F. Aragón-Durand, W. Cramer, S. Humphreys, M. Kainuma, J. Kala, N. Mahowald, Y. Mulugetta, Global warming of $1.5^{\circ}$ C. An IPCC Special Report on the impacts of global warming of $1.5^{\circ} \mathrm{C}$ above pre-industrial levels and related global greenhouse gas emission pathways, in the context of strengthening the global response to the threat of climate change, sustainable development, and efforts to eradicate poverty, Sustainable Development, and Efforts to Eradicate Poverty, (2018).

[3] U.S. Environmental Protection Agency, Inventory of U.S. Greenhouse Emissions and Sinks 1990-2018, (2020).

[4] The White House, A roadmap to build a climate-resilient economy, in, U.S. ClimateRelated Financial Risk, Washington D.C., 2021.

[5] V. Limaye, The Costs of Inaction: The Economic Burden of FossilFuels and Climate Change on Health in the United States, in: The Medical Society Consortium on Climate and Health, NRDC and WHPCA, 2021.

[6] S. Kaplan, A.B. Tran, Nearly 1 in 3 Americans experienced a weather disaster this summer, in: The Washington Post, U.S., September 4, 2021.

[7] A.A. Khasnis, M.D. Nettleman, Global warming and infectious disease, Arch Med Res, 36 (2005) 689-696. https://doi.org/10.1016/j.arcmed.2005.03.041

[8] U.S. Environmental Protection Agency, 40 CFR Parts 79 and 80 : Renewable Fuel Standard Program: Standards for 2020 and Biomass- Based Diesel Volume for 2021 and Other Changes in, Federal Register, 2020, pp. 7016-7085. 
[9] U.S. Code, Title 42 - The Public Health and Welfare, Chapter 85 Air Pollution Prevention and Control, in, 1990.

[10] U.S. Environmental Protection Agency, 40 CFR Parts 51, 52, 78 and 97: Revised Cross-State Air Pollution Rule Update for the 2008 Ozone NAAQS, in: Federal Register, 2021, pp. 23054-23235.

[11] U.S. Environmental Protection Agency, 40 CFR Part 63: Mercury and Air Toxics Standards for Power Plants Electronic Reporting Revisions, in, Federal Register, 2020, pp. 55744-55780.

[12] T.G. Bridgeman, J.M. Jones, I. Shield, P.T. Williams, Torrefaction of reed canary grass, wheat straw and willow to enhance solid fuel qualities and combustion properties, Fuel, 87 (2008) 844-856. https://doi.org/10.1016/j.fuel.2007.05.041

[13] J. Bourgois, M.C. Bartholin, R. Guyonnet, Thermal-Treatment of Wood - Analysis of the Obtained Product, Wood Science and Technology, 23 (1989) 303-310. https://doi.org/10.1007/Bf00353246

[14] W.-H. Chen, J. Peng, X.T. Bi, A state-of-the-art review of biomass torrefaction, densification and applications, Renewable and Sustainable Energy Reviews, 44 (2015) 847-866. https://doi.org/https://doi.org/10.1016/j.rser.2014.12.039

[15] Y. Donepudi, Impact of Pretreatment Methods on Fast Pyrolysis of Biomass, in Mechanical Engineering, Michigan Technological University, Houghton, MI, USA., 2017. https://doi.org/10.37099/mtu.dc.etdr/496

[16] J.S. Tumuluru, C.T. Wright, J.R. Hess, K.L. Kenney, A review of biomass densification systems to develop uniform feedstock commodities for bioenergy application, Biofuel Bioprod Bior, 5 (2011) 683-707. https://doi.org/10.1002/bbb.324 
[17] B. Arias, C. Pevida, J. Fermoso, M.G. Plaza, F. Rubiera, J.J. Pis, Influence of torrefaction on the grindability and reactivity of woody biomass, Fuel Processing Technology, 89 (2008) 169-175. https://doi.org/10.1016/j.fuproc.2007.09.002

[18] R.I. Radics, R. Gonzalez, E.M. Bilek, S.S. Kelley, Systematic Review of Torrefied Wood Economics, Bioresources, $12 \quad$ (2017) 6868-6884. https://doi.org/10.15376/biores.12.3.Radics

[19] W.Q. Li, J. Dumortier, H. Dokoohaki, F.E. Miguez, R.C. Brown, D. Laird, M.M. Wright, Regional techno-economic and life-cycle analysis of the pyrolysis-bioenergybiochar platform for carbon-negative energy, Biofuel Bioprod Bior, 13 (2019) 1428-1438. https://doi.org/10.1002/bbb.2043

[20] S. Whalley, S.J.W. Klein, J. Benjamin, Economic analysis of woody biomass supply chain in Maine, Biomass Bioenerg, $96 \quad$ (2017) 38-49. https://doi.org/10.1016/j.biombioe.2016.10.015

[21] S. Kaza, L.C. Yao, P. Bhada-Tata, F. Van Woerden, What a Waste 2.0: A Global Snapshot of Solid Waste Management to 2050, 2018.

[22] U.S. Environmental Protection Agency, Advancing Sustainable Materials Management: 2018 Fact Sheet, in, Washington DC, 2020.

[23] S. Boxman, B.F. Stanley, Analysis of MSW Landfill Tipping Fees - 2020, in, Environmental Research and Education Foundation, 2021.

[24] U.S. Environmental Protection Agency, Advancing Sustainable Materials Management: 2017 Fact Sheet, EPA 530-F-19-007 (2019). 
[25] B. Acharya, I. Sule, A. Dutta, A review on advances of torrefaction technologies for biomass processing, Biomass Conversion and Biorefinery, 2 (2012) 349-369. https://doi.org/10.1007/s13399-012-0058-y

[26] F. Campuzano, R.C. Brown, J.D. Martinez, Auger reactors for pyrolysis of biomass and wastes, Renewable \& Sustainable Energy Reviews, 102 (2019) 372-409. https://doi.org/10.1016/j.rser.2018.12.014

[27] T.A. Mamvura, G. Danha, Biomass torrefaction as an emerging technology to aid in energy production, Heliyon, 6 (2020) e 03531. https://doi.org/10.1016/j.heliyon.2020.e03531

[28] F. Cherubini, A.H. Strømman, Chapter 1 - Principles of Biorefining, in: A. Pandey, C. Larroche, S.C. Ricke, C.-G. Dussap, E. Gnansounou (Eds.) Biofuels, Academic Press, Amsterdam, 2011, pp. 3-24.

[29] Z. Xu, S.S. Kolapkar, S. Zinchik, E. Bar-Ziv, A.G. McDonald, Comprehensive kinetic study of thermal degradation of polyvinylchloride (PVC), Polymer Degradation and Stability, 176 (2020). https://doi.org/10.1016/j.polymdegradstab.2020.109148

[30] Z. Xu, S.S. Kolapkar, S. Zinchik, E. Bar-Ziv, L. Ewurum, A.G. McDonald, J. Klinger, E. Fillerup, K. Schaller, C. Pilgrim, Bypassing Energy Barriers in Fiber-Polymer Torrefaction, Frontiers in Energy Research, 9 (2021). https://doi.org/10.3389/fenrg.2021.643371

[31] A. Galadima, O. Muraza, Waste to liquid fuels: potency, progress and challenges, International Journal of Energy Research, 39 (2015) 1451-1478. https://doi.org/10.1002/er.3360

[32] A. Bauen, N. Bitossi, L. German, A. Harris, K. Leow, Sustainable Aviation Fuels Status, challenges and prospects of drop-in liquid fuels, hydrogen and electrification in 
aviation, Johnson Matthey Technology Review, 64 (2020) 263-278. https://doi.org/10.1595/205651320x15816756012040

[33] Q.Y. Li, A. Faramarzi, S. Zhang, Y. Wang, X. Hu, M. Gholizadeh, Progress in catalytic pyrolysis of municipal solid waste, Energy Conversion and Management, 226 (2020). https://doi.org/10.1016/j.enconman.2020.113525

[34] U. Arena, Process and technological aspects of municipal solid waste gasification. A review, Waste Manag, 32 (2012) 625-639. https://doi.org/10.1016/j.wasman.2011.09.025

[35] P. Brachi, F. Miccio, M. Miccio, G. Ruoppolo, Torrefaction of Tomato Peel Residues in a Fluidized Bed of Inert Particles and a Fixed-Bed Reactor, Energy \& Fuels, 30 (2016) 4858-4868. https://doi.org/10.1021/acs.energyfuels.6b00328

[36] J. Ratte, E. Fardet, D. Mateos, J.S. Hery, Mathematical modelling of a continuous biomass torrefaction reactor: TORSPYD (TM) column, Biomass Bioenerg, 35 (2011) 3481-3495. https://doi.org/10.1016/j.biombioe.2011.04.045

[37] R.W. Nachenius, F. Ronsse, R.H. Venderbosch, W. Prins, Biomass Pyrolysis, in: D.Y. Murzin (Ed.) Chemical Engineering for Renewables Conversion, Academic Press, 2013, pp. 75-139.

[38] P.N.Y. Yek, Y.W. Cheng, R.K. Liew, W.A.W. Mahari, H.C. Ong, W.H. Chen, W.X. Peng, Y.K. Park, C. Sonne, S.H. Kong, M. Tabatabaei, M. Aghbashlo, S.S. Lam, Progress in the torrefaction technology for upgrading oil palm wastes to energy-dense biochar: A review, Renewable \& Sustainable Energy Reviews, 151 (2021) 111645. https://doi.org/10.1016/j.rser.2021.111645

[39] B. Batidzirai, A.P.R. Mignot, W.B. Schakel, H.M. Junginger, A.P.C. Faaij, Biomass torrefaction technology: Techno-economic status and future prospects, Energy, 62 (2013) 196-214. https://doi.org/10.1016/j.energy.2013.09.035 


\section{Properties of Torrefied U.S. Waste Blends}

This section is based on the peer-reviewed paper titled "Properties of torrefied U.S. Waste blends" published in Frontiers in Energy Research. (2018) 6:65.

https://doi.org/10.3389/fenrg.2018.00065

\subsection{Abstract}

Power generation facilities in the U.S. are looking for a potential renewable fuel that is sustainable, low-cost, complies with environmental regulation standards, and is a drop-in fuel in the existing infrastructure. Although torrefied woody biomass meets most of these requirements, its high cost prevented its commercialization due to the use of woody biomass. Industrial waste blends (mostly renewable) are suitable for torrefaction and are an economically viable solution; this may prolong the life of some of the existing coal power plants. We focus on the torrefaction dynamics of the paper fiber-plastic waste blend of $60 \%$ fiber and $40 \%$ plastic and the characterization of its torrefied product as a function of reaction extent (mass loss). Two forms of the blend are used, one is un-densified, and the other is in the form of pellets with three times the density of the un-densified material. Torrefaction of these blends was conducted at $300^{\circ} \mathrm{C}$ in the mass loss range of $0-51 \%$. The torrefied product was characterized by moisture content, grindability, particle size distribution, energy content, molecular functional structure, and chlorine content. It was shown that although the torrefaction dynamics of the two forms differ significantly, their properties and composition depend on the mass loss. Fiber content was shown to decrease relative to plastic upon the extent of torrefaction. Further, the torrefied product demonstrates a similar grinding behavior to Powder River Basin (PRB) coal. Upon grinding, the fiber was concentrated in the smaller size fractions, while the plastic was concentrated in the larger size fractions.

\subsection{Introduction}

The U.S. Environmental Protection Agency (EPA) has accelerated regulatory pressure on utilities burning pulverized coal by issuing carbon emission guidelines on June 18, 2014 
[1]. The EPA has proposed state-by-state goals to achieve $\mathrm{CO}_{2}$ emission reductions, $30 \%$ from the power sector compared to $\mathrm{CO}_{2}$ emission levels in 2005 [2]. The ultimate fate and form of the EPA proposed rule may not be known for some time until the rule-making process is complete, but the history of utility emissions regulation and Supreme Court decisions on EPA rule-making authority indicates a high probability that some form of $\mathrm{CO}_{2}$ regulation will be implemented. Internationally, the U.S. has announced the reduction of greenhouse gas emissions by $26-28 \%$ below 2005 levels by 2025 [3].

Torrefied-biomass is a high-energy fuel that can be used in combustion, gasification, and pyrolysis, and is considered either fully or partially renewable and complies with the above EPA regulations [1]. Kiel [4] suggested the use of biomass for coal power plants. Potential users of torrefied biomass are suggested for refineries to produce bio-oil $[5,6]$ and syngas producers [7]. A considerable amount of studies, pilot-scale plants, patents, and commercial efforts have been devoted to torrefaction and torrefied materials. The entries "torrefaction" and "torrefied" in the title show 790 papers, 19 reviews, and 50 patents between 1990 and 2017. The 50 patents comprise many technologies for torrefaction, most of which are based on mechanical mixing. Although torrefaction technology is well developed, it has not yet moved to the commercial market. The consensus is that the main hindrance to the commercialization of this technology is the use of high-cost woody biomass as a feedstock $[8,9]$.

The use of wastes (for example, municipal solid wastes - MSW - or industrial manufacturing residuals - fiber and plastic blends) can be the answer to the deployment of this technology as tipping fees are paid for the waste destined for landfill. U.S. wastes possess substantial energy content that can be utilized for energy and power [10, 11]. Wastes, as a feedstock in torrefaction, has been suggested by Bar-Ziv et al. [12,13] and others, using regular torrefaction [14], wet torrefaction [15], and microwave torrefaction $[16,17]$. Some difficulties have been recognized while using waste for torrefaction because of difficulties in conveying, pretreatment, and potential emissions. Other hurdles were also identified while using waste feedstocks in torrefaction: (i) inconsistency in feedstock, (ii) possibility of high $\mathrm{Cl}, \mathrm{S}$, and $\mathrm{N}$ content, (iii) binders required for compaction of torrefied 
biomass [12, 13], (iv) high moisture content in MSW and the like, and (v) high contaminant content that leads to emissions issues.

The EPA regulatory actions [2] regarding the use of alternative fuels raise the likelihood that torrefied waste will find a market to replace pulverized coal in energy production. One other recent development affecting the market for torrefied biomass from MSW was a memorandum from the EPA's Office of Air and Radiation addressing the framework for determining the carbon neutrality of biomass [18].

Table 2.1. U.S. wastes, quantities, and heat content (on a dry basis).

\begin{tabular}{lllll}
\hline \multirow{2}{*}{ Waste type } & $\begin{array}{l}\text { Quantity, } \\
\text { in kton [19] }\end{array}$ & $\mathbf{\%}$ & MJ/kg & Source \\
\hline Paper & 19,470 & $18 \%$ & 14.7 & {$[20]$} \\
\hline Plastic & 25,100 & $23 \%$ & 35.7 & {$[21]$} \\
\hline Rubber and leather & 4,150 & $4 \%$ & 36.5 & {$[22]$} \\
\hline Textile & 10,000 & $9 \%$ & 17 & {$[23]$} \\
\hline Wood & 11,010 & $10 \%$ & $15-16$ & {$[24]$} \\
\hline Food & 29,319 & $27 \%$ & $15-16$ & {$[11]$} \\
\hline Yard trimmings & 10,790 & $10 \%$ & $15-16$ & {$[24]$} \\
\hline Total & $\mathbf{1 0 9 , 8 3 9}$ & $\mathbf{1 0 0 \%}$ & - & - \\
\hline
\end{tabular}

There is a significant amount of waste in the U.S., which is being disposed of in landfills, that can be used as an energy source. Table 2.1 summarizes the various wastes, totaling $\sim 110,000$ ton per year, as well as their calorific values. This significant amount, if torrefied, can replace coal and be considered renewable and clean fuel. From an energy perspective, except for plastic wastes with a very high heat content of $\sim 36 \mathrm{MJ} / \mathrm{kg}$, the rest have heat values in the range of $15-17 \mathrm{MJ} / \mathrm{kg}$. The weighted average heat content in U.S. waste is $\sim 21 \mathrm{MJ} / \mathrm{kg}$, comparable to that of Powder River Basin (PRB) coal with a heat content of 17 to $19 \mathrm{MJ} / \mathrm{kg}$ [25]. This indicates that one dry ton of U.S. waste can replace 1 ton of PRB coal. With current coal consumption of $\sim 650,000$ tons/d of coal in the U.S. (with over $50 \%$ PRB coal) [10], U.S. waste could replace well over $15 \%$ of the U.S. coal. 
The present paper deals with the torrefaction of certain U.S. wastes, including plastics, which can be converted into drop-in fuels to replace coal in coal power plants. Specifically, the paper deals with wastes blends from the paper/carton (wood fibers) and plastics. As such, the torrefied fuel should be shown to match the characteristics and properties of coals.

\subsection{Materials and Methods}

\subsubsection{Materials}

Table 2.2. Properties of CE material averaged over seven years.

\begin{tabular}{llllllll}
\hline $\begin{array}{l}\text { Proximate } \\
\text { Ultimate }\end{array}$ & & Ash & $\mathbf{\%}$ & Oth & ppm & $\begin{array}{l}\text { Fusion } \\
\text { Temp. }\end{array}$ & ${ }^{\circ} \mathbf{C}$ \\
\hline Moisture & $3.3 \pm 0.5$ & $\mathrm{SiO}_{2}$ & $33 \pm 18$ & $\mathrm{Cl}$ & $1162 \pm 48$ & Reducing & \\
\hline Ash, & $6.0 \pm 0.6$ & $\mathrm{~A}_{2} \mathrm{O}_{3}$ & $27 \pm 11$ & $\mathrm{~F}$ & $75 \pm 75$ & Deformation & 1,319 \\
\hline Volatiles & $83.5 \pm 2.6$ & $\mathrm{TiO}_{2}$ & $7.2 \pm 3.4$ & $\mathrm{Hg}$ & $0.01 \pm 0.01$ & Softening & 1,359 \\
\hline F. Carbon & $7.2 \pm 2.0$ & $\mathrm{Fe}_{2} \mathrm{O}_{3}$ & $0.9 \pm 0.9$ & $\mathrm{Sn}$ & $2.9 \pm 0.9$ & Hemispherical & 1,374 \\
\hline Sulfur & $0.2 \pm 0.1$ & $\mathrm{CaO}^{2}$ & $21 \pm 12$ & $\mathrm{As}$ & $1.1 \pm 0.9$ & Fluid & 1,396 \\
\hline Carbon & $55.4 \pm 1.8$ & $\mathrm{MgO}$ & $3.0 \pm 3.0$ & $\mathrm{Be}$ & $0.3 \pm 0.8$ & Oxidizing & \\
\hline Hydrogen & $7.9 \pm 0.3$ & $\mathrm{~K}_{2} \mathrm{O}$ & $0.6 \pm 0.4$ & $\mathrm{Cr}$ & $2.2 \pm 1.2$ & Deformation & 1,327 \\
\hline Nitrogen & $0.3 \pm 0.1$ & $\mathrm{Na}_{2} \mathrm{O}$ & $1.6 \pm 0.7$ & $\mathrm{Co}$ & $0.21 \pm 0.16$ & Softening & 1,369 \\
\hline Oxygen & $27.1 \pm 1.6$ & $\mathrm{MnO} 2$ & $0.02 \pm 0.01$ & $\mathrm{~Pb}$ & $1.1 \pm 1.4$ & Hemispherical & 1,384 \\
\hline HHV & $26.1 \pm 1.1$ & $\mathrm{BaO}$ & $0.2 \pm 0.2$ & $\mathrm{Ni}$ & $0.81 \pm 0.57$ & Fluid & 1,406 \\
\hline (MJ/kg) & & $\mathrm{Other}$ & $2.8 \pm 1.4$ & $\mathrm{Se}$ & $1.5 \pm 1.8$ & & \\
\hline
\end{tabular}

Convergen Energy (CE) developed a fuel by sorting and blending feedstocks of fiber and plastic, removing metal, and shredding down to $25 \mathrm{~mm}$ by $1 \mathrm{~mm}$ flakes by which waste blends of fibers (from paper, label matrix residuals, and laminated non-recyclable papers/plastics and the like) and plastics, become uniform, flowable and consistent, with a bulk density in the range $200-300 \mathrm{~kg} / \mathrm{m}^{3}$. CE also developed a pelletization process that produces pellets (12 $\mathrm{mm}$ OD and $50 \mathrm{~mm}$ long) that are rather uniform with a density of 
$750-800 \mathrm{~kg} / \mathrm{m}^{3}$ and bulk density of $400-450 \mathrm{~kg} / \mathrm{m}^{3}$. The binder for the CE palletization process was the plastic component in the blend.

CE characterized their product for over seven years with properties that showed rather consistent products. Table 2.2 shows the average properties of waste blends of $60 \%$ fiber with $40 \%$ plastics, with standard deviations of its product over seven years. As seen, the properties in Table 2.2 are indicative of reproducible and consistent material. This material was the feedstock in the torrefaction process, both in un-densified and densified forms.

In this study, both the un-densified and the densified material (pellets indicated above) were used. Table 2.1 shows both forms before torrefaction used in this study: (a) undensified CE material; and (b) CE pellets.
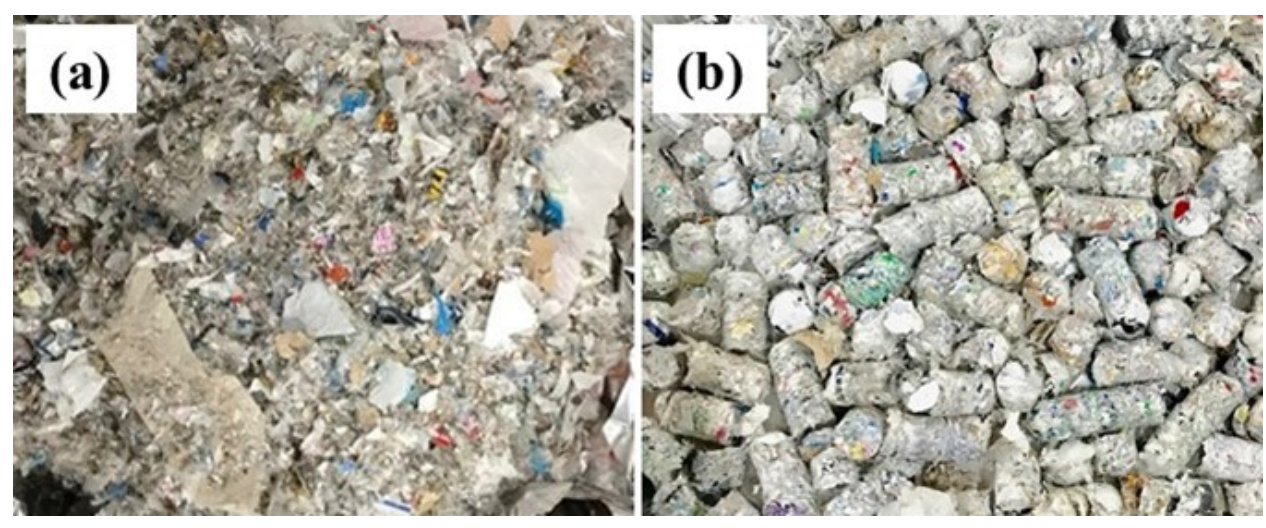

Figure 2.1. (a) Un-densified CE material. (b) Densified (pellets) CE material.

\subsubsection{Waste and Product Characterization}

The properties depicted in Table 2.2 are part of the routine characterization of CE products, both before and after pelletization. Other characterization methods are as follows. All data presented in this paper were averaged over 3-5 data points.

\subsubsection{Grinding}

Grindability is an important characteristic that has an essential impact on the applicability of torrefied material as a drop-in fuel in coal power plants. Typically, coal power plants use pulverizers of type MPS 89 [26]; however, for the grinding tests, blade grinders (that 
operate at 24,000 rpm) were used. The grinding results presented in this paper are for comparison purposes. Two blade grinders were used in this study: Model CIT-FW-800 and Model CIT-FW-200. An online power meter - Wattsup pro was used for power vs. time measurements. Also, note that CE material was torrefied in both non-densified and densified (pellets) forms, and grinding tests were carried out for both materials. Two types of grinding tests were performed as follows:

1. A 100-200 g torrefied sample (either un-densified or pellet form) was placed in the grinder, which was continuously operated for up to $120 \mathrm{~s}$ time interval (to avoid damage to the motor); the power was measured continuously during the experiment. If necessary, grinding was repeated similarly for a total of $1800 \mathrm{~s}$.

2. A 100-200 g torrefied sample was placed in the grinder and operated for short time intervals of 15-30 s. After each grinding run (time interval), the pulverized material was sifted to seven sizes, in the range of 150-2,000 $\mu \mathrm{m}$, after which all size fractions were mixed and were further pulverized for another time interval. This process was repeated until the size fractions reached asymptotic values.

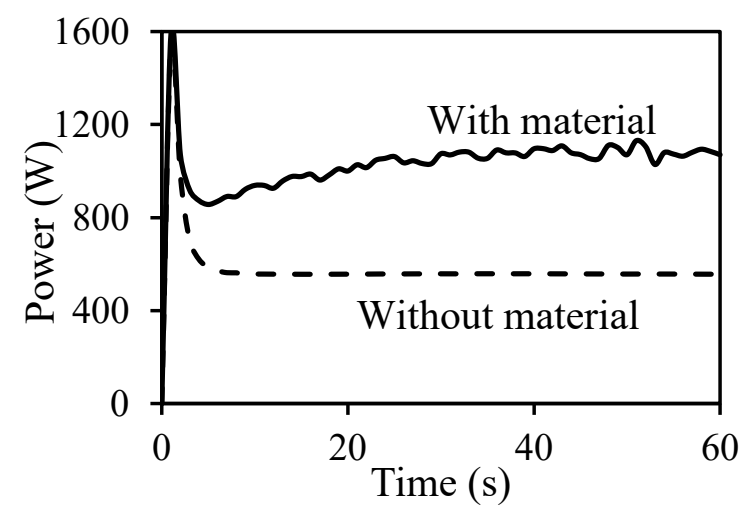

Figure 2.2. Examples of power vs. time traces of the grinder without material and with $200 \mathrm{~g}$ torrefied un-densified material.

In both methods, the power was measured with and without the sample in the grinder. The power without the sample was subtracted from the sample, which provided the net power required to grind the sample. Table 2.2 shows a typical plot of power vs. time with and 
without a sample (in this case, $200 \mathrm{~g}$ of a torrefied non-densified material at $21.4 \%$ mass loss during torrefaction). Note that an overshoot accompanies the startup in both cases.

\subsubsection{Sifting}

Sifting of the pulverized material was carried out in a W.S Tyler, RX-86 model sieve shaker. Seven size fractions were obtained with screen sizes of $75 \mu \mathrm{m}, 150 \mu \mathrm{m}, 180 \mu \mathrm{m}$, $250 \mu \mathrm{m}, 425 \mu \mathrm{m}$, and $850 \mu \mathrm{m}$. At each time interval after grinding, all the material inside the grinder was taken out and put into the shaker to sift for an hour. The weights of all the screens before and after the sifting were measured. The difference in these weights provided the sample weight of each size fraction.

\subsubsection{Chloride and Chlorine}

The chloride dissolved liquid samples from high shear mixing (described below) were diluted by a factor of a hundred. Chloride was measured in this aqueous solution using Milwaukee Instruments, MI414 model Chloride Professional Photometer. Two cuvettes were used for the experiments. One is the blank sample filled with $10 \mathrm{ml}$ of distilled water, and another cuvette filled with $10 \mathrm{ml}$ of a diluted liquid sample. Then $0.5 \mathrm{ml}$ of reagent- 1 (Thiocyanate and Mercury) was added to both cuvettes, and after $30 \mathrm{~s}$ of swirling, $0.5 \mathrm{ml}$ of reagent-2 (Nitric Acid) was added to both cuvettes. After another $30 \mathrm{~s}$ of swirling, the blank sample was first measured and zeroed; then, the liquid sample was inserted in a Chloride photometer which directly showed the chloride content of the liquid sample.

Total Chlorine in the solid phase was measured using the ASTM D4208-1 standard. The testing process included the following key steps: The weighed solid sample was burned in a bomb filled with 2-3 MPa oxygen. After the combustion, a diluted base solution (2\% $\mathrm{Na}_{2} \mathrm{CO}_{3}$ solution) was added to the bomb to react with the chloride product. Water was then used to wash the inside cylinder wall of the bomb. All the washings were collected in a beaker, and the ionic strength was adjusted using $\left(\mathrm{NaNO}_{3}\right.$ solution) [27]. The total chloride content of the solid material is determined by measuring the solution's potential with a chlorine ion-selective electrode using a potentiometric titration (916 Ti-Touch) with a silver nitrate solution. 


\subsubsection{Heat Content}

Heat content was measured by Parr 6100 Compensated Jacket Calorimeter, where $1 \mathrm{~g}$ samples were placed inside sampling bowl/tray, and the sample was connected to the electric circuit using fuse string. This setup was put into a bomb and then filled with oxygen. The bomb was then put into a bucket with $2,000 \pm 0.5 \mathrm{~g}$ of distilled water. The process involved the ignition of the sample using an ignition circuit and subsequent measurement of temperature difference after the burning of the measured sample. The calorimeter displayed the heating value based on the calibration and temperature difference.

\subsubsection{Moisture Content}

Moisture content was measured using an HFT-1000 moisture analyzer. Around $1 \mathrm{~g}$ of sample was put into the analyzer. After starting the analysis, the heating coil would heat up, and the moisture inside the material would volatilize. The analyzer would show the moisture content by measuring the weight difference before and after the experiment. Moisture content was measured before and after torrefaction. The values were relatively consistent before torrefaction; moisture was in the range of $2-3 \%$, and after torrefaction, $0 \%$.

\subsubsection{Density Measurements}

Density measurement of pellets was done using a scale (model A\&D HR-60) with readability of $0.0001 \mathrm{~g}$. Archimedes' principle/buoyancy method was used for density measurement. A simple stand with a suspended metal wire setup was used to dip the pellet in water. The procedure followed was as below:

1. The pellet was placed on a scale, and dry weight, $w$, was noted.

2. A beaker filled with a set level of distilled water was placed on the scale and tared zero.

3. The stand and wire setup were placed next to scale such that some part of the wire dipped in the water. The scale was tared zeroed again. 
4. The sample was attached to a wire, and the sample was dipped in water. Care was taken that the entire sample dipped in well and did not touch the bottom of the beaker. The reading with the suspended sample $w_{s}$, was noted.

The density was obtained from the ratio of suspended sample weight, $w_{s}$, and dry weight $w$.

\subsubsection{FTIR}

FTIR spectra were obtained on (i) 20 randomly selected pieces of mixed waste and (ii) screened fractions of the torrefied material (in triplicate) using a Nicolet-iS5 FTIR spectrometer, 64 scans, with an attenuated total reflectance accessory (ZnSe crystal, iD5) and data analyzed and averaged with the OMNIC v9.8 software and Aldrich, Hummel, and Nicolet spectral libraries. Carbonyl index (CI), cellulose index (CeI), and hydroxyl index (HI) were calculated as the ratio of the band intensity (absorbance) at $1720 \mathrm{~cm}^{-1}, 1024 \mathrm{~cm}^{-}$ ${ }^{1}$, and $3342 \mathrm{~cm}^{-1}$, respectively, to the band $2916 \mathrm{~cm}^{-1}$ for the $-\mathrm{CH}_{2}$ - groups [28].

\subsubsection{Experiments}

\subsubsection{Torrefaction}

Torrefaction experiments were carried out by placing a motionless sample at the center of a convection furnace, Lindenberg/Blue type BF51828C-1, with inert gas flow, either $\mathrm{N}_{2}$ or $\mathrm{CO}_{2}$, to avoid oxidation of the material. For un-densified $\mathrm{CE}$ material, typically samples of $150 \mathrm{~g}$ were placed in a thin aluminum foil at the furnace center, with residence time in the range of 1-40 min. For CE pellets, the sample size was $\sim 300 \mathrm{~g}$ and torrefaction residence time was between 3 to $120 \mathrm{~min}$.

\subsubsection{Removal of Soluble Minerals}

Soluble minerals in the torrefied material were removed by a method developed by Donepudi [29]. In the present study, a $7.5 \mathrm{~g}$ torrefied sample was placed in a high shear mixer of Charles Ross \& Son Company (Model HSM-100LSK-1), where water was added to the sample in a 20:1 ratio by weight, and the mixer was rotated at $\sim 7,000 \mathrm{rpm}$ for $5 \mathrm{~min}$. 
A suspension generated was filtered by an $11 \mu \mathrm{m}$ porosity paper filter (Whatman 10010155 quantitative filter paper circles), followed by another filtration by $1.6 \mu \mathrm{m}$ porosity paper filter (Whatman 1820-047 glass microfiber binder-free filter). The two filtration

processes produced a transparent solution with no apparent suspended particles or colloids. The aqueous solution was measured for chloride as described above.

\subsection{Results}

\subsubsection{Torrefaction}

As mentioned, all current torrefaction experiments were carried out by introducing undensified material and pellets in a convective furnace at $300{ }^{\circ} \mathrm{C}$, with the initial temperature of the particle, $T_{o}$, at ambient temperature. The material was placed in the furnace center and was kept stationary. In this case, the particle was heated by heat transported from the hot walls at temperature $\left(T_{w}\right)$ to the particle surface by convection; the heat was then transported into the particle by conduction. Numerous torrefaction experiments were carried out for pellets as well as un-densified material. The results show clear trends in both cases, with a delay in the onset of mass loss followed by an increase in the mass loss with time. The dynamic behavior in the two cases differed significantly; for the undensified material, the mass loss starts at around $3 \mathrm{~min}$, whereas for the pellets, it starts at around $9 \mathrm{~min}$.

Further, for the un-densified material, mass loss increase with time was faster compared to pellets. This behavior was indicative of the heat-transfer-chemical-reaction system. To determine the regime that best fits the description of the system behavior, one should start with the analysis with Biot number $(B i)$ and thermal Thiele modulus $(M)$; the former is related to the heating regime of the particle, and the latter relates to the propagation of the torrefaction reaction within the particle. The $B i$ and $M$, which are defined as:

$$
B i=\frac{h}{\lambda / L_{c}}
$$




$$
M=\frac{R^{\dagger}}{\lambda /\left(c_{p} L_{c}^{2}\right)}
$$

where $h$ is the convective heat transfer coefficient, $\lambda$ is the particle thermal conductivity, $L_{c}$ is the particle characteristic length, $R^{\dagger}$ is the torrefaction reaction rate within the particle, $c_{p}$ is the particle heat capacity, and $\rho$ is particle density.

The parameters required to determine $B i$ and $M$ from Eqs. (2.1) and (2.2) are not easy to determine as the material is not well defined and, therefore, can only provide an estimate. The value of heat transfer coefficient, $h$, was selected to be $10\left(\mathrm{~W} / \mathrm{m}^{2}-\mathrm{K}\right)$ and was the closest to the flow conditions prevailing in the furnace [30]. The value for thermal conductivity, $\lambda$, varies between $0.15(\mathrm{~W} / \mathrm{m}-\mathrm{K})$ for PVC, to $0.38(\mathrm{~W} / \mathrm{m}-\mathrm{K})$ for polyethylene $[30,31]$; for biomass and fibers the values range in 0.03-0.29 (W/m-K) [32]. A value of $0.2(\mathrm{~W} / \mathrm{m}-\mathrm{K})$ was selected, which was an average of the above. Literature data on reaction rates of the material used were even more scattered than thermal conductivity; therefore, they were measured by thermogravimetry in the furnace. The rate of mass loss of the CE material from both measurements at $300{ }^{\circ} \mathrm{C}$ was about $0.03 \% / \mathrm{s}$, where the material temperature has been equal to the wall temperature $\left(T_{w}\right)$; using the density of each form to obtain a value of $0.2-0.3\left(\mathrm{~kg} / \mathrm{m}^{3}-\mathrm{s}\right)$ for the un-densified material and $0.1-0.2\left(\mathrm{~kg} / \mathrm{m}^{3}-\mathrm{s}\right)$ for the pellets. In this study, the density was $1,150\left(\mathrm{~kg} / \mathrm{m}^{3}\right)$ for the un-densified material and $850\left(\mathrm{~kg} / \mathrm{m}^{3}\right)$ for the pellets. Heat capacity was both taken from the literature [30] and measured to yield an acceptable value of 1,600 (J/kg-K) [29]. The characteristic lengths of the two forms were measured (very accurately for the pellets and rather scattered for the un-densified material).

Table 2.3 summarizes all properties required to determine $B i$ and $M$, yielding values for (i) $B i$ of $\sim 0.1$ for the un-densified material and $\sim 0.35$ for the pellets and (ii) $M$ of $\sim 0.01$ for the un-densified material and $\sim 0.08$ for the pellets. The values for $B i$ in the range $0.1-0.35$ indicate that the rate of heat transfer by convection from the furnace walls to the particle was lower than the rate of heat transfer into the particle. The values of $M$ are in the range 0.01-0.08, which indicates that the reaction rate was significantly slower than the heat transfer into the particle, and the particles equilibrated their temperature faster than the 
reaction rate. This analysis indicates that the reaction propagation was controlled by the heat transfer rate from the furnace walls to the particle surface, after which the particle temperature equilibrates instantly.

Table 2.3. Estimated values for the parameters to determine the Bi and M.

\begin{tabular}{lll}
\hline Parameter & Value & Source \\
\hline$h, \mathrm{~W} / \mathrm{m}^{2}-\mathrm{K}$ & 10 & {$[30]$} \\
\hline$\lambda$ for CE material, W/m-K & 0.2 & {$[30]$} \\
\hline$R^{\dagger}$ for un-densified material, & 0.3 & Measured in the current study \\
$\mathrm{kg} / \mathrm{m}^{3}-\mathrm{s}$ & & \\
\hline$R^{\dagger}$ for pellets, $\mathrm{kg} / \mathrm{m}^{3}-\mathrm{s}$ & 0.2 & Measured in the current study \\
\hline$\rho$ for un-densified material, $\mathrm{kg} / \mathrm{m}^{3}$ & 1150 & Measured in the current study \\
\hline$\rho$ for pellets, $\mathrm{kg} / \mathrm{m}^{3}$ & 850 & Measured in the current study \\
\hline$c_{p}, \mathrm{~J} / \mathrm{kg}-\mathrm{K}$ & 1600 & {$[29,30]$} \\
\hline$L_{c}$ thickness for un-densified & 0.002 & Measured in the current study \\
material, $\mathrm{m}$ & & \\
\hline$L_{c}$ diameter for pellets, $\mathrm{m}$ & 0.007 & Measured in the current study \\
\hline$B i$ for un-densified material & 0.1 & Current result \\
\hline$B i$ for pellets & 0.35 & Current result \\
\hline$M$ for un-densified material & 0.01 & Current result \\
\hline$M$ for pellets & 0.08 & Current result \\
\hline
\end{tabular}

Establishing that the torrefaction reaction rate was controlled by the heat transfer from the walls to the particle surface and that the particle temperature was uniform at all times means that the reaction propagates with the rate of the ramp-up of the particle temperature. To calculate the particle temperature, the equation of the heat rate, $d Q(t) / d t$, from the walls to the particle surface was needed to be solved, which was equal to

$$
\frac{d Q(t)}{d t}=h A\left[T_{w}-T_{s}(t)\right]
$$


where $\mathrm{Tw}$ and $\operatorname{Ts}(\mathrm{t})=\mathrm{T}(\mathrm{t})$ are wall and particle surface (or particle) temperatures, respectively. $Q(t)$ is the heat required to increase the particle temperature, or

$$
Q(t)=m c_{p}\left[T(t)-T_{o}\right]+m h_{r}
$$

where $m$ and $c_{p}$ are particle mass and specific heat capacity, respectively, $T_{o}$ is the particle core temperature, which is also equal to the initial temperature of the particle, and $h_{r}$ is the enthalpy of reaction.

It was challenging to find values for $h_{r}$ as the torrefied material was not well defined; it comprises fibers (mainly cellulose) and a large variety of plastic materials. Cellulose torrefaction in the $25-300^{\circ} \mathrm{C}$ temperature range starts as an endothermic reaction and continues as an exothermic reaction [33]. Enthalpies of reaction for plastic in the same temperature range were always positive and varied in the range (12.55-147.86 J/kg) [34], which is smaller than the value of $c_{p}\left(T-T_{o}\right)(\sim 400 \mathrm{~kJ} / \mathrm{kg})$ in Eq. (2.4). Thus, for simplification, this term was ignored. Introducing Eq. (2.4), without $h_{r}$, into Eq. (2.3) and integration from $T_{w}$ to $T(t)$ yields

$$
\frac{T_{w}-T(t)}{T_{w}-T_{o}}=e^{-\frac{t}{\tau}}
$$

where $\tau$ is a characteristic time, defined as

$$
\tau=\frac{m c_{p}}{h A}
$$

For the pellets (cylinders), $\tau_{c y l}=d \rho c_{p} / 4 h$ ( $d$ is cylinder diameter, $\rho$ is particle density) and for the un-densified material (slab) it is $\tau_{s l a b}=d \rho c_{p} / 2 h$ ( $d$ is slab thickness). Rearrangement of Eq. (2.5) yields

$$
T^{*}(t)=1-\left(1-\frac{T_{o}}{T_{w}}\right) e^{-\frac{t}{\tau}}
$$

$T^{*}$ is defined as 


$$
T^{*}(t)=\frac{T(t)}{T_{w}}
$$

To model the mass loss, the torrefaction reaction rate was assumed to be represented by a first-order rate, which is a rather common assumption in many torrefaction studies [35, 36], or

$$
R^{\dagger}=\rho \frac{d \alpha(t)}{d t}=-\rho k \alpha(t)
$$

where $a=m / m_{o}$ is the ratio of mass-to-initial-mass, $k$ is rate coefficient assumed to follow an Arrhenius behavior,

$$
\rho k(T)=A^{\dagger} e^{\frac{-T_{a}}{T(t)}}
$$

where $A^{+}$is a pre-exponential factor and $T_{a}$ is a characteristic temperature equals $T_{a}=E_{a} / R$, $E_{a}$ is the activation energy, and $R$ is the gas constant. Introducing Eq. (2.10) into Eq. (2.9) and integrating yields an expression for the mass loss, $1-\alpha$, equals

$$
1-\alpha=1-e^{-\int_{0}^{t} k d t}
$$

The required values for determining $\tau$, Eq. (2.6), for each case are given in Table 2.3. Introducing these values in Eq. (2.6) yields $\tau_{s l a b}=184$ (s) and $\tau_{c y l}=475$ (s), the subscript $s l a b$ is for the un-densified material and $c y l$ is for the pellets. Using these values, the particle temperatures were calculated and presented in Figure 2.3. As noted, the particle temperature in the un-densified case increases much faster than that of the pellets. Note from Figure 2.3 that the temperature of the un-densified material reaches the wall temperature after 10 minutes, whereas for the pellets, it reaches the wall temperature after 30 minutes. 


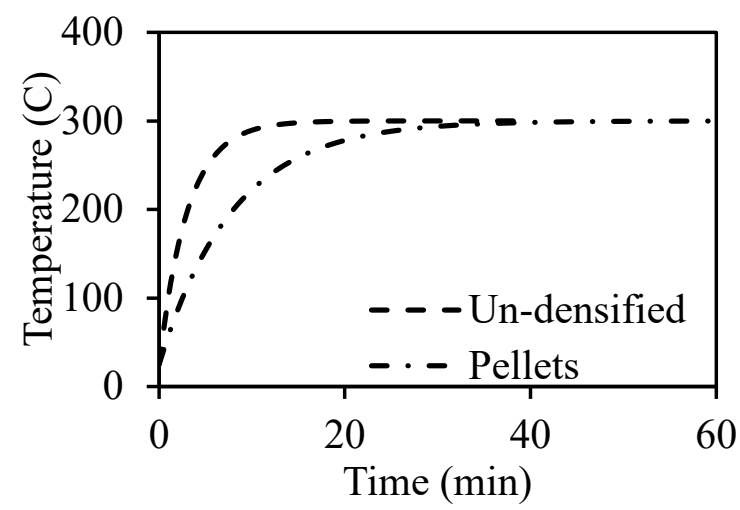

Figure 2.3. Temperature transient for the un-densified material and the pellets, using Eq. (2.7) and characteristic times of 160 (s) for the former and 475 (s) for the later.

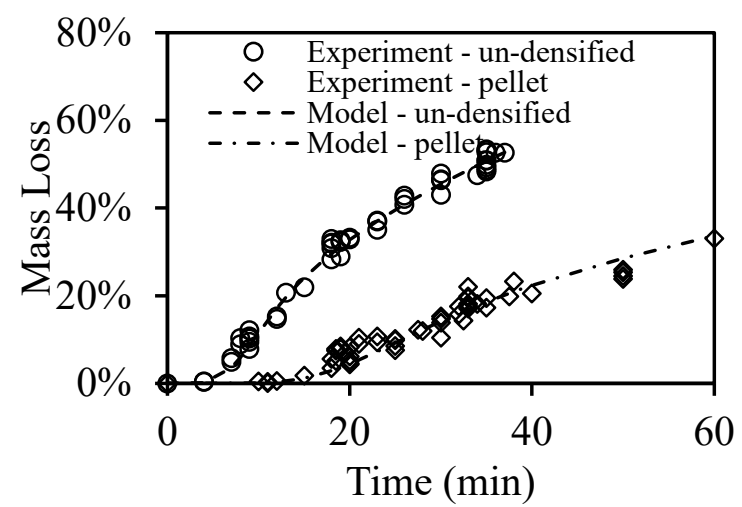

Figure 2.4. Experimental and modeled mass loss transients for the un-densified material and the pellets, using Eq. (2.11), the temperature transients of Figure 3, and fitting for Ta and $\mathrm{A} \dagger$.

The values for $\left(A^{\dagger} / \rho\right)$ and $T_{a}$ were determined by fitting the model results for mass loss of Eq. (2.11), using the temperature transients of Eq. (2.7) Figure 2.3, to the experimental results. Figure 2.4 shows the measured mass loss vs. time data (scattered results) and the model results using Eq. (2.11). Clearly, the model results yielded an excellent fit to the experimental data. The fitting process yielded for the un-densified material (slab) values of $\left(A^{\dagger} / \rho\right)_{\text {slab }}=1.23 \times 10^{8}$ and $\left(T_{a}\right)_{s l a b}=15,200(K)$, and for the pellets (slab) values of $\left(A^{\dagger} / \rho\right)$ slab $=1.08 \times 10^{8}$ and $\left(T_{a}\right)_{c y l}=15,800(\mathrm{~K})$. The values of $A^{\dagger} / \rho$ and $T_{a}$ for both forms of materials are very close to each other which is a strong indication that the model proposed here is representing the actual system behavior rather well. 


\subsubsection{Grinding Energy}

The method of determining the grinding behavior has been explained above, with power that was continuously measured as a function of time during grinding for a given sample weight. Numerous grinding tests were conducted, in the mass loss range $10-51 \%$, for the two forms of torrefied materials: un-densified and pellets. All net power transient results portrayed distinct behavior that showed two characteristic times: short and much longer. Further, the net grinding power transients for all samples fitted a double exponential rise of the form:

$$
P(t)=a_{1}\left(1-e^{-\frac{t}{\tau_{1}}}\right)+a_{2}\left(1-e^{-\frac{t}{\tau_{2}}}\right)
$$

where $\tau_{1}$ and $\tau_{2}$ are the short (1) and long (2) characteristic times, respectively, and $\mathrm{a}_{1}$ and $\mathrm{a}_{2}$ are the asymptotic values of the power for the short and long characteristic times, respectively.
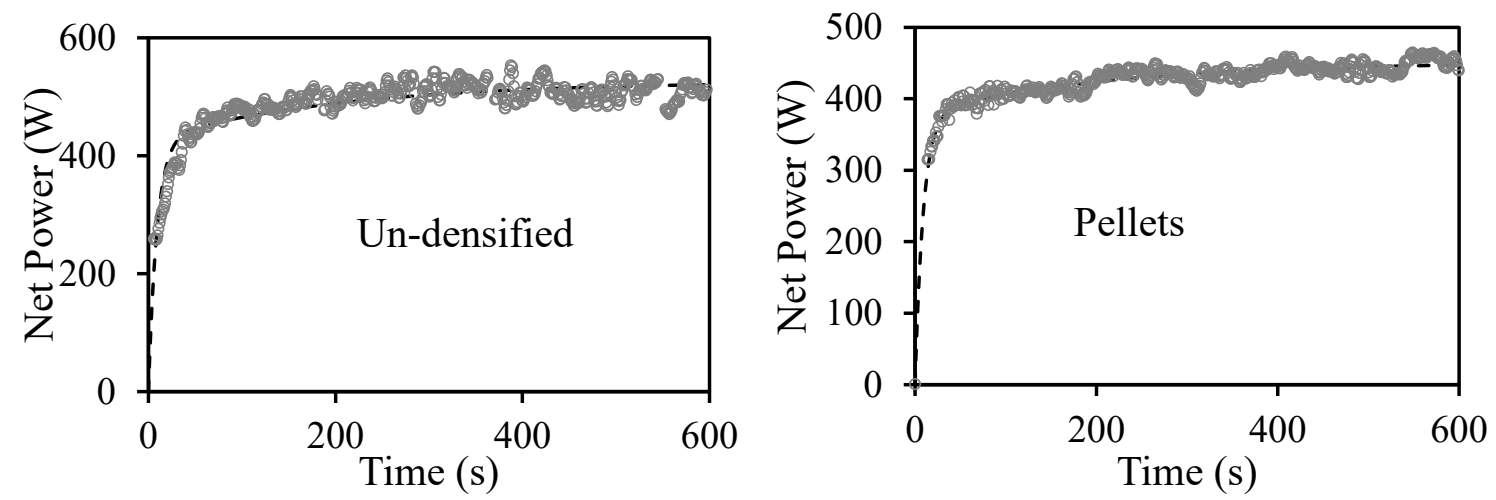

Figure 2.5. Symbols - measured net power vs. time of $200 \mathrm{~g}$ samples during grinding of torrefied CE, un-densified material and pellets. Dashed lines, fits of net power to Eq. (2.12) for the short characteristic time, $\tau_{1}=9.2 \mathrm{~s}$; and characteristic time $\tau_{2}=203.0 \mathrm{~s}$.

All results for the torrefied samples and pellets in the range 10-51\% mass loss were fitted to Eq. (2.12) to yield: for the short characteristic time of $\tau_{l}=9.1 \pm 0.5 \mathrm{~s}$, and for a long time, it was $\tau_{2}=203 \pm 10 \mathrm{~s}$ with the respective asymptotic values of $a_{1}=378.1 \mathrm{~W}$ and $a_{2}=73.0 \mathrm{~W}$ that varied within $\pm 5 \%$. To demonstrate the general behavior of torrefied samples, Figure 
2.6 shows normalized net grinding power (by the asymptotic values) vs. time for the short time range, showing clearly identical behavior for all samples tested. The dashed line in the figure is a unity line that shows the normalized asymptotic value. The fact that the grinding dynamics is characterized by two characteristic times, that significantly differ from each other, indicates clearly that there are two materials. A detailed discussion of these two materials is given in the energy content section below.

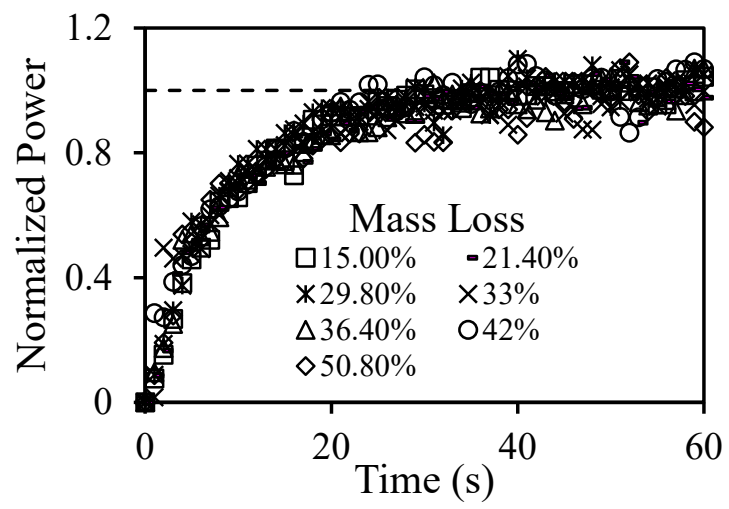

Figure 2.6. Normalized net grinding power vs time for torrefied material at various mass losses; with $\tau_{\mathrm{g}}=9.1$ (s).

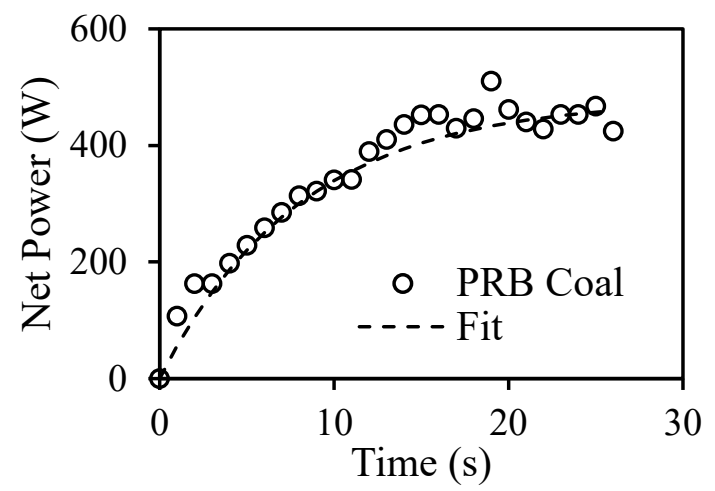

Figure 2.7. Grinding power vs. time for PRB coal with $\tau_{\mathrm{g}}=9.1$ (s).

As will be shown below, most of the material was ground and characteristic grinding energy can be determined by integrating the power over a certain time, which we selected as $1 \tau_{\mathrm{g}}, 2 \tau_{\mathrm{g}}$, and $3 \tau_{\mathrm{g}}$ (or, $8.1 \mathrm{~s}, 16.2 \mathrm{~s}, 24.3 \mathrm{~s}$ ). Table 2.4 shows the values of the specific grinding energy for three characteristic grinding times, $1 \tau_{g}, 2 \tau_{g}, 3 \tau_{g}$, where $\tau_{g}=8.1(\mathrm{~s})$ in $\mathrm{kJ} / \mathrm{kg}$ and in commonly used $\mathrm{kWh} /$ tonne units. As expected, the specific grinding energies 
increase strongly with the integration time. The values determined here are similar to values obtained in other studies at $8.23 \mathrm{kWh} /$ tonne [37]. For comparison, grinding characteristics of PRB were also studied with power vs. time results for a $200 \mathrm{~g}$ PRB coal sample shown in Figure 2.7Figure 2.6 . A fit of these results with characteristic grinding time, $\tau_{g}$, of 8.1 was done and specific grinding energies were calculated as shown in Figure 2.4. The values for the specific grinding energies for the torrefied (un-densified) material are within the experimental uncertainty to those of the PRB coal and smaller than the energy required to grind the torrefied biomass [38].

Table 2.4. Specific grinding energy

\begin{tabular}{|c|c|c|c|}
\hline \multirow[b]{2}{*}{ Grinding specific energy } & \multicolumn{3}{|c|}{ Integration time } \\
\hline & $1 \tau_{\mathrm{g}}$ & $2 \tau_{\mathrm{g}}$ & $3 \tau_{\mathrm{g}}$ \\
\hline un-densified & & & \\
\hline material, $\mathrm{kJ} / \mathrm{kg}(\mathrm{kWh} /$ tonne $)$ & $9.3 \pm 0.8(2.59)$ & $25.7 \pm 1.5(7.13)$ & $44.7 \pm 2.5(12.4)$ \\
\hline PRB coal, $\mathrm{kJ} / \mathrm{kg}$ (kWh/tonne) & $8.6 \pm 0.5(2.38)$ & $24.3 \pm 1.4(6.75)$ & $42.4 \pm 2.4(11.8)$ \\
\hline $\begin{array}{l}\text { Torrefied biomass, } \mathrm{kJ} / \mathrm{kg} \\
\text { (kWh/tonne) }\end{array}$ & N/A & N/A & $43-54(12-15)$ \\
\hline
\end{tabular}

\subsubsection{Size Distribution}

Many sifting experiments were done as a function of grinding time (or grinding energy), where the samples were sifted in the size range $150 \mu \mathrm{m}-3 \mathrm{~mm}$ in 5 size fractions: $\mathrm{x}<150$ $\mu \mathrm{m}, 150<\mathrm{x}<250 \mu \mathrm{m}, 250<\mathrm{x}<425 \mu \mathrm{m}, 425<\mathrm{x}<850 \mu \mathrm{m}, \mathrm{x}>850 \mu \mathrm{m}$ ( $\mathrm{x}$ denotes size). It was observed that after reaching steady-state (i.e., the net grinding power reached an asymptotic value), the size distribution did not change anymore. Therefore, most of the sifting experiments were done after reaching a grinding steady state. The initial sample was around 100 grams, and after grinding and sifting, there was $\sim 1$ gram of sample loss during the transferring procedure, which occurred only once during the process. Therefore, the loss was not more than $1 \%$. Although there is scatter in the results, there are clear trends: the size fraction $>850 \mu \mathrm{m}$ decreased with mass loss, and the size fraction $<150 \mu \mathrm{m}$ 
increased with mass loss, and the size fractions in between did not change much with mass loss. Therefore, the behavior in two size fractions: under and above $850 \mu \mathrm{m}$, was further investigated.

Figure 2.8 shows the size fraction as a function of mass loss for the torrefied un-densified material and pellets for these two size fractions. It is interesting to note that for each size fraction, the dependence on mass loss is rather similar (the line is a fit to a straight line). For the size under $850 \mu \mathrm{m}$, its fraction starts at $82 \%$ for $4.5 \%$ mass loss and reaches almost $100 \%$ at $51 \%$ mass loss; the size fraction above $850 \mu \mathrm{m}$ balances the smaller size fraction.

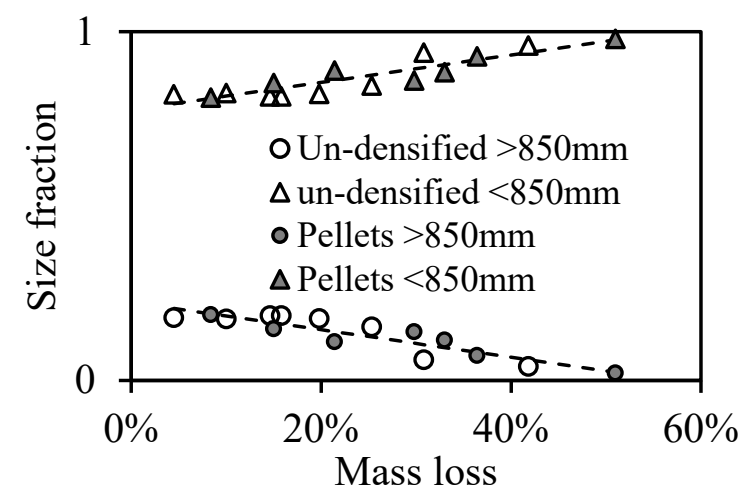

Figure 2.8. Size fraction for the torrefied un-densified material and pellets vs. mass loss for size fractions under and above $850 \mu \mathrm{m}$.

Table 2.5. Fraction $<200$ mesh of torrefied material in various mass losses

\begin{tabular}{ll}
\hline Mass loss & $\begin{array}{l}\text { Fraction } \\
<\mathbf{2 0 0} \text { mesh }\end{array}$ \\
\hline $8.4 \%$ & $67.0 \%$ \\
\hline $15.0 \%$ & $73.9 \%$ \\
\hline $21.4 \%$ & $77.3 \%$ \\
\hline $33.0 \%$ & $77.5 \%$ \\
\hline $36.4 \%$ & $89.2 \%$ \\
\hline $51.0 \%$ & $95.4 \%$ \\
\hline
\end{tabular}


Table 2.5 shows a fraction $<200$ mesh of pulverized torrefied material at various mass losses. The table indicates that above $8.4 \%$ mass loss, after grinding, the fraction of $<200$ mesh is $>70 \%$, which is consistent with the typical coal power plant requirements [39].

\subsubsection{FTIR Spectroscopic Characterization}
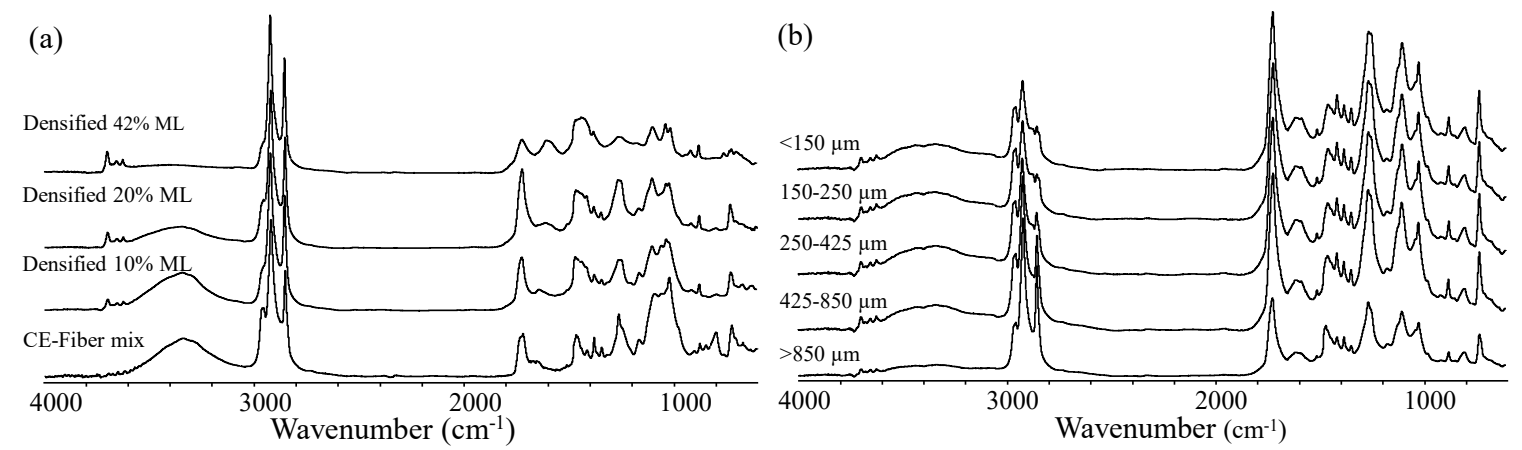

Figure 2.9. FTIR spectra of (a) CE-fiber mix and ground/screened (425-850 $\mu \mathrm{m})$ torrefied $(10,20$ and $42 \%$ mass loss $)$ densified material and (b) ground/screened $(<150 \mu \mathrm{m}, 150-250$ $\mu \mathrm{m}, 250-425 \mu \mathrm{m}, 425-850 \mu \mathrm{m}$, and $>850 \mu \mathrm{m}$ ) un-densified torrefied (30\% mass loss) material.

The CE waste mix plus fiber (20 random pieces selected) was analyzed by FTIR spectroscopy to determine their chemical identity with spectra library matching. The mix was shown to be comprised of three cellulose/paper, three polypropylene (PP), three polyethylene (PE), four polyethylene terephthalate (PET), silicone, three cellulose/silicone mixes, two paper/acrylate mix, and one nylon samples. A composite FTIR spectrum is shown in Figure 2.9a and shows the major bands associated with PE, PP, PET, and paper. No characteristic bands at $610 \mathrm{~cm}^{-1}\left(\mathrm{C}-\mathrm{Cl}\right.$ stretch) and $1425 \mathrm{~cm}^{-1}\left(\mathrm{C}-\mathrm{H}_{2}\right.$ bending) were observed for polyvinylchloride [40].

The major chemical changes that occurred upon torrefaction on densified and un-densified material and subsequent particle screening $(<150 \mu \mathrm{m}, 150<\mathrm{x}<250 \mu \mathrm{m}, 250<\mathrm{x}<425 \mu \mathrm{m}$, $425<\mathrm{x}<850 \mu \mathrm{m}$, and $>850 \mu \mathrm{m})$ after grinding were also monitored by FTIR spectroscopy. The spectra for the ground screened $425<\mathrm{x}<850 \mu \mathrm{m}$ fraction for the densified torrefied (10, 20, and $42 \%$ mass loss) material and the CE-fiber mix are shown in Figure 2.9a. The spectra 
for the ground screened fractions for the un-densified torrefied (30\% mass loss) material are shown in Figure 2.9b. Specific spectral bands can provide information on specific chemical changes that occur during thermal treatment [41]. All the samples had $\mathrm{C}-\mathrm{H}$ stretching bands assigned to methyl $\left(2960 \mathrm{~cm}^{-1}\right.$ and $\left.2870 \mathrm{~cm}^{-1}\right)$ and methylene $\left(2916 \mathrm{~cm}^{-1}\right.$ and $2850 \mathrm{~cm}^{-1}$ ) groups mainly associated with PP and PE plastic [42]. In the ground screened torrefied material, plastic was generally concentrated in the larger-sized fractions $\left(425<\mathrm{x}<850 \mu \mathrm{m}\right.$ and $>850 \mu \mathrm{m}$ ) (Figure 2.9b). The O-H stretching band $3100-3600 \mathrm{~cm}^{-1}$ was present in all samples and progressively decreased in intensity upon the extent of torrefaction due to dehydration reactions [43] (Figure 2.9b). A broad carbonyl $(\mathrm{C}=\mathrm{O})$ band at $1690-1750 \mathrm{~cm}^{-1}$ was observed and assigned to mainly an ester in linkage in PET and acrylate and an amide linkage in nylon [44]. A small band at $1505 \mathrm{~cm}^{-1}$ was assigned to lignin from paper [45]. The spectral region between 1000 and $1070 \mathrm{~cm}^{-1}$ has been assigned to $\mathrm{C}-\mathrm{O}$ stretching in wood cellulose and hemicellulose and decreased in intensity with torrefaction mass loss [46]. All samples were shown to have cis- and trans-vinylene bands at $727 \mathrm{~cm}^{-1}$ and $974 \mathrm{~cm}^{-1}$, respectively [47].

The relative changes in carbonyl, cellulose, and hydroxyl content to methylene groups (plastic) that occurred during torrefaction were examined by calculating CI, CeI, and $\mathrm{HI}$, respectively (Figure 2.10). Low CI, CeI, and HI values mean a higher level of polyolefin plastic in the material. The CI generally decreased for all torrefied samples with an increase in particle size (from $<150 \mu \mathrm{m}$ to $425<\mathrm{x}<850 \mu \mathrm{m}$ ), except for the $>850 \mu \mathrm{m}$ fraction (Figure 2.10a).

For example, in the $30 \%$ mass loss torrefied material, the CI decreased from 1.78 to 0.49 , going from $<150 \mu \mathrm{m}$ to $>850 \mu \mathrm{m}$ particle size. For the low to moderate level of torrefaction ( $8-20 \%$ mass loss), the $>850 \mu \mathrm{m}$ fraction the higher CI values could be associated with higher levels of PET plastic. Furthermore, the CI levels were also shown to decrease, associated with cleavage of the ester linkages in PET/acrylates and removal of the volatile degradation products [48], with the extent of torrefaction. 

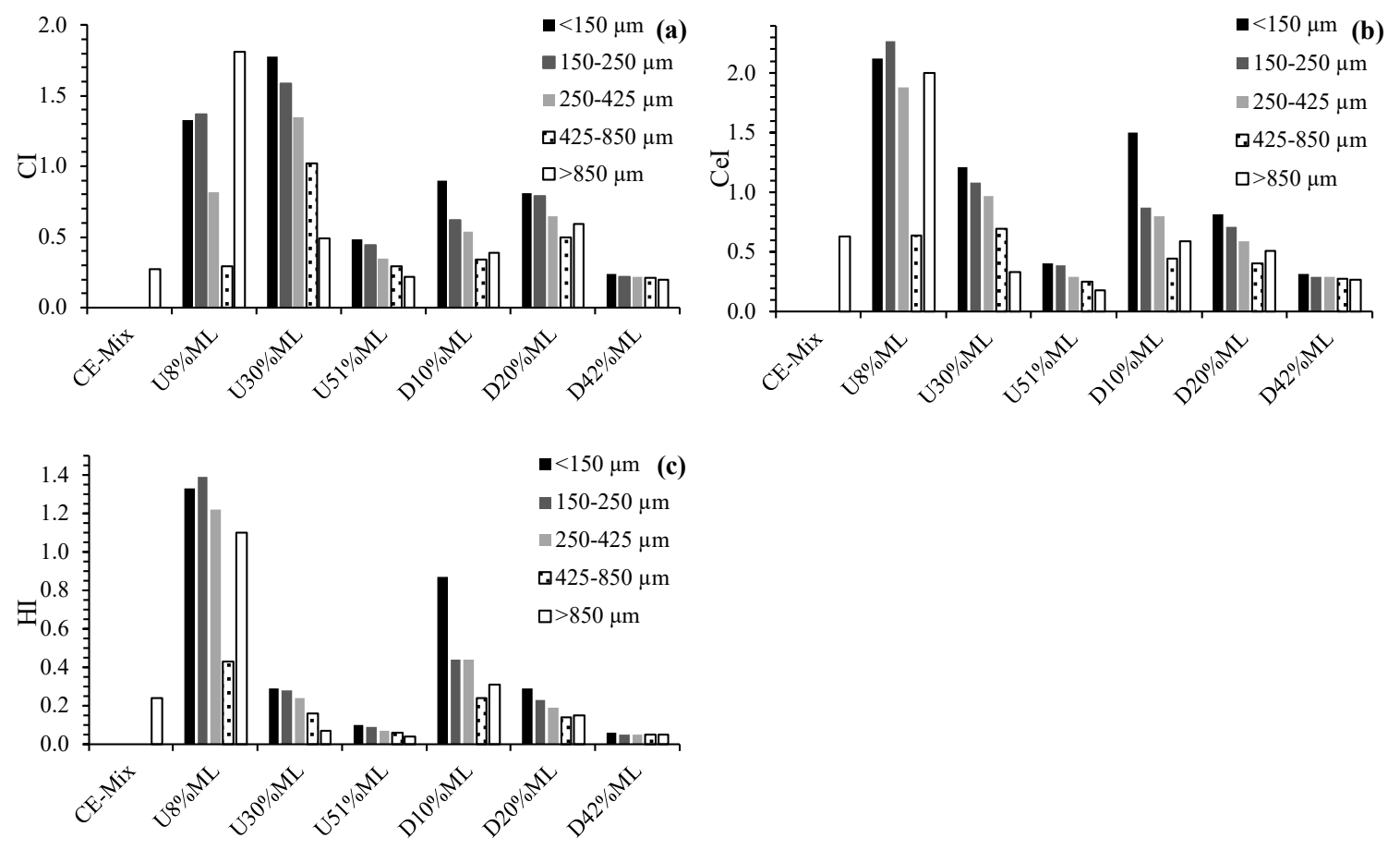

Figure 2.10. Plots showing changes in (a) carbonyl index (CI), (b) cellulose index (CeI), and (c) hydroxyl index (HI) for ground screened fractions $(<150 \mu \mathrm{m}, 150<\mathrm{x}<250 \mu \mathrm{m}$, $250<\mathrm{x}<425 \mu \mathrm{m}, 425<\mathrm{x}<850 \mu \mathrm{m}$, and $>850 \mu \mathrm{m}$ ) of torrefied densified (D) and un-densified (U) material

Generally, for both CeI (Figure 2.10b) and HI (Figure 2.10e) decreased for all torrefied materials as screened particle size increased $(<150 \mu \mathrm{m}$ to $>850 \mu \mathrm{m})$, suggesting that the cellulose fiber was mainly in the finer screened fractions. For example, in the $30 \%$ mass loss torrefied material, the $\mathrm{CeI}$ and $\mathrm{HI}$ decreased from 1.21 to 0.33 and 0.29 to 0.07 going from $<150 \mu \mathrm{m}$ to $>850 \mu \mathrm{m}$ particle size. Again, at low-moderate torrefaction levels $(8-20 \%$ mass loss), the CeI and HI levels were high, suggesting that undegraded paper fragments were collected in the $>850 \mu \mathrm{m}$ fraction. Moreover, Both CeI and $\mathrm{HI}$ were shown to decrease as torrefaction severity increased. These findings support that the cellulose content decreased relative to plastic with the extent of torrefaction due to dehydration and degradation reactions [43]. 


\subsubsection{Energy Content}
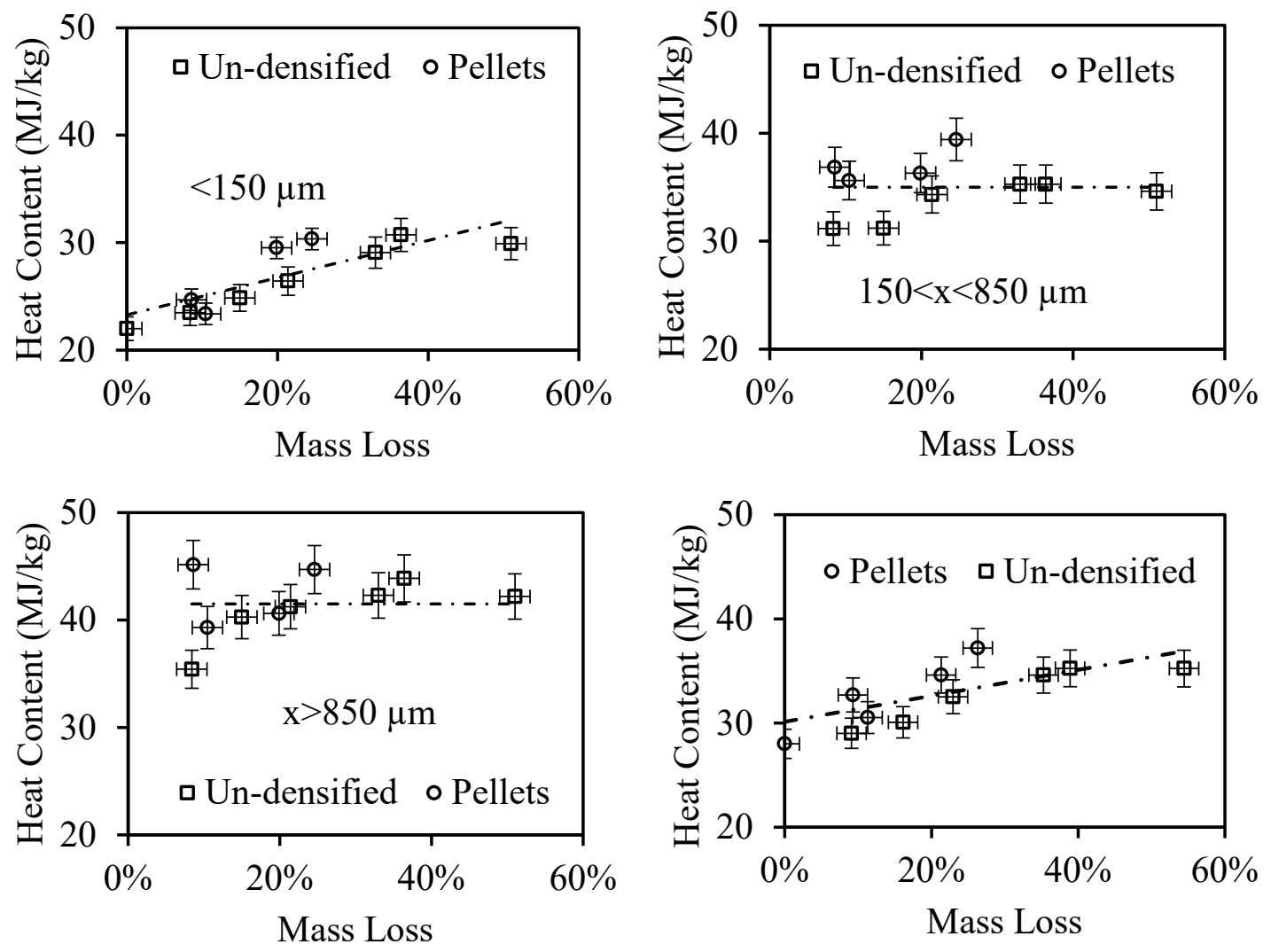

Figure 2.11. Top left. The heat content of the size fraction $\mathrm{x}<150 \mu \mathrm{m}$. Top right, same for $150<x<850 \mu \mathrm{m}$. Bottom left. Same for $\mathrm{x}>850 \mu \mathrm{m}$. Bottom right. Total heat content.

The energy content was originally measured for un-sifted pulverized samples; however, it was discovered that scooping a sample of $1 \mathrm{~g}$ for the heat content test from a $200 \mathrm{~g}$ of the pulverized material gave a very large scatter in the measured value. This was because the pulverized material has a large size distribution (as observed above), and the scooping did not necessarily give uniform size distribution. Therefore, it was decided to measure the heat content for five size fractions: $\mathrm{x}<150 \mu \mathrm{m}, 150<\mathrm{x}<250 \mu \mathrm{m}, 250<\mathrm{x}<425 \mu \mathrm{m}$, $425<x<850 \mu \mathrm{m}$, and $\mathrm{x}>850 \mu \mathrm{m}$ separately. Although the heat content for all sifted samples in these size fractions, for the sake of brevity, heat content was shown for the following consolidated fractions: $\mathrm{x}<150 \mu \mathrm{m}, 150<\mathrm{x}<850 \mu \mathrm{m}, \mathrm{x}>850 \mu \mathrm{m}$, and the calculated total heat 
content (from the fraction and heat content for each fraction). Heat content results presented here are on a dry-ash-free basis.

Figure 2.11 Top-left is a plot of the heat content of the $\mathrm{x}<150 \mu \mathrm{m}$ fraction as a function of mass loss. The point at zero mass loss is the heat content of the blend prior to torrefaction, and the dashed line is a linear trend line to lead the eye. Clearly, the main source of this fraction was pulp fibers that increase heat content with an increase in the mass loss, as predicted by Klinger et al. [49-51]. Figure 2.11 Top-right is a plot of the heat content of the $150 \mu \mathrm{m}<\mathrm{x}<850 \mu \mathrm{m}$ fraction as a function of mass loss. The heat content does not seem to change with mass loss and has an average heat content of $35 \pm 3 \mathrm{MJ} / \mathrm{kg}$; this value was lower than that of plastic, and it was assumed as a combination of fiber and plastic materials. Figure 2.11 bottom-left is a plot of the heat content of the $x>850 \mu \mathrm{m}$ fraction as a function of mass loss. The heat content does not seem to change with mass loss and has an average heat content of $41.5 \pm 3.0 \mathrm{MJ} / \mathrm{kg}$; this value was similar to most of the plastic material [52] and thus was attributed as plastic. Figure 2.11 bottom-right is a plot of the total heat content, as calculated from all fractions, as a function of mass loss. The slope of heat content increase was identical to that of the fiber.

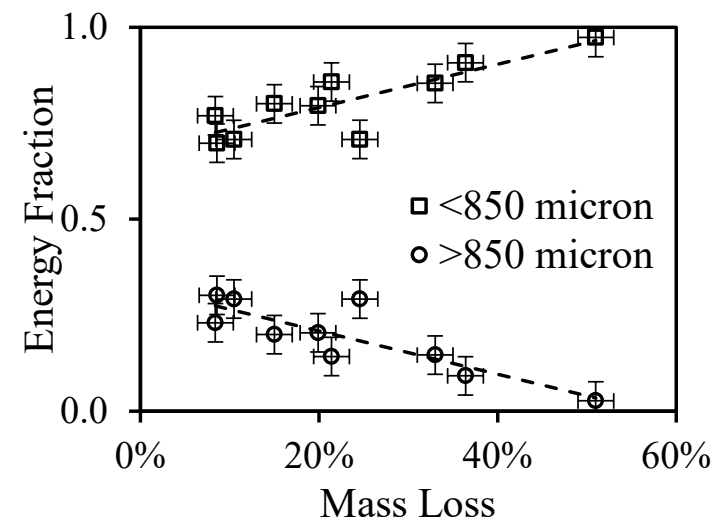

Figure 2.12. The energy contribution of the above and under $850 \mu \mathrm{m}$ size fractions to the total heat content of both un-densified material and pellets as a function of mass loss.

Although the entire sample was pulverized, two materials (fibers and plastics) clearly retain their original structure, which is indicated by the size distribution as shown above and the 
heat content as shown here. However, this material distinction diminishes as the torrefaction reaction proceeds (seen from the decrease of fraction $x>850 \mu \mathrm{m}$ ). To further quantify this process, a plot of the contribution of the $<850 \mu \mathrm{m}$ fraction, which is a combination of torrefied material (from fibers) and fibers and the fraction $>850 \mu \mathrm{m}$, which was entirely from plastic. Figure 2.12 shows results of the contribution to the total energy from each fraction, showing that the contribution from plastics was about $20 \%$ at about 5$8 \%$ mass loss and became zero at 50\% mass loss, where the plastic lost its original integrity.

\subsubsection{Chlorine Removal}

There was evidence that at the working temperatures of the torrefaction experiments $\left(300^{\circ} \mathrm{C}\right)$ in this study, chlorine from the plastic materials should have been released as $\mathrm{HCl}$ [53]. Further, Bar-Ziv and Saveliev [12] measured $\mathrm{HCl}$ in the torrefaction gas stream that was equivalent to the chlorine reduction in the solid phase. In the current study, numerous torrefaction experiments were performed as described above and measured chlorine levels in the solid phase (see details above) with no evidence of any chlorine reduction. This puzzling result can be explained by the way the current experiments were conducted, i.e., the sample was placed motionless. In this case, it was possible that in the time frame of the experiment, the diffusion of $\mathrm{HCl}$ from the solid phase was so slow that it was not released during the experiment. However, in previous experiments by Bar-Ziv and Saveliev [12], the material was torrefied in a stirred reactor [54] using much smaller size particles $(\sim 1$ $\mathrm{mm}$ ) than in the present study and clearly showed that $\mathrm{HCl}$ was released.

As mentioned, high shear experiments with the torrefied material were conducted to obtain aqueous extracts, which were filtered and measured for chloride in the solution and chlorine in the solid powder. Figure 2.13 shows results of chlorine/chloride vs. mass loss; chlorine in solid after the high shear mixing, and chloride in the filtrate (aqueous solution, adjusted for dilution). The scatter in the results was large and originated primarily from the fact that the samples were small (2-3 grams) in these experiments, and the composition may differ significantly in its content and may not well represent the actual case. Nevertheless, there was a clear trend: (i) in the aqueous solution; there was little-to-no chloride at zero mass loss (no torrefaction); (ii) the chloride in the aqueous solution 
increases gradually until $\sim 25 \%$ mass loss, after which it stays constant at an asymptotic value of $2043 \pm 207 \mathrm{ppm}$; (iii) chlorine in the solid phase has a value of $2031 \pm 129$ at zero mass loss, then decreases gradually to $\sim 10 \%$ of the initial value.

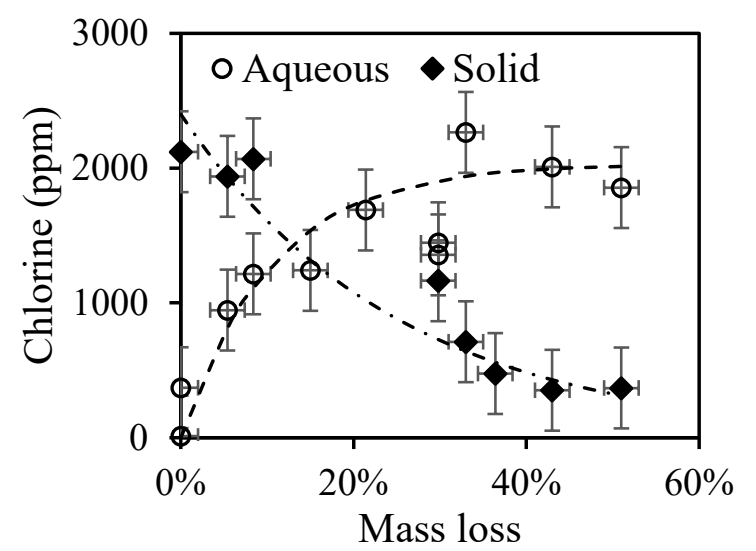

Figure 2.13. Chlorine in solid filtrate after high shear mixing and chloride in the aqueous solution (adjusted for dilution).

\subsection{Summary and Conclusion}

In the present study, blends of fiber and plastic wastes at a ratio of 60:40 (fiber-to-plastic) were used as feedstock for torrefaction. Both the un-densified material and pellets were torrefied at $300{ }^{\circ} \mathrm{C}$ with different time periods. It was observed that the two forms have significantly different torrefaction dynamics. Un-densified material takes less time to start torrefaction than the pellets due to the faster heat transfer to the un-densified material. The torrefied samples were characterized by moisture content, grindability, particle size distribution, energy content, molecular functional structure, and chlorine content. It was shown that although torrefaction dynamics is of the two forms differ significantly from each other; their properties depend on the mass loss. The fiber content was shown to decrease relative to plastic with the extent of torrefaction (mass loss) as determined by FTIR spectroscopy. Further, chemical (cellulose, hydroxyl, and carbonyl) changes were also shown to progressively decrease by torrefaction mass loss. Grinding characteristics, size distribution after grinding gave similar results as a function of mass loss during torrefaction for the forms of material. Further, the torrefied product demonstrates a similar 
grinding behavior to PRB coal. The heat content of the material with size $\mathrm{x}>850 \mu \mathrm{m}$ is much higher than that of size $\mathrm{x}<150 \mu \mathrm{m}$; the former is attributed to the plastic material, whereas the latter was attributed to the fibers. The total heat content was shown to increase with mass loss. Chlorine in the torrefied samples was removed by a high shear mixing in an aqueous solution showing that 5 minutes was sufficient to remove all chlorine after $30 \%$ mass loss. Overall, the waste blends studied in this paper showed that they could be used as a drop-in fuel in coal power generation facilities since this fuel is sustainable and lowcost, it also meets the environmental regulation standard.

\subsection{References}

[1] U.S. Environmental Protection Agency, Carbon Pollution Emission Guidelines for Existing Stationary Sources: Electric Utility Generating Units, 80 FR 64661 (2014) 6466164964.

[2] U.S. Environmental Protection Agency, Carbon pollution emission guidelines for existing stationary sources: electric utility generation units, in: EPA-HQ-OAR-2013-0602, 2015, pp. 64661-64964.

[3] D. Nakamura, S. Mufson, China, US agree to limit greenhouse gases, The Washington Post, 12 (2014).

[4] J. Kiel, Torrefaction for upgrading biomass into commodity fuel, in: Status and ECN Technology Development. EUBIONET III Workshop, Espoo, Finland, 2011.

[5] A.D. Pinho, M.B.B. de Almeida, F.L. Mendes, L.C. Casavechia, M.S. Talmadge, C.M. Kinchin, H.L. Chum, Fast pyrolysis oil from pinewood chips co-processing with vacuum gas oil in an FCC unit for second generation fuel production, Fuel, 188 (2017) 462-473. https://doi.org/10.1016/j.fuel.2016.10.032 
[6] C.X. Wang, M.R. Li, Y.M. Fang, Coprocessing of Catalytic-Pyrolysis-Derived Bio-Oil with VGO in a Pilot-Scale FCC Riser, Industrial \& Engineering Chemistry Research, 55 (2016) 3525-3534. https://doi.org/10.1021/acs.iecr.5b03008

[7] ThermoChem Recovery International. Reforming gasification. https://tri-inc.net/steamreforming-gasification/, 2018. (accessed 1 January, 2017).

[8] L. Kumar, A.A. Koukoulas, S. Mani, J. Satyavolu, Integrating Torrefaction in the Wood Pellet Industry: A Critical Review, Energy \& Fuels, 31 (2017) 37-54. https://doi.org/10.1021/acs.energyfuels.6b02803

[9] R.I. Radics, R. Gonzalez, E.M. Bilek, S.S. Kelley, Systematic Review of Torrefied Wood Economics, Bioresources, $12 \quad$ (2017) 6868-6884. https://doi.org/10.15376/biores.12.3.Radics

[10] U.S. Environmental Protection Agency, 2018 "Monthly Energy Review", in: DOE/EIA0035 (Ed.) U.S. Energy Information Administration, 2018.

[11] U.S. Environmental Protection Agency, 2010 MSW Facts and Figures Factsheet, in, 2010.

[12] E. Bar-Ziv, R. Saveliev, Torrefied-biomass from municipal solid waste for power production, ASME-Power2013-98044, (2013).

[13] E. Bar-Ziv, J. Klinger, Logistics and storage of torrefied biomass Safety aspects, Safety Consideration in Biomass Torrefaction, in: Energy-Tech Magazine Online (https://www.energy-tech.com/fuels/), 2016.

[14] H.R. Yuan, Y.Z. Wang, N. Kobayashi, D.D. Zhao, S.Y. Xine, Study of Fuel Properties of Torrefied Municipal Solid Waste, Energy \& Fuels, 29 (2015) 4976-4980. https://doi.org/10.1021/ef502277u 
[15] G.F. Mu'min, P. Prawisudha, I.N. Zaini, M. Aziz, A.D. Pasek, Municipal solid waste processing and separation employing wet torrefaction for alternative fuel production and aluminum reclamation, Waste Manag, $67 \quad$ (2017) 106-120. https://doi.org/10.1016/j.wasman.2017.05.022

[16] K.L. Iroba, O.D. Baik, L.G. Tabil, Torrefaction of biomass from municipal solid waste fractions I: Temperature profiles, moisture content, energy consumption, mass yield, and thermochemical properties, Biomass Bioenerg, 105 (2017) 320-330. https://doi.org/10.1016/j.biombioe.2017.07.009

[17] K.L. Iroba, O.D. Baik, L.G. Tabil, Torrefaction of biomass from municipal solid waste fractions II: Grindability characteristics, higher heating value, pelletability and moisture $\begin{array}{llllll}\text { adsorption, } & \text { Biomass } & \text { Bioenerg, } & 106 & \text { (2017) }\end{array}$ https://doi.org/10.1016/j.biombioe.2017.08.008

[18] J. McCabe, Addressing Biogenic Carbon Dioxide Emissions from Stationary Sources, United States Enviromental Protection Agency: Washington, DC, USA, (2014).

[19] U.S. Environmental Protection Agency, Assessing Trends in Material Generation, Recycling, Composting, Combustion with Energy Recovery and Landfilling in the United States, in: EPA530-R-17-01, 2016, pp. 91.

[20] A. Demirbaş, Physical properties of briquettes from waste paper and wheat straw mixtures, Energy Conversion and Management, 40 (1999) 437-445. https://doi.org/10.1016/s0196-8904(98)00111-3

[21] N.J. Themelis, C. Mussche, Energy and Economic value of Municipal Solid Waste (MSW), including non-recycled plastics (NRP), currently landfilled in fifty states, in, Earth Engineering Center, Columbia University, New York, 2014. 
[22] K. Unapumnuk, T.C. Keener, M. Lu, S.J. Khang, Pyrolysis behavior of tire-derived fuels at different temperatures and heating rates, J Air Waste Manag Assoc, 56 (2006) 618627. https://doi.org/10.1080/10473289.2006.10464481

[23] R. Miranda, C. Sosa-Blanco, D. Bustos-Martinez, C. Vasile, Pyrolysis of textile wastes I. Kinetics and yields, Journal of Analytical and Applied Pyrolysis, 80 (2007) 489495. https://doi.org/10.1016/j.jaap.2007.03.008

[24] P. McKendry, Energy production from biomass (Part 2): Conversion technologies, Bioresour Technol, 83 (2002) 47-54. https://doi.org/10.1016/s0960-8524(01)00119-5

[25] J.A. Luppens, A critical review of published coal quality data from the southwestern part of the Powder River Basin, Wyoming, in: Open-File Report, Reston, VA, 2011, pp. 26. https://doi.org/10.3133/ofr20111148

[26] R.F. Storm, "Blueprint" Your Pulverizer for Improved Performance, Power, 153 (2009) 60-63.

[27] Q. Zhu, Coal sampling and analysis standards, IEA Clean Coal Centre, London, United Kingdom, (2014).

[28] L.Q. Wei, A.G. McDonald, C. Freitag, J.J. Morrell, Effects of wood fiber esterification on properties, weatherability and biodurability of wood plastic composites, Polymer Degradation and Stability, $98 \quad$ (2013) 1348-1361. https://doi.org/10.1016/j.polymdegradstab.2013.03.027

[29] Y. Donepudi, Impact of Pretreatment Methods on Fast Pyrolysis of Biomass, in Mechanical Engineering, Michigan Technological University, Houghton, MI, USA., 2017. https://doi.org/10.37099/mtu.dc.etdr/496 
[30] F.P. Incropera, D.P. Dewitt, Fundamentals of Heat and Mass Transfer, John Wiley and Sons, New York, NY, 2002.

[31] J.E. Patterson, R.J. Miers, The thermal conductivity of common tubing materials applied in a solar water heater collector, in: 46th ASC Annual International Conference. Wenthworth Institute of technology, 2010, pp. 1-7.

[32] P.E. Mason, L.I. Darvell, J.M. Jones, A. Williams, Comparative Study of the Thermal Conductivity of Solid Biomass Fuels, Energy Fuels, 30 (2016) 2158-2163. https://doi.org/10.1021/acs.energyfuels.5b02261

[33] R.B. Bates, A.F. Ghoniem, Biomass torrefaction: modeling of reaction thermochemistry, Bioresour Technol, $134 \quad$ (2013) 331-340. https://doi.org/10.1016/j.biortech.2013.01.158

[34] W. Zhao, D. Liu, Y. Zhang, Study on the Influence of Pressure-Assisted Thermal Processing on PET/PE via the Change of Melting Enthalpy, Journal of Food Processing and Preservation, 41 (2017) e13135. https://doi.org/10.1111/jfpp.13135

[35] J. Lédé, Biomass Pyrolysis: Comments on Some Sources of Confusions in the Definitions of Temperatures and Heating Rates, Energies, 3 (2010) 886-898.

[36] A. Funke, E. Henrich, N. Dahmen, J. Sauer, Dimensional Analysis of Auger-Type Fast Pyrolysis Reactors, Energy Technology, 5 (2017) 119-129. https://doi.org/10.1002/ente.201600095

[37] J.H.A. Khalsa, D. Leistner, N. Weller, L.I. Darvell, B. Dooley, Torrefied Biomass Pellets-Comparing Grindability in Different Laboratory Mills, Energies, 9 (2016) 794. https://doi.org/10.3390/en9100794 
[38] L. Wang, E. Barta-Rajnai, Ø. Skreiberg, R. Khalil, Z. Czégény, E. Jakab, Z. Barta, M. Grønli, Impact of Torrefaction on Woody Biomass Properties, Energy Procedia, 105 (2017) 1149-1154. https://doi.org/10.1016/j.egypro.2017.03.486

[39] J.J. Helble, S. Srinivasachar, A.A. Boni, Factors Influencing the Transformation of Minerals during Pulverized Coal Combustion, Progress in Energy and Combustion Science, 16 (1990) 267-279. https://doi.org/Doi 10.1016/0360-1285(90)90036-3

[40] S. Krimm, V.L. Folt, J.J. Shipman, A.R. Berens, Infrared spectra and assignments for polyvinyl chloride and deuterated analogs, Journal of Polymer Science Part A: General Papers, 1 (1963) 2621-2650. https://doi.org/10.1002/pol.1963.100010809

[41] A.O. Balogun, F. Sotoudehniakarani, A.G. McDonald, Thermo-kinetic, spectroscopic study of brewer's spent grains and characterisation of their pyrolysis products, Journal of $\begin{array}{llllll}\text { Analytical and } & \text { Applied } & \text { Pyrolysis, } & 127 & \text { (2017) }\end{array}$ https://doi.org/10.1016/j.jaap.2017.09.009

[42] D.W. Mayo, Characteristic Frequencies of Alkanes, in: Course Notes on the Interpretation of Infrared and Raman Spectra, 2004, pp. 33-72.

[43] Z. Wang, B. Pecha, R.J.M. Westerhof, S.R.A. Kersten, C.Z. Li, A.G. McDonald, M. Garcia-Perez, Effect of Cellulose Crystallinity on Solid/Liquid Phase Reactions Responsible for the Formation of Carbonaceous Residues during Pyrolysis, Industrial \& Engineering Chemistry Research, $53 \quad$ (2014) 2940-2955. https://doi.org/10.1021/ie4014259

[44] D.W. Mayo, Spectra of carbonyl compounds of all kinds (factors affecting carbonyl group frequencies), Course notes on the interpretation of infrared and Raman spectra, (2004) 79-204. 
[45] O. Faix, Fourier transform infrared spectroscopy, in: Methods in lignin chemistry, Springer, 1992, pp. 83-109.

[46] K.K. Pandey, A study of chemical structure of soft and hardwood and wood polymers by FTIR spectroscopy, Journal of Applied Polymer Science, 71 (1999) 1969-1975. https://doi.org/10.1002/(Sici)1097-4628(19990321)71:12<1969::Aid-App6>3.0.Co;2-D

[47] F.A. Miller, Characteristic frequencies of alkenes (olefins), Course Notes on the Interpretation of Infrared and Raman Spectra, (2003) 73-84.

[48] O. Cepeliogullar, A.E. Putun, A pyrolysis study for the thermal and kinetic characteristics of an agricultural waste with two different plastic wastes, Waste Manag Res, 32 (2014) 971-979. https://doi.org/10.1177/0734242X14542684

[49] J. Klinger, E. Bar-Ziv, D. Shonnard, Kinetic study of aspen during torrefaction, Journal of Analytical and Applied Pyrolysis, 104 (2013) 146-152. https://doi.org/10.1016/j.jaap.2013.08.010

[50] J. Klinger, E. Bar-Ziv, D. Shonnard, Predicting Properties of Torrefied Biomass by Intrinsic Kinetics, Energy \& Fuels, 29 (2015) 171-176. https://doi.org/10.1021/ef501456p

[51] J. Klinger, E. Bar-Ziv, D. Shonnard, Unified kinetic model for torrefaction-pyrolysis, $\begin{array}{lllll}\text { Fuel Processing } & \text { Technology, } & 138 & \text { (2015) }\end{array}$ https://doi.org/10.1016/j.fuproc.2015.05.010

[52] Y.B. Sonawane, M.R. Shindikar, M.Y. Khaladkar, High Calorific Value Fuel from Household Plastic Waste by Catalytic Pyrolysis, Nature Environment and Pollution Technology, 16 (2017) 879-882.

[53] S.B. Saleh, J.P. Flensborg, T.K. Shoulaifar, Z. Sarossy, B.B. Hansen, H. Egsgaard, N. DeMartini, P.A. Jensen, P. Glarborg, K. Dam-Johansen, Release of Chlorine and Sulfur 
during Biomass Torrefaction and Pyrolysis, Energy \& Fuels, 28 (2014) 3738-3746. https://doi.org/10.1021/ef4021262

[54] S. Zinchik, J.L. Klinger, T.L. Westover, Y. Donepudi, S. Hernandez, J.D. Nabera, E. Bar-Ziv, Evaluation of fast pyrolysis feedstock conversion with a mixing paddle reactor, $\begin{array}{lllll}\text { Fuel Processing } & \text { Technology, } & 171 & \text { (2018) }\end{array}$ https://doi.org/10.1016/j.fuproc.2017.11.012 


\section{Properties of Pellets of Torrefied U.S. Waste Blends}

This section is based on the peer-reviewed paper titled "Properties of pellets of torrefied U.S. waste blends" published in Waste Management (2020) 104, 130-138. https://doi.org/10.1016/j.wasman.2020.01.009

\subsection{Abstract}

With the continued growing U.S. population, solid waste generation will increase, which will lead to undesired and significant growth in landfilling. Thermal treatment can turn these high calorific value wastes into clean fuels that can be used in small-to-large power plants. This article focuses on using blends with $40 \%$ plastic and $60 \%$ fiber wastes and converting them into clean and densified solid fuel by torrefaction and extrusion. The material was torrefied at $300{ }^{\circ} \mathrm{C}$ to obtain torrefied samples with different mass losses, ranging from $0 \%$ to a maximum of $51 \%$. The torrefaction results showed a clear synergy between plastics and fibers. The torrefied material was then extruded into $9 \mathrm{~mm}$ diameter rods, and the products were characterized by molecular functional group analysis, thermomechanical analysis, dynamic mechanical analysis, dynamic rheological measurement, density measurement, flexural testing, water absorption test, size distribution measurement, heat content test, and combustion test. The fiber content in the material decreased as mass loss increased, and the process significantly reduced the material's variabilities. The heat content increased as the mass loss increased. The plastic in the feedstock acted as a process enabler as it imparted properties like bindability, water resistance, high heat content, and increased degradation reaction rate.

\subsection{Introduction}

The world is witnessing an unprecedented accumulation of solid wastes with significant, well-documented ecological, environmental, health, and economic consequences $[1,2]$. As the population increases, the levels of wastes will continue to grow, especially the plastic waste levels that hugely impact landfilling and have been exacerbated by China's ban on importing plastic waste [3]. 
Western countries are witnessing a transition from the current disposal of solid wastes in landfills to a zero-solid waste society [4]. This grand challenge requires new technical approaches for converting and valorizing solid wastes into valuable products to create a circular economy [5]. Currently, commingled plastic fiber wastes usually end up in landfills since they are not suitable for recycling, creating challenges as well as opportunities for waste management. Production of Refuse Derived Fuel (RDF) is an existing technology to produce solid fuels from waste for some power applications, for example, in incineration plants such as cement kilns [6, 7]. As RDF cannot be pulverized, it cannot be used in power plants that require pulverized fuel.

We propose in this study to thermally treat (torrefaction) the above wastes and turn them into a fuel that can be pulverized. The developed process is also safe and low-cost, producing a drop-in fuel for the existing pulverized fuel power plants. Torrefied biomass has been proposed as a renewable substitute for coal in power generation [8]. It complies with EPA regulations [9] as well as contributes to the reduction of greenhouse gases (GHG) $[10,11]$. Fibers in comingled wastes originate from biomass, hence being considered a source of renewable energy [12]. Torrefaction technology has reached a level of maturity that it can be commercially used; however, it has not yet moved to the market. Three major hindrances in the commercialization of this technology have been identified: (1) the high cost associated with woody biomass feedstock $[13,14],(2)$ the degradation of lignin during torrefaction [15], hence lack of a binder for compaction, and (3) the high reactivity of torrefied biomass, as self-heating of the material due to slow oxidization, that imposes tremendous safety risks during the process, transportation, storage and the operation in the power plant $[2,16]$. This study used blends of plastic and fiber wastes as a feedstock, which overcome the above hindrances.

Although recycling should be prioritized for currently landfilled wastes, a large volume of non-recyclable wastes and a portion of recyclable waste ends up in the landfill. These endof-life wastes have existing collection and transportation systems as well as tipping fees that make them economically attractive. These wastes can be used as a high calorific value fuel for power applications [17]. 
Torrefied biomass is densified by two main methods: (1) pelletization [18] and (2) briquetting [19]. These methods, however, have some challenges: (1) they may require a binder, which adds cost to the final product, and (2) the pellets/briquettes of the torrefied biomass show a clear propensity for oxidation at ambient temperatures [20], and therefore may cause safety hazards in transportation, storage, and operation at the power plant [18, 21]. These two challenges were overcome by the addition of plastic to the biomass (fiber) mix. As plastic is blended with fiber, we realized that extrusion could be used for densification, a standard densification technology that makes biochar-plastic composites $[22,23]$.

Recently, Xu et al. carried a comprehensive torrefaction study on fiber-plastic (60\%/40\%) waste blend, and detailed waste composition was provided [24]. The challenges and the advantages of using wastes as feedstock were discussed. They also reported properties of the produced torrefied material as a function of the extent of torrefaction and showed that this material can be pulverized like coal and have higher heat content than most coals. The current work deals with the densification of torrefied fiber-plastic $(60 \% / 40 \%)$ waste blends. Densification is carried out by extrusion, and the produced pellet properties were characterized by a series of methods. The present study is a further development of Xu et al.'s [24] work to produce a densified fuel.

\subsection{Materials and Methods}

\subsubsection{Materials}

The samples used in this study were a fiber-plastic waste blend ( $40 \%$ plastic and $60 \%$ fiber) obtained from Convergen Energy LLC (CE). The wastes blends received by CE comprise a large variety of paper, laminated papers, plastics, and fibers consisting of several impurities (Figure 3.1) .CE has been tracking the properties of the waste blends for seven years, and the results are shown by Xu et al. CE removed any ferrous metals using a strong electric magnet, while non-ferrous were removed manually. The material was then shredded to $75-125 \mathrm{~mm}$ particle size by a shear grinder and then air-dried to $5-7 \%$ moisture content level [24]. 

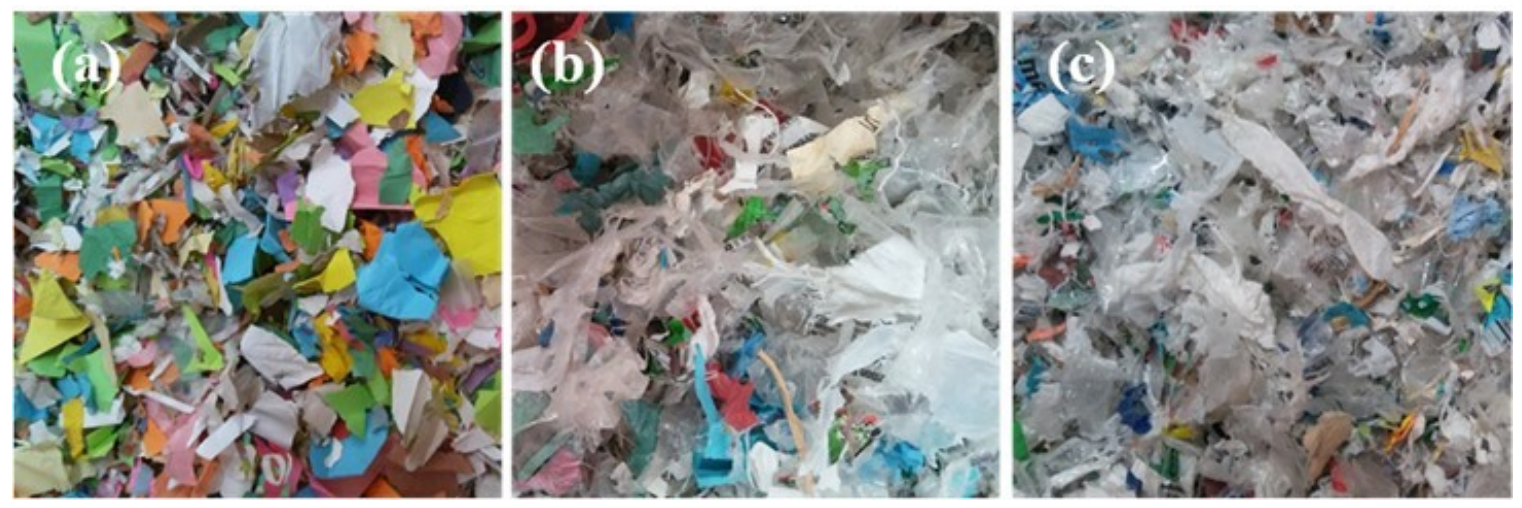

Figure 3.1. (a) fiber waste, (b) plastic waste, and (c) 60\% fiber and 40\% plastic blend.

\subsubsection{Torrefaction}

The sample was torrefied by introducing $\sim 150 \mathrm{~g}$ of CE waste blends to an aluminum pan that was placed in the center of a muffle furnace (Lindenberg/Blue type BF51828C-1) heated to $300{ }^{\circ} \mathrm{C}$ for 3 to $60 \mathrm{~min}$ [24]. An inert gas purge, either Carbon Dioxide or Nitrogen, was flown at a rate of $30 \mathrm{~L} / \mathrm{min}$ to avoid oxidation. Figure 3.2 shows a schematic of the torrefaction system. In this study, Mass loss was the dependent variable measured as a function of time.

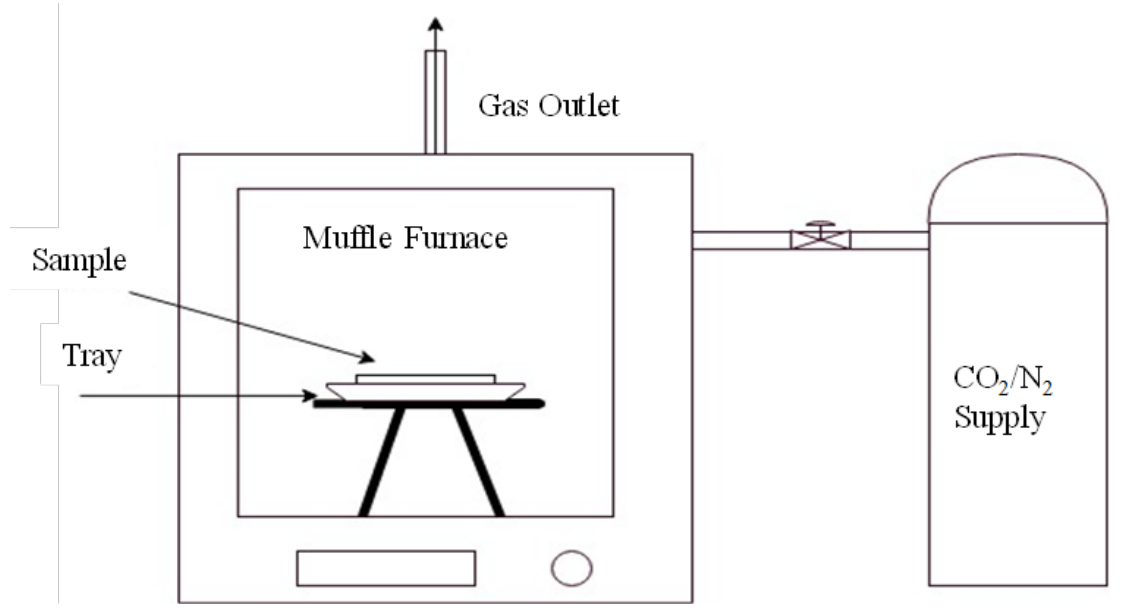

Figure 3.2. Schematic of Torrefaction system.

Modeling of heat-transfer-torrefaction reaction has been developed by $\mathrm{Xu}$ et al., under the same conditions of the current study and has proven to fit the measured data rather 
accurately [24]. The model shows the relationships between temperature and mass loss transients. Eq.(3.1) is the temperature transient $(T(t))$,

$$
T(t)=T_{w}-\left(T_{w}-T_{o}\right) e^{-t / \tau}
$$

where $T_{w}$ and $T_{o}$ are the temperatures of furnace wall and initial temperature of the particle, respectively, $\mathrm{t}$ is time and $\tau$ is a characteristic time given by Eq. (3.2),

$$
\tau=\frac{m c_{p}}{h A}
$$

This can be measured from sample mass $(m)$, heat capacity $\left(c_{p}\right)$, heat transfer coefficient of the furnace walls to the sample $(h)$, and the surface area of sample $(A)$.

The ratio of the sample mass (at a given time) to the initial sample mass is presented by $\alpha$, and the reaction was assumed to be the first-order reaction, and the reaction rate $(R)$ was given by Eq. (3.3),

$$
R=\rho \frac{d(\alpha) t}{d t}=-\rho k(\alpha) t
$$

where $k(T)$ is a rate coefficient given by Eq. (3.4),

$$
k(T)=\frac{A^{\dagger}}{\rho} e^{-T_{a} / T(t)}
$$

where $\rho$ and $A^{\dagger}$ are the density of the sample and pre-exponential factor, respectively. $T_{a}$ is a characteristic temperature given by $T_{a}=E_{a} / R$ where $E_{a}$ and $R$, are activation energy and the gas constant, respectively. Commonly, mass loss, $1-\alpha$, is used to define the extent of torrefaction, which is presented by Eq. (3.5),

$$
1-\alpha=1-e^{-\int_{0}^{t} k d t}
$$

Eq.(3.1) and (3.2) enable us to calculate the temperature transient of a given sample in our furnace. By combining Eq.(3.3), (3.4) and fine-tuning the parameters $T_{a}$ and $A^{\dagger}, 1$ - 
$\alpha$ (measured mass loss) could fit the results of the experiments. This procedure has been applied successfully by Xu et al. [24].

\subsubsection{Densification by Extrusion}

This study examined the use of extrusion to densify the torrefied fiber-plastic blend. Samples of the torrefied/non-torrefied plastic-fiber waste blends (400 g each batch) were manually fed into an $18 \mathrm{~mm}$ co-rotating twin-screw extruder (Leistritz, L/D ratio of 40, $200 \mathrm{rpm}, 4.7 \mathrm{~kW}$ motor, base torque 18\%) and extruded into a rod (9 mm Ø) and cooled by forced air [25]. The extruder is divided into eight zones with temperature controllers. Extrusion parameters, as well as zone temperatures, are given in Table 3.1.

Table 3.1. Extrusion parameters

\begin{tabular}{lllll}
\hline $\begin{array}{l}\text { Torrefaction } \\
\text { Mass loss }\end{array}$ & $\begin{array}{l}\text { Extruder barrel } \\
\text { zones }\end{array}$ & $\begin{array}{l}\text { Extruder } \\
\text { barrel zone }\end{array}$ & $\begin{array}{l}\text { Torque } \\
(\%)\end{array}$ & $\begin{array}{l}\text { Die } \\
\text { pressure } \\
(\mathbf{\%})\end{array}$ \\
\hline $\mathbf{2 - 5}$ temp. $\left({ }^{\circ} \mathbf{C}\right)$ & $\mathbf{6 - 8}$ temp. $\left({ }^{\circ} \mathbf{C}\right)$ & & $500-600$ \\
\hline 10.8 & 170 & 160 & 50 & $200-300$ \\
\hline 31.7 & 160 & 150 & 35 & $100-150$ \\
\hline 51 & 160 & 150 & 30 & 100 \\
\hline
\end{tabular}

\subsubsection{Characterization}

\subsubsection{FTIR Characterization}

Fourier-Transform Infrared Spectroscopy (FTIR) spectral analysis was performed for (i) 30 pieces randomly chosen from plastic waste, (ii) 30 pieces randomly chosen from fiber waste; (iii) 30 pieces randomly chosen from the waste blend, and (iv) sliced sections of extruded non-torrefied/ torrefied material with an FTIR spectrometer (Thermo-Scientific Nicolet-iS5), 64 scans, with an attenuated total reflectance accessory (ZnSe crystal, iD5). OMNIC v9.8 software and Aldrich, Hummel, and Nicolet spectral libraries were used to analyze the data. Carbonyl index (CI), cellulose index (CeI), and hydroxyl index (HI) were 
obtained as a ratio of the band intensity (absorbance) at $1720 \mathrm{~cm}^{-1}, 1024 \mathrm{~cm}^{-1}$, and 3342 $\mathrm{cm}^{-1}$, respectively, to the band $2916 \mathrm{~cm}^{-1}$ for the $-\mathrm{CH}_{2}$ - groups [26].

\subsubsection{Thermal Analysis}

Thermomechanical analysis (TMA) was performed with Perkin Elmer TMA 7 instrument on sliced discs $(0.5 \mathrm{~mm} \times 9 \mathrm{~mm} \varnothing)$ from the extruded rod using the penetration probe (static force $10 \mathrm{mN}$ ) from 30 to $200{ }^{\circ} \mathrm{C}$ at $5{ }^{\circ} \mathrm{C} / \mathrm{min}$. Data were analyzed using Pyris v8 software to determine the onset softening temperature. Dynamic mechanical analysis (DMA) was carried out in 3-point bending mode (15 $\mathrm{mm}$ span) on hot-pressed extruded rod samples $\left(2 \times 5.5 \times 20 \mathrm{~mm}^{3}\right)$ using a Perkin Elmer DMA-7 instrument (1 Hz and $0.5 \%$ strain) with refrigerated cooling from -50 to $120{ }^{\circ} \mathrm{C}$ at a ramp rate of $3{ }^{\circ} \mathrm{C} / \mathrm{min}$.

\subsubsection{Rheology}

Dynamic rheological measurements $\left(\mathrm{G}^{\prime}, \mathrm{G}^{\prime \prime}\right.$, and $\left.\eta^{*}\right)$ were carried out on a Bohlin CVO 100 rheometer, using serrated parallel plates $(25 \mathrm{~mm} \varnothing)$, in an oscillating mode with an extended temperature control module on pressed disc $(3 \mathrm{~mm} \times 25 \mathrm{~mm} \varnothing)$ samples. Experiments were performed in the linear viscoelastic region. Measurements were carried out at $180{ }^{\circ} \mathrm{C}$ in the frequency range of 0.01 to $100 \mathrm{~Hz}$ at an applied strain of $0.5 \%$ [27]. Data were analyzed using the Bohlin rheology v6.51 software.

\subsubsection{Density}

Weight divided by volume. The weight of the pellet was measured using a scale (A\&D HR-60) with readability of $0.0001 \mathrm{~g}$. Since the surface of the extruded pellets was very smooth, cylinder-shaped pellets were cut from them to calculate cylinder volume. The diameter $(d)$ and length of the cylinder $(l)$ were measured using a caliper (Fowler Electronic Caliper) with a resolution of $0.01 \mathrm{~mm}$. The density was obtained by calculating using the formula mass/cylinder volume.

Volume displacement method. The dry weight of the pellet, $m$, was measured using a scale (A\&D HR-60) with readability of $0.0001 \mathrm{~g}$. A $100 \mathrm{ml}$ graduated cylinder partially filled with distilled water was prepared, and the reading $V_{o}$ was recorded. The pellet was placed 
into water. The volume reading with immersed pellet, $V$, was recorded. The density was obtained by calculating the ratio $m /\left(V-V_{o}\right)$.

\subsubsection{Flexural Testing}

The extruded rod samples (150 mm long) were hot-pressed (PHI hydraulic press, $300 \mathrm{x}$ $300 \mathrm{~mm}^{2}$ ) slowly at $140{ }^{\circ} \mathrm{C}$ over $20 \mathrm{~min}$ to a thickness of $3.25 \mathrm{~mm}$, then cooled to room temperature under load. The flattened material was cut into flexural specimens $(3.25 \times 16$ x $60 \mathrm{~mm}^{3}$ ). Three-point flexural tests (strength and modulus) were performed on the specimens ( $\geq 6$ replicates) according to ASTM Standard D 790-07 [28] with a crosshead speed of $1.31 \mathrm{~mm} / \mathrm{min}$, a span of $52 \mathrm{~mm}$, tested until specimen failure or $5 \%$ strain, whichever occurred first on an Instron 5500R-1132 universal test machine (5 kN load cell). Data were collected and processed using Bluehill v3 software (Instron).

\subsubsection{Water Absorption}

The extruded sample was put into a vial and then filled with distilled water until the sample was fully submerged or the vial was full. The original weight was recorded, the sample after a certain period was taken out, surface water was removed, and the net weight was measured. Water absorption is defined as the net weight of the sample over the original weight.

\subsubsection{Size Distribution Analysis}

For the size distribution analysis, 200g of pellets were ground for $120 \mathrm{~s}$. During grinding, the motor power was monitored (by Watts Up pro power analyzer and data logger). Grinding was done, up to $1,800 \mathrm{~s}$, until grinding power stabilized at an asymptotic value [24]. The ground sample was then moved to a sieve shaker (W.S Tyler, RX-86) with four screens (sizes of $150 \mu \mathrm{m}, 250 \mu \mathrm{m}, 425 \mu \mathrm{m}$, and $850 \mu \mathrm{m}$ ). The sieve shaker was operated for an hour to obtain five different fractions. Each fraction was weighted to determine the material size distribution after grinding. 


\subsubsection{Heat Content}

Previous experience has shown that the results of the material heat content have large variabilities if the sample was directly taken after grinding. This was due to the nature of the blend, as grinding generates particles of different sizes. The ground material was sifted into five different fractions (as discussed above) to resolve this issue. Each fraction from the size distribution was tested for heat content, measured using a bomb calorimeter (Parr 6100 ). For each measurement, a crucible containing $\sim 1 \mathrm{~g}$ of the sample was placed into a bomb filled with oxygen ( $400 \mathrm{psi}$ ), and the bomb was submerged into a jacket filled with distilled water $(2,000 \mathrm{~g})$. The sample was ignited, and the heat released during the combustion was transferred to the water in the jacket. The heat content was calculated using a calorimeter that monitored the water's temperature difference in the jacket before and after the combustion. After fully analyzing all fractions from the sifting, a weighted average was calculated to determine the heat content of the sample.

\subsubsection{Combustion Test}

The extruded rods with different mass losses were cut into equal dimension pellets (24.8 $\mathrm{mm} \times 9.55 \mathrm{~mm} \varnothing, 2 \mathrm{~g}$ ) and were placed on a tared porcelain crucible (Fisher brand FB-965$\mathrm{G})$ then placed in a muffle furnace (Lindenberg/Blue type BF51828C-1) set at $900{ }^{\circ} \mathrm{C}$. The experiments were done at different times, starting from $1 \mathrm{~min}$. After each experiment, the crucible was removed from the furnace and placed in the desiccator. The weight was recorded after it was cooled to room temperature. If there was $>2 \mathrm{mg}$ difference between the current and previous experiment, the crucible would be re-furnaced until the difference was $<2 \mathrm{mg}$ (ASTM D 5630-94) [29].

\subsection{Results and Discussion}

\subsubsection{Torrefaction}

Fiber and plastic wastes were torrefied separately and as a blend. Figure 3.3 shows photos of the original waste blend as well as selective torrefied material used for extrusion. 


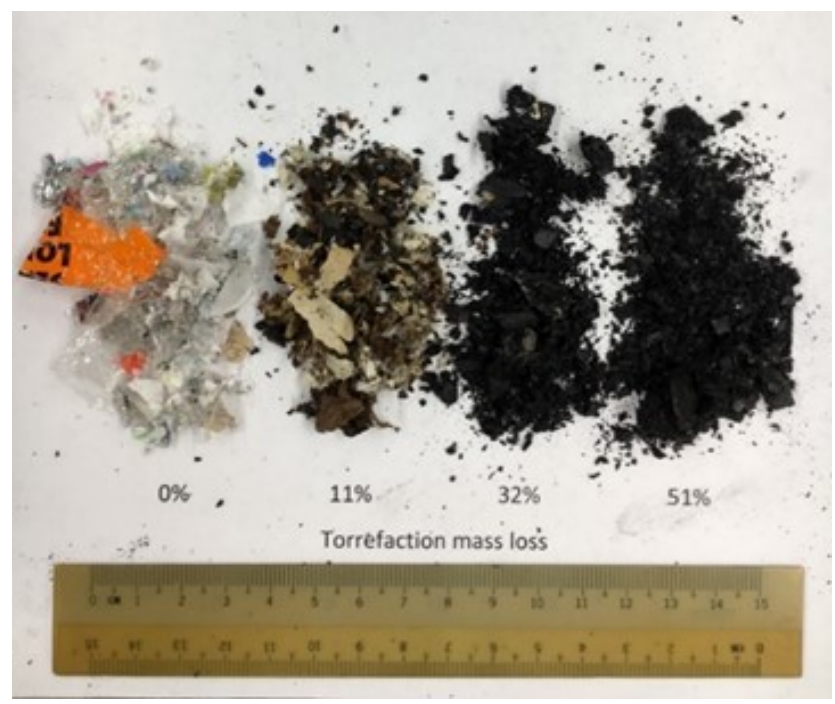

Figure 3.3. The photograph shows the original waste plastic mix and torrefied material at $11 \%, 32 \%$, and $51 \%$ mass loss.

According to Eq. (3.2), the characteristic time for fiber, plastic and blend were $\tau_{\text {fiber }}=136$ $(\mathrm{s}), \tau_{\text {plastic }}=300(\mathrm{~s})$ and $\tau_{\text {blend }}=184(\mathrm{~s})$, respectively. Figure 3.4 Top portrays temperature transients calculated by Eq. (3.5) for the fiber, plastic, and the blend, reaching $300^{\circ} \mathrm{C}$. The differences between the three transients arise from differences in the properties of the three materials, as summarized by Xu et al., [24]. Figure 3.4 Bottom shows measured mass loss for fiber, plastic, and blend torrefied at $300{ }^{\circ} \mathrm{C}$. For the three materials, mass loss remained zero for 4-5 $\mathrm{min}$ then it started to increase gradually. The figure also includes model results for each material and the expected model behavior of the blend. Experimental results for the mass loss for the plastic waste (square symbols) show a slow increase with time, whereas the measured results for the fiber waste (circle symbols) show a much faster mass loss increase with time. Each of the mass loss transients was also modeled (dashed lines in Figure 3.4 Bottom), showing perfect fit to experimental data, as explained above (see Eq.(3.5)), and the kinetic parameters were drawn from the fitting process. 

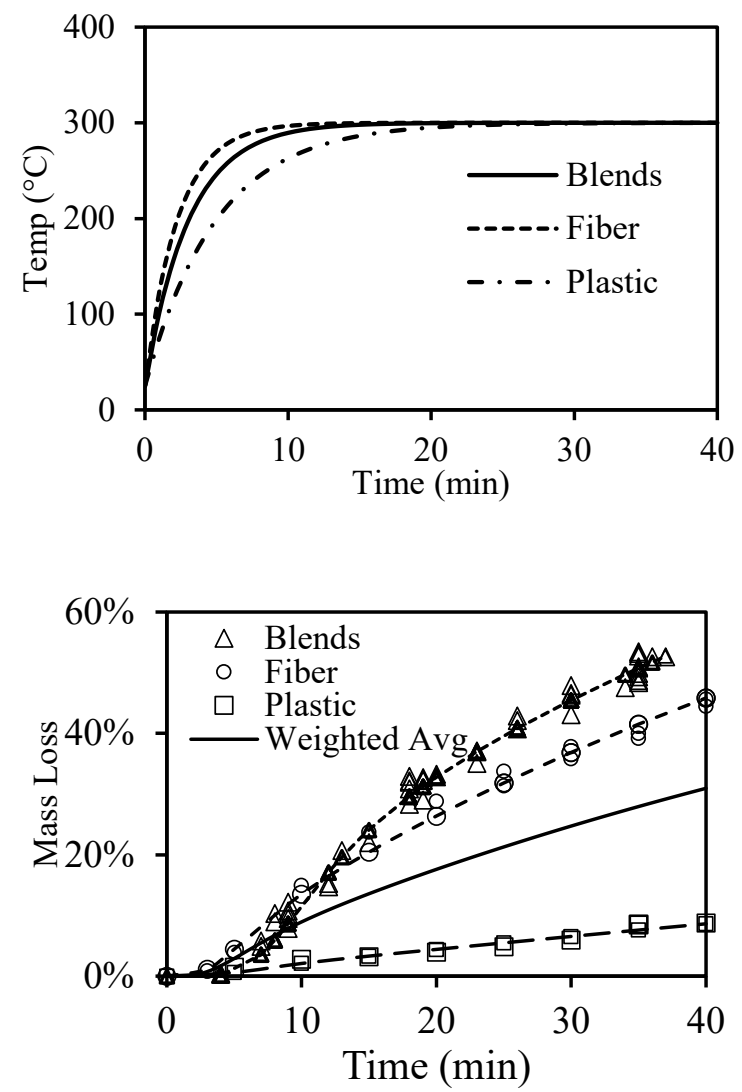

Figure 3.4. Top - temperature transients are calculated by Eq.(4.1) or the fiber, plastic, and the blend, reaching $300{ }^{\circ} \mathrm{C}$. Bottom - a mass loss for the fiber, plastic, and blend. The figure also shows model results for each component and the expected model behavior for the blend.

The parameters obtained by the fitting as follows: (i) fiber: $\left(A^{\dagger} / \rho\right)_{\text {fiber }}=2,997$ and $\left(T_{a}\right)_{\text {fiber }}=5,369(\mathrm{~K})$, (ii) plastic: $\left(A^{\dagger} / \rho\right)_{\text {plastic }}=2,558$ and $\left(T_{a}\right)_{\text {plastic }}=6,383(\mathrm{~K})$, and (iii) blend: $\left(A^{\dagger} / \rho\right)_{\text {blend }}=1.2 * 10^{8}$ and $\left(T_{a}\right)_{\text {blend }}=15,258(\mathrm{~K})$. The important point is that these kinetic parameters were used to predict the mass loss behavior for the plastic-fiber waste blend, assuming each component does not influence the other. In this case, evidently, the resultant behavior should have been between the fiber and plastic transients, as shown by the solid line in the figure. However, the actual experimental data for the blend show much faster mass loss transients (triangle symbols) than expected. This is direct evidence that there is 
a strong reaction (synergy) between the fiber (mostly cellulose polymers) and the plastic material (mostly hydrocarbon polymers).

Although at this stage we did not carry out solid-state characterization measurements that might shed direct light on the reactions between the two polymers, it can be hypothesized that hydrogen atoms from the hydrocarbon polymer react with either, $\mathrm{COOH}, \mathrm{CO}$ or $\mathrm{OH}$ groups in the cellulosic polymer and enhance the stripping of these groups, thus increasing the reaction rate of the degradation of the cellulosic polymer. Similar behavior was observed by Nallar and Wong, where high-density polyethylene accelerated the thermal degradation of the cellulose [30].

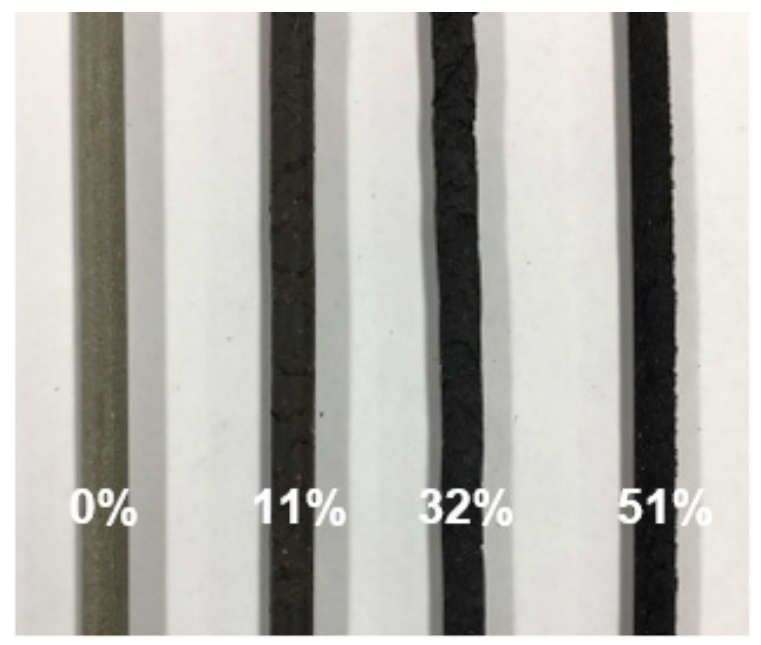

Figure 3.5. Photograph showing the extruded rods made from a non-torrefied waste blend ( $0 \%$ mass loss) and torrefied materials at $11 \%, 32 \%$, and $51 \%$ mass loss.

\subsubsection{Extruded Pellets}

Samples of a non-torrefied waste blend ( $0 \%$ mass loss) and torrefied waste blend (11\%, $32 \%$, and 51\% mass loss) were compounded and extruded into rods (Figure 3.5). Compounding homogenized both the non-torrefied and torrefied materials into a uniform extrudate. The addition of the plastic in the feedstock has enabled the extrusion process because the high temperature melted the plastic, which acted as a lubricant. The molten plastic encapsulated the fiber to form a consistent/uniform extruded rod. To minimize 
surface cracking, the extruder barrel temperature was decreased by at least $10^{\circ} \mathrm{C}$ for the torrefied material than the original waste blend (Table 3.1). The smoothness of the extrudate surface depended strongly on the die temperature that had to be adjusted to get the desired surface quality.

\subsubsection{FTIR Spectroscopy}

Despite the differences in the relative standard deviations, important information regarding the material in the blend can be obtained. FTIR spectroscopy was employed to examine the major chemical changes that occurred in the waste blend samples upon torrefaction [31]. FTIR measurements were performed on samples prior to and after the torrefaction. Details on FTIR measurements and consequent conclusions regarding the chemical changes during torrefaction are given below.
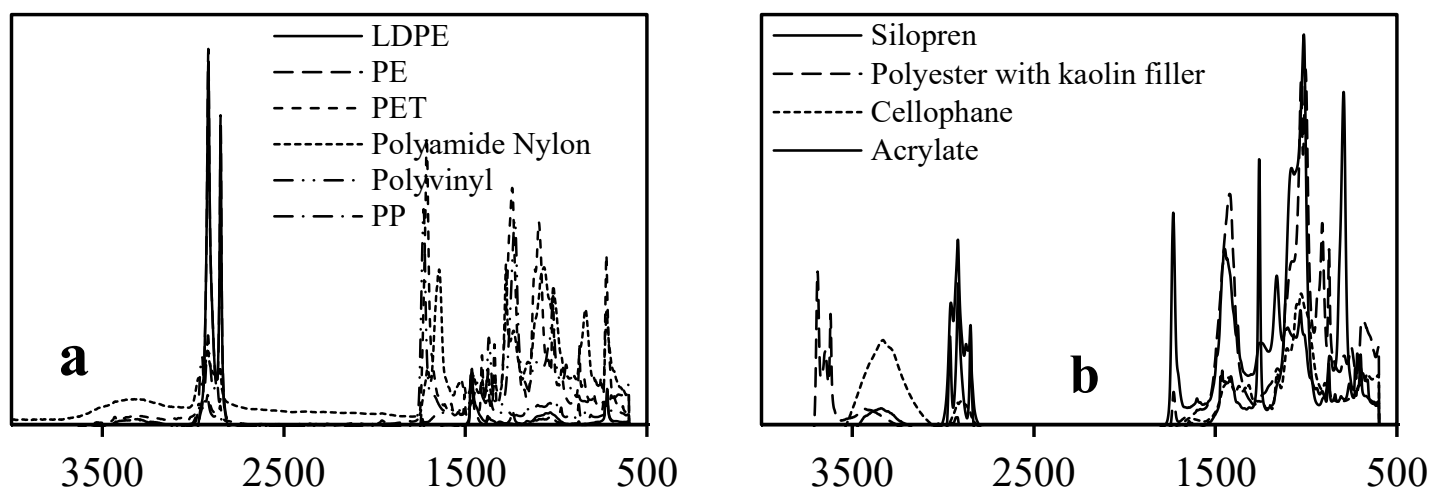

Figure 3.6. Materials identified from raw feedstock, (a) plastics; (b) fibers.

The feedstock used was a blend of $40 \%$ plastic and $60 \%$ fiber wastes. FTIR experiments were done 30 times for fiber waste (Figure 3.1a) and plastic waste (Figure 3.1b) to determine the chemical identity prior to the blending. Figure 3.6a showed that plastic wastes mainly consist of low-density polyethylene, polyethylene, polyethylene terephthalate, polyamide-nylon, polyvinyl, polypropylene, and some other materials. Figure $3.6 \mathrm{~b}$ showed that there are silopren, polyester with kaolin filler, and acrylate/paper mix together with cellophane/cellulose in the fiber wastes. The results from Figure 3.6 indicated the large variabilities in the feedstock. 
Figure 3.7 shows FTIR spectra of a composite average of 30 waste blend pieces, extruded mixed plastic waste ( $0 \%$ mass loss), and extruded torrefied (11\%, 32\%, and $51 \%$ mass loss) material. C -H stretching bands were observed in every sample and were attributed to methyl $\left(2960 \mathrm{~cm}^{-1}\right.$ and $\left.2870 \mathrm{~cm}^{-1}\right)$ and methylene $\left(2916 \mathrm{~cm}^{-1}\right.$ and $\left.2850 \mathrm{~cm}^{-1}\right)$ groups [32]. The two methylene bands were of comparable intensity for all samples, and the methyl group decreased with the extent of torrefaction. It was observed that there exists $\mathrm{O}-\mathrm{H}$ stretching band in all the samples at the region between 3100 and $3600 \mathrm{~cm}^{-1}$, and the intensity gradually reduced as mass loss increased. At $1690-1750 \mathrm{~cm}^{-1}$, a broad carbonyl $(\mathrm{C}=\mathrm{O})$ band was detected mainly assigned to (i) an ester in linkage in PET and acrylate and (ii) amide linkage in nylon [33]. Paper was recognized due to a small band at $1505 \mathrm{~cm}^{-1}$. Wood cellulose and hemicellulose were also identified at the region at $1000-1070 \mathrm{~cm}^{-1}$ [34]. Cis- band at $727 \mathrm{~cm}^{-1}$ and trans-vinylene bands at $974 \mathrm{~cm}^{-1}$, were found in all the samples [35].

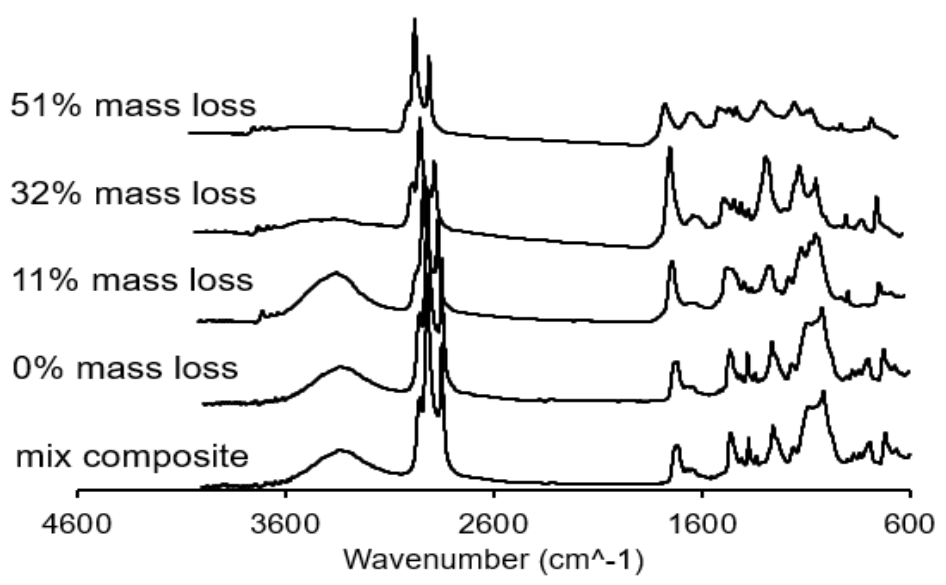

Figure 3.7. FTIR spectra of a composite average of 30 waste blend pieces, extruded mixed plastic ( $0 \%$ mass loss), and extruded torrefied ( $11 \%, 32 \%$, and $51 \%$ mass loss) material.

The relative changes in hydroxyl, carbonyl, and cellulose that occurred during torrefaction were analyzed by calculating HI, CI, and CeI, respectively (Figure 3.8). The HI and CeI decreased respectively from 0.27 to 0.02 and from 0.51 to 0.20 upon torrefaction $(0 \%$ to $51 \%$ mass loss). These results support that the reduction in cellulose content was due to 
dehydration and degradation reactions [36]. The $\mathrm{CI}$ increased from 0.26 to 0.34 at $32 \%$ mass loss, then decreased to 0.21 at $51 \%$ mass loss, and this change could not be explained.

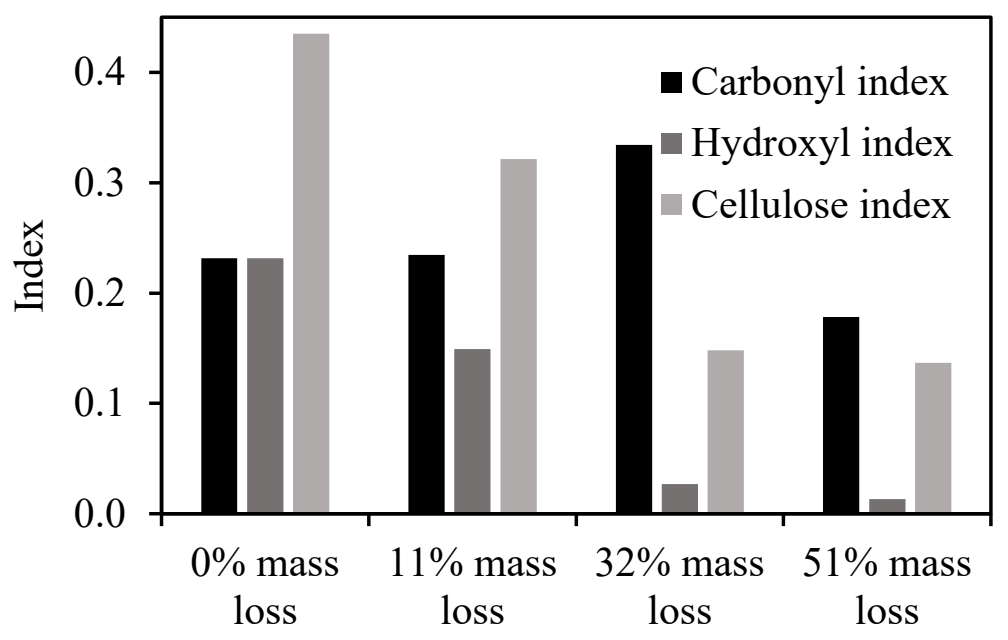

Figure 3.8. Plot showing changes in hydroxyl (HI), carbonyl (CI), and cellulose (CeI) indices with the extent of torrefaction (mass loss).

\subsubsection{Material Variability and Homogeneity}

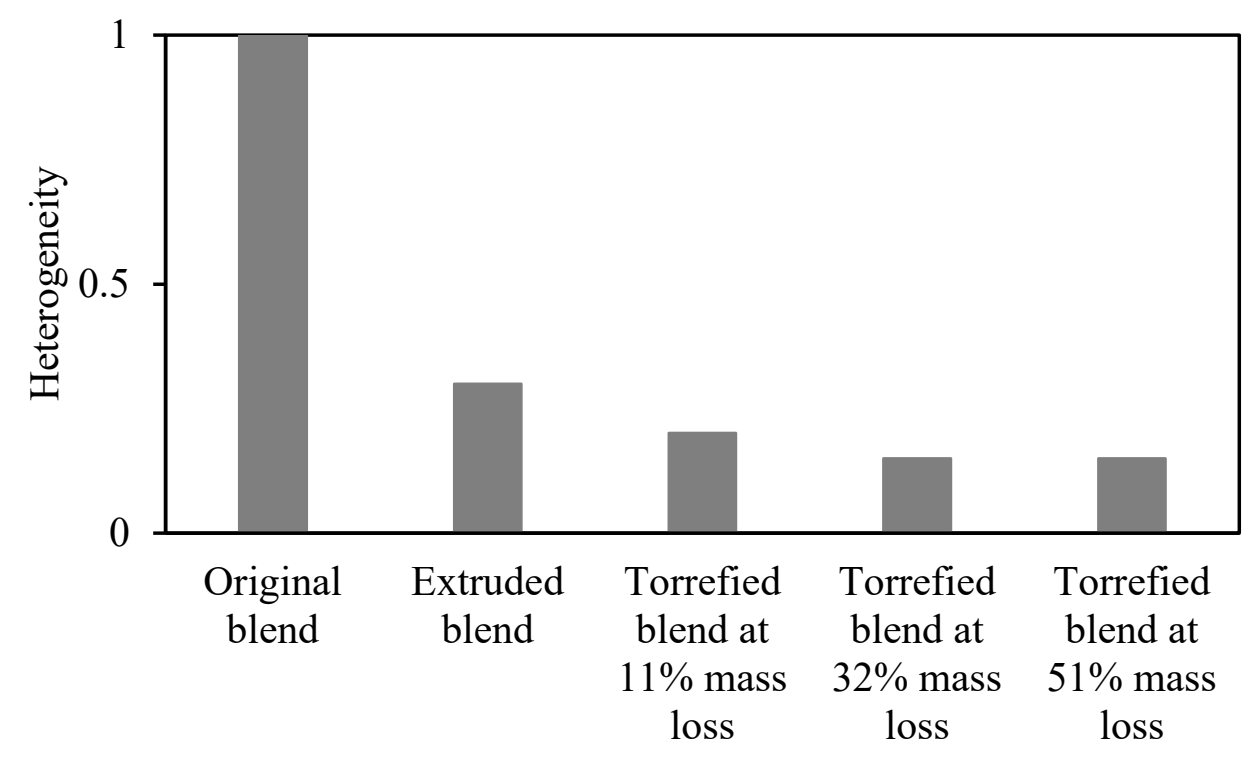

Figure 3.9. Heterogeneity as defined by STD/IN of IR spectra measured. 
FTIR spectroscopy shows that there exist large variabilities in the raw feedstock (Figure 3.6). Perhaps one of the most important roles of extrusion and torrefaction of samples containing plastic is the ability to reduce the heterogeneity of the initial waste blend significantly. To note, heterogeneity (or non-uniformity) was defined by the term standard deviation/intensity (STD/In) of the 30 IR spectra measured -the larger the term, the greater is the heterogeneity of the blend. Figure 3.9 shows the normalized heterogeneity for the various samples: from left to right is the original fiber-plastic blend, followed by the same blend that was extruded, which reduced the heterogeneity by $\sim 70 \%$, followed by the $10 \%$ mass loss blend, which reduced another $10 \%$ of heterogeneity and the number finally stabilized at $\sim 15 \%$ after the mass loss reached $32 \%$. The combination of torrefaction followed by the extrusion process decreased the heterogeneity of the original blend by a factor of 7. This indicated that the extrusion process reduced the variabilities of the material since the plastics were melted and the feedstock was well-mixed inside the reactor before getting extruded.

\subsubsection{Thermomechanical Analysis (TMA)}

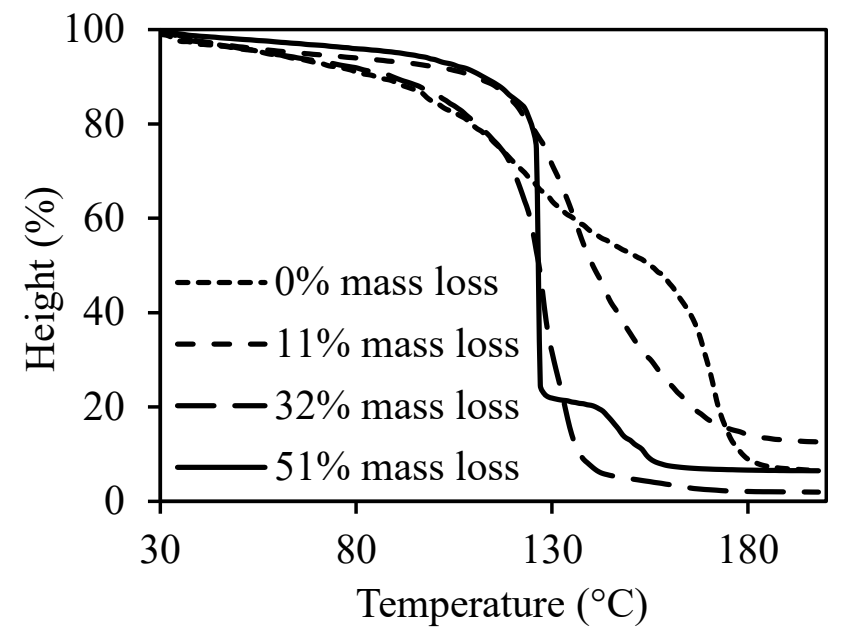

Figure 3.10. TMA thermograms of the extruded torrefied ( $0 \%$ to $51 \%$ mass loss) samples.

TMA was performed on the extruded torrefied material to determine the materials' softening point Figure 3.10. Table 3.2 shows the softening temperature $\left(\mathrm{T}_{\mathrm{s}}\right)$ onset for the extruded torrefied materials. The waste blend was shown to have two gradual, softening 
temperatures $\left(\mathrm{T}_{\mathrm{s}-1}\right.$ and $\left.\mathrm{T}_{\mathrm{s}-2}\right)$ at $102{ }^{\circ} \mathrm{C}$ and $164{ }^{\circ} \mathrm{C}$, and these coincide with the melting temperatures of low-density polyethylene (LDPE) $\left(98-115^{\circ} \mathrm{C}\right)$ and polypropylene (160$\left.175^{\circ} \mathrm{C}\right)$ [37]. The gradual change in probe height during the thermal transition is likely due to the reinforcing effect of cellulose/paper in the sample. As the waste blend was torrefied (11\% mass loss), $\mathrm{T}_{\mathrm{s}-1}$ increased slightly to $120{ }^{\circ} \mathrm{f}$ then progressively decreased to $109{ }^{\circ} \mathrm{C}$ (51\% mass loss). Furthermore, the 51\% mass loss torrefied material had two transitions $\left(\mathrm{T}_{\mathrm{s}-2}\right.$ and $\left.\mathrm{T}_{\mathrm{s}-3}\right)$ at $123{ }^{\circ} \mathrm{C}$ (sharp) and $142{ }^{\circ} \mathrm{C}$.

Table 3.2. Softening temperatures for the extruded material determined using TMA.

\begin{tabular}{lllll}
\hline $\begin{array}{l}\text { Torrefied } \\
\text { material }\end{array}$ & $\begin{array}{l}\mathbf{0 \%} \text { mass } \\
\text { loss }\end{array}$ & $\begin{array}{l}\mathbf{1 1 \%} \text { mass } \\
\text { loss }\end{array}$ & $\begin{array}{l}\mathbf{3 2 \%} \text { mass } \\
\text { loss }\end{array}$ & $\begin{array}{l}\mathbf{5 1 \%} \text { mass } \\
\text { loss }\end{array}$ \\
\hline $\mathrm{T}_{\mathrm{s}-1}\left({ }^{\circ} \mathrm{C}\right)$ & 102 & 120 & 112 & 109 \\
\hline $\mathrm{T}_{\mathrm{s}-2}\left({ }^{\circ} \mathrm{C}\right)$ & 164 & $\mathrm{NA}$ & $\mathrm{NA}$ & 123 \\
\hline $\mathrm{T}_{\mathrm{s}-3}\left({ }^{\circ} \mathrm{C}\right)$ & $\mathrm{NA}$ & $\mathrm{NA}$ & $\mathrm{NA}$ & 142 \\
\hline
\end{tabular}

\subsubsection{Dynamic Rheological Results}

Dynamic rheological measurements were also obtained on the extruded torrefied melts. Figure 3.11 shows the dynamic elastic $\left(G^{\prime}\right)$ and viscous $\left(G^{\prime \prime}\right)$ moduli and complex viscosity $\left(\eta^{*}\right)$ as a function of frequency at $180^{\circ} \mathrm{C}$. For all melt samples $\mathrm{G}^{\prime}$ and $\mathrm{G}^{\prime \prime}$ were shown to increase with angular frequency (Figure $3.11 \mathrm{a}$ and $\mathrm{b}$ ). Torrefaction of the waste blend to $51 \%$ mass loss was shown to increase both $\mathrm{G}^{\prime}$ and $\mathrm{G}^{\prime \prime}>2$-fold (at $1 \mathrm{~Hz}$ ). Over the angular frequency range examined, the $\mathrm{G}^{\prime}$ was higher than $\mathrm{G}^{\prime \prime}$, indicating an elastic response predominated at $180{ }^{\circ} \mathrm{C}$. The $\eta^{*}$ was shown to decrease with an increase in angular frequency, showing a shear-thinning behavior for the melts, and this trend has been observed in reprocessed mixed plastic wastes [38] (Figure 3.11c). The $\eta^{*}$ (at $1 \mathrm{~Hz}$ ) was also shown to increase from $16,800 \mathrm{~Pa} \cdot \mathrm{s}$ for the waste blend extrudate to $40,000 \mathrm{~Pa} \cdot \mathrm{s}$ for the $51 \%$ mass loss torrefied extrudate. 

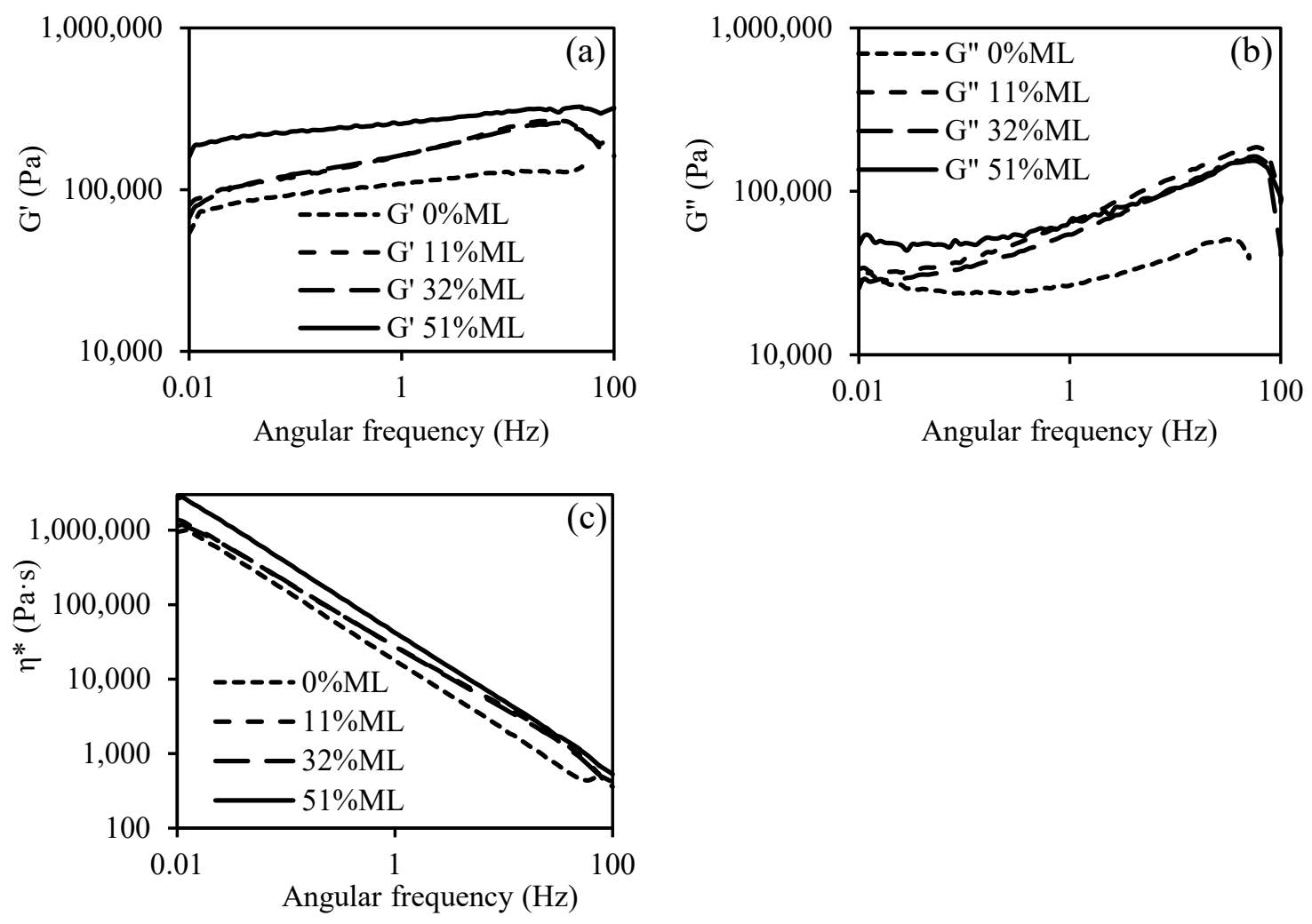

Figure 3.11. Dynamic rheology showing (a) elastic moduli (G'), (b) viscous moduli (G") and (c) complex viscosity $\left(\eta^{*}\right)$ as a function of frequency for torrefied waste blend extrudates at $180^{\circ} \mathrm{C}$.

\subsubsection{Density and Mechanical Properties}

The density (volume displacement method) of the extruded torrefied rod samples ranged between 1082 to $1189 \mathrm{~kg} / \mathrm{m}^{3}$. The density determined by weight/volume gave comparable values. Results are summarized in Table 3.3.

The results of the flexural tests on the extruded torrefied material are shown in Table 3.3. The mean flexural modulus for the extruded torrefied samples ( 0 to $51 \%$ mass loss) was between 1,354 and 1,500 MPa. The modulus for the 51\% mass loss torrefied material was significantly lower than the other three samples. 
Table 3.3. Softening temperatures for the extruded material determined by TMA.

\begin{tabular}{|c|c|c|c|c|}
\hline & $\begin{array}{ll}0 \% & \text { mass } \\
\text { loss } & \end{array}$ & $\begin{array}{l}11 \% \text { mass } \\
\text { loss }\end{array}$ & $\begin{array}{l}32 \% \text { mass } \\
\text { loss }\end{array}$ & $\begin{array}{l}51 \% \text { mass } \\
\text { loss }\end{array}$ \\
\hline Density* $\left(\mathrm{kg} / \mathrm{m}^{3}\right)$ & $1142(36)$ & $1082(21)$ & $1134(30)$ & $1189(48)$ \\
\hline Density** $\left(\mathrm{kg} / \mathrm{m}^{3}\right)$ & 1124 & 1087 & 1144 & 1191 \\
\hline Flexural modulus (MPa) & $1,400(98)$ & $1,500(106)$ & $1,404(82)$ & $1,354(53)$ \\
\hline Flexural strength (MPa) & $10.67(0.77)$ & $8.23(0.53)$ & $10.94(0.63)$ & $7.66(1.22)$ \\
\hline $\begin{array}{l}\text { Storage modulus } \mathrm{E}^{\prime} \\
(\mathrm{MPa}) \text { at } 20^{\circ} \mathrm{C}\end{array}$ & 389 & 467 & 507 & 670 \\
\hline Tan $\delta$ at $20^{\circ} \mathrm{C}$ & 0.069 & 0.068 & 0.086 & 0.103 \\
\hline $\begin{array}{l}\text { Temperature at max loss } \\
\text { modulus } \mathrm{E}^{\prime \prime}\left({ }^{\circ} \mathrm{C}\right)\end{array}$ & 94 & 77 & 59 & 53 \\
\hline
\end{tabular}

*Determined by volume displacement method; **determined by weight divided by volume; Standard Deviation in parentheses.

The modulus of these materials was comparable to polypropylene (1,170-1,720 MPa) [39]. The mean flexural strength for the extruded torrefied samples ( 0 to $51 \%$ mass loss) was between 7.66 MPa and 10.94 MPa and similar to LDPE (12 MPa) [40]. The 0\% and 32\% mass loss extruded torrefied material was significantly stronger than the $11 \%$ and $51 \%$ mass loss samples.
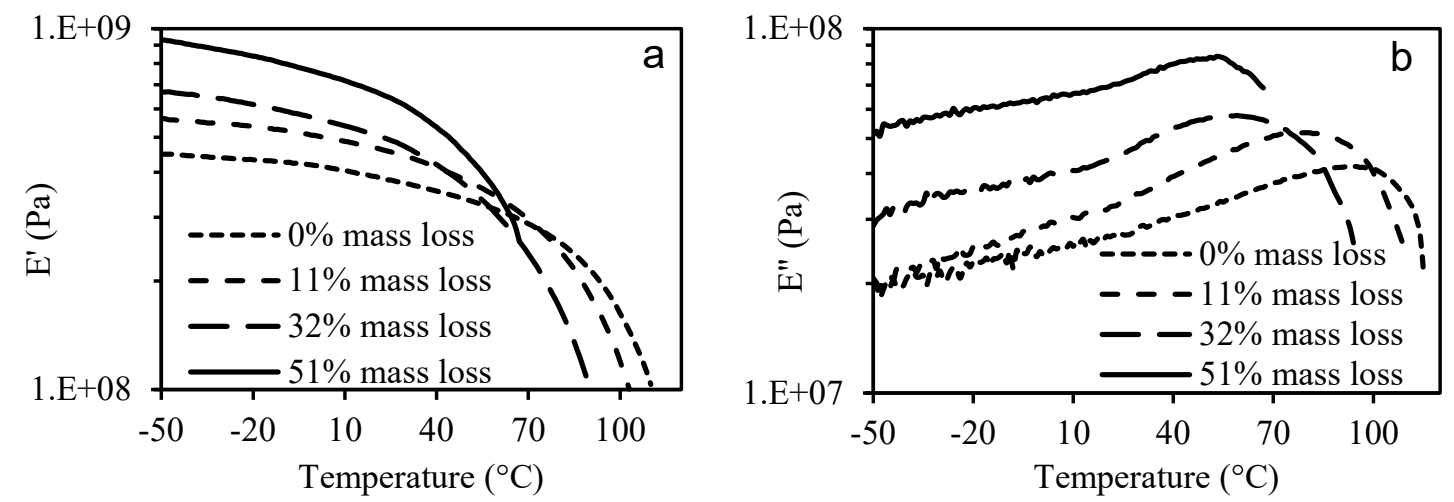

Figure 3.12. (a) storage modulus (E') and (b) loss modulus (E") 
DMA analysis was performed on the extruded material (Figure 3.12). The storage modulus $\left(E^{\prime}\right), \tan \delta$ values at $20^{\circ} \mathrm{C}$, and temperature at maximum loss modulus ( $\left.E^{\prime \prime}\right)$ of the extruded torrefied material values are given in Table 3.3. The 51\% mass loss material had the highest $\mathrm{E}^{\prime}$ value at $670 \mathrm{MPa}$, while the mixed plastic waste ( $0 \%$ mass loss) had the lowest at 389 MPa. A similar trend has been found existing on natural fiber polypropylene composites [41]. This might be due to the lower fiber content at a higher mass loss, while the reinforcement imparted by the fiber could allow stress transfer from the matrix to the fiber [42]. Additionally, with an increase in torrefaction mass loss, the temperature at maximum loss modulus showed a shift to a lower value.

\subsubsection{Water Resistance}

A sample of torrefied (20\% mass loss) and extruded material was used in the water absorption experiment. Four samples were submerged in water for 30 days. Samples were taken out for water intake measurements after 1,3,11,25, and 30 days (Figure 3.13). Surface water was removed, and the weight of the sample was taken. Material disintegration was not observed. The results are given in Figure 3.13, showing water intake (as the weight difference, in percent) reached an asymptotic value after five days to $0.7 \%$, indicating that these extruded pellets did not absorb water. This can be attributed to the plastic melting around the fiber. This creates a protective layer that prevents water absorption. In addition, it can be hypothesized that the protective layer prevents oxygen from accessing the active sites created by the degradation of the cellulosic polymers.

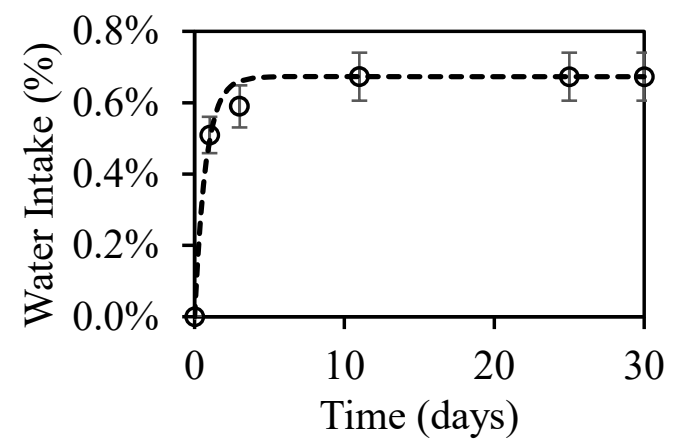

Figure 3.13. Water intake of extruded, $20 \%$ mass loss, torrefied material as a function in time. 


\subsubsection{Size Distribution}

As shown by $\mathrm{Xu}$ et al., the fractions above and below $850 \mu \mathrm{m}$ represent the changes in the material structure (physical and structural) as the mass loss increases [24]. Figure 3.14 shows the size distribution of the extruded torrefied pellets with $0 \%, 11 \%, 32 \%$, and $51 \%$ mass loss. It was clear that after grinding, the size fraction below $850 \mu \mathrm{m}$ went up as mass loss increased, and it almost reached $100 \%$ at $51 \%$ mass loss, and the size fraction above $850 \mu \mathrm{m}$ went down accordingly.

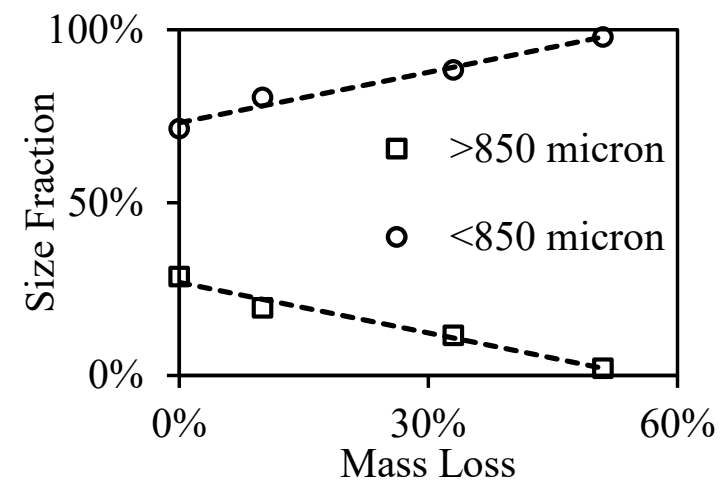

Figure 3.14. Size fractions of the extruded pellets after grinding.

\subsubsection{Heat Content}

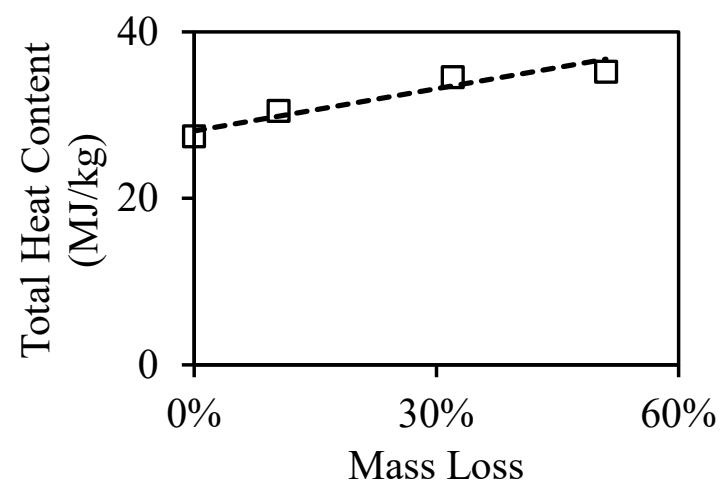

Figure 3.15. The total heat content of the extruded pellets at a different mass loss.

To avoid sampling issues, the material was ground and sifted into five different fractions. The heat content of fractions was measured, and the total heat content was calculated based 
on the weighted average. Figure 3.15 shows the heat content for the pellets with the function of mass loss. The heat content increased from $28.1 \mathrm{MJ} / \mathrm{kg}$ to $35.2 \mathrm{MJ} / \mathrm{kg}$ as the mass loss increased to $51 \%$.

\subsubsection{Combustion Test}
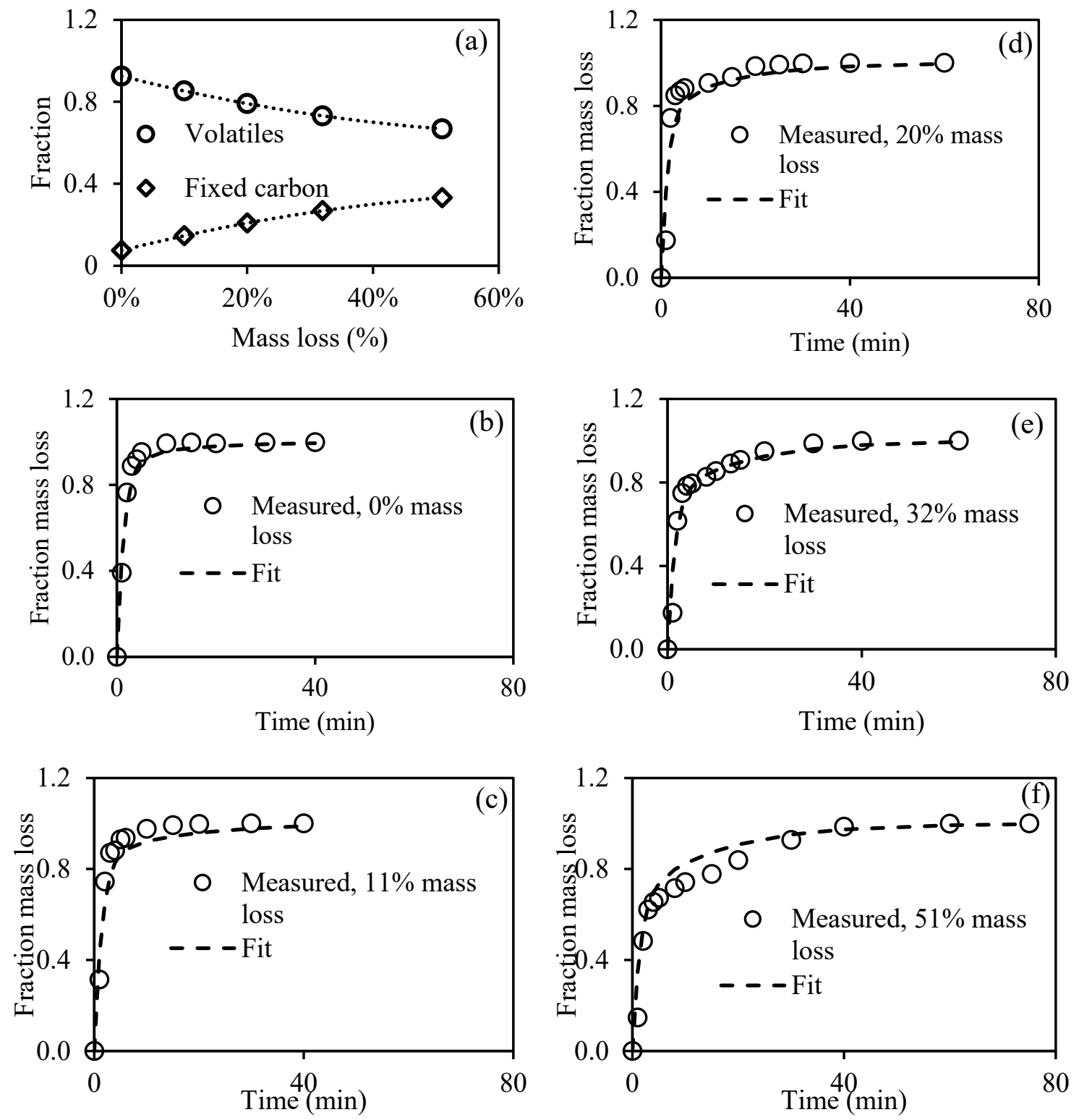

Figure 3.16. Volatile content and fixed carbon as measured as a function of torrefaction mass loss (a). Combustion tests plotted as mass loss fraction vs. time for non-torrefied pellets (b), torrefied pellets at 11-51\% mass loss (c-f). 
The extruded pellets produced can be burned as is in stokers, moving grates, and other boilers [43] without grinding. In this case, it is essential to study the combustion behavior of the pellets. When the pellets are heated up, the volatile matter is first released and burned in the gas phase at a fast rate, then the fixed carbon burns at a much slower rate; this behavior is comparable to that of biomass and coal combustion.

The two-stage combustion behavior is expected to behave according to the following equation $\alpha=a_{1}\left(1-e^{-\frac{t}{\tau_{1}}}\right)+a_{2}\left(1-e^{-\frac{t}{\tau_{2}}}\right)$ where $\alpha$ is the fraction of the burned material (pellet), $a_{1}$ and $a_{2}$ are the fractions of volatile and fixed carbon, respectively. The characteristic times $\tau_{1}$ and $\tau_{2}$ represent the volatile burning and fixed carbon burning, respectively. The values of $a_{1}$ [44] and $a_{2}$ were measured for each mass loss. The values $\tau_{1}$ and $\tau_{2}$ were fitted from experimental data and were kept identical in all the cases (all the mass loss values). Figure 3.16a shows measured volatile content and fixed carbon as a function of mass loss. It has shown that the volatile matter of the material decreases with the extent of torrefaction, and the fixed carbon increases accordingly.

Figure 3.16b-f shows combustion test results, plotted as mass loss fraction vs. time, for non-torrefied pellets (Figure 3.16b) and torrefied pellets with mass losses in the range of $10-51 \%$ (Figure 3.16c-f). The characteristic times for the volatile matter were found to be $1.49 \mathrm{~min}$ and $15.62 \mathrm{~min}$, respectively. It is to be noted that these results are for the specific pellet configurations, i.e., if we take the external surface $\left(8.89 \mathrm{~cm}^{2}\right)$ into consideration as a linear parameter, we will get $0.17 \mathrm{~min} / \mathrm{cm}^{2}$ and $1.76 \mathrm{~min} / \mathrm{cm}^{2}$.

\subsection{Summary and Conclusion}

In this study, waste blends consisting of $40 \%$ plastic and $60 \%$ fiber at different mass losses were used as the feedstock for the extrusion, and the extruded products were characterized. The FTIR results showed that the fiber to plastic ratio decreased as the mass loss increased, and the extrusion process significantly increased the homogeneities of the feedstock. Additionally, the torrefaction also further reduced the variabilities of the material. Chemical changes (carbonyl, hydroxyl, and cellulose index) also showed that cellulose 
content reduced due to the dehydration and degradation reactions. Further, these reactions increased the heat content of the material and broke the fiber structure allowing grinding to be more effective. At $51 \%$ mass loss, close to $100 \%$ of the material was below 850 microns after grinding. As mass loss increased, the temperature at maximum loss modulus showed a slight shift to a lower value. The dynamic rheological results also showed that the elastic response was predominated at $180^{\circ} \mathrm{C}$, and the melts of the material have a shear thinning behavior which was also observed in reprocessed mixed plastic wastes. It has shown that the volatile matter of the material decreases with the extent of torrefaction, and the fixed carbon increases accordingly. The plastic in the feedstock acted as a process enabler as it imparted properties like bindability, water resistance, high heat content, and increasing the reaction rate of the degradation. Overall, the extruded pellets could be a drop-in fuel for small-to-large power plant facilities and reduce the amount of waste going to landfills.

\subsection{References}

[1] M. El-Fadel, A.N. Findikakis, J.O. Leckie, Environmental Impacts of Solid Waste Landfilling, Journal of Environmental Management, 50 (1997) 1-25. https://doi.org/10.1006/jema.1995.0131

[2] B. Arias, C. Pevida, J. Fermoso, M.G. Plaza, F. Rubiera, J.J. Pis, Influence of torrefaction on the grindability and reactivity of woody biomass, Fuel Processing Technology, 89 (2008) 169-175. https://doi.org/10.1016/j.fuproc.2007.09.002

[3] C. Wang, L.F. Zhao, M.K. Lim, W.Q. Chen, J.W. Sutherland, Structure of the global plastic waste trade network and the impact of China's import Ban, Resour Conserv Recy, 153 (2020) 104591. https://doi.org/10.1016/j.resconrec.2019.104591

[4] K. Bolton, K. Rousta, Solid Waste Management Toward Zero Landfill, in: M.J. Taherzadeh, K. Bolton, J. Wong, A. Pandey (Eds.) Sustainable Resource Recovery and Zero Waste Approaches, Elsevier, 2019, pp. 53-63. 
[5] A. Paletta, W. Leal, A.L. Balogun, E. Foschi, A. Bonoli, Barriers and challenges to plastics valorisation in the context of a circular economy: Case studies from Italy, Journal of Cleaner Production, 241 (2019) 118149. https://doi.org/ARTN 118149

10.1016/j.jclepro.2019.118149

[6] N. Chatziaras, C.S. Psomopoulos, N.J. Themelis, Use of waste derived fuels in cement industry: a review, Manag Environ Qual, 27 (2016) 178-193. https://doi.org/10.1108/Meq$\underline{01-2015-0012}$

[7] R. Sarc, K.E. Lorber, Production, quality and quality assurance of Refuse Derived Fuels (RDFs), Waste $\quad$ Manag, $33 \quad$ (2013) 1825-1834. https://doi.org/10.1016/j.wasman.2013.05.004

[8] M.J.C. van der Stelt, H. Gerhauser, J.H.A. Kiel, K.J. Ptasinski, Biomass upgrading by torrefaction for the production of biofuels: A review, Biomass and Bioenergy, 35 (2011) 3748-3762. https://doi.org/10.1016/j.biombioe.2011.06.023

[9] U.S. Environmental Protection Agency, Carbon pollution emission guidelines for existing stationary sources: electric utility generation units, in: EPA-HQ-OAR-2013-0602, 2015, pp. 64661-64964.

[10] G.-A. Tsalidis, Y. Joshi, G. Korevaar, W. de Jong, Life cycle assessment of direct cofiring of torrefied and/or pelletised woody biomass with coal in The Netherlands, Journal of Cleaner Production, 81 (2014) 168-177. https://doi.org/10.1016/j.jclepro.2014.06.049

[11] L.J.R. Nunes, J.C.O. Matias, J.P.S. Catalao, A review on torrefied biomass pellets as a sustainable alternative to coal in power generation, Renewable \& Sustainable Energy Reviews, 40 (2014) 153-160. https://doi.org/10.1016/j.rser.2014.07.181 
[12] C. Rodríguez-Monroy, G. Mármol-Acitores, G. Nilsson-Cifuentes, Electricity generation in Chile using non-conventional renewable energy sources - A focus on biomass, Renewable and Sustainable Energy Reviews, 81 (2018) 937-945. https://doi.org/10.1016/j.rser.2017.08.059

[13] L. Kumar, A.A. Koukoulas, S. Mani, J. Satyavolu, Integrating Torrefaction in the Wood Pellet Industry: A Critical Review, Energy \& Fuels, 31 (2017) 37-54. https://doi.org/10.1021/acs.energyfuels.6b02803

[14] R.I. Radics, R. Gonzalez, E.M. Bilek, S.S. Kelley, Systematic Review of Torrefied Wood Economics, Bioresources, $12 \quad$ (2017) 6868-6884. https://doi.org/10.15376/biores.12.3.Radics

[15] J. Park, J.J. Meng, K.H. Lim, O.J. Rojas, S. Park, Transformation of lignocellulosic biomass during torrefaction, Journal of Analytical and Applied Pyrolysis, 100 (2013) 199206. https://doi.org/10.1016/j.jaap.2012.12.024

[16] C. Ceballos, D. Catalina, K. Hawboldt, R. Hellleur, Effect of production conditions on self-heating propensity of torrefied sawmill residues, Fuel, 160 (2015) 227-237. https://doi.org/10.1016/j.fuel.2015.07.097

[17] U.S. Environmental Protection Agency, 2010 MSW Facts and Figures Factsheet, in, 2010.

[18] W. Stelte, A.R. Sanadi, L. Shang, J.K. Holm, J. Ahrenfeldt, U.B. Henriksen, Recent Developments in Biomass Pelletization - a Review, Bioresources, 7 (2012) 4451-4490.

[19] J.S. Tumuluru, C.T. Wright, J.R. Hess, K.L. Kenney, A review of biomass densification systems to develop uniform feedstock commodities for bioenergy application, Biofuel Bioprod Bior, 5 (2011) 683-707. https://doi.org/10.1002/bbb.324 
[20] Y. Donepudi, Impact of Pretreatment Methods on Fast Pyrolysis of Biomass, in Mechanical Engineering, Michigan Technological University, Houghton, MI, USA., 2017. https://doi.org/10.37099/mtu.dc.etdr/496

[21] E. Bar-Ziv, J. Klinger, Logistics and storage of torrefied biomass Safety aspects, Safety Consideration in Biomass Torrefaction, in: Energy-Tech Magazine Online (https://www.energy-tech.com/fuels/), 2016.

[22] M.A. Hanaffi Mohd Fuad, H.M. Faizal, M.R.A. Rahman, Z.A. Latiff, Torrefaction of densified empty fruit bunches with addition of plastics waste, Biofuels, 11 (2018) 491-501. https://doi.org/10.1080/17597269.2018.1457312

[23] X.Q. Wang, Z.M. Yu, A.G. McDonald, Effect of Different Reinforcing Fillers on Properties, Interfacial Compatibility and Weatherability of Wood-plastic Composites, Journal of Bionic Engineering, 16 (2019) 337-353. https://doi.org/10.1007/s42235-019$\underline{0029-0}$

[24] Z. Xu, S. Zinchik, S.S. Kolapkar, E. Bar-Ziv, T. Hansen, D. Conn, A.G. McDonald, Properties of Torrefied U.S. Waste Blends, Frontiers in Energy Research, 6 (2018). https://doi.org/10.3389/fenrg.2018.00065

[25] O.O. Adefisan, L. Wei, A.G. McDonald, Evaluation of plastic composites made with Laccosperma secundiflorum and Eremospatha macrocarpa canes, Maderas: Ciencia y Tecnologia, 19 (2017) 517-524. https://doi.org/10.4067/S0718-221X2017005000044

[26] L.Q. Wei, A.G. McDonald, C. Freitag, J.J. Morrell, Effects of wood fiber esterification on properties, weatherability and biodurability of wood plastic composites, Polymer Degradation and Stability, $98 \quad$ (2013) 1348-1361. https://doi.org/10.1016/j.polymdegradstab.2013.03.027 
[27] S.P. Luo, J.Z. Cao, A.G. McDonald, Interfacial Improvements in a Green Biopolymer Alloy of Poly(3-hydroxybutyrate-co-3-hydroxyvalerate) and Lignin via in Situ Reactive Extrusion, Acs Sustainable Chemistry \& Engineering, 4 (2016) 3465-3476. https://doi.org/10.1021/acssuschemeng.6b00495

[28] ASTM International, ASTM D790-07 Standard Test Methods for Flexural Properties of Unreinforced and Reinforced Plastics and Electrical Insulating Materials, in, ASTM International, West Conshohocken, PA, 2007.

[29] ASTM International, ASTM D5630-13 Standard test method for ash content in plastics, in, Annual Book of ASTM Standards, West Conshohocken, PA, 2001.

[30] M. Nallar, H.W. Wong, Enhanced Levoglucosan Yields from the Copyrolysis of Cellulose and High-Density Polyethylene, Acs Sustainable Chemistry \& Engineering, 7 (2019) 9480-9488. https://doi.org/10.1021/acssuschemeng.9b00765

[31] A.O. Balogun, F. Sotoudehniakarani, A.G. McDonald, Thermo-kinetic, spectroscopic study of brewer's spent grains and characterisation of their pyrolysis products, Journal of $\begin{array}{lllll}\text { Analytical and } & \text { Applied } & \text { Pyrolysis, } & 127 & \text { (2017) }\end{array}$ https://doi.org/10.1016/j.jaap.2017.09.009

[32] D.W. Mayo, Characteristic Frequencies of Alkanes, in: Course Notes on the Interpretation of Infrared and Raman Spectra, 2004, pp. 33-72.

[33] D.W. Mayo, Spectra of carbonyl compounds of all kinds (factors affecting carbonyl group frequencies), Course notes on the interpretation of infrared and Raman spectra, (2004) 79-204.

[34] K.K. Pandey, A study of chemical structure of soft and hardwood and wood polymers by FTIR spectroscopy, Journal of Applied Polymer Science, 71 (1999) 1969-1975. https://doi.org/10.1002/(Sici)1097-4628(19990321)71:12<1969::Aid-App6>3.0.Co;2-D 
[35] F.A. Miller, Characteristic frequencies of alkenes (olefins), Course Notes on the Interpretation of Infrared and Raman Spectra, (2003) 73-84.

[36] Z. Wang, B. Pecha, R.J.M. Westerhof, S.R.A. Kersten, C.Z. Li, A.G. McDonald, M. Garcia-Perez, Effect of Cellulose Crystallinity on Solid/Liquid Phase Reactions Responsible for the Formation of Carbonaceous Residues during Pyrolysis, Industrial \& Engineering Chemistry Research, $53 \quad$ (2014) 2940-2955. https://doi.org/10.1021/ie4014259

[37] C.A. Harper, Modern plastics handbook, McGraw-Hill Education, 2000.

[38] K. Hamad, M. Kaseem, F. Deri, Recycling of waste from polymer materials: An overview of the recent works, Polymer Degradation and Stability, 98 (2013) 2801-2812. https://doi.org/10.1016/j.polymdegradstab.2013.09.025

[39] M. Shah, J. Stanek, S. Handwerger, Differential localization of heat shock proteins 90, 70, 60 and 27 in human decidua and placenta during pregnancy, Histochem J, 30 (1998) 509-518. https://doi.org/10.1023/a:1003259907014

[40] S. Kormin, F. Kormin, M.D.H. Beg, M.B.M. Piah, Physical and mechanical properties of LDPE incorporated with different starch sources, IOP Conference Series: Materials Science and Engineering, 226 (2017) 012157. https://doi.org/10.1088/1757$\underline{899 x / 226 / 1 / 012157}$

[41] M. Tajvidi, R.H. Falk, J.C. Hermanson, Effect of natural fibers on thermal and mechanical properties of natural fiber polypropylene composites studied by dynamic mechanical analysis, Journal of Applied Polymer Science, 101 (2006) 4341-4349. https://doi.org/10.1002/app.24289 
[42] A.K. Rana, B.C. Mitra, A.N. Banerjee, Short jute fiber-reinforced polypropylene composites: Dynamic mechanical study, Journal of Applied Polymer Science, 71 (1999) $531-539$.

[43] D. Taulbee, J. Neathery, D. Patil, N. Sowder, B. O'Daniel, M. Montross, Combustion of briquettes and fuels pellets prepared from blends of biomass and fine coal, in: International Coal Preparation Congress 2010 Conference Proceedings, 2010, pp. 161-170.

[44] T.-P. Testing. Testing. https://www.twinportstesting.com, 2019. (accessed 26 February, 2019). 


\section{Integration of Thermal Treatment and Extrusion by Compounding for Processing Various Wastes for Energy Applications}

This section is based on the peer-revied paper titled "Integration of Thermal Treatment and Extrusion by Compounding for Processing Various Wastes for Energy Applications," published in Energy \& Fuels (2021) 35, 15, 12227-12236.

https://doi.org/10.1021/acs.energyfuels.1c01836

\subsection{Abstract}

Waste generation is increasing, and a significant portion of the wastes is being landfilled. Torrefaction of such wastes to produce clean fuels is one of the potential solutions. This paper studied the torrefaction of mixed fiber-plastic wastes at $300^{\circ} \mathrm{C}$ in an integrated torrefaction-extrusion screw reactor with a throughput of up to $70 \mathrm{~kg} / \mathrm{h}$. The study experimentally measured the thermo-mechanical properties of the torrefaction-extrusion process and the pellets produced. The study presents the results for thermal dynamics, the effect of shaft configuration on residence time, Specific Mechanical Energy (SME), Heat Transfer Coefficient (U), Specific heat (C) of mixed wastes, and mechanical and rheological properties of pellets. First, the thermal dynamics of the system were studied along the corresponding response of heaters with and without the flow of materials is measured. Residence time measurement showed $20 \%$ and $40 \%$ cut flighting had about 2.3 and 3.7 times more residence time compared to regular screw. The specific heat of the heterogeneous mix blend was measured at $1.58 \mathrm{~kJ} / \mathrm{kg}^{\circ} \mathrm{C}$. The average overall heat transfer coefficient was measured experimentally for the reactor at $52.5 \mathrm{~W} / \mathrm{m}^{2 \circ} \mathrm{C}$. The correlation between specific mechanical energy and mass flow showed a more than three times

decrease in specific energy consumed when the feed rate was increased from $\sim 10 \mathrm{~kg} / \mathrm{h}$ to $50 \mathrm{~kg} / \mathrm{h}$. Thermomechanical analysis, flexural testing, and rheological testing were performed on the produced pellets to measure pellet properties. 


\subsection{Introduction}

In 2017, the US generated about 120 million tons of fiber (paper, paperboard, and wood) and plastic wastes combined, of which 58.31 million tons were landfilled [1]. With increased waste generation and a $2.6 \%$ annual reduction in US landfill capacity, the US is anticipated to have only 10-15 years of landfill capacity remaining by 2021 [2]. In parallel, based on the current five-year trend, the average year-over-year tipping fees paid by the consumer have steadily increased by $2.8 \%$ since 2016 , with the US national average at $\$ 53.72 /$ ton for the year 2020 [3]. There are numerous additional challenges like the Chinese ban $[4,5]$ on US plastic waste import, lack of markets for recycled materials, lack of producer responsibility, lack of recycling and composting opportunities for consumers, etc. [6]. All these challenges have created a sense of urgency to address the wastes treatment challenge.

To treat and valorize these wastes, one of the pathways is thermal treatment. Thermal treatment technologies like torrefaction, pyrolysis, and gasification have widely been explored as sustainable and economical pathways and also as alternatives to traditional landfilling [7,8]. The current study focuses on torrefaction, a mild thermal treatment process in an oxygen-free or drastically reduced oxygen environment [9]. The main product for the torrefaction is the solid fraction that can be used in power and heat application [10]. Various types of reactor technologies like rotating drum, screw, multiple hearth furnace (MHF), fluidized bed, belt, and vibrating grate, and microwave reactor have been developed and are used for carrying out these thermal processes [9, 11]. These thermal treatment technologies have been extensively used and tested with biomass as a feedstock at various scales [11]. As our technology integrates torrefaction with extrusion (and pelletization), the following paragraph discusses the pelletization process in the biomass/wood pellet industry. The typical pellet production process involves four key steps: (i) collection and debarking (for wood), (ii) grinding of the feedstock, (iii) drying, and (iv) pelletization. The pelletization is done using various methods like the hot press, briquetting and most commonly using pellet mills $[12,13]$. For fiber-plastic waste pellets production, the current state-of-the-art technologies are similar to the biomass and wood 
pellet industry and most commonly involve the use of pellet mills to produce pellets. Applications of the fiber-plastic pellets include (i) as feedstock for upgrading [14, 15] to liquid transportation fuels and sustainable aviation fuels using pyrolysis or gasification, and (ii) solids fuels for use in cement kilns or small power plants [16-18]. The mixed waste plastic (with no to little fibers) pellets also find applications in the production of polymer alloys or composites materials for producing items like shingles and construction blocks.

Converse to the traditional biomass and wood pelleting industry, with the use of wastes containing various plastics waste streams; traditional technologies face technical challenges like (i) batch-to-batch inconsistencies, (ii) heterogeneities within the waste stream, (iii) difficulties in conveying and bridging due to the low density $\left(\sim 50 \mathrm{~kg} / \mathrm{m}^{3}\right)$, (iv) extreme difficulties in feeding and extruding mixed fiber plastics. All these factors impose techno-economic barriers in recycling and the development of waste treatment technologies. To address the technological challenges with the use of fiber-plastic wastes and to meet the needs of the heat and power industry, our team developed a torrefactionextrusion system using a modified screw reactor. Screw reactors have been studied for several decades, especially in the plastic extrusion industry [19]. Several past studies also have explored its use with various types of biomass and similar materials. Kelkar et al. [20] used spent coffee grounds in a single auger reactor at a federate of $1-1.5 \mathrm{~kg} / \mathrm{h}$. AtienzaMartínez et al. used a lab-scale auger reactor to torrefy sewage sludge [21]. Zinchik et al. tested ten different biomass types in a screw reactor with a feed rate of $0.1 \mathrm{~kg} / \mathrm{h}$ [22]. Brown et al. developed a lab-scale auger reactor for biomass fast pyrolysis using red oak [23]. Numerous such studies $[9,22-26]$ have been performed using a screw or auger reactor, along with several others reviewed in detail by Brown et al. [23] and Campuzano et al. [11]. However, almost all these studies mainly focus on biomass material with heat transfer material and have standard screws designs (unmodified) with separate or no compaction process. This study used a screw, modified with cuts in the flights, to produce torrefied pellets from fiber-plastic waste material. The integration of this modified screw design for torrefaction with an extruder used for compaction and pelletization is a novel system and has not been studied before. The current study focuses on this fiber-plastic waste stream that is common in the Material Recovery Facility (MRF) and Refused Derived Fuel (RDF) 
pellet industry. It also broadly applies to any waste stream that contains organic wastes and plastics. We studied various blend ratios of fiber-plastic wastes. However, as the $60 \%$ mixed fiber waste and $40 \%$ mixed plastic waste blend was studied extensively for the onstream operation of $\sim 700$ hours, it is presented as a case study to demonstrate the properties of the pilot system and the products. This study also aims to shed light on the above topics and provide heat dynamics of a screw torrefaction system, the heat capacity of the fiber-plastic blend, specific energy consumption, relation between residence time and screw configuration.

The properties of the final torrefied product are often dictated by the incoming material properties and the extent of torrefaction. The extent of torrefaction is governed by two key factors: reaction kinetics and heat transfer. Reaction kinetics and waste dechlorination mechanisms have been studied for the fiber-plastic blends in the team's previous studies $[22,27,28]$ and will not be discussed. For studying heat transfer, it is important to obtain heat transfer dynamics and specific heat of the material. Heat transfer dynamics are dependent on the system configuration, type of material, and scale of the process. Out of these parameters, scale and configuration of the system configuration remained fixed during the study, but, despite the presence of a large database for the heat capacity of various materials, the measurement of heat capacity is challenging as the material used is heterogeneous in nature and changes from batch to batch. To model the actual temperature of the material inside the reactor, heat capacity measurements are essential for every batch. An experimental method to measure the heat capacity of the material blend was developed in this study.

This study also attempts to experimentally measure various other thermo-mechanical properties of the material and the system. The other key properties that were measured are the heat transfer coefficient of the system, the residence time for different configurations, specific mechanical energy, and material properties like density, pellet durability, thermomechanical analysis (TMA), rheology, flexural strength and modulus, and FTIR characterization. Current literature on the heat transfer coefficient and specific energy is presented below. 
The experimental measurement of the heat transfer coefficient is challenging due to the dynamic nature and moving components of screw reactors. Some simulation efforts have been made by using the Eulerian method [29] or the Discrete Elements Method [30] (DEM) to model mass and heat transfer in screw reactors. Funke et al. [31] simulated heat transfer in a twin-screw auger type reactor using biomass and heat carrier material and observed its strong dependence on mixing quality and the ratio of heat carrier to biomass particles. This simulation study claimed to achieve heat transfer coefficients in the range of 150 to $350 \mathrm{~W} / \mathrm{m}^{2} \mathrm{~K}$, comparable to a fluidized bed reactor. Qi et al. [32] developed a heat transfer model using DEM in a double screw reactor and reported total heat transfer coefficients between 70 and $100 \mathrm{~W} / \mathrm{m}^{2} \mathrm{~K}$ depending on various operating conditions. Waje et al. [33] studied the thermal performance of a screw dryer and found an overall heat transfer coefficient between 46 and $102 \mathrm{~W} / \mathrm{m}^{2} \mathrm{~K}$. Thus, there is a large variability of heat transfer coefficient predictions is made by the simulation (between 46 to $350 \mathrm{~W} / \mathrm{m}^{2} \mathrm{~K}$ ) studies, largely due to several assumptions made for simplification purposes during the modeling. Also, most of these studies simulate a small lab scale $(\leq 3 \mathrm{~kg} / \mathrm{h})$ system with twin screws and heat transfer materials. The current study attempts to experimentally measure the heat transfer coefficient in a single screw reactor at a larger scale (up to 70 $\mathrm{kg} / \mathrm{h}$ ) without heat transfer material.

The specific extrusion energy or specific mechanical energy (SME) is the amount of mechanical energy required to carry out the extrusion process; specifically, it is work input from the drive motor into the material being extruded [34]. SME is an important process parameter that influences product characteristics like density and material hardness [35] and depends on multiple process parameters like viscosity, screw speed, barrel temperature, moisture, material type, average material size, and configuration of the screw [34-37]. Several studies have reported SME for twin-screw auger reactors: Godavarti et al.[34] reported 43 to $67.8 \mathrm{kWh} / \mathrm{t}$ for cornmeal material in a twin-screw reactor (length $/$ diameter $(\mathrm{L} / \mathrm{D})=28.6)$ at $16.5 \mathrm{~kg} / \mathrm{h}$. Schmid et al. [37] reported $122 \pm 5$ to $222 \pm 10 \mathrm{kWh} / \mathrm{t}$ for chokeberry pomace powder in a $26 \mathrm{~mm}$ diameter co-rotating twin-screw reactor (L/D $=29)$ at $10 \mathrm{~kg} / \mathrm{h}$ and 200-800 rpm. Sasimowski et al. [36] derived empirical correlation of $\mathrm{SME}=2221.4-13.027 n+0.034 n^{2}$ where $n$ is rpm of extruder. The study reported a $45 \%$ 
decrease (474 to $260 \mathrm{kWh} / \mathrm{t}$ ) in SME with a fourfold increase in rpm from 50 to $200 \mathrm{rpm}$ for poly (butylene succinate) - wheat bran blend in a twin-screw reactor $(\mathrm{L} / \mathrm{D}=40)$ with material temperature ranging from 123 to $155^{\circ} \mathrm{C}$. Based on the literature review, very few SME studies are performed on single screw reactors with fiber-plastic waste as a feedstock.

The residence time measurement is the time spent by the material in the reactor. The residence time in a regular screw is approximately given by the residence time equation $\mathrm{t}_{\text {res }}=c / v$, where $c$ and $v$ are the number of pitches in the screw and rotation frequency, respectively [22]. However, due to the complex geometry of the modified screw (paddle) used in the study, it is difficult to predict the exact residence time of the material. Various approaches have been developed in the past to predict the residence time of material in complex screw designs, some of which are as follows. Zinchik et al. used the approach of calculating the effective number of pitches followed by curve fitting the data for numerous experiments to calculate the residence time [22]. Lepschi et al. used fluorescence spectroscopy to measure the residence time and residence time distribution in the corotating twin-screw reactor [38]. While, Nikitine et al. calculated residence time using $\mathrm{t}_{\text {res }}=\tau \rho V / M$, where $\tau$ is fill rate, $\rho$ is density, $V$ is extruder "free" volume, $M$ is mass flow rate and developed a model to predict the distribution [39]. In this study, the measurement was simplified and the residence time for various screw configurations was measured experimentally based on the observation of the power consumption data. More details about the approach are presented in Section 2.2.

The previous works $[10,22,28,40]$ by the team studied torrefaction from microgram to few grams scale and developed a detailed understanding of reaction kinetics, chlorine removal in the torrefaction, material properties of the feedstock, and pellets. Based on these studies, a large torrefaction system with a throughput of up to $70 \mathrm{~kg} / \mathrm{h}$ was developed. This study presents the thermo-mechanical test results from hundreds of hours of operation performed on the system. 


\subsection{Materials and Methods}

\subsubsection{Material Identification and Preparation.}

The fiber-plastic waste material used in the experiments was supplied by Convergen Energy (CE) LLC. The waste blend used is a fiber-plastic waste blend with $40 \%$ mixed plastic and 60\% fiber (paper, cardboard). FTIR analysis was conducted on the incoming materials to identify the exact types of fiber/plastics in the feedstock. Analysis was carried on 30 randomly chosen pieces using an FTIR spectrometer (Thermo-Scientific Nicolet Summit Pro) with an attenuated total reflection (ATR) accessory (ZnSe crystal, iD5). OMNIC V9 software, plastic standards (low-density polyethylene (LDPE) from Rainer Plastics Inc, high-density polyethylene (HDPE) from Equistar Petrothene LB01000, and polypropylene (PP) from Amcor), and Aldrich, Hummel, and Nicolet spectral libraries were used to analyze the data.

The blend mainly comprises paper, laminated paper, label matrix residuals, laminated nonrecyclable papers, and a wide mix of plastics including LDPE, HDPE, PP, Polyethylene terephthalate (PET), and traces of polyamides (nylon). More details are provided in Section 4.4.

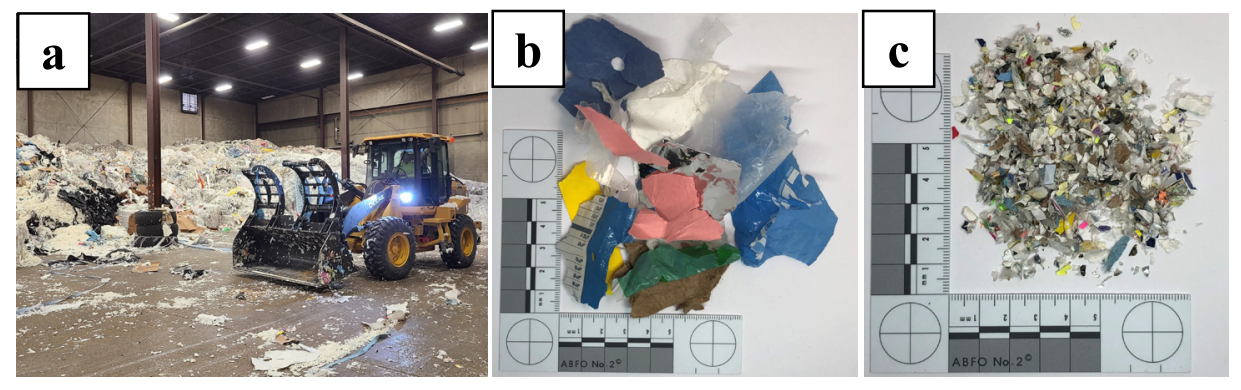

Figure 4.1. Various stages of the fiber-plastic waste pre-processing and corresponding particle sizes: a. Tipping-floor stage where fibers and plastics are blended ( $\geq 300 \mathrm{~mm}) ; \mathrm{b}$. Shredding Stage $1(\leq 50 \mathrm{~mm})$; c. Shredding Stage $3(\leq 3 \mathrm{~mm})$.

Figure 4.1 shows various stages in the feedstock preparation process for the abovedescribed blend. The waste feedstock, which consists of paper and plastic, was hauled 
separately to the tipping floor from the various generation sources. The separate paper and plastic were then mixed in a ratio of 60:40 using the loader, as shown in Figure 4.1a. Ferrous and non-ferrous metals were then removed from the blend before the shredding processes. The material was shredded using a two-stage shredding process. In stage 1, the material was shredded by a series of common industrial shredders to a size of $\leq 50 \mathrm{~mm}$. In stage 2, final shredding was carried out in-house using a cross-cut shredder (Allegheny, Model: $16-75 \mathrm{CX}$ ) to a size of $\leq 3 \mathrm{~mm}$. The final stage shredding is carried out at comparatively low speeds $(<200 \mathrm{rpm})$ as high-speed shredding $(>1000 \mathrm{rpm})$ tends to cause fluffing up of the material.

The typical shredded material bulk density ranged from $50-70 \mathrm{~kg} / \mathrm{m}^{3}$. The moisture content ranged between 1.4 - 5.5\%. More details regarding the material, such as proximate analysis, ultimate analysis, ash content, and fusion temperatures, are provided in the previous study [28]. These properties are average results of tests carried over a several-year period at CE's production facility.

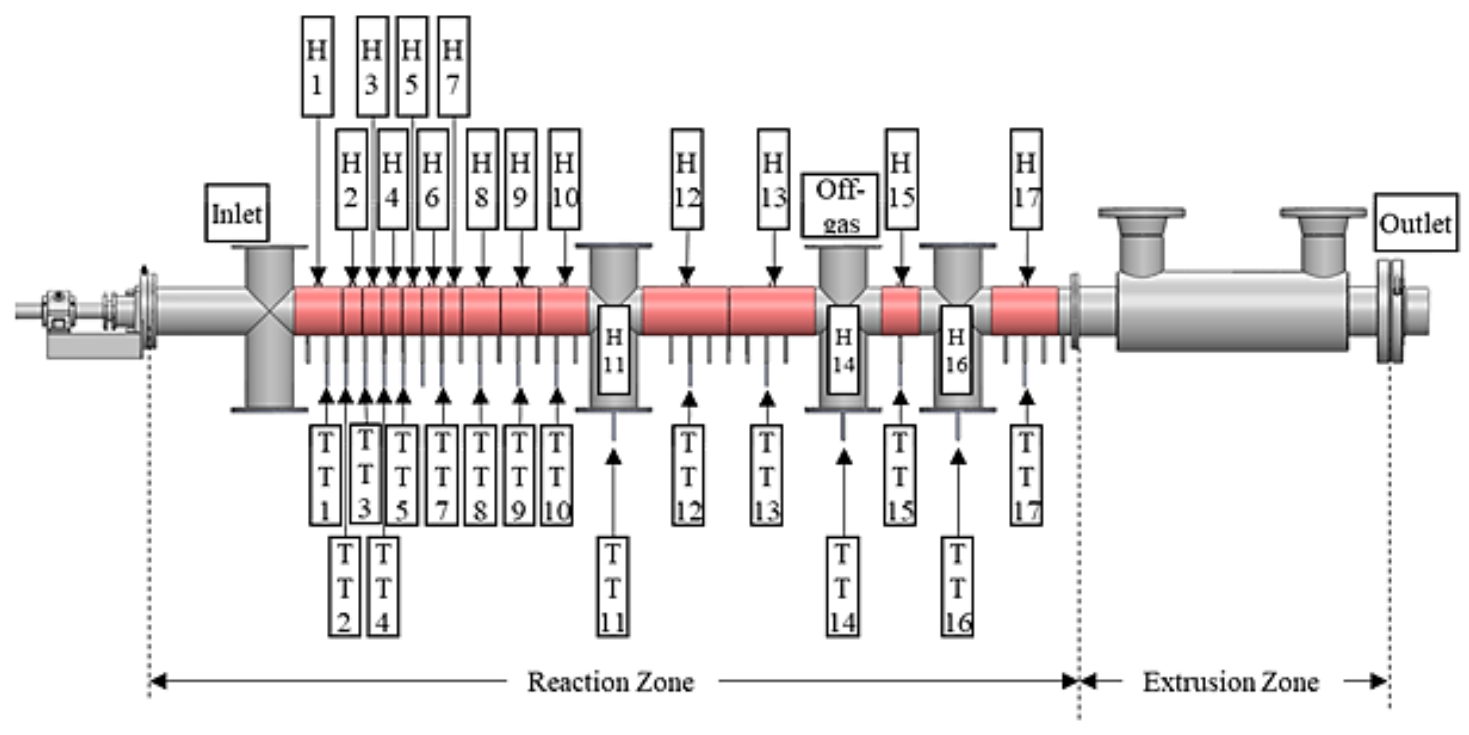

Figure 4.2. Integrated Torrefaction-Extrusion system showing the heaters (H1 to H14) and thermocouples (TT1 to TT17). 


\subsubsection{Equipment.}

Figure 4.2 shows the reactor-extruder setup used for the experiment. The total combined length of reactor and extruder is $3.3 \mathrm{~m}$. The system consists of a single shaft with different zones, defined by different function-specific flights mounted on it. In the reaction zone, the flights are modified with cuts to increase the residence time. The reaction zone has $\mathrm{L}$ of $2.67 \mathrm{~m}$ and $\mathrm{D}$ of $101.6 \mathrm{~mm}$ with a paddle (screw) pitch of $76.2 \mathrm{~mm}$. The flights in the extruder section are modified to have a decreasing variable pitch to achieve the compaction required for the formation of pellets. There are a total of 12 flights in the extruder section, starting with $76.2 \mathrm{~mm}$ and gradually decreasing to $25.4 \mathrm{~mm}$. The $\mathrm{L} / \mathrm{D}$ ratio of the extruder section is 6 , which is smaller as compared to typical modern extruders L/D ratios of 18 to 40 [41]. Shorter L/D allows for lower torque and power requirements [41]. There are four access ports to the reactor, each with top and bottom access. Port 1 top (from left) is used as an inlet to the reactor, and Port 3 top is used to send off-gasses to the condensers and gas cleanup system (not shown). The rest are used for maintenance access. The material is thermally treated in the reactor section and continues into the extrusion section, which is $101.6 \mathrm{~mm}$ in $\mathrm{D}$ and $102.4 \mathrm{~mm}$ in total L. At the end of the extruder, the material is extruded in the form of long rods using a die with 8 holes of $12.7 \mathrm{~mm} \mathrm{D}$ each. The extruded rods are cut into pellet form using the cuter attached to the die (not shown). Two shafts were used in this study, first with $20 \%$ cuts and $40 \%$ cuts. The latter was used only for residence time study as described in Section 2.3.3.

The reactor is heated using a series of electric band heaters. All the band heaters are operated at $480 \mathrm{~V}$ and have a capacity ranging from $2 \mathrm{~kW}$ to $5 \mathrm{~kW}$. The heaters are configured in five sets as follows: (a) set 1, located between port 1 and 2, consists of 10 heaters of total $30 \mathrm{~kW}$ in a sequence of $1 \times 5 \mathrm{~kW}, 6 \times 2 \mathrm{~kW}, 2 \times 4 \mathrm{~kW}$, and $1 \times 5 \mathrm{~kW}$; (b) set 2, located between port 2 and 3, consists of 2 heaters of total $9 \mathrm{~kW}$; (c) set 3, located between port 3 and 4, consists of 1 heater of total $4 \mathrm{~kW}$; (d) set 4 , located after port 4, consists of 1 heater of total $6.5 \mathrm{~kW}$ and (e) set 5 consists of 3 heaters in the access port bottoms with $2.5 \mathrm{~kW}$ each. The distance of heaters $\mathrm{H} 1$ to $\mathrm{H} 17$ from the center of the inlet port is $0.19,0.24,0.29,0.34,0.39,0.44,0.5,0.56,0.60,0.70,0.83,0.98,1.21,1.44,1.59$, 
1.69 , and $1.84 \mathrm{~m}$ respectively. The extruder temperature was precisely controlled using an air-cooled heat exchanger jacket. The oxygen-free environment is maintained by (a) using a mechanical airlock on the inlet side, (b) a material seal created by the extruder on the outlet side, and (c) flowing nitrogen at $\sim 4.7 \mathrm{lpm}$. All the condensable and non-condensable gases produced during the process are sent to a conditioning system consisting of Dry Sorbent Injection, condensers, and demister filter attached to port 3 of the reactor-extruder system (not shown). The material was metered using a volumetric feed auger equipped with a hopper.

All the process data was acquired using Automation Direct - Productivity 3000 PLC and Aveva Indusoft Web Studio HMI version 8.1. All the process parameters like thermocouple temperature (TT1 to TT17), duty cycles of the heaters, pressures, motor rotation speeds, motor load, etc., were measured in real-time at an acquisition rate of 1 measurement/sec.

\subsubsection{Experimental Procedures.}

\subsubsection{Mass Flow Rate.}

The mass flow rate was measured automatically using four load cells attached to the pellet cooling unit at the outlet. The load cells were calibrated before the experiments. The weight was measured continuously with a resolution of $0.1 \mathrm{~g}$. The experiment was repeated for various rotation frequencies of the feed auger from 0 to $16 \mathrm{rpm}$.

\subsubsection{Thermal Dynamics.}

To understand the stability of the system, thermal dynamics were measured for several hours. The PID parameters of the heaters were optimized to minimize the overshoot of the temperatures. The heating was started at the setpoint temperature of $300^{\circ} \mathrm{C}$ with a typical ramp-up time between 4 to $8 \mathrm{~h}$. After the set temperature was reached, the system was maintained at a steady state for a minimum of $2 \mathrm{~h}$ to ensure all the components had reached the set point. All the temperatures were within $\pm 1^{\circ} \mathrm{C}$ of the setpoint temperatures. The data 
for heat losses used in other heat transfer calculations were collected at this point. The material feed into the reactor, and the dynamic response of the system was recorded.

\subsubsection{Residence Time}

In the reactor, the relevant residence time is from the inlet to the point where the material flows into the extruder. As the screw had cuts, it was not possible to theoretically calculate the residence time using the standard formulae for the screw. A new method based on observation of the reactor motor power behavior was developed for the measurement. When the material reaches the extruder zone, there is an increase in the power of the motor rotating the shaft, which is indicative of the material entering the extruder. Since the reaction zone is free of any compaction units, the motor load can only increase once the material reaches the extrusion zone. The experiment was carried out as follows: (a) the feed auger motor was turned off; (b) the reactor motor was rotating continuously at a given setpoint; (c) the feed auger was turned on at a given frequency, then turned off at a predetermined time interval; (d) the reactor was emptied by monitoring the reactor motor load (return to load values recorded in step b). After a given experiment, the rotation frequency of the reactor motor was changed, and steps (a-d) were repeated. Details regarding the interpretation of plots is provided below. As there are cuts in the screw that delayed the material movement, it is expected that more cuts would result in a longer residence time. The experiment was repeated for screw with $20 \%$ cuts and $40 \%$ cuts. The percent cut is calculated by the formula in Equation (4.1).

$$
\text { Cut }(\%)=1-\frac{\text { Area of paddle }}{\text { Area of full screw }}
$$




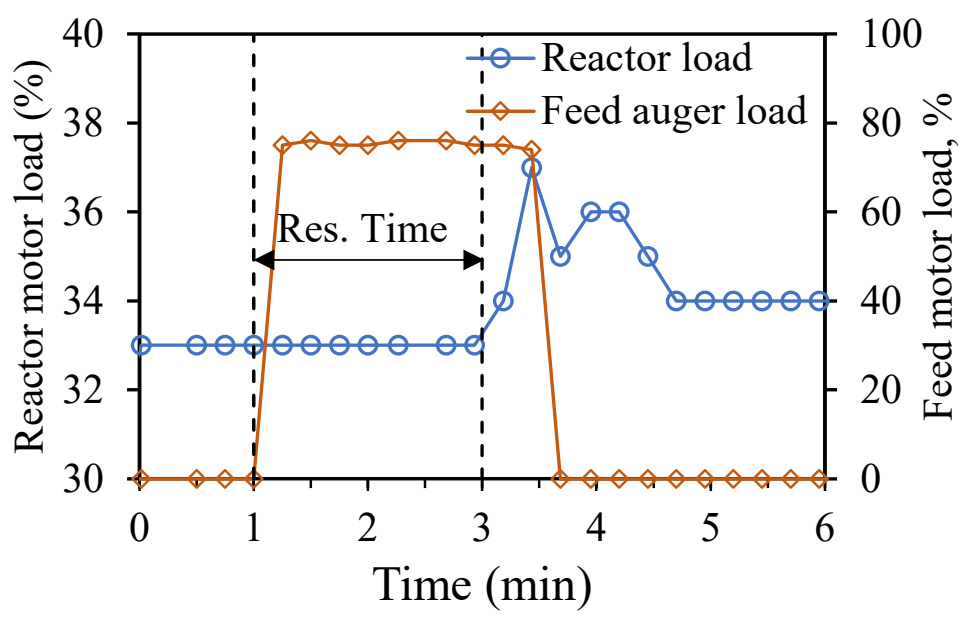

Figure 4.3. Reactor and Feed Motor Load vs. Time showing the measurement procedure of residence time.

Figure 4.3 shows the typical measurement for the residence time. In the reactor configuration shown in Figure 4.2, the residence time is denoted as the time required for the material to travel from the inlet of the reactor to the start of the extruder. As it is difficult to predict the exact residence time using the conventional method of timing the material feed from inlet to outlet due to the integration of screw and extruder as well as cuts on the screw, and variability in material densities, the method described above was used. As seen for the measurement in Figure 4.3, initially the feed auger is off as seen from the $0 \%$ feed motor load and the reactor is operating at a normal load of $\sim 33 \%$ motor load. At $1 \mathrm{~min}$, the feed motor is turned on, represented by the rise in the feed motor curve (orange); meanwhile, the reactor motor load continues to be maintained at $33 \%$, showing the resistance-free travel of material in the reactor zone. At $3 \mathrm{~min}$, the reactor load curve (blue) rises, signaling that material has reached the extruder. As defined earlier, this time from 1 to $3 \mathrm{~min}$ is thus defined as the residence time. After some time, the feed auger was stopped, as represented by the drop in the feed motor load curve and the resulting fall of the reactor motor load. This process is repeated several times by changing the reactor shaft speeds. 


\subsubsection{Specific Heat.}

Specific Heat was calculated based on Equation 2,

$$
c=\frac{q}{\dot{\mathrm{m}}\left(T_{\text {out }}-T_{\text {in }}\right)}
$$

Where $T_{\text {out }}$ is the temperature of the material exiting the reactor and $T_{\text {in }}$ is the environmental temperature. First, the specific energy, $\mathrm{q} / \mathrm{m}(\mathrm{kJ} / \mathrm{kg})$, was calculated using the slope of $\mathrm{q} v \mathrm{v}$. $\dot{m}$ plot. The specific heat (c) was calculated using the ratio of specific energy and temperature difference.

\subsubsection{Temperature Profile.}

To model the temperature profile of the material, net heat supplied heat capacity, and moisture content is needed. Net heat supplied is defined as the difference between heat supplied with the material flow and heat losses to the surrounding. The heat losses were calculated as follows: (a) system was heated until the steady-state temperature was reached with temperature within $\pm 0.5^{\circ} \mathrm{C}$; (b) after reaching the steady-state condition, the heater duty cycle (DC), defined as the 'on' time of the heater ranging from 0 to $100 \%$, was recorded; (c) heat lost to the surrounding was calculated by multiplying the duty cycle and the capacity of the heat $(\mathrm{kW})$. The material was then flown into the system. After achieving DC steady-state condition, the heat supplied to the material was calculated by measuring the DC and multiplying it with the heater capacity $(\mathrm{kW})$, similar to the calculation of the heat losses. Based on the moisture content, the sensible and latent heat absorbed by the water was subtracted to convert the net heat supplied to a moisture-free (MF) basis. The material temperature was then calculated using Equation (4.3).

$$
T_{\text {material }}=T_{\text {setpoint }}-\frac{\dot{m} c}{q}
$$

where, $\dot{m}$ is the material flow rate $(\mathrm{kg} / \mathrm{s}), c$ is the heat capacity of the material $\left(\mathrm{kJ} / \mathrm{kg}^{\circ} \mathrm{C}\right)$, and $\mathrm{q}(\mathrm{W})$ is the net heat supplied on a moisture-free basis. 
2.3.6. Overall Heat Transfer Coefficient. Overall Heat Transfer Coefficient (U) for combined modes of heat transfer is measured in this study. The general definition of heat transfer coefficient is given by Equation 4 .

$$
U=\frac{q^{\prime \prime}}{\Delta T}
$$

where $q$ " is heat flux $\left(\mathrm{W} / \mathrm{m}^{2}\right), \mathrm{U}$ is average overall heat transfer coefficient $\left(\mathrm{W} / \mathrm{m}^{2} \mathrm{~K}\right)$ and $\Delta \mathrm{T}\left({ }^{\circ} \mathrm{C}\right)$ is the difference in temperature between the reactor surface and the material. Overall Heat Transfer Coefficient was measured by plotting the heat flux, $q$ " against the temperature difference. The slope of the plot indicates the value of $U$.

2.3.7. Specific Mechanical Energy. It is defined as energy divided by output rate, as explained in Equation (4.5).

$$
S M E=\frac{P}{\dot{\mathrm{m}}}
$$

where $S M E$ is the Specific Mechanical Energy (kWh/tonne); $P=$ Drive Motor Power $(\mathrm{kW})$; $\dot{\mathrm{m}}$ is the throughput (tonne).

\subsection{Material Characterization.}

2.4.1. Thermomechanical Analysis (TMA). TMA of the produced pellets was performed using Perkin Elmer Model TMA 7 instrument on sliced discs $(0.5 \mathrm{~mm}$ x $\varnothing 9 \mathrm{~mm})$ from the extruded rod using the penetration probe (static force $10 \mathrm{mN}$ ) from 30 to $200{ }^{\circ} \mathrm{C}$ at 5 ${ }^{\circ} \mathrm{C} / \mathrm{min}$. Data were analyzed using Pyris v8 software to determine the onset softening temperature.

2.4.2. Flexural Testing. The extruded pellet samples and LDPE, HDPE, and PP reference materials were hot-pressed (PHI hydraulic press, $\left.300 \times 300 \mathrm{~mm}^{2}\right)$ slowly at $140{ }^{\circ} \mathrm{C}(180$ ${ }^{\circ} \mathrm{C}$ for $\mathrm{PP}$ ) over $20 \mathrm{~min}$ to a thickness of $3.25 \mathrm{~mm}$ and then cooled to room temperature under load. The flattened material was cut into flexural specimens of size $3.25 \mathrm{~mm}$ x 16 $\mathrm{mm}$ x $60 \mathrm{~mm}$. Three-point flexural tests (strength and modulus) were performed on the 
specimens ( $\geq 6$ replicates) according to Standard D 790-07 with a crosshead speed of 1.31 $\mathrm{mm} / \mathrm{min}$, a span of $52 \mathrm{~mm}$, tested until specimen failure or $5 \%$ strain, whichever occurred first on an Instron 5500R-1132 universal test machine (5 kN load cell). Data were collected and processed using Bluehill v3 software (Instron).

2.4.3. Dynamic Rheological Testing. Dynamic rheological measurements (storage modulus $\left(G^{\prime}\right)$, viscous modulus $\left(G^{\prime \prime}\right)$, and complex viscosity $\left(\eta^{*}\right)$ ) were carried out on the produced pellets using a Bohlin CVO 100 rheometer, using serrated parallel plates $(25 \mathrm{~mm} \varnothing)$, in an oscillating mode with an extended temperature control module on pressed disc $(3 \mathrm{~mm} \times 25$ $\mathrm{mm}$ Ø) samples. Experiments were performed in the linear viscoelastic region. Measurements were carried out at a temperature of $180{ }^{\circ} \mathrm{C}$ within a frequency range of 0.01 to $100 \mathrm{~Hz}$ at an applied strain of $0.5 \%$ [42]. Data were analyzed using the Bohlin rheology v6.51 software.

2.4.4. Pellet Durability Index. Pellet Durability Index (PDI) measurement was carried according to 'ASAE Pellet Durability Test Standard S269.5' and 'ASTM E11-87 specification for wire-cloth sieves for testing'. The Pellet durability tester used was supplied by Seedburo Equipment Company [43]. The equipment consists of a box with four compartments in series, each measuring $305 \mathrm{~mm} \times 305 \mathrm{~mm} \times 127 \mathrm{~mm}$ and a $229 \mathrm{~mm}$ $\times 51 \mathrm{~mm}$ plate fixed symmetrically on one side. To measure the PDI index, the pellets were first sieved using an $11.1 \mathrm{~mm}$ screen to ensure no fines were present in the pellets. $500 \mathrm{~g}$ of fines-free pellets were then tumbled in the PDI tester for $10 \mathrm{~min}$ at $50 \mathrm{rpm}$. The pellets were then screened using an $11.1 \mathrm{~mm}$ screen, and the weight of fines-free pellets was measured. PDI was calculated using Equation (4.6).

$$
P D I=\frac{\text { Wt.of pellets after tumbling }(\mathrm{g})}{\text { Wt.of pellets before tumbling }(\mathrm{g})} \times 100
$$

\subsection{Results and Discussion}

Figure 4.4 shows the FTIR results performed on the feedstock to identify its various constituents, showing various fibers and plastics. The major components are: (a) LDPE, 
(b) PP, (c) PET, (d) Polyamide-Nylon, (e) Polyvinyl, (f) Silopren, (g) Acrylate, (h) Cellophane, and (i) Polyester with kaolin filler. The individual IR spectra were obtained by testing multiple individual pieces, randomly picked up from the waste feedstock, and then scanning them through the infrared spectrometer.
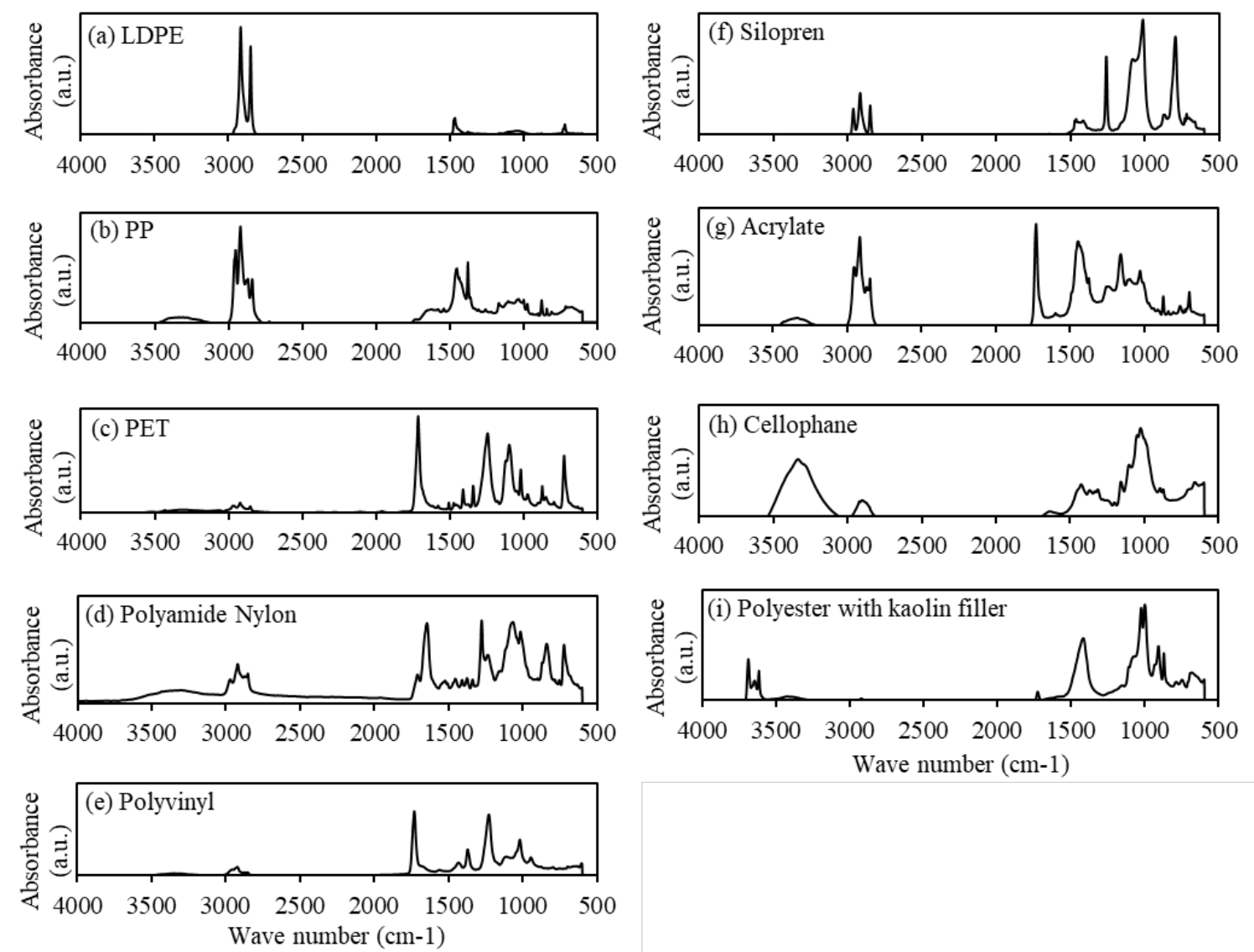

Figure 4.4. Infrared spectra of various materials identified in waste feedstock showing various plastic polymers, rubbers, and fibers: LDPE, PP, PET, Polyamide-Nylon, Polyvinyl, Acrylate, Polyester with kaolin filler; Rubber: Silopren and Fiber: Cellophane/cellulose. 


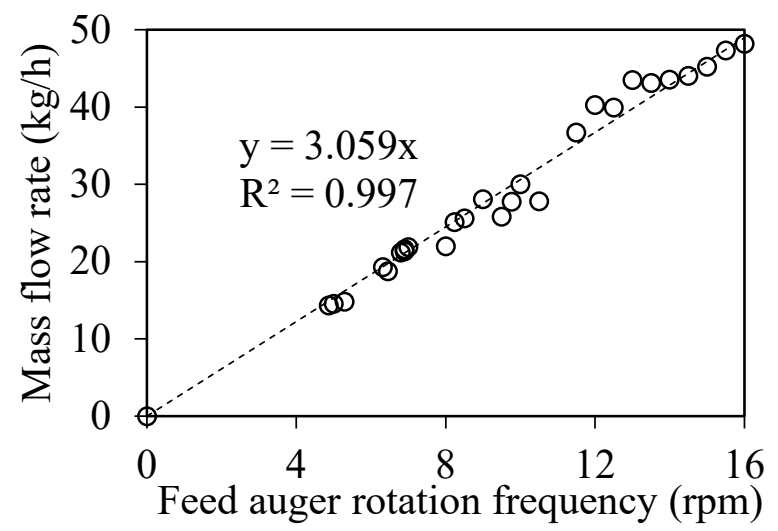

Figure 4.5. Mass flow rate vs. feed auger rotation frequency.

Figure 4.5 shows the mass flow rate vs. the feed auger rotation frequency. The mass flow rate was measured for 0 to $16 \mathrm{rpm}$ of the feed auger rotation frequency. Even though the material was inhomogeneous due to shredding and preprocessing, the dosing system was able to dose the material at a very consistent feed rate for the batch. The correlation found was mass flow rate $(\mathrm{kg} / \mathrm{h})=3.059 \times$ feed auger rotation frequency $(\mathrm{rpm})$. The $\mathrm{R}^{2}$ value was 0.997 .
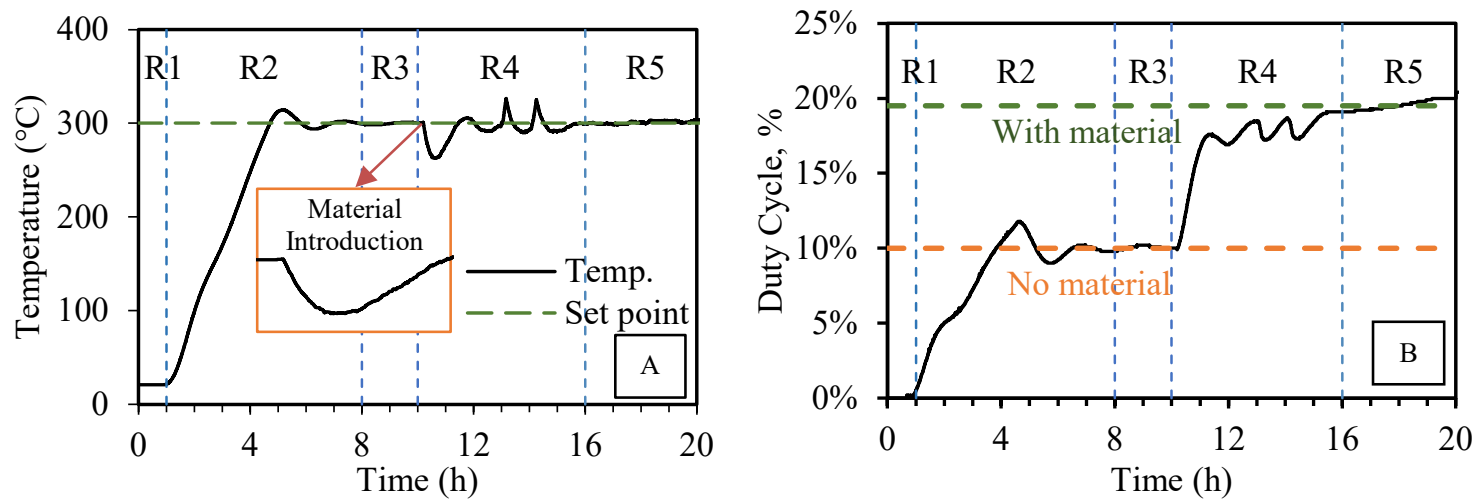

Figure 4.6. Thermal Dynamics of the system showing five regions, R1 - no heating region; R2 - ramp up region; R3- stability without material region; R4 - material flow startup region, and R5 - stability region with material for (A) Temperature of the system; (B) DC of the heaters. 
Figure 4.6 shows the thermal dynamics of the system. The setpoint is set at $300^{\circ} \mathrm{C}$, and the ramp-up time was set at $4 \mathrm{~h}$. For clarity, the thermal dynamics of only one heater are shown. Note that similar dynamics are observed in all heaters. Some differences are observed due to the location and inter-compensation of neighboring heaters. The temperature and the heater DC response can be distributed into five regions. In region $\mathrm{R} 1$, the system is at room temperature, and the $\mathrm{DC}$ of the heater is at $0 \%$ as the heaters are not operating. After the heaters are turned on, as shown in region $\mathrm{R} 2$, the heaters ramp up the temperature at a rate corresponding to the ramp-up timer. The PID controller parameters govern the response of the heater to the temperature change. Longer ramp-up time allows for lesser temperature overshoot and undershoot.

After the set temperatures are reached, the DC of the heater stabilizes (10\% in this case); the system is maintained at the same temperature for at least two additional hours to allow every part of the reactor to have a uniform temperature. The next step is to flow the material inside the reactor. As shown by region R4, as the material is introduced in the reactor, the temperature drops (Figure 4.6a inset), and the DC of the heaters increase. Some startup instabilities are observed due to the start-up procedure and approach a steady-state condition later. After the entry into region R5, the heater's duty cycles and the temperatures continue towards stability, and both the curves flattened. The source of instabilities in the duty cycle is due to the heater control system (PID control) trying to compensate for the temperature changes caused by the flow of material. In the 12- and 16-hour region, the fluctuations resulted from over-and under-compensation was resulting from the PID controller that regulates the heater.

Figure 4.7a shows the residence time measurement vs. Inverse shaft speed of two different cut auger (paddle) reactor configurations compared to auger configuration without any cuts/paddles. The first paddle configuration consists of $20 \%$ cuts, while the second consists of $40 \%$ cuts. Figure $4.7 \mathrm{~b}$ shows a SolidWorks ${ }^{\circledR}$ model showing the $40 \%$ cut section of the modified paddle configuration. It was found that the auger with no cuts has a slope of 22 (unitless) while the paddle and cut paddles have a slope of 50.7 and 81.0, respectively, showing 2.3 and 3.7 times increase in the residence times at given speed compared to the 
auger. The increase of residence time is due to the conveying inefficiency introduced by the cut auger design. The cut reduces the mass flow rate but allows to increase the residence time significantly in the same length of the reactor. This also increases the volume of the material inside the reactor allowing a higher fill rate (volume fraction).
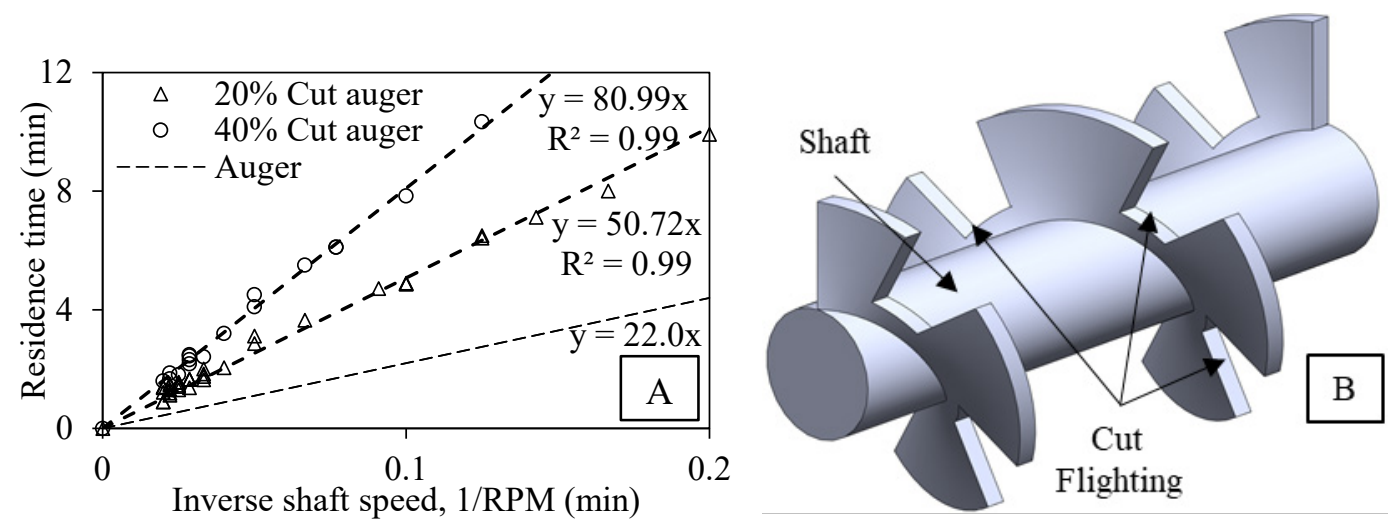

Figure 4.7. A. Residence Time vs. Inverse Shaft Speed for different shaft configurations (Auger: $0 \%$ cut, $20 \%$ cut auger, and $40 \%$ cut auger); B. SolidWorks ${ }^{\circledR}$ model showing modified auger with $40 \%$ cuts.

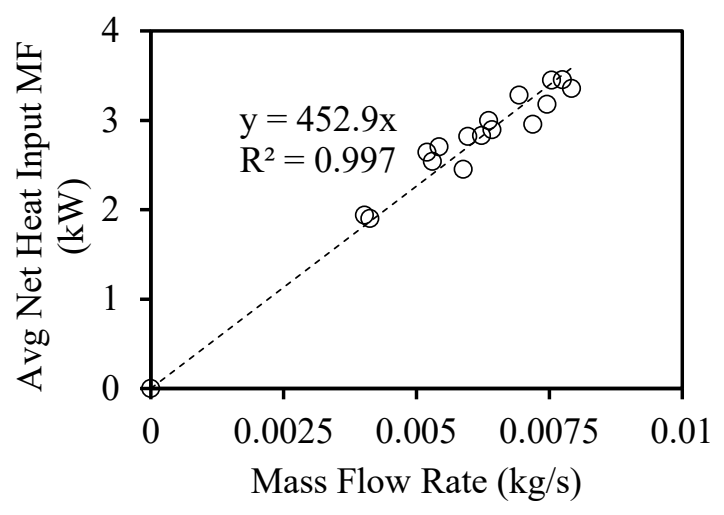

Figure 4.8. Average Net Heat Input (moisture-free basis) vs. Mass flow rate. Specific Heat (C) of material can be calculated as $1.58 \mathrm{~kJ} / \mathrm{kg}-{ }^{\circ} \mathrm{C}$.

Figure 4.8 shows the average net heat input on a moisture-free basis vs. the mass flow rate. Specific Heat (C) of material can be calculated using the ratio of (average net heat input / mass flow rate) and $\Delta \mathrm{T}$ as per Equation (4.2). The temperature difference, $\Delta \mathrm{T}$, in this study is $285^{\circ} \mathrm{C}$ (environment temperature was measured at $15^{\circ} \mathrm{C}$ ). The slope of the plot is equal 
to $453(\mathrm{~kJ} / \mathrm{kg})$ with an $\mathrm{R}^{2}$ of 0.997 . Considering the temperature difference, the value of specific heat for the mixed blend used can be calculated as $1.58 \mathrm{~kJ} / \mathrm{kg}^{\circ} \mathrm{C}$. This specific heat value is in line with the range of specific heat values measured by other studies.

We calculated the temperature profile in the reactor as explained in Section 2.3.5; the temperature profile depends on mass flow rate, material and thermal properties, and reactor heat transfer coefficient. Results shown in Figure 4.9 are for the mass flow rate of 22.5 $\mathrm{kg} / \mathrm{h}$. It can be observed that the temperature reached $100^{\circ} \mathrm{C}$ in about $0.5 \mathrm{~min}$, followed by $0.2 \mathrm{~min}$ of constant temperature due to the water phase transition from liquid to vapor. The temperature then continues to rise further until $300^{\circ} \mathrm{C}$. The maximum residence time in the reactor is $3.3 \mathrm{mins}$ at $22.5 \mathrm{~kg} / \mathrm{h}$.

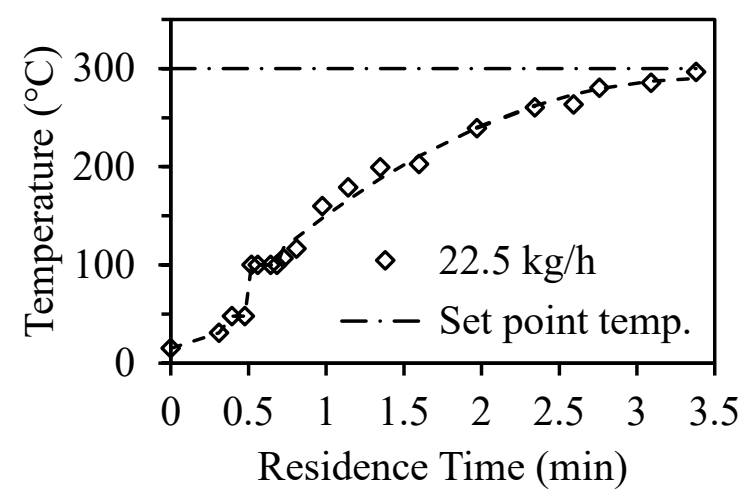

Figure 4.9. Material temperature profile vs. residence time.

The overall heat transfer coefficient, $U$, from the reactor walls to the flowing material was determined from the heat supplied by the various heaters (heater power and the heater width are given for all heaters) that can provide the heat power for each heater as the duty cycle are continuously measured. At full power (duty cycle equal 1) the heat flux of all heaters is identical. We note that the reactor is operated at constant surface temperatures throughout its entire length. To maintain the required temperature set-point the PLC changes the duty cycle of the respective heater. It should be mentioned that there are some heat losses that are measured accurately when there is no material in the reactor. These heat losses are in the range $2-3 \%$ and are subtracted from the measured heating rate at the respective location. Thus, from the net duty cycle of each heater we can determine the heat 
flux in the specific location in the reactor. We also note that there are zones in the reactors with no heaters (See Figure 4.2); thus, the duty cycles of neighboring heaters will affect each other to compensate for the lack of heaters in these zones. This will cause the heat flux data to be scattered. Plotting the heat flux, $q^{\prime \prime}(x)$, vs., $\left[T_{s}-T_{m}(x)\right]$, where $T_{s}$ and $T_{m}(x)$ are the surface temperature (set point) and the mean material temperature (calculated in Figure 4.9), respectively, should provide the overall heat transfer coefficient, $U$, from

$$
q^{\prime \prime}(x)=U\left[T_{s}-T_{m}(x)\right]
$$

Figure 4.10 shows $q^{\prime \prime}(x)$, vs., $\left[T_{s}-T_{m}(x)\right]$, noticing very large scatter as explained above. The measured value of the $U$ ranges from 35 to $70 \mathrm{~W} / \mathrm{m}^{2 \circ} \mathrm{C}$ with an average value at 52.5 $\mathrm{W} / \mathrm{m}^{2 \circ} \mathrm{C}$. This value is in line with the universal heat transfer coefficient value range of 46 to $350 \mathrm{~W} / \mathrm{m}^{2 \circ} \mathrm{C}$ reported in the literature for screw reactors.

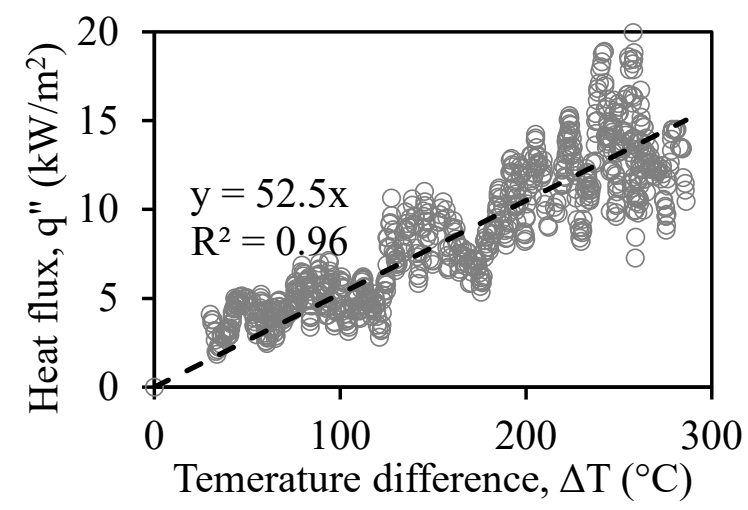

Figure 4.10. Average heat transfer coefficient (U) based on the slope of heat flux vs. $\Delta \mathrm{T}$ plot. 


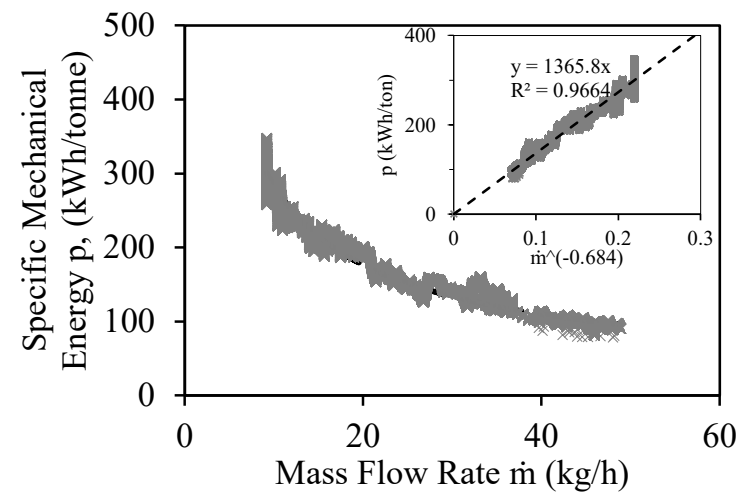

Figure 4.11. Specific mechanical energy (SME) vs. mass flow rate of the torrefactionextrusion process. Inset shows the plot of $\dot{\mathrm{m}}^{-0.684} \mathrm{vs.} \mathrm{specific} \mathrm{mechanical} \mathrm{energy.}$

Figure 4.11 shows the plot of specific mechanical energy vs. the mass flow rate. It can be observed that specific mechanical energy is high, around $335 \mathrm{kWh} / \mathrm{t}$ at $9 \mathrm{~kg} / \mathrm{h}$, and it drops to $90 \mathrm{kWh} / \mathrm{t}$ close to $50 \mathrm{~kg} / \mathrm{h}$. It is anticipated to go down further as the mass flow rate increases and then starts increasing again as more material is pushed into the reactor than its handling capacity. The specific mechanical energy goes down with the increase in mass flow rate and can be attributed to friction.

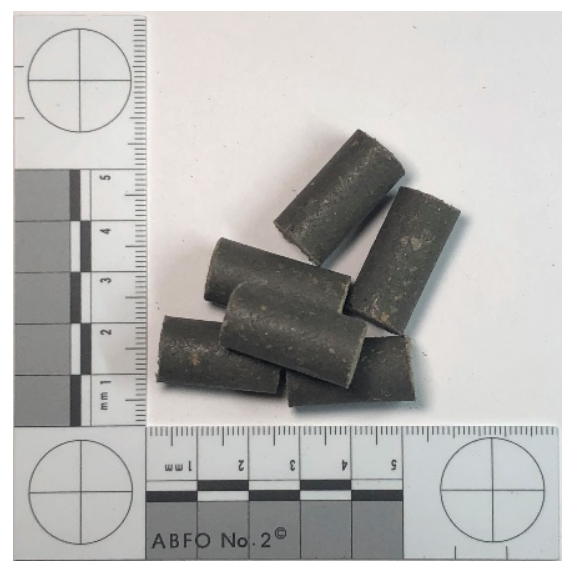

Figure 4.12 shows the pellet extruded from the fiber-plastic waste material. Pellets of 12.7 $\mathrm{mm} \mathrm{D}$ and $25.4 \mathrm{~mm} \mathrm{~L}$. The pellets had color ranging from light gray to black depending 
on the extent of torrefaction. In the fiber-plastic blend pellets, plastic acted as a binder and encapsulated the fibrous material to form more consistent and uniform pellets, which were consistent with our previous study [10]. The produced pellets have a good surface finish and good water resistance [10]. To address the homogeneity of the pellets, Infrared spectroscopy was performed for both the feedstock and the pellets to quantify the change in the degree of heterogeneity of feedstock due to the compounding process in the production of pellets. Appendix I shows (a) 30 IR overlapping spectra of as-is material (b) 30 IR spectra after the homogenization (c) comparison of the average of 30 spectra before the process and after the process. Appendix I (a) shows the spectra of various materials in the feedstock appearing distinctly; this shows that feedstock was heterogeneous in nature. Figure I (b) shows that all 30 spectra of pellets overlapped, indicating that the material was homogenized and appeared as a single spectrum. Figure I (c) shows the comparison of the average of the 30 spectra before and after the extrusion process; the spectra are almost identical, thus showing the homogeneous nature of produced pellets.

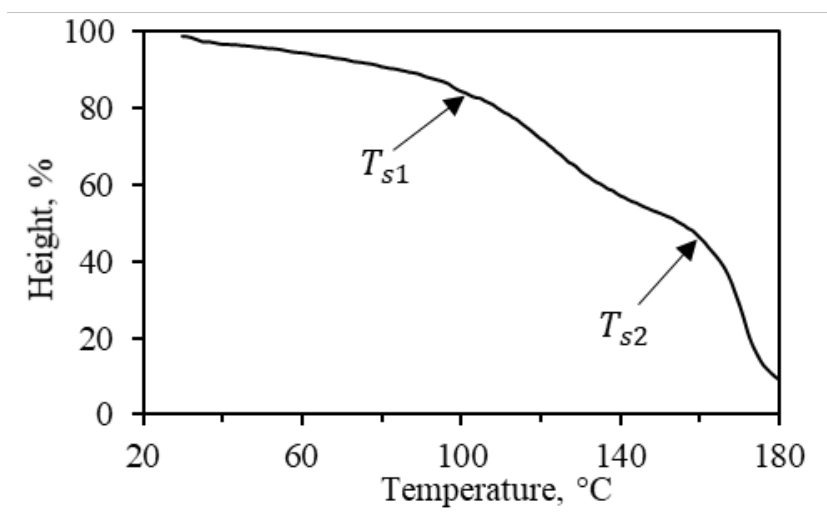

Figure 4.13. Thermomechanical analysis thermogram of extruded pellets showing two softening temperatures at $102^{\circ} \mathrm{C}$ and $164^{\circ} \mathrm{C}$.

Figure 8.1 shows the TMA results for the pellets. Two softening temperatures, $\mathrm{T}_{\mathrm{s} 1}$ and $\mathrm{T}_{\mathrm{s} 2}$, were observed at $102^{\circ} \mathrm{C}$ and $164^{\circ} \mathrm{C}$. These two temperatures correspond to the melting temperature of LDPE $\left(98-115^{\circ} \mathrm{C}\right)$ and PP $\left(160-175^{\circ} \mathrm{C}\right)$, respectively. This waste stream comprises mostly mixed plastic wastes and fiber waste. The various plastic components melt in the range of $120-300^{\circ} \mathrm{C}$. The reactor temperature reaches $300-400^{\circ} \mathrm{C}$, which means 
that the plastic components melt within the reactor. However, the fiber component does not melt. As the plastic components melt, they incapsulate the fiber particles and generate a rather homogeneous blend. This blend undergoes chemical degradation. Approaching the extruder outlet where the temperatures are in the range of $150-170^{\circ} \mathrm{C}$, the blend solidifies.

Table 4.1. Flexural modulus and strength values of extruded mixed plastic-paper, LDPE, HDPE, and PP.

\begin{tabular}{lll}
\hline Material & $\begin{array}{l}\text { Flexural modulus } \\
(\mathbf{M P a})\end{array}$ & $\begin{array}{l}\text { Flexural strength } \\
\mathbf{( M P a )}\end{array}$ \\
\hline Mixed plastic-fiber & $1,400 \pm 94$ & $10.67 \pm 0.77$ \\
\hline LDPE & $213 \pm 36$ & $7.14 \pm 0.75$ \\
\hline HDPE & $1,047 \pm 42$ & $27.4 \pm 0.6$ \\
\hline PP & $1,423 \pm 34$ & $36.9 \pm 0.4$ \\
\hline
\end{tabular}

The extruded mixed plastic-fiber pellets were compression molded into specimens and tested for their flexural properties (strength and modulus), with example results shown in Table 4.1. The mean flexural modulus was $1,400 \mathrm{MPa}$, and the mean flexural strength was 10.7 MPa. For comparison, the flexural properties of compression-molded LDPE, HDPE, and PP are given in Table 4.1. The mixed plastic-fiber material has a flexural modulus comparable to PP and strength comparable to LDPE.

Dynamic rheological measurement was also obtained on the extruded torrefied pellets. Figure 4.14 shows the results for complex viscosity $\left(\eta^{*}\right)$ as a function of viscosity at $180^{\circ} \mathrm{C}$. The $\eta^{*}$ is seen decreasing with the increase of angular frequency, showing shear thinning behavior. For example, the $\eta^{*}$ at 1 and $30 \mathrm{~Hz}$ were 16,800 and $738 \mathrm{~Pa}$.s, respectively. Similar behavior has been observed in reprocessed plastic wastes [10] and plastic-fiber wastes [44]. 


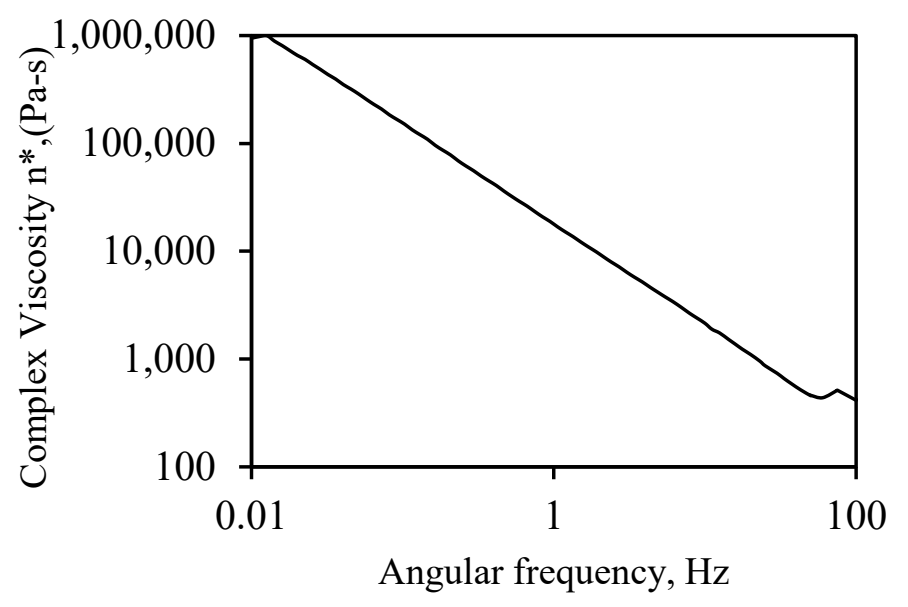

Figure 4.14. Flow curves showing complex viscosity vs. shear rate of plastic waste at $180^{\circ} \mathrm{C}$.

Pellet Durability Index (PDI) measurement was measured for five samples of $500 \mathrm{~g}$ each. The average pellet durability index was $98.27 \pm 0.56 \%$. This index indicates the high durability of pellets and minimum fines production.

To ensure the robustness of the process in treating different feedstocks, we also investigated other feedstocks, such as mixed plastic wastes, MRF residues, etc., and have successfully obtained good results both for the process and product characteristics. The results for other waste streams and detailed analysis of these materials will be presented in future studies.

\subsection{Conclusion}

Torrefaction of mixed fiber-plastic sourced from industrial wastes was carried out at $300^{\circ} \mathrm{C}$ in an integrated torrefaction-extrusion screw reactor with a throughput of up to $70 \mathrm{~kg} / \mathrm{h}$. The study experimentally measured thermo-mechanical properties of both the process and the pellets produced. Residence time for the reactor was measured, and it was found that $20 \%$ and $40 \%$ cut flighting had about 2.3 and 3.7 times respectively more residence time compared to regular screw. The average overall heat transfer coefficient was measured experimentally for the reactor at $52.5 \mathrm{~W} / \mathrm{m}^{2 \circ} \mathrm{C}$. The correlation between specific mechanical energy and mass flow showed a more than 3 times decrease in specific energy 
consumed when the feed rate was increased from $\sim 10 \mathrm{~kg} / \mathrm{h}$ to $50 \mathrm{~kg} / \mathrm{h}$. TMA, flexural testing, rheological, and pellet durability testing were performed on the produced pellets to measure pellet properties showed that the pellet had good processability and mechanical properties (durable). In conclusion, the system is able to produce high-quality torrefied pellets with low specific energy costs.

\section{Author Contributions}

Shreyas S. Kolapkar: Methodology, Investigation, Writing - original draft; Stas Zinchik: Investigation, Writing - review and editing; Zhuo $\mathrm{Xu}$ - Investigation, Writing - review and editing; Armando McDonald: Supervision, Investigation, Writing - review and editing; Ezra Bar-Ziv: Conceptualization, Supervision, Investigation, Writing - review and editing. All authors have approved the final version of the manuscript.

\section{Funding Sources}

We acknowledge the support from (1) National Science Foundation grant number 1827364; (2) U.S. Department of Energy, Office of Energy Efficiency and Renewable Energy (EERE), Bioenergy Technologies Office (BETO), under DOE Idaho Operations Office Contract DE-AC07-05ID14517 (3) Michigan Translational Research and Commercialization (MTRAC) program by the State of Michigan, Grant Number RC109248.

\section{Acknowledgment}

We acknowledge the support from (1) National Science Foundation grant number 1827364; (2) U.S. Department of Energy, Office of Energy Efficiency and Renewable Energy (EERE), Bioenergy Technologies Office (BETO), under DOE Idaho Operations Office Contract DE-AC07-05ID14517 (3) Michigan Translational Research and Commercialization (MTRAC) program by the State of Michigan, Grant Number RC109248. 


\section{Appendix}

The appendix includes (a) FTIR spectral comparison for mixed plastic wastes showing homogenization, (b) proximate, ultimate, and ash analysis for feedstock, (c) proximate analysis of torrefied pellets, and (d) specific power consumption comparison. The Appendix is available at: https://pubs.acs.org/doi/10.1021/acs.energyfuels.1c01836

\subsection{References}

[1] U.S. Environmental Protection Agency, Advancing Sustainable Materials Management: 2017 Fact Sheet, EPA 530-F-19-007 (2019).

[2] J. Thompson. US landfill capacity to drop $15 \%$ over next 5 years. https://wihresourcegroup.wordpress.com/2018/06/20/us-landfill-capacity-to-drop-15over-next-5-years/, 2018. (accessed 6 March, 2020).

[3] D. Kantner, B.F. Stanley. Environmental Research and Education Foundation Analysis of MSW Landfill Tipping Fees: April 2019. www.erefdn.org, 2019. (accessed 10 March, 2021).

[4] A.L. Brooks, S. Wang, J.R. Jambeck, The Chinese import ban and its impact on global plastic waste trade, Sci Adv, 4 (2018). https://doi.org/10.1126/sciadv.aat0131

[5] C. Katx. Piling Up: How China's Ban on Importing Waste Has Stalled Global Recycling. Yale School of Environment. https:/e360.yale.edu/features/piling-up-howchinas-ban-on-importing-waste-has-stalled-global-recycling, 2021. (accessed 3 September, 2021).

[6] A. Truelove, C. Katan, The State of Recycling National Survey, in, U.S. PIRG Education Fund and Environment America - Research and Policy Center, 2019. 
[7] N.A.F. Abdul Samad, N.A. Jamin, S. Saleh, Torrefaction of Municipal Solid Waste in Malaysia, Energy $\quad$ Procedia, $138 \quad$ (2017) 313-318. https://doi.org/10.1016/j.egypro.2017.10.106

[8] U.S. Department of Energy - EERE, Waste-to-Energy from Municipal Solid Waste, in, 2019.

[9] M. Cremers, J. Koppejan, J. Middelkamp, J. Witkamp, S. Sokhansanj, S. Melin, S. Madrali, Status Overview of Torrefaction Technologies - A review of the commercialisation status of biomass torrefaction, IEA bioenergy, 2015.

[10] S. Zinchik, Z. Xu, S.S. Kolapkar, E. Bar-Ziv, A.G. McDonald, Properties of pellets of torrefied U.S. waste blends, Waste Manag, $104 \quad$ (2020) 130-138. https://doi.org/10.1016/j.wasman.2020.01.009

[11] F. Campuzano, R.C. Brown, J.D. Martinez, Auger reactors for pyrolysis of biomass and wastes, Renewable \& Sustainable Energy Reviews, 102 (2019) 372-409. https://doi.org/10.1016/j.rser.2018.12.014

[12] H.J.P.L. de Souza, M.D.C. Arantes, G.B. Vidaurre, C.R. Andrade, A.d.C.O. Carneiro, D.P.L. de Souza, T.d.P. Protásio, Pelletization of eucalyptus wood and coffee growing wastes: Strategies for biomass valorization and sustainable bioenergy production, Renewable Energy, 149 (2020) 128-140. https://doi.org/10.1016/j.renene.2019.12.015

[13] N. Setkit, X. Li, H. Yao, N. Worasuwannarak, Torrefaction behavior of hot-pressed pellets prepared from leucaena wood, Bioresour Technol, 321 (2021) 124502. https://doi.org/10.1016/j.biortech.2020.124502

[14] U.S. Department of Energy - EERE, Alternative Aviation Fuels: Overview of Challenges, Opportunities, and Next Steps, in, 2017. 
[15] I. Martínez, G. Grasa, M.S. Callén, J.M. López, R. Murillo, Optimised production of tailored syngas from municipal solid waste (MSW) by sorption-enhanced gasification, $\begin{array}{lllll}\text { Chemical Engineering } & \text { Journal, } & 401 & \text { (2020) } & 126067 .\end{array}$ https://doi.org/10.1016/j.cej.2020.126067

[16] Convergen-Energy. Renewable \& sustainable fuel. https://www.convergenenergy.com/our-fuels/, 2021. (accessed 6 March, 2021).

[17] P.A. Corp. Renewable energy - recycled fuel pellets. http://www.pelletamerica.com/, 2021. (accessed 6 March, 2021).

[18] W.T. Kwon, S.Y. Bae, Utilization of waste plastics as a fuel in the fluidized bed calciner for cement kiln process, Mater Sci Forum, 486-487 (2005) 399-402. https://doi.org/DOI 10.4028/www.scientific.net/MSF.486-487.399

[19] I.F. Laucks, The Screw as a Carbonizing Machine, Industrial \& Engineering Chemistry, 19 (2002) 9-11. https://doi.org/10.1021/ie50205a004

[20] S. Kelkar, C.M. Saffron, L. Chai, J. Bovee, T.R. Stuecken, M. Garedew, Z.L. Li, R.M. Kriegel, Pyrolysis of spent coffee grounds using a screw-conveyor reactor, Fuel Processing Technology, 137 (2015) 170-178. https://doi.org/10.1016/j.fuproc.2015.04.006

[21] M. Atienza-Martínez, J.F. Mastral, J. Ábrego, J. Ceamanos, G. Gea, Sewage Sludge Torrefaction in an Auger Reactor, Energy \& Fuels, 29 (2014) 160-170. https://doi.org/10.1021/ef501425h

[22] S. Zinchik, J.L. Klinger, T.L. Westover, Y. Donepudi, S. Hernandez, J.D. Nabera, E. Bar-Ziv, Evaluation of fast pyrolysis feedstock conversion with a mixing paddle reactor, $\begin{array}{lllll}\text { Fuel Processing } & 171 & \text { Technology, } & \text { 12018) }\end{array}$ https://doi.org/10.1016/j.fuproc.2017.11.012 
[23] J.N. Brown, Development of a lab-scale auger reactor forbiomass fast pyrolysis and process optimizationusing response surface methodology, in Mechanical Engineering, Iowa State University, Ames, Iowa, 2009.

[24] J.N. Brown, R.C. Brown, Process optimization of an auger pyrolyzer with heat carrier using response surface methodology, Bioresour Technol, 103 (2012) 405-414. https://doi.org/10.1016/j.biortech.2011.09.117

[25] J.D. Martinez, R. Murillo, T. Garcia, A. Veses, Demonstration of the waste tire pyrolysis process on pilot scale in a continuous auger reactor, J Hazard Mater, 261 (2013) 637-645. https://doi.org/10.1016/j.jhazmat.2013.07.077

[26] J. Recari, C. Berrueco, N. Puy, S. Alier, J. Bartroli, X. Farriol, Torrefaction of a solid recovered fuel (SRF) to improve the fuel properties for gasification processes, Applied Energy, 203 (2017) 177-188. https://doi.org/10.1016/j.apenergy.2017.06.014

[27] Z. Xu, J.W. Albrecht, S.S. Kolapkar, S. Zinchik, E. Bar-Ziv, Chlorine Removal from U.S. Solid Waste Blends through Torrefaction, Applied Sciences, 10 (2020). https://doi.org/10.3390/app10093337

[28] Z. Xu, S. Zinchik, S.S. Kolapkar, E. Bar-Ziv, T. Hansen, D. Conn, A.G. McDonald, Properties of Torrefied U.S. Waste Blends, Frontiers in Energy Research, 6 (2018). https://doi.org/10.3389/fenrg.2018.00065

[29] X.G. Shi, F. Ronsse, R. Nachenius, J.G. Pieters, 3D Eulerian-Eulerian modeling of a screw reactor for biomass thermochemical conversion. Part 2: Slow pyrolysis for char production, Renewable Energy, $143 \quad$ (2019) 1477-1487. https://doi.org/10.1016/j.renene.2019.05.088 
[30] F.L. Qi, M.M. Wright, A DEM modeling of biomass fast pyrolysis in a double auger reactor, International Journal of Heat and Mass Transfer, 150 (2020) 119308. https://doi.org/10.1016/j.ijheatmasstransfer.2020.119308

[31] A. Funke, R. Grandl, M. Ernst, N. Dahmen, Modelling and improvement of heat transfer coefficient in auger type reactors for fast pyrolysis application, Chemical Engineering and Processing-Process Intensification, 130 (2018) 67-75. https://doi.org/10.1016/j.cep.2018.05.023

[32] F.L. Qi, M.M. Wright, Particle scale modeling of heat transfer in granular flows in a double screw reactor, Powder Technology, 335 (2018) 18-34. https://doi.org/10.1016/j.powtec.2018.04.068

[33] S.S. Waje, B.N. Thorat, A.S. Mujumdar, An experimental study of the thermal performance of a screw conveyor dryer, Drying Technology, 24 (2006) 293-301. https://doi.org/10.1080/07373930600564506

[34] S. Godavarti, M.V. Karwe, Determination of specific mechanical energy distribution on a twin-screw extruder, J Agr Eng Res, 67 (1997) 277-287. https://doi.org/DOI 10.1006/jaer.1997.0172

[35] F. Berzin, A. Tara, L. Tighzert, B. Vergnes, Importance of Coupling Between Specific Energy and Viscosity in the Modeling of Twin Screw Extrusion of Starchy Products, Polymer Engineering and Science, 50 (2010) 1758-1766. https://doi.org/10.1002/pen.21702

[36] E. Sasimowski, L. Majewski, M. Grochowicz, Efficiency of Twin-Screw Extrusion of Biodegradable Poly (Butylene Succinate)-Wheat Bran Blend, Materials (Basel), 14 (2021). https://doi.org/10.3390/ma14020424 
[37] V. Schmid, J. Steck, E. Mayer-Miebach, D. Behsnilian, M. Bunzel, H.P. Karbstein, M.A. Emin, Extrusion Processing of Pure Chokeberry (Aronia melanocarpa) Pomace: Impact on Dietary Fiber Profile and Bioactive Compounds, Foods, 10 (2021). https://doi.org/10.3390/foods10030518

[38] A. Lepschi, G. Gerstorfer, J. Miethlinger, Determining the residence time distribution of various screw elements in a co-rotating twin-screw extruder by means of fluorescence spectroscopy, in: AIP Conference, 1664, 020005, 2015.

[39] C. Nikitine, E. Rodier, M. Sauceau, J. Fages, Residence time distribution of a pharmaceutical grade polymer melt in a single screw extrusion process, Chem Eng Res Des, 87 (2009) 809-816. https://doi.org/10.1016/j.cherd.2008.10.008

[40] Z. Xu, S.S. Kolapkar, S. Zinchik, E. Bar-Ziv, A.G. McDonald, Comprehensive kinetic study of thermal degradation of polyvinylchloride (PVC), Polymer Degradation and Stability, 176 (2020). https://doi.org/10.1016/j.polymdegradstab.2020.109148

[41] H.F. Giles Jr., J.R. Wagner Jr., E.M. Mount III, Extrusion: The Definitive Processing Guide and Handbook, 1st ed., William Andrew Publishing, Norwich, NY, 2005.

[42] S.P. Luo, J.Z. Cao, A.G. McDonald, Interfacial Improvements in a Green Biopolymer Alloy of Poly(3-hydroxybutyrate-co-3-hydroxyvalerate) and Lignin via in Situ Reactive Extrusion, Acs Sustainable Chemistry \& Engineering, 4 (2016) 3465-3476. https://doi.org/10.1021/acssuschemeng.6b00495

[43] C. Stark, A. Fahrenholz, Evaluating Pellet Quality, in, Kansas State University Agricultural Experiment Station and Cooperative Extension Service, 2015, pp. 1-3.

[44] Z. Xu, S.S. Kolapkar, S. Zinchik, E. Bar-Ziv, L. Ewurum, A.G. McDonald, J. Klinger, E. Fillerup, K. Schaller, C. Pilgrim, Bypassing Energy Barriers in Fiber-Polymer 
Torrefaction, Frontiers in Energy Research, 9 (2021). https://doi.org/10.3389/fenrg.2021.643371 


\section{Integrated Torrefaction-Extrusion System for Solid Fuel Pellet Production from Mixed Fiber-Plastic Wastes: Techno-Economic Analysis and Life Cycle Assessment}

This section is based on the peer-revied paper titled "Integration Torrefaction-Extrusion System for Solid Fuel Production from Mixed Fiber-Plastic Wastes: Techno-Economic Analysis and Life Cycle Assessment," published in Fuel Processing Technology (2022). https://doi.org /10.1016/j.fuproc.2021.107094

\subsection{Abstract}

The world is witnessing an unprecedented generation and accumulation of fiber-plastic wastes resulting in various challenges due to inconsistency, waste-stream heterogeneity, conveying issues, self-heating, and difficulty in pelletization. This study presents a novel pilot-scale system that integrates torrefaction and extrusion to convert mixed fiber-plastic waste into fuel pellets. The produced pellets have low cost, high heating value, better uniformity, and low environmental impact. They can be used as solid fuels or as feedstock for pyrolysis and gasification. To evaluate the pellet cost and its environmental impact, we performed Techno-Economic Analysis (TEA) and Life Cycle Assessment (LCA). The TEA integrates research findings from the torrefaction-extrusion project with the technoeconomic models and estimates the costs, energy consumption, and mass balances for pelletizing and torrefaction. The analysis indicates that the baseline cost of producing uniform pellets is about $\$ 55.28$ /dry tonne (2020\$). LCA results indicate that the torrefied product has cradle-to-gate embodied greenhouse gas emissions that are net negative, although they are higher than a comparable forest-derived woodchip product. Fossil energy demand for the torrefied product is lower than the forest-derived chip, indicating the torrefied product has strong potential for use as an environmentally beneficial feedstock for future processing. 


\subsection{Introduction}

As the world population continues to increase, so does waste generation. It is anticipated that, by 2050, humans will generate wastes at a record high of 3.4 billion tonnes per year worldwide [1]. As a result, we are witnessing an unprecedented accumulation of fiber/plastic wastes in landfills, land, and oceans with well-documented negative consequences $[2,3]$. To address this, some countries have adapted the waste-to-energy approach as a preferred path [4]; however, the downside of this approach is that waste-toenergy can be costly due to high operational and gas cleanup costs to meet emission standards [5]. In parallel, in the U.S., states like Florida and California have mandated the approach of high recycling rates $[6,7]$, but with world events like the Chinese ban on recyclable imports [8], critical issues with recycling have surfaced. Apart from these challenges, recycling cost is often driven up due to barriers like (a) inconsistencies of wastes, (b) heterogeneity in the waste stream, (c) bridging and conveying issues due to the low feedstock density, (c) inefficient separation technologies for recyclable polymers, and (d) difficulties in flowing wastes into reactors. As we strive to become truly sustainable, these challenges must be addressed.

One pathway to address these challenges is the thermo-chemical pathway of torrefaction. It is a process of heating the feedstock at temperatures usually ranging from $250^{\circ} \mathrm{C}$ to $350^{\circ} \mathrm{C}$ in the absence of oxygen or in an oxygen-starved environment [9, 10]. Torrefaction converts the feedstock mainly into solids, which can be used as a solid fuel in cofiring boilers and cement kilns or upgraded to transportation fuels, sustainable aviation fuels, and chemicals through catalytic pyrolysis or gasification [11-14]. Torrefaction using biomass as a feedstock has been studied extensively [15-18] and has been regarded as a promising energy source [19-22]. However, biomass presents several disadvantages, as pointed by the five years long industrial-scale study by Nunes [23] and several other studies [19, 24] like low feedstock density, problems associated with logistics and handling, high raw material prices, high moisture contents, self-heating, difficulty in pelletizing and excessive wear of production equipment. 
The current study focuses on the torrefaction of fiber-plastic waste blends; the use of plastic along with fiber (biomass) addresses the biomass-related issues mentioned above in Nunes's study [23]. It has been discovered that plastic acts as an enabler to the torrefactionextrusion process by providing higher calorific value [25], significantly reducing selfheating tendency by encapsulation of reactive torrefied fiber [26], acting as a lubricant to reduce the wear and tear of the production equipment, facilitating material binding during the extrusion-pelletization processes and also making produced pellets water repellant [25]. Along with biomass, torrefaction of fiber-plastic wastes has also been extensively studied and documented [10, 25, 27, 28].

The torrefaction technology presented in the current study is an integrated torrefactionextrusion technology that can produce torrefied pellets from a mix of fiber and plastic wastes. Both paddles and the extruder have been extensively studied independently; for instance, Bar-Ziv et al. studied the use of paddles for torrefaction of biomass at a commercial scale and have successfully shown its suitability to produce bio-coal briquettes [29], and Zinchik et al. studied the paddle reactors at lab scale and produced pyrolysis oils [30] and recently Kolapkar et al. [31] have studied a torrefaction-extrusion reactor and presented the thermo-mechanical properties of the torrefied pellets. In addition, extrusion has also been studied and has been used extensively in the plastic industry for several decades [32]. The integrated paddle and extrusion reactor used in this study, also referred to as torrefaction-extrusion reactor, uses a single shaft, which mixes the waste blend, heats it, degrades the blend while removing chlorine, and finally extrudes it into uniform pellets. These pellets are ready to be used for combustion for power applications or upgraded to liquid/gaseous products and chemicals. This is a pilot-scale unit operating at a throughput of 800 tonnes/yr. The team has developed it with the notion of scaling it up to a full commercial scale. The reactor-extruder part has been described in detail in the previous studies [26,31]. The current study provides comprehensive details on the integrated system and for each component, beginning from the waste processing stage all the way to the pellet storage, providing operation and energy data. 
For the successful market implementation of torrefaction technologies, International Energy Agency provided the following key recommendations [20]: the need for production scale-up, end-user confidence, lower product price, standards for sustainability and traceability, product standards, and torrefying wastes. We performed techno-economic analysis (TEA) and life-cycle assessment (LCA) to substantiate that this technology addresses these recommendations for future market implementation; we performed technoeconomic analysis (TEA) and Life-cycle assessment (LCA). The TEA for the torrefactionextrusion system is aimed at deriving the product cost at a commercial scale. Literature was surveyed for understanding the comparative cost of delivered torrefied biomass and mixed fiber-plastic wastes.

Costs of biomass torrefaction have been extensively studied [33, 34] (and references cited therein), showing that the cost of biomass is a significant contribution to the overall cost. Whalley et al. [35] indicated that in the U.S., the delivered cost of biomass ranged from $\$ 8$-\$82/green tonne, International Renewable Energy Agency states that the cost of forest residues and wood waste range between $\$ 10$ to $\$ 30 /$ tonne while energy crops (corn stover, straw) cost \$39-\$60/tonne. Wright et al. [36] estimate the cost of biomass (corn stover) to be $\$ 83 /$ tonne. It is observed that biomass cost largely depends on the type of biomass, production source, and transport cost and has been reported as high as \$110/tonne [34] based on these factors. If this feedstock cost is further normalized based on moisture content and the mass loss that will occur in the torrefaction process, the cost of biomass per tonne of torrefied material may increase further by $\$ 60-80 /$ tonne torrefied material.

In contrast to biomass, a tipping fee is paid for wastes (MSW and industrial waste consisting of fibers and plastic). U.S. average tipping fee ranges from $\$ 50.87-\$ 55.72$ per U.S. short ton (1 U.S. short ton $=0.907$ metric tonnes) [37]. Assuming that the torrefied fiber-plastic waste product requires 1.5 times the incoming waste [10, 25], considering the moisture content and mass loss required, the average tipping fee per tonne of the torrefied product increases to $\$ 84.11-\$ 92.13$. In terms of economics, for feedstock cost/tonne of torrefied fuel, the use of fiber-plastic wastes can be a considerable incentive compared to biomass (negative $\sim \$ 83$ /tonne vs. $\sim \$ 60 /$ tonne, a difference of $\sim \$ 143 /$ tonne). This number 
may increase even further if the cost per energy basis is factored in, as plastic in the wastes adds to the blend's overall heating value. Thus, using fiber-plastic wastes has not only significant economic benefits but also operational and safety benefits. The TEA provided in this study provides the cost of the product based on the capital and operating costs.

In addition to the technical and economic feasibility, the environmental sustainability of the process and product should also be considered. Untreated or improperly treated, fiberplastic wastes can have detrimental environmental as well as health impacts [38]. With growing awareness about the environmental impacts of processes, LCA has become a popular tool to quantify the environmental impact. An LCA study by Sauve et al. estimated the environmental impact of landfills for MSW and showed $\mathrm{CO}_{2}$ emissions ranged between 124 to $841 \mathrm{~kg} \mathrm{CO}_{2}$ equivalent/tonne [2]. Dong et al. studied the impact of incineration and pyrolysis and reported $416 \mathrm{~kg} \mathrm{CO}_{2}$ equivalent/tonne for the incineration process and 420 $\mathrm{kg} \mathrm{CO}_{2}$ equivalent/tonne emission for pyrolysis [39]. Recent work on MSW conversion to liquid transportation fuels indicates that MSW can serve as a feedstock to produce fuels and chemicals with favorable environmental profiles compared to conventional fossil products [40]. It should be noted that moisture is present in the fiber-plastic wastes. Our current system can handle moisture content of up to $10 \%$. Any content above that value should be handled by an additional dryer, which is not included in this study. The inclusion of a dryer should affect both LCA and TEA.

Overall, the current study documents (a) the development of a proposed solution to address the issues described; (b) conduct TEA; and (c) conduct LCA of the mixed fiber-plastic waste torrefaction system. We explore the development and production of torrefied pellets from presorted plastic and fiber wastes, which can be utilized as a fuel to produce heat and power. This study includes (i) data from an integrated pilot-scale system operating at up to $\sim 800$ tonne/yr producing pellets, and (ii) TEA and LCA for a commercial scale 100,000 tonne/yr system, which includes a heat management system where the torrefaction gas stream (comprising some heating value) is burnt in a furnace, and the flue gases are used for drying and process heat [29]. 


\subsection{Materials and Methods}

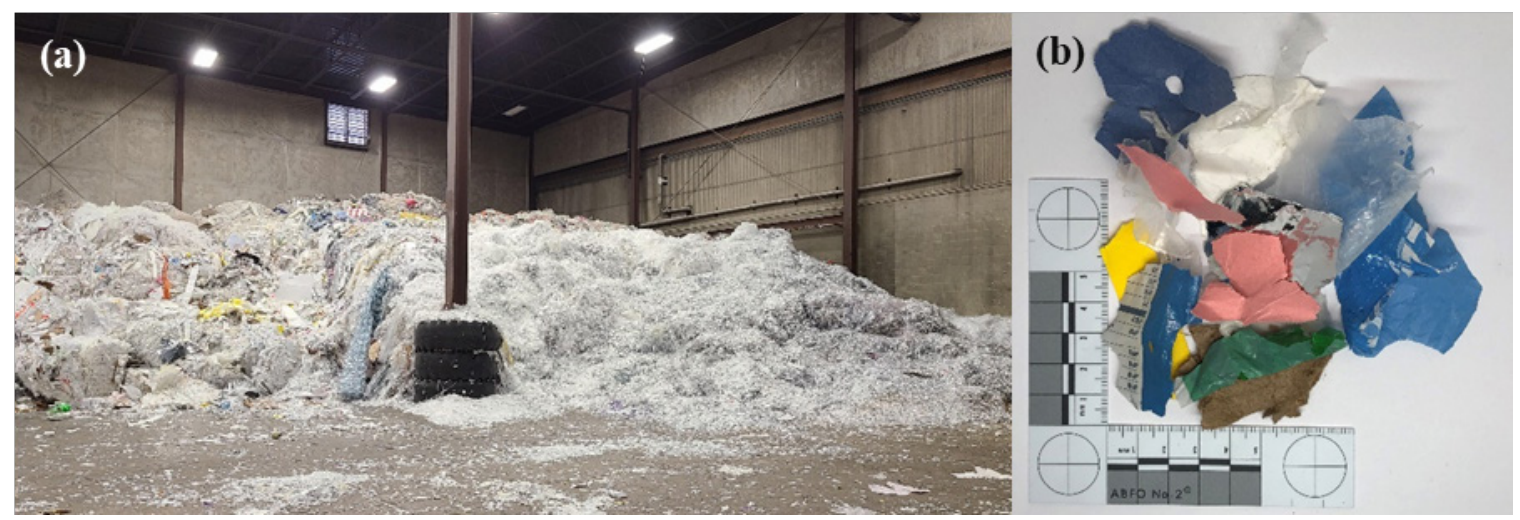

Figure 5.1. (a) Presorted mixed fiber-plastic 'as-received' on the tipping floor; (b) mixed fiber-plastic after three-stage shredding to size $\leq 50 \mathrm{~mm}$.

The blend of fiber-plastic wastes material was supplied by Convergen Energy (CE) LLC. It was shredded using various-stage shredding process from as-received material on the tipping floor, see Figure 5.1(a), to $\leq 50 \mathrm{~mm}$, see Figure 5.2(b). Shredding is accomplished first by a Vecoplan RG-98 to $\leq 300 \mathrm{~mm}$, then by Vecoplan VAZ-2500 to $\leq 50 \mathrm{~mm}$. The feedstock is a blend of fiber-plastic wastes presorted by removing stones, glass, and metals. The shredded material was adjusted to provide consistent heat content of $25 \mathrm{MJ} / \mathrm{kg}$, by tuning the fiber-to-plastic ratio, commonly requiring $60 \%-40 \%$, fiber-to-plastic blend. After this shredding stage, the received material's density (as received from Convergen Energy and shown in Figure 5.1a) is between 40 to $70 \mathrm{~kg} / \mathrm{m}^{3}$. Further shredding was carried out to a size of $\leq 3 \mathrm{~mm}$ at the pilot plant using Allegheny 16-75CX, see Figure 5.2(a). The material's density after this shredding stage is between 105 to $120 \mathrm{~kg} / \mathrm{m}^{3}$. Pellets produced using the integrated torrefaction-extrusion are shown in Figure 5.2(b). The pellets presented show two different levels of torrefaction extent. 

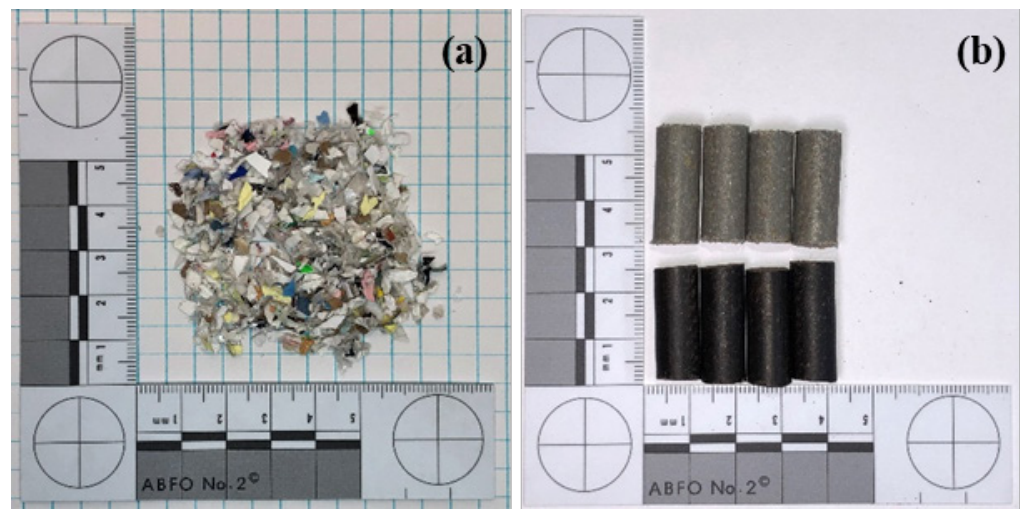

Figure 5.2. (a) Mixed fiber-plastic waste after shredding to $\leq 3 \mathrm{~mm}$, and (b) Pellets produced in the pilot-scale system using the mixed fiber-plastic waste at different levels of torrefaction.

FTIR spectroscopy was used to identify the types of fiber and plastics present in the blend of incoming materials using a Thermo-Scientific Nicolet Summit Pro spectrometer with an attenuated total reflection (ATR) accessory (Zn-Se crystal, iD5). Hundreds of randomly chosen pieces were analyzed using the OMNIC V-9 software package, plastic standards (low-density polyethylene from Rainer Plastics, Inc., high-density polyethylene from Equistar Petrothene LB01000, and polypropylene (PP) from Amcor), and Aldrich, Hummel, and Nicolet spectral libraries. The main types of the plastics identified using an FTIR analysis were Low-density Polyethylene (LDPE), High-density Polyethylene (HDPE), Polypropylene (PP), Polyethylene Terephthalate (PET), and traces of Polyamides (Nylon), while identified fibers mainly comprised of paper, cardboard, and carton. Detailed physical and thermo-mechanical characteristics of the biogenic (fibers, paper, etc.) as well as the plastic portion of the feedstock used in this work are detailed in our earlier study. Additional insights on the chemical kinetics of fibers are presented in our separate past study on fiber wastes. 


\subsubsection{The Pilot-Scale Integrated Torrefaction-Extrusion System}

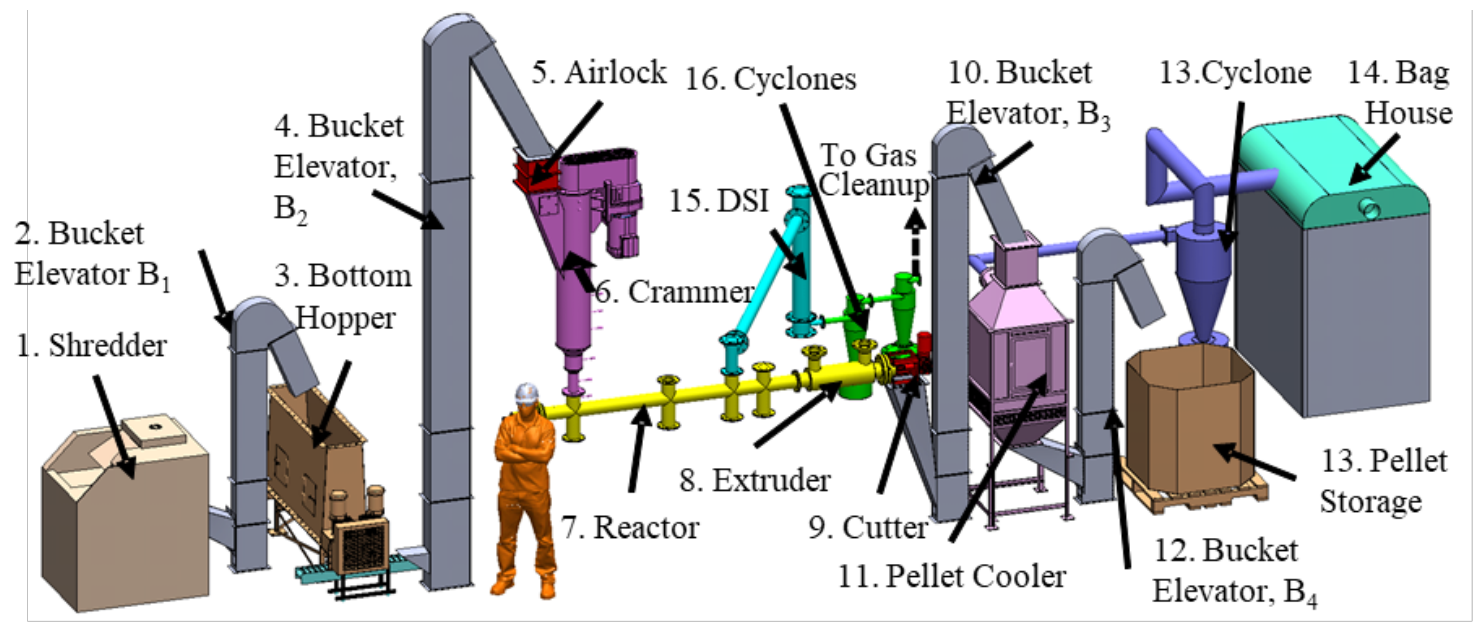

Figure 5.3. Scheme of the pilot-scale torrefaction-extrusion process.

The scheme of the integrated torrefaction-extrusion system is presented in Figure 5.3. The feedstock is introduced in a shredder (1) where it is downsized to a $\sim 3 \mathrm{~mm}$ size and then conveyed using bucket elevator $\mathrm{B}_{1}$ (2) to a live bottom hopper (3) that monitors the feed rate further downstream. This is followed by material conveying by a bucket elevator $\mathrm{B}_{2}$ (4) into crammer (5) that preheats and densifies the material and creates an air seal preventing air from entering the reactor (6). The material then flows into a paddle reactor (7), where it mixes well, heats up, and undergoes a thermal decomposition through torrefaction. The torrefied material in the reactor flows into the extruder (8), densifying it into long rods. The extruder temperature is controlled by a heating/cooling system (not shown) using oil (Therminol XP) as heat transfer fluid. The long rods are cut into pellets of predetermined size using the cutter (9). Note that the reactor is continuously purged by nitrogen (not shown) to ensure an oxygen-free environment, and an induced-draft (ID) fan removes the off-gases into a furnace that burns the organic material in this stream. The cut pellets are conveyed using a bucket elevator $\mathrm{B}_{3}(10)$ to the pellet cooler (11) for cooling. The cooled pellets are conveyed again using bucket elevator $\mathrm{B}_{4}(12)$ to the pellet storage box (13). We note that the extruder outlet also acts as an airlock to prevent air from entering the reactor. The gas stream generated from the torrefaction process is cleaned by passing it through Dry Sorbent Injection (DSI) (15) and two cyclones (16) connected in series to a 
gas cleanup system (not shown). We note that the gas stream can be utilized to provide some of the process energy. The following sections detail each of the key components of the system.

\subsubsection{Shredding}

Downsizing was found to be an essential pre-process for torrefaction and extrusion. Lowshear shredding allows the material to be downsized to $\sim 3 \mathrm{~mm}$ flakes without 'fluffing up' - a volumetric expansion effect caused by the presence of fibers. The main advantages of the low-shear downsizing approach are: (i) up to three times density increase, thus reducing downstream components' size; (ii) prevents the formation of very-low-density fluffy material caused by high-shear shredding; (iii) produces a significantly more uniform blend than the incoming material, and (iv) reduces the material bridging tendency. Shredding to $\leq 3 \mathrm{~mm}$ was accomplished by Allegheny cross-cut shredder model 16-75CX, using a 7.5 $\mathrm{kW}$ motor; a conveyor was used to feed the shredder, operating at a speed of $23 \mathrm{~m} / \mathrm{min}$. After passing through cutters, the material is cross-cut and reduced to a size of $3 \mathrm{~mm}$ broad stripes. Further reduction in particle size can be achieved using recirculation of material.

\subsubsection{Live Bottom Hopper}

Accurate material feeding is essential for the well-controlled torrefaction process. Figure 5.4a shows the live bottom hopper developed and manufactured in-house for this purpose. The live bottom hopper has the following characteristics: (a) negative hopper angle, i.e., the width at the bottom is larger than the top with a $3^{\circ}$ incline, (b) independently controlled variable pitch screws. The negative hopper angle avoids any occurrence of bridging during the material flow. The variable pitch allows maintaining a constant material level in the hopper. The weight of the bottom hopper is monitored continuously using four load cells (not shown) placed under the legs. Each leg has vibration insulating pads to insulate the motor vibration from the load reading. 


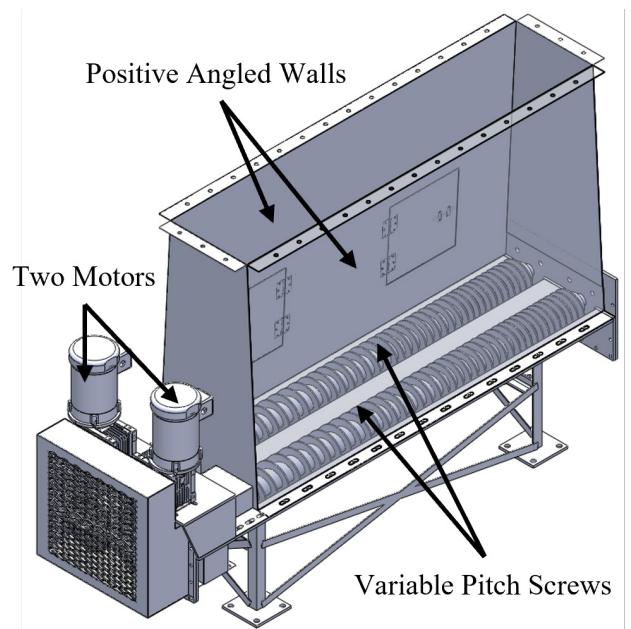

Figure 5.4. Live bottom hopper with positive angles and independently controlled variable pitch screws

\subsubsection{Bucket Elevators}

Four bucket elevators are used for conveying the material from one piece of equipment to the other. Bucket elevators are known for their suitability and reliability in conveying bulk material. The bucket elevators used in the system are U-series bucket elevators of various heights and capacities manufactured by Universal Industries, Inc.

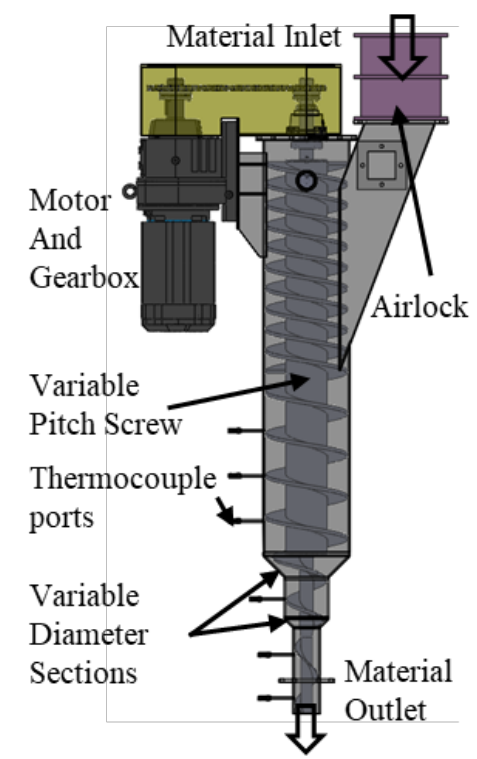

Figure 5.5. Schematic showing the airlock and various components of the crammer. 


\subsubsection{Airlock and Crammer}

Continuous and stable feeding is critical for the operation of any fuel-producing facility. Wastes are known to have flowability problems such as bridging in hoppers due to various reasons like heterogeneity, different particle size, density, high moisture content, and compressibility [41]. A standard solution to this problem is to limit the type of material used or to use pneumatic or mechanical agitation techniques. However, neither provides an efficient solution for the mixed fiber-plastic waste used in this study. We developed a crammer that can provide a constant mechanical agitation and direct the material downwards to deal with this issue and densify the material. Figure 5.5 presents a schematic of the airlock and a crammer unit. The material is continuously fed by gravity from the top to the airlock. The airlock used in the system is an S8 series double-flap type airlock by Plattco ${ }^{\circledR}$ Corporation. One flap out of the two in the airlock is always in the closed position, allowing the airlock to maintain a positive seal constantly. The airlock is followed by material dropping in a sharp $70^{\circ}$ angle crammer chute with polytetrafluoroethylene (PTFE) coating to prevent material buildup. The material is then received by a double helix auger that ensures proper and fast material feeding into the main chamber. As the material continues to flow, it is compacted with two-stage cross-section reductions from $0.30 \mathrm{~m}$ to $0.15 \mathrm{~m}$ and $0.15 \mathrm{~m}$ to $0.10 \mathrm{~m}$, respectively. This reduction generates a higher friction coefficient that compresses the material from $\sim 50 \mathrm{~kg} / \mathrm{m}^{3}$ to $650-700 \mathrm{~kg} / \mathrm{m}^{3}$.

The crammer is equipped with six external electrical heating elements, maintained at 180$220^{\circ} \mathrm{C}$, to dry (up to $10 \%$ moisture content) the incoming fiber-plastic waste and to help soften the plastics in the mix and form paste-like material, reducing friction with the crammer's walls. The crammer temperature was selected according to a differential scanning calorimetry (DSC) measurement that indicates phase transition (melting) of the major plastic components. One of the major advantages of crammer is its $100 \%$ fill rate which leads to a compact footprint, high rate of heat transfer, the ability to dry the material to yield a uniform paste and input material into the mouth of the reactor at a high mass feed rate. It is important to note that the crammer requires plastic for operation; it does not work 
with $100 \%$ fiber; experiments show that at least $10-15 \%$ plastic is required to enable smooth working.

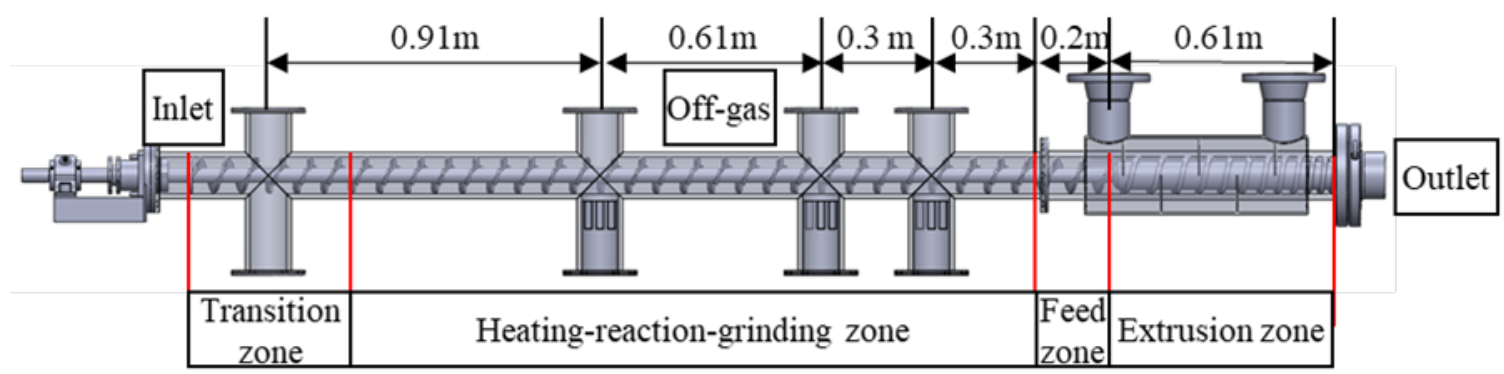

Figure 5.6. Integrated torrefaction-extrusion reactor showing the scale and various zones.

\subsubsection{Torrefaction-Extrusion Reactor}

The fiber-plastic waste material is mixed, heated, torrefied, and extruded to produce rods before being cut into pellets. Figure 5.6 shows the integrated torrefaction-extrusion reactor. It is described in detail in a previous study [31]; a brief description is provided below for convenience. The reactor is made of a 4-inch diameter shell externally heated by a series of electrical heaters. The shaft, 1.5 inches in diameter, is made from 15-5PH stainless steel. The reactor is designed with 4 zones: (i) transition zone; (ii) heating-reaction-grinding zone; (iii) feed zone (pre-extrusion); and (iv) extrusion zone. Each zone is designed to address a unique problem. Zone (i) addresses the feeding-related issue, ensuring a smooth and fast transition from the inlet of the reactor to the next zone. Zone (ii) is designed to maximize residence time and increase the mixing of the materials. As residence time and temperature determine the rate and extent of torrefaction, this design has significantly improved residence time by up to a factor of 3 compared to a regular screw reactor [31]. Enhanced mixing has been proven to improve heat transfer from the walls and radial temperature uniformity [26]. Zones (iii) and (iv) compact the material to a density suitable for storage and transportation while maintaining a low $\mathrm{L} / \mathrm{D}$ ratio. At the end of the extruder, the material is guided to the die using a unique die design. The compressed material at the die also creates a plug, or an airlock, preventing oxygen penetration into the reaction area. While torrefaction occurs at $250-350{ }^{\circ} \mathrm{C}$, extrusion temperature is critical for ensuring 
optimal pellet quality, occurring at $160-180{ }^{\circ} \mathrm{C}$, which requires efficient cooling (described following).

We note that in a regular torrefaction plant, each of the functions mentioned above is carried in a separate reactor or component [42]. The plastic in the blend is enabled to carry all these stages (heating-reaction-grinding and extrusion) in one reactor by one shaft as the plastic turns the blend into a paste after melting.

The extruder temperature was controlled by an oil heating/cooling system using mineral oil due to its high heat capacity and safety characteristics. The system used for temperature control was manufactured by Heat Exchange and Transfer Inc, PA, USA, using Therminol $\mathrm{XP}^{\circledR}$ oil. During the startup, the oil is heated using an inbuilt $15 \mathrm{~kW}$ heater, while during the operation, it is cooled using a $73-\mathrm{kW}$ capacity oil to the water heat exchanger.

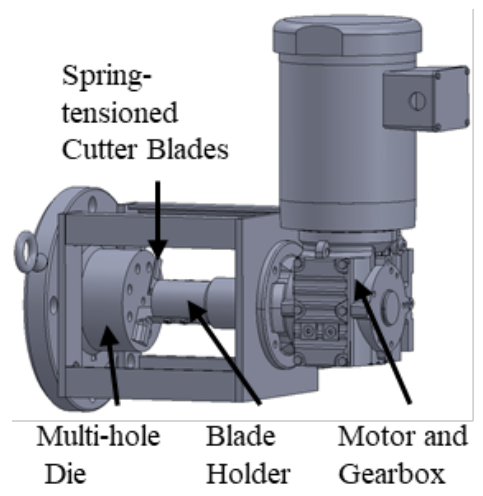

Figure 5.7. Scheme showing the cutter.

\subsubsection{Cutter}

Pellet cutting is essential in the pelletization process. The ring die produces multiple rods (8-hole, 0.5 -inch diameter) that must be cut to produce pellets. Figure 5.7 shows the cutter, with multiple blades developed for throughput up to $200 \mathrm{~kg} / \mathrm{h}$. The cutter is attached to the extruder with its spring-tensioned blades to maintain contact with the outer surface of the ring die. The blades are manufactured from tool steel alloy and are thermally treated to a hardness of HRC 55 for extended life and reduced blade dullness. To produce a uniform length of pellets, the rotation speed of the cutter is coupled using a PLC code with the die 
pressure measurement; as for a given material and temperature, extrusion velocity is a function of die pressure.

\subsubsection{Pellet Cooler}

Pellets exit at a temperature in the range of $160-180^{\circ} \mathrm{C}$ and must be cooled before storage and transportation. A commercial counterflow cooler of $500 \mathrm{~kg} / \mathrm{h}$ capacity manufactured by Münch-Edelstahl GmbH is used as part of the system. Pellets are conveyed from the cutter by a bucket elevator into an airlock on the top of the cooler. This is followed by a gravity drop of pellets into the cooler, where air enters from the sides, counter flows, and is dragged by a blower through a cyclone (to collect fines). Air then passes through a bag filter to block particulates under 0.5 micron from being released to the environment.

\subsubsection{Mass Flow Rate and Energy Measurements}

To measure mass flow rate and energy required to operate each component in the system, the following five parameters were measured: (i) moisture content before and after the process, (ii) weight measurement of feedstock (inlet), and the pellets produced (outlet) (iii) heat content of the pellets (iv) process heat used by the crammer and reactor units (v) specific electrical energy for the live bottom hopper, crammer, reactor, cutter, bucket elevator, and the pellet cooler.

\subsubsection{Moisture}

Moisture was measured using HFT 1000 Moisture Analyzer by Data Support Inc. Minimum of five measurements were performed per batch to have accurate moisture measurement. This facilitates the measurement of the mass lost in the form of vaporization of water during the torrefaction. The moisture content was measured for the feedstock $\left(\dot{m}_{\text {moisture_in }}\right)$ and for the produced pellets $\left(\dot{m}_{\text {moisture_out }}\right)$.

\subsubsection{Mass Flow Rate}

Mass Flow Rate was determined by measuring the weight using load cells manufactured by Omega (Model: TWA5 series), placed under: (i) bottom hopper and (ii) pellet cooler. 
This allows the measure the net feed $\left(\dot{m}_{\text {netfeed_in }}\right)$ entering the reactor using Equation (5.1).

$$
\dot{m}_{\text {netfeed_in }}=\dot{m}_{\text {feed }_{\text {in }}}(1-\% \text { moisture_in })
$$

where $\dot{m}_{\text {feed_in }}$ is the feedstock entering the crammer, including the moisture, and $\%$ moisture_in is the measured \% of moisture in the feedstock. The final weight of produced pellets is measured using Equation (5.2) below,

$$
\dot{m}_{\text {netfeed_out }}=\dot{m}_{\text {feed_out }}(1-\% \text { moisture_out })
$$

where, $\dot{m}_{\text {feed_out }}$ is the feedstock in the storage unit after cooling and \%moisture_out is the measured $\%$ of moisture in the pellets.

The mass lost to the gas stream in the torrefaction was calculated using Equation (5.3),

$$
\text { Mass Loss }=1-\frac{\dot{m}_{\text {netfeed_out }}}{\dot{m}_{\text {netfeed_in }}}
$$

\subsubsection{Heat Content}

Heat Content was measured before and after torrefaction using a bomb calorimeter (Parr Instrument Company, Model 6100). A typical experiment involved a $1 \mathrm{~g}$ grounded mixed waste sample placed into a porcelain crucible. The bomb was then filled with oxygen $(\sim 400$ psi) and was submerged into a jacket filled with $2000 \mathrm{~g}$ of distilled water. The sample was ignited, and the heat released was measured in the form of the temperature difference of the water in the jacket before and after the combustion. The relation between the heat and chlorine (a crucial pollutant of interest for solid fuel users) content with respect to mass loss was studied $[9,10,25]$ and is summarized in the Results section. The mass loss and chlorine content of the same material torrefied in a batch reactor and the continuous pilotscale reactor are compared. Instead of temperature and time, mass loss is used as a universal variable $[9,10,25]$, to present the heat and chlorine content results for torrefaction. 


\subsubsection{Process Heat}

As electric heaters are used to heat the crammer and the reactor, the process heat utilized was measured by multiplying the percent duty cycle (defined as the time the heater is on over the cycle time) of the electric heaters and the maximum power of the heaters. This allowed the measurement of the process heat utilized by the crammer and the reactor at specific feed rates and temperatures. More details regarding the configuration of heaters are presented in the previous study $[26,31]$.

\subsubsection{Specific Electrical Energy (e)}

Specific Electrical Energy (e) can be defined using Equation (5.4),

$$
\text { Specific Electrical Energy }(e)=\frac{\text { Energy consumed }}{\text { Mass flow rate }(\dot{m})}
$$

where $e$ is the specific electrical energy required to drive each of the motors in the system (for the shredder, live bottom hopper, bucket elevators, crammer unit, reactor unit, and the cutter) and $\dot{m}$ is the mass flow rate through the equipment.

The live bottom hopper, the reactor, and the crammer are controlled using a variable frequency drive (VFD), which provides the required electrical information, and $\dot{E}$ was measured as a function of mass flow rate. The bucket elevators and the pellet cooler were not operated by VFDs, and a current transmitter was connected to their power supply for measuring their $e$. All the data was processed using a commercially available Series-P3 PLC (by Automation Direct) unit. The Indusoft V8.1 HMI software was used as the data acquisition system.

For the shredder, $e$ was measured using three different materials: (a) plastic films $(\rho=35.16$ $\left.\mathrm{kg} / \mathrm{m}^{3}\right)$, (b) mix fiber-plastic films $\left(\rho=76.17 \mathrm{~kg} / \mathrm{m}^{3}\right)$, and (c) mix fiber-plastic fines $\left(\rho=263.34 \mathrm{~kg} / \mathrm{m}^{3}\right)$ to understand the effect of density and different shredded materials. The

current was measured at every $0.25 \mathrm{~s}$. The mass flow rate was increased from $0 \mathrm{~kg} / \mathrm{h}$ to flood feed (max) for each material in increments of $30 \mathrm{~kg} / \mathrm{h}$. 
For the live bottom hopper, $e$ was measured using mixed fiber-plastic films $(\rho=76.17$ $\mathrm{kg} / \mathrm{m}^{3}$ ). The bottom hopper has been tested with several different materials during past experiments; the aim here is to demonstrate the consistent flow of material using the rotation frequency (rpm) vs. mass flow rate plot. To measure the specific energy consumption current was measured at a frequency of $4 \mathrm{~Hz}$. The mass flow rate was increased by increasing the frequency by $15 \mathrm{~Hz}$ intervals. All the experiments were triplicated.

For the reactor, $e$ was measured for fiber-plastic wastes in the earlier study [31]. It has been summarized in the result section. The details about measurements for crammer and other equipment are specified in the Results section.

\subsubsection{TEA Process Modeling for Commercial Scale}

The unit discussed in this study was designed and developed with commercialization in mind. To assess the economic viability of this technology, this study shows the TEA of the commercial system. The objective of the TEA is to assess the cost of a complete commercial-scale torrefaction plant, of 100,000 tonnes/yr, based on this pilot-scale technology.

\subsubsection{Process Modeling Boundary}

The system boundary for the TEA encompassed processes and equipment delineated in Figure 5.8. 


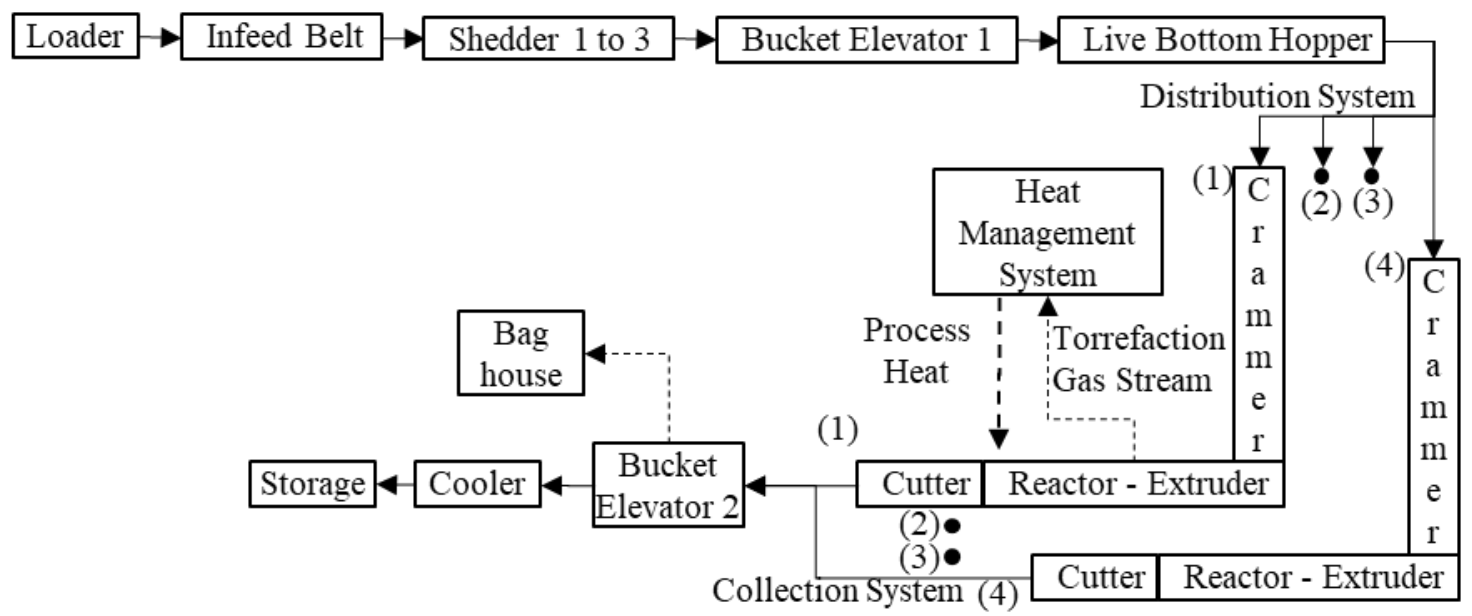

Figure 5.8. Simplified block diagram of the commercial scale torrefaction process.

A loader delivers waste materials to an infeed belt, following which the materials undergo size reduction using a three-stage shredding process. Using a live bottom hopper and bucket elevator, the materials are then conveyed to a system that distributes the material into four identical reactor-extruder-cutter setups that perform the torrefaction process and cut the extruded rods. Material coming through the four streams is combined using a pellet collection. A bucket elevator then conveys the material into a cooling process, following which the pre-processed materials are conveyed into storage. The system boundary for the TEA does not include building or land costs because they depend strongly on location.

\subsubsection{Cost Estimation Methodology}

The Idaho National Laboratory's (INL) Biomass Logistics Model (BLM) was used to estimate biomass feedstock logistics cost and energy consumption estimates. The BLM utilizes an approach that combines methodologies described by the American Society of Agricultural and Biological Engineers and Agriculture and Applied Economics [43, 44]. These methodologies encompass cost estimation procedures for agricultural machinery management ranging from equipment performance, field efficiency, repairs and maintenance, fuel and lubrication, insurance, housing and taxes, labor, as well as capital recovery calculations to compute the annualized value of capital $[43,44]$. The BLM analytic engine is built in the systems dynamic's software package Powersim ${ }^{\mathrm{TM}}$. The BLM 
is designed to work with various biofuel conversion platforms and accommodates a range of feedstock types.

In this study, we incorporated information from a collection of databases that provide a) engineering performance data for hundreds of equipment systems, b) spatially explicit labor cost datasets, and c) local tax and regulation data. We simulated the flow of feedstock through the entire supply chain while tracking changes in feedstock characteristics (i.e., moisture content, dry matter, ash content, and dry bulk density) and calculating cost and energy consumption [45]. Plant level costs, including installation, personnel (operators, engineers, and maintenance staff), and maintenance costs, are added to the per tonne cost of pre-processing estimated using equipment-related data, financial assumptions, and energy usage data.

Table 5.1. Operation parameters used for the TEA.

\begin{tabular}{lll}
\hline Operation Parameters & Value & Unit \\
\hline Annual production & 100,000 & dry tonnes/year \\
\hline Required raw materials & 151,976 & wet tonnes/year \\
\hline Annual operation days & 350 & days/year \\
\hline Daily operating hours & 24 & hrs/day \\
\hline Initial moisture content (W.B.) & $6 \%$ & \\
\hline Final moisture content (W.B.) & $0.1 \%$ & \\
\hline
\end{tabular}

\subsubsection{Assumption and Cost Breakdown}

It is assumed that this unit can produce 100,000 dry tonnes of torrefied materials annually, at $24 \mathrm{hr} /$ day and 350 days/yr. Operational parameters used in the TEA are listed in Table 5.1, whereas general and equipment-related assumptions based on teams' procurement and construction experience of similar-sized equipment are listed in Table 5.2. 
Table 5.2. General assumptions made for the TEA. Costs are presented in 2020\$.

\begin{tabular}{|c|c|c|}
\hline \multicolumn{3}{|l|}{ Interest Rate $=8 \%$} \\
\hline \multicolumn{3}{|l|}{ Insurance and Tax $=2 \%$} \\
\hline \multicolumn{3}{|c|}{ Maintenance $=3 \%$ of Capital and Installation costs } \\
\hline \multicolumn{3}{|c|}{ Electricity cost $=0.065 \$ / \mathrm{kWh}$} \\
\hline \multicolumn{3}{|c|}{ Natural gas cost $=7.55 \$ / \mathrm{MMBtu}$} \\
\hline \multicolumn{3}{|l|}{ Diesel cost $=2.55 \$ /$ gal } \\
\hline \multirow[t]{3}{*}{ Equipment } & Assumpti & \\
\hline & Machine & Purchase \\
\hline & Life & Price \\
\hline Loader & 6 years & $\$ 250,000$ \\
\hline Infeed Belt & 15 years & $\$ 50,000$ \\
\hline Three-stage Shredder & 5 years & $\$ 6,000,000$ \\
\hline Live Bottom Hopper & 15 years & $\$ 250,000$ \\
\hline Bucket Elevator & 15 years & $\$ 100,000$ \\
\hline Distributor & 15 years & $\$ 100,000$ \\
\hline Crammer and Torrefier & 15 years & $\$ 350,000$ \\
\hline Cutter & 10 years & $\$ 50,000$ \\
\hline Pellet Collector & 15 years & $\$ 200,000$ \\
\hline Cooler & 15 years & $\$ 100,000$ \\
\hline Conveyor to Storage & 15 years & $\$ 100,000$ \\
\hline Heat Management System & 15 years & $\$ 750,000$ \\
\hline Gauges and Analyzers & 15 years & $\$ 750,000$ \\
\hline
\end{tabular}

In this study, we incorporated information from a collection of databases that provide a) engineering performance data for hundreds of equipment systems, b) spatially explicit labor cost datasets, and c) local tax and regulation data. We simulated the flow of feedstock through the entire supply chain while tracking changes in feedstock characteristics (i.e., moisture content, dry matter, ash content, and dry bulk density) and calculating cost and 
energy consumption [45]. Plant level costs, including installation, personnel (operators, engineers, and maintenance staff), and maintenance costs, are added to the per tonne cost of pre-processing estimated using equipment-related data, financial assumptions, and energy usage data.

\subsubsection{LCA Process Modeling for Commercial Scale}

The goal and scope of the LCA portion of this study are to determine the environmental impacts of the torrefied product, produced in a full commercial-scale torrefaction plant, of 100,000 tonnes/yr, based on this technology. The environmental impacts can be compared to other studies of similar materials to compare the specific torrefaction processing or other intermediate products to illustrate the environmental tradeoffs associated with using this MSW-derived intermediate instead of fossil-based or bio-derived products. The environmental impacts of interest in this work are cumulative greenhouse gas (GHG) emissions, often described as the global warming potential of the process, and fossil energy demand. Wood chips from forest residues are used as a comparable product. The system boundary of the LCA study will include the loading and size reduction of the fiber-plastic waste before torrefaction, as described above, but does not include collection and transport because this collection and transport activity would still be occurring in the same fashion if the municipal solid waste was still being taken to a landfill. The LCA study will incorporate the impacts of diverting the fiber-plastic wastes from their prior fate, assumed to be disposed of in a landfill. Torrefaction operations and emissions are included in the system boundary. The waste contains a mixture of materials, some derived from biogenic carbon (such as paper, carton, cardboard), and some from fossil carbon (plastics). When accounting for GHG emissions of these bio-derived products, it is common to account for the carbon initially sequestered from the atmosphere when the bio-based products were created and then add in the emissions of carbon-containing gases released from the system along each subsequent process in the system boundary. We have done that carbon accounting here to facilitate a comparison with the forest-based wood chips, which are also bio-based and remove carbon from the atmosphere as they are made into an intermediate wood chip product. In the absence of this torrefaction system, the waste is assumed to be 
sent to a landfill, where a portion of the biogenic carbon is converted to methane and carbon dioxide, while a portion of the biogenic carbon is effectively sequestered in the landfill along with the fossil-derived carbon. When the waste avoids the landfill and is sent instead to the torrefaction system, avoidance of the landfill carbon emissions and biogenic carbon sequestration is also included in the system boundary of this LCA. Landfill carbon dynamics change over the landfill's life and vary considerably based on the landfill operating conditions and the surrounding climate. In the current study, landfill carbon assumptions were developed using the GREET 2019 spreadsheet LCA tool [46], using IPCC reference data and assuming an actively managed landfill with a landfill gas collection efficiency of $45 \%$, and a subsequent flaring of the collected gas at $95 \%$ conversion to $\mathrm{CO}_{2}$. The primary uses for the torrefied pellet would likely be as a feedstock for future processing into fuels and chemicals. For this study, we establish a functional unit for the LCA as the MJ of energy present in $1 \mathrm{~kg}$ of torrefied product (31.4 MJ). For the forest-derived wood chip comparison product, which has an assumed lower heating value of $16.3 \mathrm{MJ} / \mathrm{kg}$ [47], $1.93 \mathrm{~kg}$ of wood chips would be needed to provide the same level of service as $1 \mathrm{~kg}$ of torrefied pellet.

\subsubsection{Life Cycle Inventory Development:}

Below in Table 5.3 are the key life cycle inputs and key assumptions for the base case scenario and the forest-derived wood pellet comparison. LCA modeling was performed in the SimaPro modeling software, using the Ecoinvent version 3 database of inputs [48] to generate the entire life cycle inventory for each scenario. 
Table 5.3. Key life cycle input data and assumptions.

\begin{tabular}{|c|c|c|c|}
\hline Item & $\begin{array}{l}\text { Baseline } \\
\text { Scenario }\end{array}$ & $\begin{array}{l}\text { Wood chip } \\
\text { comparison }\end{array}$ & Comments \\
\hline $\begin{array}{l}\text { Material } \\
\text { composition }\end{array}$ & $\begin{array}{l}57 \% \text { Paper } \\
(43.5 \% \quad \text { C), } \\
38 \% \quad \text { Plastic } \\
(60 \% \quad \text { C), } 5 \% \\
\text { Ash }(0 \% \text { C) }\end{array}$ & $\begin{array}{l}100 \% \text { wood } \\
(50 \% \mathrm{C})\end{array}$ & 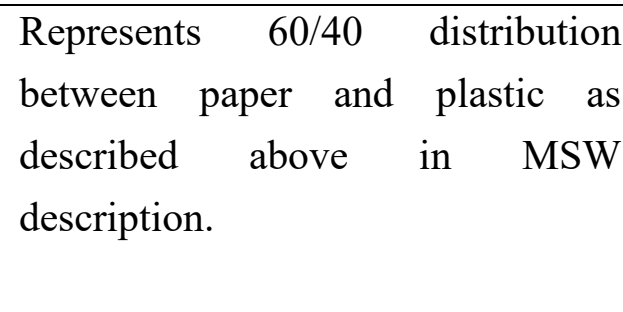 \\
\hline $\begin{array}{l}\text { Lower } \\
\text { heating } \\
\text { value of } \\
\text { product }\end{array}$ & $31.4 \mathrm{MJ} / \mathrm{kg}$ & $\begin{array}{l}16.3 \mathrm{MJ} / \mathrm{kg} \\
\text { dry chips }\end{array}$ & $\begin{array}{l}\text { Based on the initial composition of } \\
\text { MSW, with } 18 \% \text { energy loss and } \\
30 \% \text { mass loss during torrefaction. }\end{array}$ \\
\hline $\begin{array}{l}\text { Fuel } \\
\text { consumption }\end{array}$ & $\begin{array}{ll}0.226 & \mathrm{MJ} / \mathrm{kg} \\
\text { product } & \end{array}$ & $\begin{array}{l}0.641 \mathrm{MJ} / \mathrm{kg} \\
\text { dry product }\end{array}$ & $\begin{array}{l}\text { MSW: Based on fuel consumption } \\
\text { of } 4 \text { loaders for } 8400 \mathrm{hrs} / \mathrm{yr} \text { at } 4.7 \\
\text { gals/hr; Wood chips: Based on } \\
\text { collection, processing, and transport } \\
\text { assumptions from [49] }\end{array}$ \\
\hline $\begin{array}{l}\text { Electricity } \\
\text { consumption }\end{array}$ & $\begin{array}{ll}0.23 & \mathrm{MJ} / \mathrm{kg} \\
\text { product } & \end{array}$ & 0 & $\begin{array}{l}\text { Based on unit operations in } \\
\text { Table 5.7. The energy consumption } \\
\text { by equipment type is presented in } \\
\text { Table 5.7. Shredding and Crammer- } \\
\text { Torrefaction units are the largest } \\
\text { energy consumers. }\end{array}$ \\
\hline $\begin{array}{l}\text { Natural Gas } \\
\text { consumption }\end{array}$ & $\begin{array}{ll}0.0006 & \mathrm{MJ} / \mathrm{kg} \\
\text { product } & \end{array}$ & 0 & $\begin{array}{l}\text { For periodic torrefaction startup, } \\
\text { averaged over the year of operation }\end{array}$ \\
\hline $\begin{array}{l}\text { Landfilling } \\
\text { assumptions } \\
\text { (prior fate) }\end{array}$ & $\begin{array}{l}19.3 \mathrm{~g} \mathrm{CH} / \text { dry } \\
\mathrm{kg} \mathrm{MSW}, 231 \mathrm{~g} \\
\mathrm{CO}_{2} / \text { dry } \quad \mathrm{kg} \\
\mathrm{MSW}, \\
139 \mathrm{~g} \text { biogenic C } \\
\text { sequestered/dry } \\
\mathrm{kg} \mathrm{MSW}\end{array}$ & $\mathrm{N} / \mathrm{A}$ & $\begin{array}{l}\text { Disposal to the landfill with } 45 \% \\
\text { landfill gas collection efficiency, } \\
\text { flaring of LFG at } 95 \% \text { efficiency - } \\
\text { these carbon flows are avoided as a } \\
\text { result of MSW diversion to } \\
\text { torrefaction system [46] }\end{array}$ \\
\hline
\end{tabular}


Electricity impacts were generated by modifying the standard US electricity eco profile for medium-voltage electricity present within Ecoinvent by updating it to include the most current distribution of the electricity grid mix from the U.S. EPA E-grid database [50], which consists of $23.3 \%$ coal, $38.4 \%$ natural gas, $19.6 \%$ nuclear, $6.8 \%$ hydroelectric, $7.1 \%$ wind, and other minor components as the most current U.S. reference case.

This modification resulted in an electricity mix that had a $\sim 40 \%$ lower GHG emissions profile than the standard Ecoinvent version 3 data with reference data from just seven years earlier (2019 vs. 2012), which is an impressive change in a relatively short period. Carbon losses during torrefaction processing were estimated to be $8 \%$ of dry MSW weight, based on prior modeling work in this area [51].

\subsubsection{Life Cycle Impact Assessment}

Life cycle impacts were assessed within SimaPro using the IPCC 100a method to assess the global warming potential of the scenarios, expressed as $\mathrm{kg}$ of $\mathrm{CO}_{2}$-equivalent emissions from all climate-active gases including $\mathrm{CO}_{2}, \mathrm{CH}_{4}$, refrigerants, and others. The cumulative energy demand method was used to determine the nonrenewable fossil energy demand of the scenarios in MJ fossil energy per kg of product.

\subsection{Results and Discussion}

\subsection{Pilot Scale System}

\subsubsection{Shredding}

The energy required to operate the shredder, which operates at low shear, was measured for various materials at various densities. Three different materials: plastic films ( $\rho=35.16$ $\left.\mathrm{kg} / \mathrm{m}^{3}\right)$, mix fiber-plastic material $\left(\rho=76.17 \mathrm{~kg} / \mathrm{m}^{3}\right)$, and mix fiber-plastic $\left(\rho=263.34 \mathrm{~kg} / \mathrm{m}^{3}\right)$ were tested. Most plastic and fiber wastes in all the different materials are films with thickness typically ranging between $0.05-2 \mathrm{~mm}$. The specific electrical energy consumed as a function of mass flow rate allows us to calculate the shredding cost for the shredder's operation. Figure 5.9(a) shows the specific energy consumed by the shredder vs. the volume flow rate, with the clear observation that the lower the density, the higher the 
electric specific energy consumption. It also implies that the lower the density, the larger shredder required for a given mass feed rate. Figure 5.9(b) shows the specific energy consumed by the shredder vs. the mass flow rate, with the clear observation that it is not dependent on density; the specific energy consumption was similar across all the materials: it reduced from $100 \mathrm{kWh} /$ tonne to $10 \mathrm{kWh} /$ tonne.
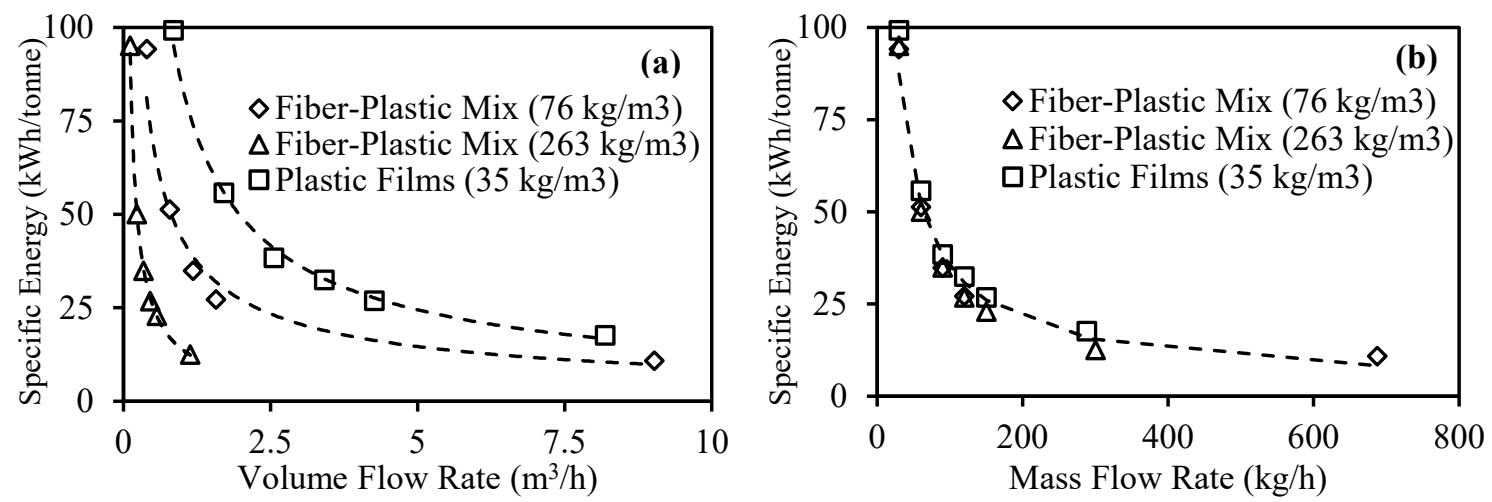

Figure 5.9. (a) Specific energy vs. volume flow rate for the stage III shredder; (b) Specific energy vs. mass flow rate for the stage III shredder.

\subsubsection{Live Bottom Hopper}

For the live bottom hopper, the key aim is to provide consistent dosing of the material. The rheological nature of the feedstock has a strong influence on the consistent operation of the live bottom hopper and its efficiency for accurate dosing. Klinger et al. and Idaho National Lab [41,52-54] thoroughly studied flow models, both computationally and experimentally, for biomass-based materials supported by measurements particle density, surface friction, elastic modulus, morphology (size and shape), internal friction, hopper wall friction angles, and hopper width. Assessing all these materials and the rheological properties of our wastes is difficult; however, we realized through numerous experimentations that the type of shredder and shape of the shredded material has the strongest influence on the flowability of the material. As indicated above, low shear shredders appear to generate flakes that flow better than high shear shredders. 
Further, stripe-shaped flakes were found to cause bridging, whereas square-shaped flakes prevent bridging. The angle of the walls of the feeder is also critical. Our feeder was designed and constructed following these experiments and findings. The mass flow rate of a specific material vs. the rotation frequency was found to be an excellent indicator of the suitability of the feeder and the bridging propensity. Screw augers operating at flood-fed conditions are outstanding feeders providing a very accurate mass flow rate, provided no bridging occurs.

Figure 5.10(a) shows the mass flow rate of striped shaped flakes (3-mm wide and 12-mm long) produced from our shredder when the material was shredded in a single pass. Clearly, the mass flow rate is irregular and cannot be used for conveying and dosing. When the striped material was passed a second time through the shredder, square flakes were produced (3-mm by $3-\mathrm{mm}$ as shown in the inset) were produced; the mass flow rate of this material is depicted in Figure 5.10(b), showing a linear increase with the rotation frequency, with clear, consistent material flow.
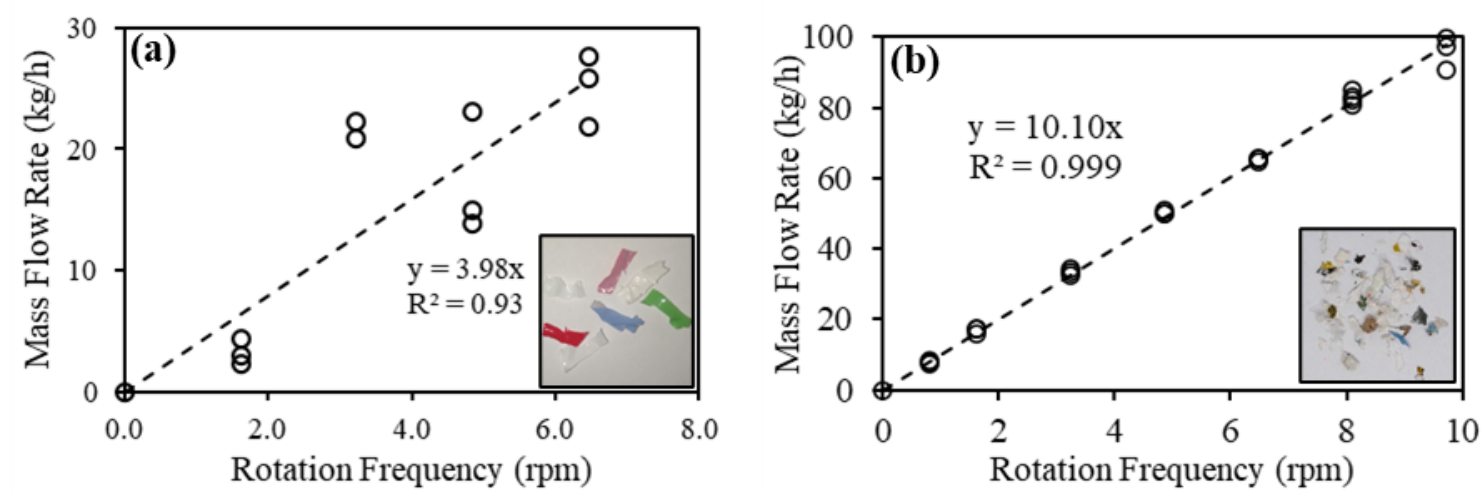

Figure 5.10. Mass flow rate vs. rotation speed of live bottom hopper shaft for (a) bridging material; and (b) non-bridging material. The inset in (a) shows the strip-shaped flakes material with a tendency to bridge, and the inset in (b) shows the square-shaped flakes. 


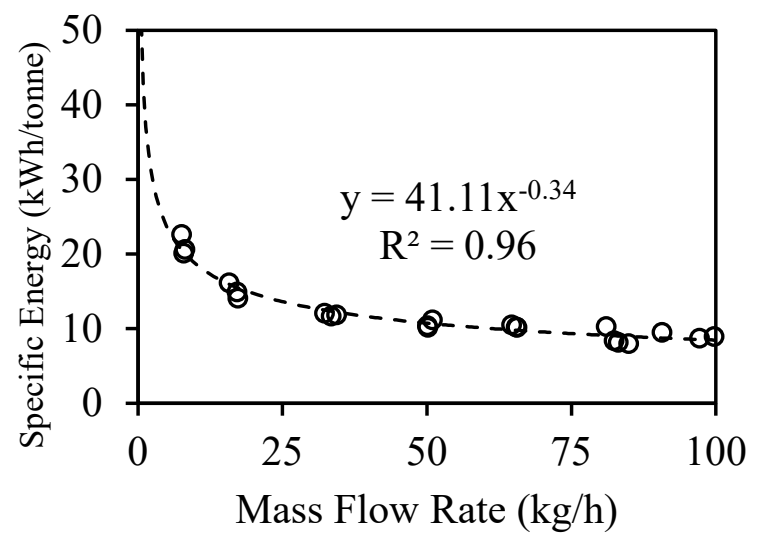

Figure 5.11. Specific electrical energy (e) vs. mass flow (m) rate for live bottom hopper.

Figure 5.11 shows the specific energy consumption of the live bottom hopper decreasing with the increase in the mass flow rate. For mixed fiber-plastic material with a density of $149 \mathrm{~kg} / \mathrm{m}^{3}$ that was shredded to the size of 3-mm by 3-mm, Equation (5.5) can calculate the specific energy:

$$
e=41.11 \times \dot{\mathrm{m}}^{-0.34}
$$

where $e$ is the specific energy consumed by the live bottom hopper, and $\dot{m}$ is the mass flow rate of material from the live bottom hopper. The behavior of the specific energy for the live bottom hopper decreases with mass flow rate; for example, for a 1 tonne/hr mass flow rate, the specific energy is $3.9 \mathrm{kWh} /$ tonne.

\subsubsection{Crammer}

For the crammer, estimated electrical consumption (based on experimental runs) for a material compression factor of $\sim 17$ is at $40 \mathrm{kWh} /$ tonne, and the heating requirement is 50 $\mathrm{kWh} /$ tonne. However, it is essential to note that the crammer load, and as a result, the specific electrical energy consumption is very sensitive to the rotation frequency of the crammer and the temperature setpoint. $e$ vs. rotation frequency and $e$ vs. temperature have a strong non-linear correlation. During the experimentation, a sudden drop of load and energy consumption of $\sim 50 \%$ is observed after the crammer frequency exceeds $10 \mathrm{rpm}$ for 60:40 fiber plastic blend materials at $200^{\circ} \mathrm{C}$. This can be attributed to the factors like 
change in viscosity and several rheological factors. Thus, we believe the complex nature of the crammer behavior deserves a separate study to quantify the energy consumption relationship. However, to understand that average energy consumption at normal operating conditions is at the average value of $40 \mathrm{kWh} /$ tonne reported above can be used.

The crammer temperature was selected from the DSC trace measured for the material used and shown in Figure 5.12. The peaks represent an endothermic process attributed to phase transitions. The first peaks at around $100-125^{\circ} \mathrm{C}$ are attributed to polyethylene (PE) melting; the peak around $170^{\circ} \mathrm{C}$ is attributed to the melting of polypropylene (PP); these two plastics constitute the majority of the plastic waste. The peal around $250^{\circ} \mathrm{C}$ is attributed to polyethylene terephthalate (PET) melting. We selected to operate the crammer at 180$190^{\circ} \mathrm{C}$ as both PE and PP melted, and PET can be dissolved into them, thus creating a flowing paste.

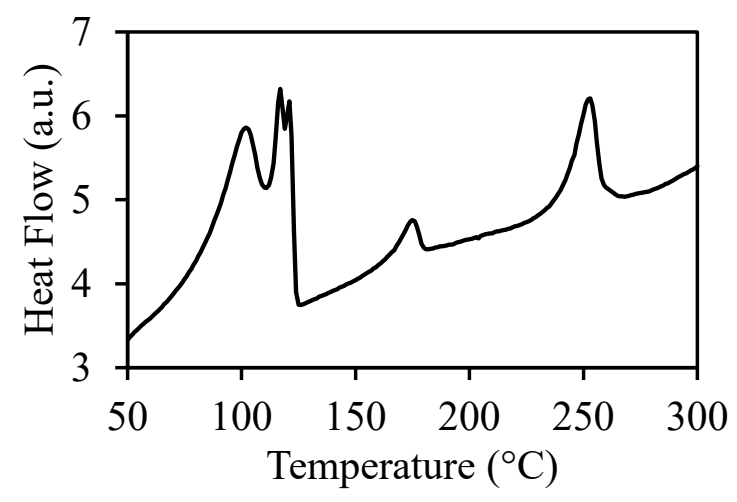

Figure 5.12. DSC of the fiber-plastic waste blend.

\subsubsection{Torrefaction-Extrusion Reactor}

For the reactor, the specific mechanical energy of $335 \mathrm{kWh} /$ tonne is required to convey and extrude the material at an average mass flow rate of $9 \mathrm{~kg} / \mathrm{h}$; it drops to $94 \mathrm{kWh} /$ tonne at 50 $\mathrm{kg} / \mathrm{h}$, further drops to $12 \mathrm{kWh} /$ tonne at 1 tonne/hr. The correlation between the specific energy required and mass flow rate is presented in Equation (5.6).

$$
e=1370 \times \dot{\mathrm{m}}^{-0.684}
$$

An additional $125 \mathrm{kWh} /$ tonne of thermal energy is required to heat the material to $350^{\circ} \mathrm{C}$. 


\subsubsection{Bucket Elevators}

For the bucket elevators, the energy consumption was measured at $0.36 \pm 0.04 \mathrm{kWh} /$ tonne for the pellets with a bulk density of $500 \mathrm{~kg} / \mathrm{m}^{3}$.

\subsubsection{Cutter}

For the cutter, the average energy consumption is $0.07 \mathrm{kWh}$, with maximum consumption at $0.85 \mathrm{kWh}$. The power consumption is a function of the rotation frequency, which translates to pellet length and the type of material.

\subsubsection{Mass Balance}

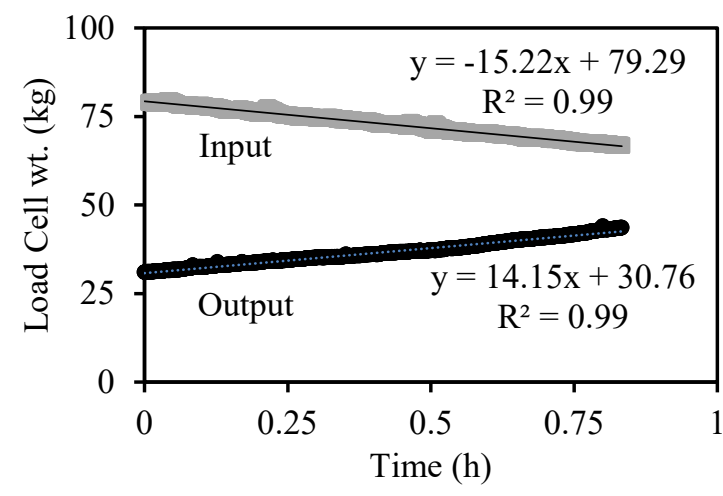

Figure 5.13. Typical load cell measurements show mass input at the live bottom hopper and mass output at the pellet cooler. Mass loss can be calculated from the difference in slopes ( $7 \%$ for the example above).

As described earlier, the mass balance is a tool to calculate mass lost in the torrefaction process. Figure 5.13 shows the mass flow rate to the system measured by the load cells from the live bottom hopper and the output flow rate shown by the load cells under the pellet cooler. The figure shows that the slope of the plot of respective measurements represents the mass flow rate in and out of the system. The difference in their slopes denotes the mass lost during the torrefaction at the set conditions.

To validate the accuracy of the load cell-based mass balance measurements and resulting mass loss calculation, the mass entering and exiting the system was measured using a 
manual batch sampling process. This process involved controlled feeding of feedstock using pre-weighed batched of $\sim 2-3 \mathrm{~kg}$ at regular time intervals of 3-5 minutes. The produced pellets were then collected with same time interval ranging between 3-5 minutes. These results were repeated for 30-60 min to allow multiple iterations. The results obtained using this process matched with results from the load cell measurement method.

\subsubsection{Heat and Chlorine Contents}

Figure 5.14 shows the heat and chlorine contents of the $60 \%$ fiber and $40 \%$ plastic material from a lab-scale batch setup and pilot-scale continuous setup. It can be observed that instead of the specific temperature and residence time combination, mass loss can be used as a universal variable to quantify the heat and chlorine content of the material.

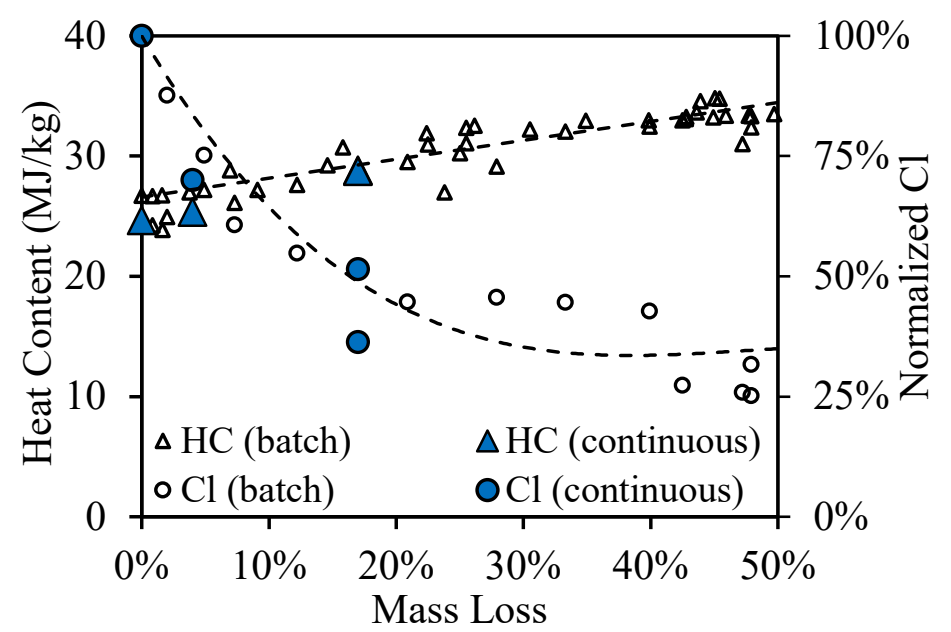

Figure 5.14. Heat Content vs. Mass Loss and Normalized $\mathrm{Cl}$ content vs. Mass Loss using batch and continuous reactor setup.

It can be observed that with the increase in the mass loss from $0 \%$ to $50 \%$, the heat content increases from $\sim 25 \mathrm{MJ} / \mathrm{kg}$ to $\sim 34 \mathrm{MJ} / \mathrm{kg}$ while the $\mathrm{Cl}$ content decreases by up to $\sim 70 \%$. The ppm levels vary batch to batch; however, the $\mathrm{Cl}$ removal is independent of the initial ppm levels of $\mathrm{Cl}$. Also, the $\mathrm{Cl}$ removal is a function of mass, and the type of reactor (batch vs. continuous) does not play a major role. Using this relationship expressed in Figure 5.14, mass loss can be used as an indicator to derive the properties of the produced pellets and 
vice-versa. In other words, the mass balance is a simple method of mass loss measurement that can be used for online calculation of the properties of the produced pellets.

\subsubsection{Commercial Scale System TEA}

Details of the above-described pilot-scale system can be used for the techno-economic and lifecycle assessments. Based on the assumptions and machine performance, the system's total cost is estimated to be $\$ 55.28$ /dry tonne (2020\$), which includes preprocessing costs at the equipment level and other plant-level costs comprising installation, labor, and maintenance. For the complete pre-processing and torrefaction stage, the cost breakdown is presented. It indicates that the most important costs are attributable to the crammer and torrefier ( $\$ 10.08 /$ dry tonne) and the three-stage shredder $(\$ 8.38 /$ dry tonne). The crammer and torrefier contribute $41.55 \%$, and the three-stage shredder contribute to $34.55 \%$ of the preprocessing and torrefaction stage cost.

Table 5.4. Breakdown of costs for fiber-plastic pre-processing and torrefaction unit operations.

\begin{tabular}{|c|c|c|}
\hline Equipment & Fuel/Unit & Value \\
\hline Loader & Diesel (gal/dry tonne) & 0.45 \\
\hline Infeed Belt & Electricity (kWh/dry tonne) & 0.38 \\
\hline Three Stage Shredder & Electricity (kWh/dry tonne) & 33.06 \\
\hline Live Bottom Hopper & Electricity (kWh/dry tonne) & 0.38 \\
\hline Bucket Elevator 1 & Electricity (kWh/dry tonne) & 0.38 \\
\hline Distributor & Electricity (kWh/dry tonne) & 0.38 \\
\hline Crammer and Torrefier ${ }^{\mathrm{a}}$ (4 units) & Electricity (kWh/dry tonne) & 33.06 \\
\hline Cutter (4 units) & Electricity (kWh/dry tonne) & 0.38 \\
\hline Pellet Collector & Electricity (kWh/dry tonne) & 0.55 \\
\hline Bucket Elevator 2 & Electricity (kWh/dry tonne) & 0.38 \\
\hline Cooler & Electricity (kWh/dry tonne) & 0.77 \\
\hline Conveyor to Storage & Electricity (kWh/dry tonne) & 0.38 \\
\hline Heat Management System & Electricity (kWh/dry tonne) & 0.38 \\
\hline
\end{tabular}


At the plant level, annual labor costs ( $\$ 16.62 /$ dry tonne) and installation costs $(\$ 9.50 /$ dry tonne) are the largest contributors to total costs presented in Table 1.2. Installation costs include costs incurred for installation, testing, commissioning, operators' training, costs incurred for engineering designs, and a $10 \%$ contingency reserve.

Table 5.5. Breakdown of total costs at the plant. Costs are reported in $2020 \$$.

\begin{tabular}{ll}
\hline & Cost (\$/dry tonne) \\
\hline Preprocessing cost per dry tonne (Capital) & $\$ 24.25$ \\
\hline Installation cost per dry tonne & $\$ 9.50$ \\
\hline Labor cost per dry tonne & $\$ 16.62$ \\
\hline Maintenance cost per dry tonne & $\$ 4.91$ \\
\hline Total cost per dry tonne & $\$ \mathbf{\$ 5 . 2 8}$ \\
\hline
\end{tabular}

Energy requirements can be upscaled well using the various specific energy correlations found in the sections above. The capital costs are estimated from the pilot-scale costs and the experience the Michigan Tech teams acquired when building an 80,000 tonnes/yr torrefaction facility [55]. Energy consumption by fuel types was estimated to enable LCA and is presented in Table 5.6. The system is designed to be self-sustaining, whereby the gas stream from the torrefaction process is utilized in the heat management system. However, approximately $48 \mathrm{MMBtu}$ of natural gas is used in the start-up phase.

Table 5.6. Energy consumption by fuel type.

\begin{tabular}{ll}
\hline Fuel Type & MMBtu/dry tonne \\
\hline Diesel & 0.0624 \\
\hline Electricity & 0.2407 \\
\hline Natural gas & 0.0006 \\
\hline
\end{tabular}


Table 5.7. Energy consumption by equipment type.

\begin{tabular}{lll}
\hline Equipment & Fuel/Unit & Value \\
\hline Loader & Diesel (gal/dry tonne) & 0.41 \\
\hline Infeed Belt & Electricity (kWh/dry tonne) & 0.35 \\
\hline Three Stage Shredder & Electricity (kWh/dry tonne) & 30.0 \\
\hline Live Bottom Hopper & Electricity (kWh/dry tonne) & 0.35 \\
\hline Bucket Elevator 1 & Electricity (kWh/dry tonne) & 0.35 \\
\hline Distributor & Electricity (kWh/dry tonne) & 0.35 \\
\hline Crammer and Torrefier (4 units) & Electricity (kWh/dry tonne) & 30.0 \\
\hline Cutter (4 units) & Electricity (kWh/dry tonne) & 0.35 \\
\hline Pellet Collector & Electricity (kWh/dry tonne) & 0.50 \\
\hline Bucket Elevator 2 & Electricity (kWh/dry tonne) & 0.35 \\
\hline Cooler & Electricity (kWh/dry tonne) & 0.70 \\
\hline Conveyor to Storage & Electricity (kWh/dry tonne) & 0.35 \\
\hline Heat Management System & Electricity (kWh/dry tonne) & 0.35 \\
\hline
\end{tabular}

The energy consumption by equipment type is presented in Table 5.7. It can be observed that Shredding and Crammer-Torrefaction units are the largest energy consumers.

\section{Sensitivity Analysis for TEA}

The crammer-torrefier unit contributes nearly $42 \%$ of total pre-processing costs, we performed sensitivity analysis on three parameters price, energy usage, and throughput impacting this equipment to evaluate its influence at a system level. Under the base case, the parameters are as follows: energy usage $(33.07 \mathrm{kWh} /$ tonne $)$, the purchase price $(\$ 350,000)$, throughput (4 crammer-torrefier units). We evaluated pre-processing costs wherein the parameters are $\pm 25 \%$ compared to the base case assumptions. Additionally, changes in the number of units of crammer-torrefier are accompanied by a change in the number of cutters as these two pieces of equipment are used sequentially as per the system design. The results are presented in Table 5.8. 
Table 5.8. Sensitivity Analysis for Crammer-Torrefier Unit.

\begin{tabular}{llll}
\hline \multicolumn{4}{l}{ Total Cost* $\mathbf{\text { ( } / \text { dry tonne) }}$} \\
\hline & $\begin{array}{l}\text { Energy } \\
\text { Usage }\end{array}$ & $\begin{array}{l}\text { Equipment Purchase } \\
\text { Price }\end{array}$ & Throughput \\
\hline $25 \%$ below baseline & $\$ 53.13$ & $\$ 54.90$ & $\$ 58.24$ \\
\hline Baseline & $\$ 55.28$ & $\$ 55.28$ & $\$ 55.28$ \\
\hline $25 \%$ above Baseline & $\$ 57.43$ & $\$ 55.64$ & $\$ 52.33$ \\
\hline
\end{tabular}

*Costs are reported in $2020 \$$.

\subsubsection{Commercial Scale System LCA}

Life cycle assessment results are shown below in Table 5.9 for GHG emissions and fossil energy demand of the torrefied pellet product and the wood chip comparison. Large $\mathrm{CO}_{2}$ sequestration credits are observed for both products due to the large amount of biogenic carbon currently sequestered in the product. The credit is larger for each $\mathrm{kg}$ of torrefied pellet than for each $\mathrm{kg}$ of wood chip $(-1.98 \mathrm{~kg} \mathrm{CO} 2 \mathrm{eq} / \mathrm{kg}$ pellet vs. $-1.83 \mathrm{~kg} \mathrm{CO} 2 \mathrm{eq} / \mathrm{kg}$ wood chip) despite the higher proportion of biogenic carbon in the wood chips, because in the torrefied product case we are also accounting for the avoided emissions that would have occurred if the MSW feedstock had been disposed of in a landfill, most notably the methane emissions that are a particularly potent greenhouse gas. Emissions of $\mathrm{CO}_{2}$ during the torrefaction process are included and are a key component of the overall emissions profile, contributing roughly 20 times more to the global warming potential of the torrefied pellet than either the diesel fuel or electricity used in materials handling and pre-processing. The cumulative result is still negative for the torrefied product because the biogenic carbon credit and avoided landfill emissions are larger than process emissions at this intermediate stage of the overall use of this material. If the torrefied product were to be converted to a fuel product and combusted, those process and combustion emissions would have to be counted towards the full life cycle emissions of the final product.

Similarly, for the wood chip product, the emissions resulting from processing are important but still overcome by the significant biogenic carbon credit for wood sequestration of atmospheric carbon. 
Table 5.9. LCA results for torrefaction system compared to wood chips.

\begin{tabular}{lccc}
\hline Scenario & $\begin{array}{c}\text { Torrefie } \\
\text { d Pellet }\end{array}$ & $\begin{array}{l}\text { Wood } \\
\text { Chip }\end{array}$ & Notes \\
\hline Global Warming Potential (in kg CO2 & eq/kg product) & \\
\hline $\begin{array}{l}\text { Avoided emissions and } \\
\text { biogenic carbon credit }\end{array}$ & -1.98 & -1.83 & \\
\hline Process emissions & & & \\
\hline Total per kg product & 0.468 & 0.053 & a \\
\hline $\begin{array}{l}\text { Total on an equivalent functional unit } \\
\text { basis (per 31.4 MJ product) }\end{array}$ & -1.51 & -1.78 & \\
\hline
\end{tabular}

\begin{tabular}{llll}
\hline \multicolumn{4}{l}{ Fossil Energy Demand (MJ /kg product) } \\
\hline Total per kg product & 0.73 & -1.83 & \\
\hline Total on an equivalent functional unit & $0.73 \mathrm{MJ}$ & $1.59 \mathrm{MJ}$ & \\
basis (per 31.4 MJ product) & & \\
\hline
\end{tabular}

a(i) Torrefied pellet: $90 \%$ due to torrefaction emissions, $6 \%$ electricity, $4 \%$ diesel.

(ii) Wood chips: $42 \%$ collection/processing, $58 \%$ transport

b(i) Torrefied pellet: $56 \%$ electricity, $44 \%$ diesel. (ii) Wood chips: $42 \%$ collection/processing, $58 \%$ transport.

Importantly, because $1.93 \mathrm{~kg}$ of wood chips are required for each $\mathrm{kg}$ of torrefied product to account for the equivalent functional unit (31.4 MJ of each product), this negative result in an intermediate stage assessment of the global warming becomes magnified in comparison to the torrefied product. When both products are converted to fuels and combusted, this apparent difference in the environmental profile may be reduced as the emissions are accounted for in all life cycle stages. The comparison is somewhat reversed when considering the fossil energy demand of both products. Fossil energy demand for the torrefied pellet $(0.73 \mathrm{MJ} / \mathrm{kg}$ pellet) is due to the use of electricity (56\%) and diesel fuel (44\%) during the material handling prior to torrefaction. This impact is lower than the fossil energy demand associated with collecting and transporting wood chips $(0.83 \mathrm{MJ} / \mathrm{kg}$ wood chips), and this difference is again magnified when the products are put on an equivalent 
basis with the same functional unit. Wood collection and transport are highly sensitive to the specifics of the operation, including the equipment mix used and the transport distance [56], so specific inputs related to a particular operation would make the comparison useful when assessing the relative merits of one feedstock over another. However, in general, it appears that the MSW-derived torrefied pellet can have a favorable profile when compared to biogenic feedstocks.

\subsubsection{Sensitivity Analysis for LCA}

Table 5.10 presents the sensitivity analysis for the LCA. The environmental impacts of the MSW-derived pellet are expected to be sensitive to both the material composition of the MSW and the assumptions made about the prior fate of the MSW. The mix of biogenic vs. fossil components of the MSW, as well as the particular types of biogenic materials in the MSW, will have an impact on the ultimate composition and energy content of the processed pellet, as well as a significant impact on the carbon dynamics within the landfill, which will then impact the process life cycle when avoided landfill emissions are accounted for. Similarly, the climatic conditions of the landfill and the effective management of the landfill in terms of collection of landfill gas and treatment of that gas through flaring or energy generation will impact the landfill emissions that are ultimately avoided when MSW is instead diverted to the torrefaction process. Although a majority of large landfills in the U.S. now have some type of landfill gas collection system, many small landfills exist throughout the U.S. and elsewhere where minimal or no landfill gas collection is performed, and even sound landfill gas collection systems cannot prevent fugitive emissions of methane from occurring over time. As an illustration of these two points, the following scenarios were assessed to understand the GHG emissions impact from even small changes in these key assumptions. The LCA results for these scenarios indicate that both of these assumptions are important. The results appear to be highly sensitive to changing MSW composition for the reasons mentioned above. Additional cases of different MSW compositions will be investigated in future work to verify the processing outcomes of these different MSW streams after torrefaction and to understand the potential differences in their dynamics with a landfill to determine the net effect of MSW diversion. 
Table 5.10. LCA scenario analysis results.

Scenario

Global Warming Potential

(kg CO2eq / kg product)

Base case: $45 \%$ LFG collection efficiency, -1.512

Composition: 57\% Paper, 38\% Plastic, 5\% Ash

Lower LFG collection efficiency (30\% vs. $45 \%) \quad-1.71$ (13\% decrease)

Higher LFG collection efficiency (60\% vs. $45 \%) \quad-1.31$ (13\% increase)

\subsection{Conclusion}

Pilot-scale torrefaction technology integrating paddles and extrusion for solid fuel pellet production is presented. This technology resolves biomass-associated challenges like selfheating, difficulty in biomass pelletization, and cost. It also addresses challenges related to the waste fiber-plastic, such as inconsistency, waste-stream heterogeneity, and conveying issues. The produced pellets have low cost, better uniformity, high heating value, and low environmental impact. TEA demonstrates that the baseline cost of pre-processing fiberplastic wastes is estimated at $\$ 55.28 /$ dry tonne (2020\$). The crammer-torrefier unit accounts for $\$ 10.08 /$ dry tonne (nearly $42 \%$ ) of the pre-processing costs. Under a range of scenarios, wherein important parameters are varied, pre-processing costs range between $\$ 52.33$ dry tonne and $\$ 58.24 /$ dry tonne. The torrefaction system's life cycle assessment studies illustrate that the pellets can be produced with a net negative global warming potential at this intermediate stage of the life cycle, with a low fossil energy demand relative to a wood chip comparison project. Specific carbon dynamics are highly sensitive to fiber-plastic waste composition and assumptions regarding the prior fate of these materials in the landfill, which will be the subject of future study. 


\section{Author Contribution}

Shreyas S. Kolapkar; Stas Zinchik; Ezra Bar-Ziv: Pilot unit development; Investigation, Methodology, Writing- Original draft preparation, review, and editing. Pralhad Burli; Yingqian Lin; Damon S. Hartley; Jordan Klinger: TEA; Writing- original draft for TEA. Robert Handler: LCA; Writing- Original draft for LCA.

\section{Acknowledgment}

We acknowledge support from (1) NSF-PFI Award \# 1827364, (2) INL Award number \#209856, (3) MTRAC Award \# RC-109248-MTU-Bar-Ziv-2019. We would like to thank Dr. Armando G. McDonald for the DSC analysis.

\subsection{References}

[1] S. Kaza, L.C. Yao, P. Bhada-Tata, F. Van Woerden, What a Waste 2.0: A Global Snapshot of Solid Waste Management to 2050, 2018.

[2] G. Sauve, K. Van Acker, The environmental impacts of municipal solid waste landfills in Europe: A life cycle assessment of proper reference cases to support decision making, J Environ Manage, 261 (2020) 110216. https://doi.org/10.1016/j.jenvman.2020.110216

[3] M.R. Mendes, T. Aramaki, K. Hanaki, Comparison of the environmental impact of incineration and landfilling in Sao Paulo City as determined by LCA, Resour Conserv Recy, 41 (2004) 47-63. https://doi.org/10.1016/j.resconrec.2003.08.003

[4] U.S. Environmental Protection Agency. Sustainable Materials Management: NonHazardous Materials and Waste Management Hierarchy | Sustainable Materials Management. $\quad$ https://www.epa.gov/smm/sustainable-materials-management-nonhazardous-materials-and-waste-management-hierarchy, 2020. (accessed September 4, 2021). 
[5] M. Nelles, J. Grünes, G. Morscheck, Waste Management in Germany - Development to a Sustainable Circular Economy?, Procedia Environmental Sciences, 35 (2016) 6-14. https://doi.org/10.1016/j.proenv.2016.07.001

[6] T.G. Townsend, S. Laux, M. Anshassi, Florida Solid Waste Management: State of the State, in, Gainesville, FL, 2018.

[7] CalRecycle, State of Disposal and Recycling in California for Calendar Year 2016 (DRRR-2017-1612), in, State of California: Department of Resources and Recovery, 2017.

[8] A.L. Brooks, S. Wang, J.R. Jambeck, The Chinese import ban and its impact on global plastic waste trade, Sci Adv, 4 (2018). https://doi.org/10.1126/sciadv.aat0131

[9] Z. Xu, S.S. Kolapkar, S. Zinchik, E. Bar-Ziv, L. Ewurum, A.G. McDonald, J. Klinger, E. Fillerup, K. Schaller, C. Pilgrim, Bypassing Energy Barriers in Fiber-Polymer Torrefaction, Frontiers in Energy Research, 9 (2021). https://doi.org/10.3389/fenrg.2021.643371

[10] Z. Xu, S. Zinchik, S.S. Kolapkar, E. Bar-Ziv, T. Hansen, D. Conn, A.G. McDonald, Properties of Torrefied U.S. Waste Blends, Frontiers in Energy Research, 6 (2018). https://doi.org/10.3389/fenrg.2018.00065

[11] M.J. Prins, K.J. Ptasinski, F.J.J.G. Janssen, More efficient biomass gasification via torrefaction, Energy, 31 (2006) 3458-3470. https://doi.org/10.1016/j.energy.2006.03.008

[12] Q. Chen, J.S. Zhou, B.J. Liu, Q.F. Mei, Z.Y. Luo, Influence of torrefaction pretreatment on biomass gasification technology, Chinese Science Bulletin, 56 (2011) 1449-1456. https://doi.org/10.1007/s11434-010-4292-z 
[13] Z. Chen, M. Wang, E. Jiang, D. Wang, K. Zhang, Y. Ren, Y. Jiang, Pyrolysis of Torrefied Biomass, Trends Biotechnol, $36 \quad$ (2018) 1287-1298. https://doi.org/10.1016/j.tibtech.2018.07.005

[14] V. Srinivasan, S. Adhikari, S.A. Chattanathan, S. Park, Catalytic Pyrolysis of Torrefied Biomass for Hydrocarbons Production, Energy \& Fuels, 26 (2012) 7347-7353. https://doi.org/10.1021/ef301469t

[15] M.N. Cahyanti, T. Doddapaneni, T. Kikas, Biomass torrefaction: An overview on process parameters, economic and environmental aspects and recent advancements, Bioresour Technol, 301 (2020) 122737. https://doi.org/10.1016/j.biortech.2020.122737

[16] R.W. Nachenius, T.A. van de Wardt, F. Ronsse, W. Prins, Torrefaction of pine in a bench-scale screw conveyor reactor, Biomass Bioenerg, 79 (2015) 96-104. https://doi.org/10.1016/j.biombioe.2015.03.027

[17] B. Batidzirai, A.P.R. Mignot, W.B. Schakel, H.M. Junginger, A.P.C. Faaij, Biomass torrefaction technology: Techno-economic status and future prospects, Energy, 62 (2013) 196-214. https://doi.org/10.1016/j.energy.2013.09.035

[18] E.A. Silveira, S. Luz, K. Candelier, L.A. Macedo, P. Rousset, An assessment of biomass torrefaction severity indexes, Fuel, $288 \quad$ (2021). https://doi.org/10.1016/j.fuel.2020.119631

[19] Y.Q. Niu, Y. Lv, Y. Lei, S.Q. Liu, Y. Liang, D.H. Wang, S.E. Hui, Biomass torrefaction: properties, applications, challenges, and economy, Renewable \& Sustainable Energy Reviews, 115 (2019). https://doi.org/10.1016/j.rser.2019.109395

[20] M. Cremers, J. Koppejan, J. Middelkamp, J. Witkamp, S. Sokhansanj, S. Melin, S. Madrali, Status Overview of Torrefaction Technologies - A review of the commercialisation status of biomass torrefaction, IEA bioenergy, 2015. 
[21] T.R. Brown, A techno-economic review of thermochemical cellulosic biofuel $\begin{array}{lllll}\text { pathways, } & \text { Bioresour } & \text { Technol, } & 178 & \text { (2015) }\end{array}$ https://doi.org/10.1016/j.biortech.2014.09.053

[22] F.L. Qi, M.M. Wright, Particle scale modeling of heat transfer in granular flows in a double screw reactor, Powder Technology, 335 (2018) 18-34. https://doi.org/10.1016/j.powtec.2018.04.068

[23] L.J.R. Nunes, A Case Study about Biomass Torrefaction on an Industrial Scale: Solutions to Problems Related to Self-Heating, Difficulties in Pelletizing, and Excessive Wear of Production Equipment, Applied Sciences-Basel, $10 \quad$ (2020). https://doi.org/10.3390/app10072546

[24] W.H. Chen, B.J. Lin, Y.Y. Lin, Y.S. Chu, A.T. Ubando, P.L. Show, H.C. Ong, J.S. Chang, S.H. Ho, A.B. Culaba, A. Petrissans, M. Petrissans, Progress in biomass torrefaction: Principles, applications and challenges, Progress in Energy and Combustion Science, 82 (2021). https://doi.org/10.1016/j.pecs.2020.100887

[25] S. Zinchik, Z. Xu, S.S. Kolapkar, E. Bar-Ziv, A.G. McDonald, Properties of pellets of torrefied U.S. waste blends, Waste Manag, 104 (2020) 130-138. https://doi.org/10.1016/j.wasman.2020.01.009

[26] S. Zinchik, Paddle Mixer-Extrusion Reactor for Torrefaction and Pyrolysis, in Mechanical Engineering, Michigan Technological University, Houghton, MI, USA, 2019. https://doi.org/10.37099/mtu.dc.etdr/906

[27] Z. Xu, S.S. Kolapkar, S. Zinchik, E. Bar-Ziv, J. Klinger, E. Fillerup, K. Schaller, C. Pilgrim, Kinetic Study of Paper Waste Thermal Degradation, Polymer Degradation and Stability, 191 (2021). https://doi.org/10.1016/j.polymdegradstab.2021.109681 
[28] Z. Xu, J.W. Albrecht, S.S. Kolapkar, S. Zinchik, E. Bar-Ziv, Chlorine Removal from U.S. Solid Waste Blends through Torrefaction, Applied Sciences, 10 (2020). https://doi.org/10.3390/app10093337

[29] E. Bar-Ziv, R. Saveliev, M. Perelman, Torrefaction apparatus and process US009193916B2, in: U.S.P.a.T. Office (Ed.), EB Clean Energy Ltd., U.S., 2015.

[30] S. Zinchik, J.L. Klinger, T.L. Westover, Y. Donepudi, S. Hernandez, J.D. Nabera, E. Bar-Ziv, Evaluation of fast pyrolysis feedstock conversion with a mixing paddle reactor, $\begin{array}{lllll}\text { Fuel Processing } & \text { Technology, } & 171 & \text { (2018) }\end{array}$ https://doi.org/10.1016/j.fuproc.2017.11.012

[31] S.S. Kolapkar, S. Zinchik, Z. Xu, A.G. McDonald, E. Bar-Ziv, Integration of Thermal Treatment and Extrusion by Compounding for Processing Various Wastes for Energy Applications, Energy \& Fuels, $35 \quad$ (2021) 12227-12236. https://doi.org/10.1021/acs.energyfuels.1c01836

[32] P.G. Lafleur, B. Vergnes, Polymer Extrusion, John Wiley and Sons, Chinchester, UK, 2014.

[33] R.I. Radics, R. Gonzalez, E.M. Bilek, S.S. Kelley, Systematic Review of Torrefied Wood Economics, Bioresources, $12 \quad$ (2017) 6868-6884. https://doi.org/10.15376/biores.12.3.Radics

[34] W.Q. Li, J. Dumortier, H. Dokoohaki, F.E. Miguez, R.C. Brown, D. Laird, M.M. Wright, Regional techno-economic and life-cycle analysis of the pyrolysis-bioenergybiochar platform for carbon-negative energy, Biofuel Bioprod Bior, 13 (2019) 1428-1438. https://doi.org/10.1002/bbb.2043 
[35] S. Whalley, S.J.W. Klein, J. Benjamin, Economic analysis of woody biomass supply chain in Maine, Biomass Bioenerg, $96 \quad$ (2017) 38-49. https://doi.org/10.1016/j.biombioe.2016.10.015

[36] M.M. Wright, D.E. Daugaard, J.A. Satrio, R.C. Brown, Techno-economic analysis of biomass fast pyrolysis to transportation fuels, Fuel, 89 (2010) S11-S19. https://doi.org/10.1016/j.fuel.2010.07.029

[37] S. Boxman, B.F. Stanley, Analysis of MSW Landfill Tipping Fees - 2020, in, Environmental Research and Education Foundation, 2021.

[38] G. Vinti, V. Bauza, T. Clasen, K. Medlicott, T. Tudor, C. Zurbrugg, M. Vaccari, Municipal Solid Waste Management and Adverse Health Outcomes: A Systematic Review, Int J Environ Res Public Health, 18 (2021). https://doi.org/10.3390/ijerph18084331

[39] J. Dong, Y.J. Tang, A. Nzihou, Y. Chi, Key factors influencing the environmental performance of pyrolysis, gasification and incineration Waste-to-Energy technologies, Energy Conversion and Management, $196 \quad$ (2019) 497-512. https://doi.org/10.1016/j.enconman.2019.06.016

[40] U.R. Gracida-Alvarez, L.M. Keenan, J.C. Sacramento-Rivero, D.R. Shonnard, Resource and Greenhouse Gas Assessments of the Thermochemical Conversion of Municipal Solid Waste in Mexico, Acs Sustainable Chemistry \& Engineering, 4 (2016) 5972-5978. https://doi.org/10.1021/acssuschemeng.6b01143

[41] N.C. Crawford, N. Nagle, D.A. Sievers, J.J. Stickel, The effects of physical and chemical preprocessing on the flowability of corn stover, Biomass Bioenerg, 85 (2016) 126-134. https://doi.org/10.1016/j.biombioe.2015.12.015 
[42] C. Wilèn, P. Jukola, T. Järvinen, K. Sipilä, F. Verhoeff, J. Kiel, Wood torrefaction pilot tests and utilisation prospects, in, VTT, Finland, 2013.

[43] AAEA, Commodity costs and returns estimation handbook, American Agricultural Economics Association, Ames, IA, 2000.

[44] ASABE, ASAE D497.5 FEB2006 Standards: Agricultural machinery management data, American Society of Agricultural and Biological Engineers, St. Joseph, MI, 2006.

[45] K.G. Cafferty, D.J. Muth, J.J. Jacobson, K.M. Bryden, Model Based Biomass System Design of Feedstock Supply Systems for Bioenergy Production, in: Volume 2B: 33rd Computers and Information in Engineering Conference, 2013.

[46] A.N. Laboratory. GREET® Model: The Greenhouse gases, Regulated Emissions, and Energy use in Technologies Model. Center for Transportation Research, Energy System Division, Argonne National Laboratory. https://greet.es.anl.gov/, 2019. (accessed 3 March, 2021).

[47] E. Toolbox. Wood and Biomass Heat. Engineering Toolbox. https://www.engineeringtoolbox.com/wood-biomass-combustion-heat-d 440.html, 2003. (accessed 1 June, 2021).

[48] B.P. Weidema, C. Bauer, R. Hischier, C. Mutel, T. Nemecek, C. Reinhard, G. Wenet. Data quality guideline for the ecoinvent database version 3. Ecoinvent Report 1 (v3). Swiss Cent. Life Cycle Invent. 3. https://ecoinvent.org/database/methodology-of-ecoinvent-

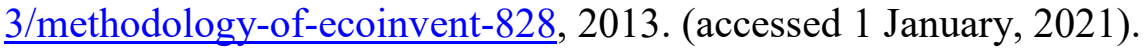

[49] J. Han, A. Elgowainy, I. Palou-Rivera, J.B. Dunn, M. Wang, Well-to-Wheels Analysis of Fast Pyrolysis Pathways with GREET, in, Energy Systems Division, Argonne National Laboratory, Oak Ridge, TN 2011. 
[50] U.S.E.P. Agency. eGRID 2019 Summary Data. https://www.epa.gov/egrid/summarydata, 2021. (accessed 1 June, 2021).

[51] J. Klinger, E. Bar-Ziv, D. Shonnard, Predicting Properties of Torrefied Biomass by Intrinsic Kinetics, Energy \& Fuels, 29 (2015) 171-176. https://doi.org/10.1021/ef501456p

[52] Y.M. Lu, W.C. Jin, J. Klinger, T.L. Westover, S. Dai, Flow characterization of compressible biomass particles using multiscale experiments and a hypoplastic model, Powder Technology, 383 (2021) 396-409. https://doi.org/10.1016/j.powtec.2021.01.027

[53] Y.D. Xia, J.J. Stickel, W.C. Jin, J. Klinger, A Review of Computational Models for the Flow of Milled Biomass Part I: Discrete-Particle Models, Acs Sustainable Chemistry \& Engineering, 8 (2020) 6142-6156. https://doi.org/10.1021/acssuschemeng.0c00402

[54] W.C. Jin, J.J. Stickel, Y.D. Xia, J. Klinger, A Review of Computational Models for the Flow of Milled Biomass Part II: Continuum-Mechanics Models, Acs Sustainable $\begin{array}{llllll}\text { Chemistry } & \& & \text { Engineering, } & 8 & \text { (2020) }\end{array}$ https://doi.org/10.1021/acssuschemeng.0c00412

[55] J. Mody, R. Saveliev, E. Bar-Ziv, M. Perelman, Production and Characterization of Biocoal for Coal-Fired Boilers, ASME Power Conference Volume 1: Fuels and Combustion, Material Handling, Emissions., (2014). https://doi.org/10.1115/power2014$\underline{32036}$

[56] D. Abbas, R.M. Handler, Life-cycle assessment of forest harvesting and transportation operations in Tennessee, Journal of Cleaner Production, 176 (2018) 512-520. https://doi.org/10.1016/j.jclepro.2017.11.238 


\section{Continuous Production Run and Test Burn}

In order to test the robustness and continuous production ability of the system, several test runs and production runs were carried out. Along with several test runs, the system was successfully operated onstream (24 hours operation, all 7 days of week) for $800+$ hours. From this run, a total of 8-tonne pellets were sent to Convergen Energy LLC for a test burn. The pellets passed the required quality standards and were able to handle drop-in fuels. An additional 10 tonnes of material will be produced in the systems in the near future, which will undergo additional emission testing. 


\section{Overall Dissertation Conclusions}

This study was aimed at the production of solid fuels for power applications. We studied the torrefaction of blends of fiber and plastic wastes at a ratio of $60: 40$ (at $300{ }^{\circ} \mathrm{C}$ with different residence times) and the properties and characteristics of the products. It was found that mass loss is an appropriate variable that can substitute temperature and residence time and was used extensively in this study. We used two forms of the fiber-plastic blends, one is in a flake form, referred to as "fluff" (bulk density of $50-70 \mathrm{~kg} / \mathrm{m}^{3}$ ), the other was densified by a factor of 7-9. It was observed that the two forms of the blend have significantly different torrefaction dynamics. The fluff takes less time to heat prior to torrefaction compared to the densified blend, which is due to the faster heat transfer to the fluff. Although the torrefaction dynamics of the two forms differ significantly, the torrefied material showed identical behavior of the properties vs. the mass loss. Improvement in the heat content and grindability was shown to increase with mass loss while the chlorine was reduced. Overall, the waste blends studied in this paper showed that they can be used as a drop-in fuel in coal power plants and torrefaction processes since this fuel is low-cost meets the environmental combustion regulations. These findings were obtained from bench-scale experiments using samples of 150 gr. From these experiments, kg-torrefied samples were prepared to be used for extrusion.

Extrusion of torrefied samples was also studied on a bench scale using 400-gr samples. We analyzed the extruded products that showed a significant increase in homogeneity, reaching intrinsic density. From the extrusion experiments, we concluded that the plastics act as a process enabler, binder, water repellent, increase of heat content, and increase the reaction rate of the fibers' degradation. These experiments revealed the importance of extrusion to produce densified (in the form of pellets in this study) material for power applications.

It was realized that torrefaction-extrusion plays a major role in the production of solid fuels. Consequently, a system integrating torrefaction with extrusion has been developed based on a screw reactor with a throughput of up to $70 \mathrm{~kg} / \mathrm{h}$. We experimentally studied the thermo-mechanical behavior of the process and the properties of the pellets produced. We 
showed that $20 \%$ and $40 \%$ cut flighting increased the residence time by 2.3-3.7 compared to regular screws. The average overall heat transfer coefficient was measured for the reactor at $52.5 \mathrm{~W} / \mathrm{m}^{2}{ }^{\circ} \mathrm{C}$. The correlation between specific mechanical energy and mass flow showed 3 times decrease in specific energy consumed when the feed rate was increased from $\sim 10 \mathrm{~kg} / \mathrm{h}$ to $50 \mathrm{~kg} / \mathrm{h}$. TMA, flexural testing, rheological, and pellet durability testing were performed on the produced pellets showed that the pellet had good processability and mechanical properties (durable). In conclusion, we found that the integrated torrefaction-extrusion reactor can produce high-quality torrefied pellets with low specific energy.

The torrefaction-extrusion reactor was the basis of an integrated system, referred to as a pilot-scale system, that was built that comprised the (i) preprocessing of the fiber-plastic blend feedstock, (ii) torrefaction-extrusion, (iii) pellet cutting, (iv) pellet cooling, and (v) conveying to storage. The system included other peripherical equipment. This system served as the basis for comprehensive techno-economic (TEA) and lifecycle (LCA) assessment studies. The TEA demonstrates that the baseline cost of pre-processing fiberplastic wastes is estimated at $\$ 55.28$ dry tonne (2020\$) and ranges between $\$ 52.33$ dry tonne and $\$ 58.24 /$ dry tonne under a range of scenarios. The torrefaction system's LCA illustrates that the pellets can be produced with a net negative global warming potential at this intermediate stage of the life cycle, with a low fossil energy demand relative to a wood chip comparison project.

Overall, we demonstrated:

1. fiber-plastic wastes can be used as a potential feedstock for torrefaction.

2. the properties of torrefied extruded waste and pellets are suitable for power applications.

3. successful development, design, and implementation of a pilot-scale system for the conversion of waste to fuel.

4. the TEA shows a low cost of pellet fuel production and LCA with net negative global warming potential. 


\section{Future Work}

With the reduced popularity and preference for solid fuel, other applications need to be explored in the future. One such application is the mixed plastic waste alloys. These alloys can be prepared using the same system developed in this work with modifications like removing flight cuts. This will enable the production of alloyed mixed plastic waste that can be used for structural applications like making shingles, flooring, bathroom components. Figure 8.1 shows a sample of alloy-based roof shingles produced from the mixed plastic waste pellets.

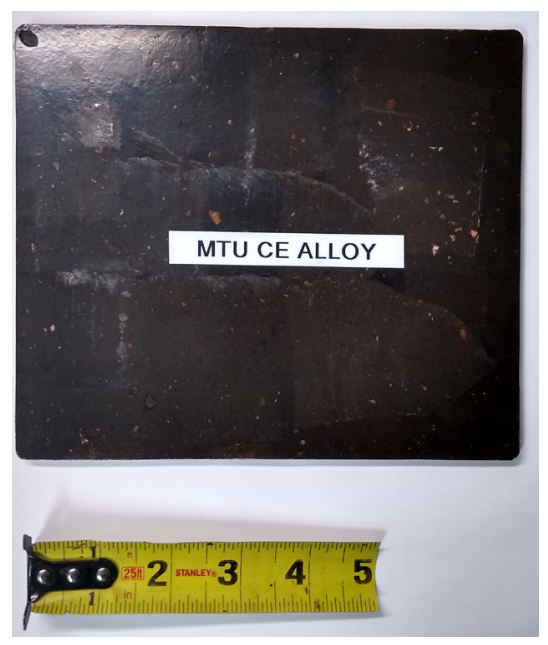

Figure 8.1. Shingle produced from mixed plastic waste alloy. Credits: Dr. Armando McDonald (University of Idaho).

To better understand the properties of incoming material and to predict the properties of the produced product, it is essential to analyze the incoming materials and identify the types of incoming fiber and plastics. This also enables tight quality control of the product. To further this work team has already procured a mid-FTIR spectrometer from NLIR (Denmark) that can perform high-speed spectroscopy at $400 \mathrm{~Hz}$. In the future, this system will be integrated with the torrefaction-extrusion system to have online monitoring of incoming feedstock, enabling the tuning of operational process parameters. 


\section{A Appendix: Torrefaction System Photo}

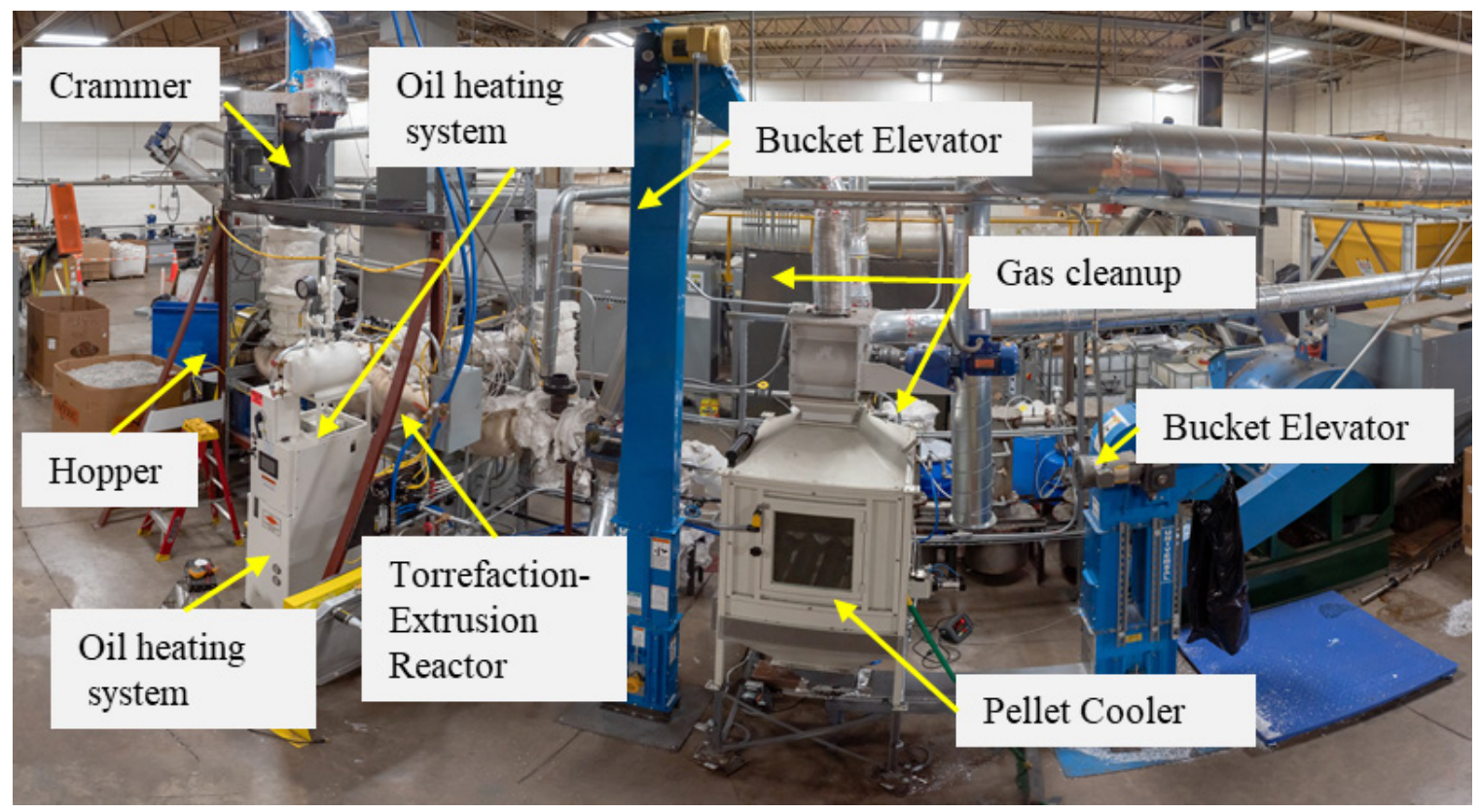

Photo of Complete Torrefaction-Extrusion system with various components. 


\section{B Copyright documentation}

\section{Copyright permission from the publisher for:}

S.S. Kolapkar, S. Zinchik, Z. Xu, A.G. McDonald, E. Bar-Ziv, Integration of Thermal Treatment and Extrusion by Compounding for Processing Various Wastes for Energy Applications, Energy \& $\quad$ Fuels, $35 \quad$ (2021) 12227-12236. https://doi.org/10.1021/acs.energyfuels.1c01836

10/14/21, 1:27 PM Rightslink® by Copyright Clearance Center

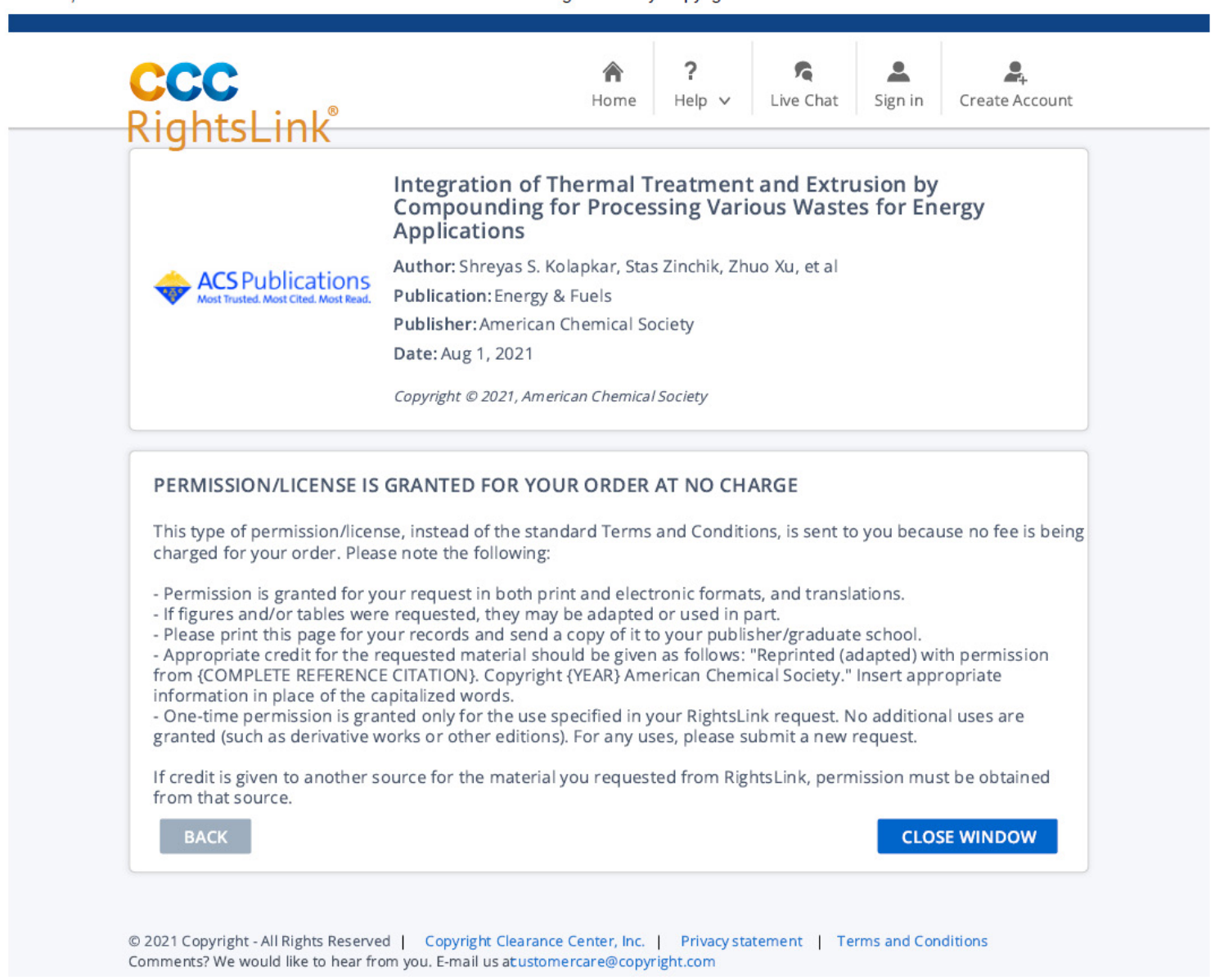




\section{Copyright permission from the publisher for:}

S.S. Kolapkar, S. Zinchik, P. Burli, Y. Lin, D.S. Hartley, J. Klinger, R. Handler, E. BarZiv, Integrated torrefaction-extrusion system for solid fuel pellet production from mixed fiber-plastic wastes: Techno-economic analysis and life cycle assessment, Fuel Processing Technology, 226 (2022) 107094. https://doi.org/10.1016/j.fuproc.2021.107094

Integrated torrefaction-extrusion system for solid fuel pellet production
from mixed fiber-plastic wastes: Techno-economic analysis and life cycle
assessment
Author:
Shreyas S. Kolapkar,Stas Zinchik, Pralhad Burli,Yingqian Lin, Damon S. Hartley,jordan
Klinger, Robert Handler, Ezra Bar-Ziv
Publication: Fuel Processing Technology
Publisher: Elsevier
Date: February 2022
O 2021 Elsevier B.V. All rights reserved.

\section{Journal Author Rights}

Please note that, as the author of this Elsevier article, you retain the right to include it in a thesis or dissertation, provided it is not published commercially. Permission is not required, but please ensure that you reference the journal as the original source. For more information on this and on your other retained rights, please visit: https://www.elsevier.com/about/our-business/policies/copyright\#Author-rights

BACK

CLOSE WINDOW 


\section{Copyright permission from the publisher for:}

Z. Xu, S. Zinchik, S.S. Kolapkar, E. Bar-Ziv, T. Hansen, D. Conn, A.G. McDonald, Properties of Torrefied U.S. Waste Blends, Frontiers in Energy Research, 6 (2018). https://doi.org/10.3389/fenrg.2018.00065

The publication is in the public domain or licensed for reuse under Creative Commons license 4.0 .

Keywords: waste, fiber, plastic, torrefaction, grindability, energy content, chlorine content, FTIR spectroscopy

Citation: Xu Z, Zinchik S, Kolapkar SS, Bar-Ziv E, Hansen T, Conn D and McDonald AG (2018) Properties of Torrefied U.S. Waste Blends. Front. Energy Res. 6:65. doi: 10.3389/fenrg.2018.00065

Received: 12 April 2018; Accepted: 19 June 2018;

Published: 13 July 2018.

Edited by:

Allison E. Ray, Idaho National Laboratory (DOE), United States

Reviewed by:

Muhammad Aziz, Tokyo Institute of Technology, Japan

Maria Puig-Arnavat, Technical University of Denmark, Denmark

Copyright (c) 2018 Xu, Zinchik, Kolapkar, Bar-Ziv, Hansen, Conn and McDonald. This is an open-access article distributed under the terms of the Creative Commons Attribution License (CC BY). The use, distribution or reproduction in other forums is permitted, provided the original author(s) and the copyright owner(s) are credited and that the original publication in this journal is cited, in accordance with accepted academic practice. No use, distribution or reproduction is permitted which does not comply with these terms.

*Correspondence: Ezra Bar-Ziv, ebarziv@mtu.edu

Disclaimer: All claims expressed in this article are solely those of the authors and do not necessarily represent those of their affiliated organizations, or those of the publisher, the editors and the reviewers. Any product that may be evaluated in this article or claim that may be made by its manufacturer is not guaranteed or endorsed by the publisher. 


\section{Copyright permission from the publisher for:}

S. Zinchik, Z. Xu, S.S. Kolapkar, E. Bar-Ziv, A.G. McDonald, Properties of pellets of torrefied U.S. waste blends, Waste Management, 104 (2020) 130-138. https://doi.org/10.1016/j.wasman.2020.01.009

10/14/21, 1:51 PM Rightslink@ by Copyright Clearance Center

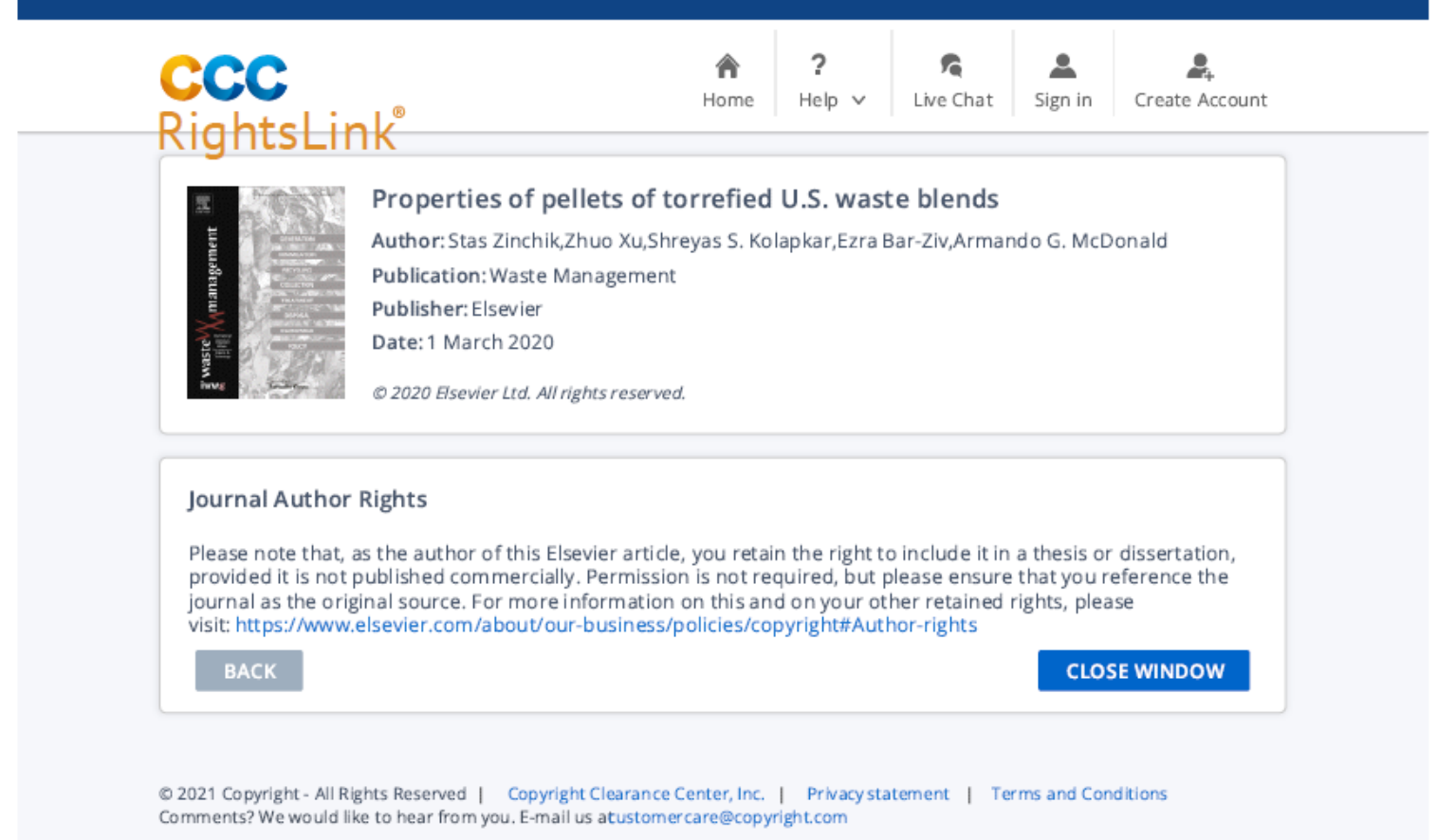




\title{
Permission from publisher to reuse Table 1.2
}

\author{
ELSEVIER LICENSE \\ TERMS AND CONDITIONS
}

Oct 28,2021

This Agreement between Mr. Shreyas Kolapkar ("You") and Elsevier ("Elsevier") consists of your license details and the terms and conditions provided by Elsevier and Copyright

Clearance Center.

License Number $\quad 5177600277695$

License date $\quad$ Oct 28,2021

Licensed Content Elsevier

Publisher

Licensed Content

Publication

Energy

Licensed Content Title

Biomass torrefaction technology: Techno-economic status and future prospects

Licensed Content Author

B. Batidzirai,A.P.R. Mignot,W.B. Schakel,H.M.

Junginger,A.P.C. Faaij

Licensed Content Date Dec 1, 2013

Licensed Content Volume 62

Licensed Content Issue n/a

Licensed Content Pages 19

Start Page $\quad 196$ 


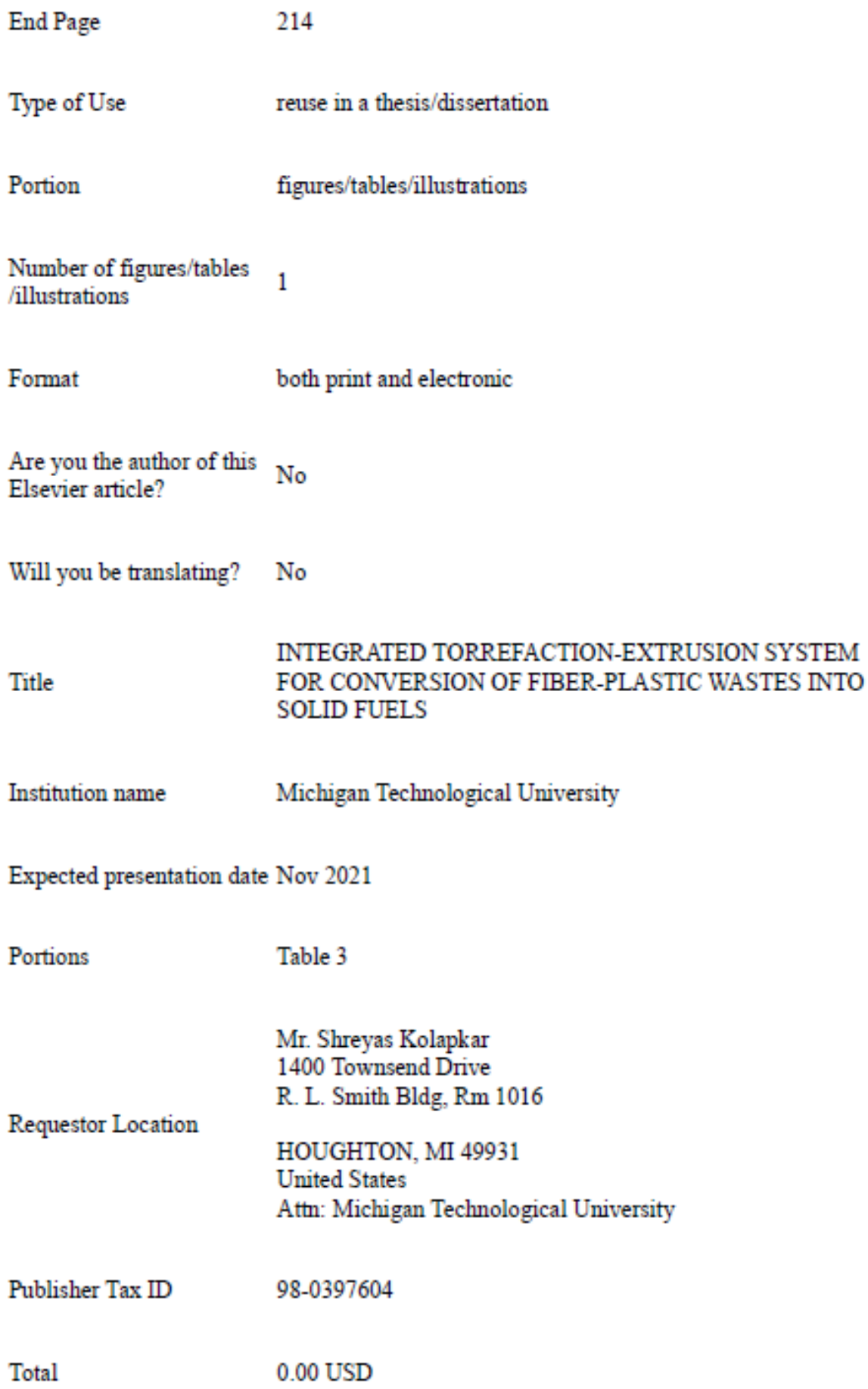

Total $\quad 0.00$ USD 